Cochrane Database of Systematic Reviews

\title{
Antioxidants for preventing and reducing muscle soreness after exercise (Review)
}

Ranchordas MK, Rogerson D, Soltani H, Costello JT

Ranchordas MK, Rogerson D, Soltani H, Costello JT.

Antioxidants for preventing and reducing muscle soreness after exercise.

Cochrane Database of Systematic Reviews 2017, Issue 12. Art. No.: CD009789.

DOI: 10.1002/14651858.CD009789.pub2.

www.cochranelibrary.com 
TABLE OF CONTENTS

HEADER

ABSTRACT

PLAIN LANGUAGE SUMMARY

SUMMARY OF FINDINGS

BACKGROUND

OBJECTIVES

METHODS

RESULTS

Figure 1.

Figure 2.

Figure 3.

Figure 4.

Figure 5.

DISCUSSION

Figure 6.

Figure 7.

AUTHORS' CONCLUSIONS

ACKNOWLEDGEMENTS

REFERENCES

CHARACTERISTICS OF STUDIES

DATA AND ANALYSES

Analysis 1.1. Comparison 1 Antioxidant supplementation vs. placebo for delayed onset muscle soreness (all studies), Outcome

1 Muscle soreness up to 6 hours; random-effects model.

Analysis 1.2. Comparison 1 Antioxidant supplementation vs. placebo for delayed onset muscle soreness (all studies), Outcome 2 Muscle soreness at 24 hours; random-effects model.

Analysis 1.3. Comparison 1 Antioxidant supplementation vs. placebo for delayed onset muscle soreness (all studies), Outcome 3 Muscle soreness at 48 hours; random-effects model.

Analysis 1.4. Comparison 1 Antioxidant supplementation vs. placebo for delayed onset muscle soreness (all studies), Outcome 4 Muscle soreness at 72 hours; random-effects model.

Analysis 1.5. Comparison 1 Antioxidant supplementation vs. placebo for delayed onset muscle soreness (all studies), Outcome 5 Muscle soreness at 96 hours; random-effects model.

Analysis 1.6. Comparison 1 Antioxidant supplementation vs. placebo for delayed onset muscle soreness (all studies), Outcome 6 Muscle soreness (follow-ups: 120, 144 and 168 hours); random-effects model.

Analysis 1.7. Comparison 1 Antioxidant supplementation vs. placebo for delayed onset muscle soreness (all studies), Outcome 7 Muscle soreness up to 6 hours - all at same scale (0 to 10; worst pain).

Analysis 1.8. Comparison 1 Antioxidant supplementation vs. placebo for delayed onset muscle soreness (all studies), Outcome 8 Muscle soreness at 24 hours - all at same scale (0 to 10; worst pain).

Analysis 1.9. Comparison 1 Antioxidant supplementation vs. placebo for delayed onset muscle soreness (all studies), Outcome 9 Muscle soreness at 48 hours - all at same scale (0 to 10; worst pain).

Analysis 1.10. Comparison 1 Antioxidant supplementation vs. placebo for delayed onset muscle soreness (all studies), Outcome 10 Muscle soreness at 72 hours - all at same scale (0 to 10; worst pain).

Analysis 1.11. Comparison 1 Antioxidant supplementation vs. placebo for delayed onset muscle soreness (all studies), Outcome 11 Muscle soreness at 96 hours - all at same scale (0 to 10; worst pain).

Analysis 1.12. Comparison 1 Antioxidant supplementation vs. placebo for delayed onset muscle soreness (all studies), Outcome 12 Muscle soreness at 24 hours. Subgroup analysis by type of exercise (whole body aerobic vs. mechanically induced). ......... Analysis 1.13. Comparison 1 Antioxidant supplementation vs. placebo for delayed onset muscle soreness (all studies), Outcome 13 Muscle soreness at 48 hours. Subgroup analysis by type of exercise (whole body aerobic vs. mechanically induced).

Analysis 1.14. Comparison 1 Antioxidant supplementation vs. placebo for delayed onset muscle soreness (all studies), Outcome 14 Muscle soreness at 24 hours. Subgroup analysis by funding sources (funded by food company or provider of antioxidant supplements vs. not funded by food company or provider of antioxidant supplements).

Analysis 1.15. Comparison 1 Antioxidant supplementation vs. placebo for delayed onset muscle soreness (all studies), Outcome 15 Muscle soreness at 48 hours. Subgroup analysis by funding sources (funded by food company or provider of antioxidant supplements vs. not funded by food company or provider of antioxidant supplements). 
Analysis 1.16. Comparison 1 Antioxidant supplementation vs. placebo for delayed onset muscle soreness (all studies), Outcome 16 Muscle tenderness measured in Newtons (all follow-up times).

Analysis 1.17. Comparison 1 Antioxidant supplementation vs. placebo for delayed onset muscle soreness (all studies), Outcome 17 Muscle tenderness measured in $\mathrm{kg}$ (all follow-up times).

Analysis 1.18. Comparison 1 Antioxidant supplementation vs. placebo for delayed onset muscle soreness (all studies), Outcome 18 30-second Wingate average peak power output (W/kg) (post 7 days of intervention).

Analysis 1.19. Comparison 1 Antioxidant supplementation vs. placebo for delayed onset muscle soreness (all studies), Outcome 1920 m Sprint time (s).

Analysis 1.20. Comparison 1 Antioxidant supplementation vs. placebo for delayed onset muscle soreness (all studies), Outcome 20 Maximal oxygen consumption ( $\mathrm{mL} / \mathrm{kg} / \mathrm{min}$ ) (post 42 days of supplementation).

Analysis 1.21. Comparison 1 Antioxidant supplementation vs. placebo for delayed onset muscle soreness (all studies), Outcome 21 Agility (seconds).

Analysis 1.22. Comparison 1 Antioxidant supplementation vs. placebo for delayed onset muscle soreness (all studies), Outcome 226 second sprint maximal power (Watts) (all follow-up times).

Analysis 1.23. Comparison 1 Antioxidant supplementation vs. placebo for delayed onset muscle soreness (all studies), Outcome 23 Maximal voluntary isometric contraction measured as percentage change from baseline.

Analysis 1.24. Comparison 1 Antioxidant supplementation vs. placebo for delayed onset muscle soreness (all studies), Outcome 24 Maximal voluntary isometric contraction measured in Newton metres.

Analysis 1.25. Comparison 1 Antioxidant supplementation vs. placebo for delayed onset muscle soreness (all studies), Outcome 25 Maximal voluntary isometric contraction measured in Newtons.

Analysis 1.26. Comparison 1 Antioxidant supplementation vs. placebo for delayed onset muscle soreness (all studies), Outcome 26 Maximal voluntary isometric contraction measured in Newton metres per $\mathrm{kg}$ of body mass.

Analysis 1.27. Comparison 1 Antioxidant supplementation vs. placebo for delayed onset muscle soreness (all studies), Outcome 27 Maximal voluntary isometric contraction measured in $\mathrm{kg}$.

Analysis 1.28. Comparison 1 Antioxidant supplementation vs. placebo for delayed onset muscle soreness (all studies), Outcome 28 Range of motion (all follow-up times).

ADDITIONAL TABLES

APPENDICES

CONTRIBUTIONS OF AUTHORS 
[Intervention Review]

\section{Antioxidants for preventing and reducing muscle soreness after exercise}

Mayur K Ranchordas ${ }^{1}$, David Rogerson ${ }^{1}$, Hora Soltani², Joseph T Costello3

1Department of Sport, Sheffield Hallam University, Sheffield, UK. ${ }^{2}$ Centre for Health and Social Care Research, Sheffield Hallam

University, Sheffield, UK. ${ }^{3}$ Department of Sport and Exercise Science, University of Portsmouth, Portsmouth, UK

Contact address: Mayur K Ranchordas, Department of Sport, Sheffield Hallam University, Collegiate Crescent Campus, A221 Collegiate Hall, Ecclesall Road, Sheffield, South Yorkshire, S10 2BP, UK. m.ranchordas@shu.ac.uk, m.ranchordas@gmail.com.

Editorial group: Cochrane Bone, Joint and Muscle Trauma Group.

Publication status and date: New, published in Issue 12, 2017.

Citation: Ranchordas MK, Rogerson D, Soltani H, Costello JT. Antioxidants for preventing and reducing muscle soreness after exercise. Cochrane Database of Systematic Reviews 2017, Issue 12. Art. No.: CD009789. DOI: 10.1002/14651858.CD009789.pub2.

Copyright @ 2017 The Cochrane Collaboration. Published by John Wiley \& Sons, Ltd.

\section{A B S T R A C T}

\section{Background}

Muscle soreness typically occurs after intense exercise, unaccustomed exercise or actions that involve eccentric contractions where the muscle lengthens while under tension. It peaks between 24 and 72 hours after the initial bout of exercise. Many people take antioxidant supplements or antioxidant-enriched foods before and after exercise in the belief that these will prevent or reduce muscle soreness after exercise.

\section{Objectives}

To assess the effects (benefits and harms) of antioxidant supplements and antioxidant-enriched foods for preventing and reducing the severity and duration of delayed onset muscle soreness following exercise.

\section{Search methods}

We searched the Cochrane Bone, Joint and Muscle Trauma Group Specialised Register, the Cochrane Central Register of Controlled Trials, MEDLINE, Embase, SPORTDiscus, trial registers, reference lists of articles and conference proceedings up to February 2017.

\section{Selection criteria}

We included randomised and quasi-randomised controlled trials investigating the effects of all forms of antioxidant supplementation including specific antioxidant supplements (e.g. tablets, powders, concentrates) and antioxidant-enriched foods or diets on preventing or reducing delayed onset muscle soreness (DOMS). We excluded studies where antioxidant supplementation was combined with another supplement.

\section{Data collection and analysis}

Two review authors independently screened search results, assessed risk of bias and extracted data from included trials using a pre-piloted form. Where appropriate, we pooled results of comparable trials, generally using the random-effects model. The outcomes selected for presentation in the 'Summary of findings' table were muscle soreness, collected at times up to 6 hours, 24, 48, 72 and 96 hours postexercise, subjective recovery and adverse effects. We assessed the quality of the evidence using GRADE.

\section{Main results}

Fifty randomised, placebo-controlled trials were included, 12 of which used a cross-over design. Of the 1089 participants, 961 (88.2\%) were male and 128 (11.8\%) were female. The age range for participants was between 16 and 55 years and training status varied from sedentary to moderately trained. The trials were heterogeneous, including the timing (pre-exercise or post-exercise), frequency, dose, duration and type of antioxidant supplementation, and the type of preceding exercise. All studies used an antioxidant dosage higher than the recommended 
daily amount. The majority of trials (47) had design features that carried a high risk of bias due to selective reporting and poorly described allocation concealment, potentially limiting the reliability of their findings.

We tested only one comparison: antioxidant supplements versus control (placebo). No studies compared high-dose versus low-dose, where the low-dose supplementation was within normal or recommended levels for the antioxidant involved.

Pooled results for muscle soreness indicated a small difference in favour of antioxidant supplementation after DOMS-inducing exercise at all main follow-ups: up to 6 hours (standardised mean difference (SMD) -0.30, 95\% confidence interval (CI) -0.56 to $-0.04 ; 525$ participants, 21 studies; low-quality evidence); at 24 hours (SMD $-0.13,95 \% \mathrm{Cl}-0.27$ to $0.00 ; 936$ participants, 41 studies; moderate-quality evidence); at 48 hours (SMD $-0.24,95 \% \mathrm{Cl}-0.42$ to $-0.07 ; 1047$ participants, 45 studies; low-quality evidence); at 72 hours (SMD $-0.19,95 \% \mathrm{Cl}-0.38$ to -0.00; 657 participants, 28 studies; moderate-quality evidence), and little difference at 96 hours (SMD $-0.05,95 \% \mathrm{Cl}-0.29$ to $0.19 ; 436$ participants, 17 studies; low-quality evidence). When we rescaled to a 0 to $10 \mathrm{~cm}$ scale in order to quantify the actual difference between groups, we found that the $95 \% \mathrm{Cls}$ for all five follow-up times were all well below the minimal important difference of $1.4 \mathrm{~cm}$ : up to $6 \mathrm{hours}$ (MD - $0.52,95 \% \mathrm{Cl}-0.95$ to -0.08 ); at 24 hours (MD - $0.17,95 \% \mathrm{Cl}-0.42$ to 0.07 ); at 48 hours (MD $-0.41,95 \% \mathrm{Cl}-0.69$ to -0.12 ); at 72 hours (MD $-0.29,95 \% \mathrm{Cl}-0.59$ to 0.02 ); and at 96 hours (MD $-0.03,95 \% \mathrm{Cl}-0.43$ to 0.37 ). Thus, the effect sizes suggesting less muscle soreness with antioxidant supplementation were very unlikely to equate to meaningful or important differences in practice. Neither of our subgroup analyses to examine for differences in effect according to type of DOMS-inducing exercise (mechanical versus whole body aerobic) or according to funding source confirmed subgroup differences. Sensitivity analyses excluding cross-over trials showed that their inclusion had no important impact on results.

None of the 50 included trials measured subjective recovery (return to previous activities without signs or symptoms).

There is very little evidence regarding the potential adverse effects of taking antioxidant supplements as this outcome was reported in only nine trials (216 participants). From the studies that did report adverse effects, two of the nine trials found adverse effects. All six participants in the antioxidant group of one trial had diarrhoea and four of these also had mild indigestion; these are well-known side effects of the particular antioxidant used in this trial. One of 26 participants in a second trial had mild gastrointestinal distress.

\section{Authors' conclusions}

There is moderate to low-quality evidence that high dose antioxidant supplementation does not result in a clinically relevant reduction of muscle soreness after exercise at up to 6 hours or at 24, 48, 72 and 96 hours after exercise. There is no evidence available on subjective recovery and only limited evidence on the adverse effects of taking antioxidant supplements. The findings of, and messages from, this review provide an opportunity for researchers and other stakeholders to come together and consider what are the priorities, and underlying justifications, for future research in this area.

\section{PLAIN LANGUAGE SUMMARY}

\section{Antioxidants for preventing and reducing muscle soreness after exercise}

\section{Background and aim of the review}

Muscle soreness typically occurs after intense or unaccustomed exercise. It peaks between 24 and 72 hours after the initial bout of exercise. Many people take antioxidant supplements such as vitamin C and/or E or antioxidant-enriched foods such as tart cherry or pomegranate juice before and after exercise in the belief that these will prevent or reduce muscle soreness after exercise.

\section{Results of the search}

We searched medical databases up to February 2017 for studies that compared antioxidant supplementation with a control intervention such as a placebo (a dummy pill or drink that had no antioxidant) or no treatment. We found 50 studies, all of which compared antioxidant supplementation with a placebo. These reported results for a total of 1089 participants. Of these, nearly 9 out of 10 were male. The age range for participants was between 16 and 55 years and their training status varied from sedentary to moderately trained. The studies were very varied such as in the type and dosage of the antioxidant supplement and the type of exercises used to cause muscle soreness. All studies used an antioxidant dosage higher than the recommended daily amount.

\section{Key results}

There is evidence that high dose antioxidant supplementation may slightly reduce muscle soreness at up to 6 hours and at 24,48 and 72 hours follow-up but not at 96 hours. However, these reductions were so small that they were unlikely to make any difference. None of the trials reported on outcomes related to subjective recovery, such as return to previous activities without signs or symptoms.

Only nine studies reported on adverse effects and only two found adverse effects. All six participants in the antioxidant group of one trial had diarrhoea and four of these also had mild indigestion; these are well-known side effects of the particular antioxidant used in this study. One of 26 participants in a second trial had mild gastrointestinal distress.

\section{Quality of the evidence}


We considered the evidence for muscle soreness to be 'moderate' or 'low' quality. This was mainly because the majority of studies had aspects that could have affected the reliability of their results and in some cases because of variation in the results of the studies. This means there is some uncertainty about the findings and further research may provide evidence that could change our conclusions.

\section{Authors' conclusions}

Antioxidant supplementation does not appear to reduce muscle soreness early on or at one, two, three or four days after exercise. 


\begin{tabular}{|c|c|c|c|c|c|c|}
\hline \multicolumn{7}{|c|}{$\begin{array}{l}\text { S U M M A R Y O F F I N D I N G S } \\
\text { Summary of findings for the main comparison. Summary of findings: antioxidants versus placebo }\end{array}$} \\
\hline \multicolumn{7}{|c|}{ Antioxidants compared with placebo or no treatment for preventing and reducing muscle soreness after exercise } \\
\hline \multicolumn{7}{|c|}{$\begin{array}{l}\text { Patient or population: mainly physically active individuals }{ }^{1} \text { partaking in exercise }{ }^{2} \text { designed to produce delayed onset muscle soreness } \\
\text { Settings: controlled laboratory studies and field-based studies } \\
\text { Intervention: antioxidant supplements } 3 \text {. These fell into } 3 \text { main categories: whole natural food source (e.g. bilberry juice, cherry, pomegranate juice); antioxidant extract or } \\
\text { mixed antioxidants (e.g. black tea extract, curcumin); and vitamin C or E or both combined. } \\
\text { Comparison: all were placebo controls }\end{array}$} \\
\hline \multirow[t]{3}{*}{ Outcomes } & \multicolumn{2}{|c|}{ Illustrative comparative risks $(95 \% \mathrm{Cl})$} & \multirow{3}{*}{$\begin{array}{l}\text { Relative effect } \\
(95 \% \mathrm{Cl})\end{array}$} & \multirow{3}{*}{$\begin{array}{l}\text { No of partici- } \\
\text { pants } \\
\text { (studies) }\end{array}$} & \multirow{3}{*}{$\begin{array}{l}\text { Quality of the } \\
\text { evidence } \\
\text { (GRADE) }\end{array}$} & \multirow[t]{3}{*}{ Comments } \\
\hline & Assumed risk & $\begin{array}{l}\text { Corresponding } \\
\text { risk }\end{array}$ & & & & \\
\hline & $\begin{array}{l}\text { Control (place- } \\
\text { bo or no antioxi- } \\
\text { dants) }\end{array}$ & $\begin{array}{l}\text { Antioxidant sup- } \\
\text { plementation }\end{array}$ & & & & \\
\hline \multirow[t]{2}{*}{$\begin{array}{l}\text { Muscle sore- } \\
\text { ness } \\
\text { Follow-up: im- } \\
\text { mediately up to } \\
6 \text { hours post-ex- } \\
\text { ercise }\end{array}$} & \multirow[t]{2}{*}{$\begin{array}{l}\text { The mean level } \\
\text { of muscle sore- } \\
\text { ness in the con- } \\
\text { trol group ranged } \\
\text { from } 1.0 \text { to } 8.3 \mathrm{~cm} \\
\text { (adjusted to a } 0 \\
\text { to } 10 \mathrm{~cm} \text { scale) }\end{array}$} & \multirow[t]{2}{*}{$\begin{array}{l}\text { The mean level of } \\
\text { muscle soreness } \\
\text { after antioxidant } \\
\text { supplementation } \\
\text { was } 0.30 \text { standard } \\
\text { deviations lower } \\
\text { (0.56 to } 0.04 \text { lower) }\end{array}$} & \multirow[t]{2}{*}{$\begin{array}{l}\text { SMD }-0.30 \\
(-0.56 \text { to }-0.04)\end{array}$} & \multirow[t]{2}{*}{$\begin{array}{l}525 \\
\left(21 \text { studies }^{4}\right)\end{array}$} & \multirow[t]{2}{*}{$\begin{array}{l}\oplus \oplus \odot \ominus \\
\text { low }^{5}\end{array}$} & $\begin{array}{l}\text { One 'rule of thumb' is that } 0.2 \text { represents a small } \\
\text { difference, } 0.5 \text { a moderate difference and } 0.8 \text { a } \\
\text { large difference. } \\
\text { Based on this 'rule of thumb', this result equates to } \\
\text { a small to moderate difference in favour of antioxi- } \\
\text { dant supplementation. }\end{array}$ \\
\hline & & & & & & $\begin{array}{l}\text { However, when we rescaled the data to a } 0 \text { to } 10 \\
\mathrm{~cm} \text { scale, the MD was lower by } 0.52 \mathrm{~cm}(0.95 \text { to } 0.08 \\
\mathrm{cm} \text { lower). These are all under the typical MID for } \\
\text { pain (taken here as } 1.4 \mathrm{~cm}) \text {. }\end{array}$ \\
\hline $\begin{array}{l}\text { Muscle sore- } \\
\text { ness } \\
\text { Follow-up: } 24 \\
\text { hours }\end{array}$ & $\begin{array}{l}\text { The mean level } \\
\text { of muscle sore- } \\
\text { ness in the con- } \\
\text { trol group ranged } \\
\text { from } 0.21 \text { to } 8.8 \\
\mathrm{~cm} \text { (adjusted to a } \\
0 \text { to } 10 \mathrm{~cm} \text { scale) }\end{array}$ & $\begin{array}{l}\text { The mean level of } \\
\text { muscle soreness } \\
\text { after antioxidant } \\
\text { supplementation } \\
\text { was } \mathbf{0 . 1 3} \text { standard } \\
\text { deviations lower } \\
\text { (0.27 to } 0.00 \text { lower) }\end{array}$ & $\begin{array}{l}\text { SMD }-\mathbf{0 . 1 3} \\
(-0.27 \text { to }-0.00)\end{array}$ & $\begin{array}{l}936 \\
\left(41 \text { studies }^{4}\right)\end{array}$ & $\begin{array}{l}\oplus \oplus \oplus \ominus \\
\text { moderate }\end{array}$ & $\begin{array}{l}\text { Based on the above 'rule of thumb', this result } \\
\text { equates to a small difference in favour of antioxi- } \\
\text { dant supplementation. } \\
\text { However, when we rescaled the data to a } 0 \text { to } 10 \\
\mathrm{~cm} \text { scale, the MD was lower by } 0.17 \mathrm{~cm} \text { ( } 0.42 \text { lower } \\
\text { to } 0.07 \text { higher). These are all under the typical MID } \\
\text { for pain (taken here as } 1.4 \mathrm{~cm} \text { ). }\end{array}$ \\
\hline
\end{tabular}




\begin{tabular}{|c|c|c|c|c|c|c|}
\hline $\begin{array}{l}\text { luscle sore- } \\
\text { less } \\
\text { ollow-up: } 48\end{array}$ & $\begin{array}{l}\text { The mean level } \\
\text { of muscle sore- } \\
\text { ness in the con- } \\
\text { trol group ranged } \\
\text { from } 0.32 \text { to } 9.56 \\
\mathrm{~cm} \text { (adjusted to a } \\
0 \text { to } 10 \mathrm{~cm} \text { scale) }\end{array}$ & $\begin{array}{l}\text { The mean level of } \\
\text { muscle soreness } \\
\text { after antioxidant } \\
\text { supplementation } \\
\text { was } \mathbf{0 . 2 4} \text { standard } \\
\text { deviations lower } \\
\text { ( } 0.42 \text { to } 0.07 \text { lower) }\end{array}$ & $\begin{array}{l}\text { SMD }-\mathbf{0 . 2 4} \\
(-0.42 \text { to }-0.07)\end{array}$ & $\begin{array}{l}1047 \\
\left(45 \text { studies}^{7}\right)\end{array}$ & $\begin{array}{l}\oplus \oplus \ominus \ominus \\
\text { low }^{8}\end{array}$ & $\begin{array}{l}\text { Based on the above 'rule of thumb', this result } \\
\text { equates to a small difference in favour of antioxi- } \\
\text { dant supplementation. } \\
\text { However, when we rescaled the data to a } 0 \text { to } 10 \\
\mathrm{~cm} \text { scale, the MD was lower by } 0.41 \mathrm{~cm}(0.69 \text { to } 0.12 \\
\text { lower). These are all under the typical MID for pain } \\
\text { (taken here as } 1.4 \mathrm{~cm} \text { ). }\end{array}$ \\
\hline $\begin{array}{l}\text { Muscle sore- } \\
\text { ness } \\
\text { Follow-up: } 72 \\
\text { hours }\end{array}$ & $\begin{array}{l}\text { The mean level } \\
\text { of muscle sore- } \\
\text { ness in the con- } \\
\text { trol group ranged } \\
\text { from } 0.5 \text { to } 8.5 \mathrm{~cm} \\
\text { (adjusted to a } 0 \\
\text { to } 10 \mathrm{~cm} \text { scale) }\end{array}$ & $\begin{array}{l}\text { The mean level of } \\
\text { muscle soreness } \\
\text { after antioxidant } \\
\text { supplementation } \\
\text { was } \mathbf{0 . 1 9} \text { standard } \\
\text { deviations lower } \\
\text { ( } 0.38 \text { to } 0.00 \text { lower) }\end{array}$ & $\begin{array}{l}\text { SMD }-\mathbf{0 . 1 9} \\
(-0.38 \text { to }-0.00)\end{array}$ & $\begin{array}{l}657 \\
\left(28 \text { studies }^{4}\right)\end{array}$ & $\begin{array}{l}\oplus \oplus \oplus \ominus \\
\text { moderate }^{6}\end{array}$ & $\begin{array}{l}\text { Based on the above 'rule of thumb', this result } \\
\text { equates to a small difference in favour of antioxi- } \\
\text { dant supplementation. } \\
\text { When we rescaled the data to a } 0 \text { to } 10 \mathrm{~cm} \text { scale, } \\
\text { the MD was lower by } 0.29 \mathrm{~cm}(0.59 \text { lower to } 0.02 \\
\text { higher). These are all under the typical MID for pain } \\
\text { (taken here as } 1.4 \mathrm{~cm} \text { ). }\end{array}$ \\
\hline $\begin{array}{l}\text { Muscle sore- } \\
\text { ness } \\
\text { Follow-up: } 96 \\
\text { hours }\end{array}$ & $\begin{array}{l}\text { The mean level } \\
\text { of muscle sore- } \\
\text { ness in the con- } \\
\text { trol group ranged } \\
\text { from } 0.2 \text { to } 5.6 \mathrm{~cm} \\
\text { (adjusted to a } 0 \\
\text { to } 10 \mathrm{~cm} \text { scale) }\end{array}$ & $\begin{array}{l}\text { The mean level of } \\
\text { muscle soreness } \\
\text { after antioxidant } \\
\text { supplementation } \\
\text { was } \mathbf{0 . 0 5} \text { standard } \\
\text { deviations lower } \\
\text { (0.29 lower to } 0.19 \\
\text { higher) }\end{array}$ & $\begin{array}{l}\text { SMD }-\mathbf{0 . 0 5} \\
(-0.29 \text { to } 0.19)\end{array}$ & $\begin{array}{l}436 \\
\left(17 \text { studies }^{4}\right)\end{array}$ & $\begin{array}{l}\oplus \oplus \ominus \ominus \\
\text { low }^{8}\end{array}$ & $\begin{array}{l}\text { Based on the above 'rule of thumb', this result } \\
\text { equates to a small difference in favour of antioxi- } \\
\text { dant supplementation but also includes a small ef- } \\
\text { fect in favour of placebo or no antioxidants. } \\
\text { However, when we rescaled the data to a } 0 \text { to } 10 \\
\mathrm{~cm} \text { scale, the MD was lower by } 0.03 \mathrm{~cm}(0.43 \text { lower } \\
\text { to } 0.37 \text { higher). These are all under the typical MID } \\
\text { for pain (taken here as } 1.4 \mathrm{~cm} \text { ). }\end{array}$ \\
\hline $\begin{array}{l}\text { Subjective re- } \\
\text { covery }\end{array}$ & See comment & See comment & - & See comment & - & $\begin{array}{l}\text { None of the } 50 \text { studies included in this review mea- } \\
\text { sured subjective recovery (return to previous activ- } \\
\text { ities without signs or symptoms). }\end{array}$ \\
\hline Adverse events & See comment & See comment & - & $\begin{array}{l}\text { See comment } \\
9 \text { studies } \\
\text { ( } 216 \text { partici- } \\
\text { pants) }\end{array}$ & $\begin{array}{l}\oplus \ominus \ominus \ominus \\
\text { very low } 9\end{array}$ & $\begin{array}{l}\text { Adverse effects were considered in only } 9 \text { studies } \\
\text { and actual events reported in } 2 \text { studies. One study } \\
\text { reported that all } 6 \text { participants in the antioxidant } \\
\text { supplementation group } 10 \text { had diarrhoea ( } 5 \text { mild, } 1 \\
\text { severe); } 4 \text { participants also reported mild indiges- } \\
\text { tion. One placebo group participant also had mild } \\
\text { indigestion. The second study reported mild gas- } \\
\text { trointestinal distress in } 1 \text { of } 26 \text { participants taking } \\
\text { the antioxidant supplement. }\end{array}$ \\
\hline
\end{tabular}

CI: confidence interval; RR: risk ratio; MD: mean difference; MID: minimal important difference; SMD: standardised mean difference 
High quality: Further research is very unlikely to change our confidence in the estimate of effect. Thus we are confident that the true effect lies close to what was found in the research

Moderate quality: Further research is likely to have an important impact on our confidence in the estimate of effect and may change the estimate. Thus, the true effect is likely to be close to what was found, but there is a possibility that it is substantially different

Low quality: Further research is very likely to have an important impact on our confidence in the estimate of effect and is likely to change the estimate. Thus, the true effect may be substantially different from what was found

Very low quality: We are very uncertain about the estimate.

1Although some participants were sedentary, the majority of participants were recreationally active or moderately trained athletes. No data were included from highly trained elite athletes. Most trial participants were male.

2Muscle damage was induced either mechanically (e.g. resistance-based exercise) or through whole body aerobic exercise (e.g. running, cycling, bench stepping).

${ }^{3}$ Typically, supplementation was taken before, the day of and after exercise for up to several days. The supplements were all taken orally, either as capsules, powders or drinks. All studies used an antioxidant dosage higher than the recommended daily amount.

4 In this analysis, one study tested two antioxidants compared with placebo control.

5 We downgraded the quality of evidence one level for serious study limitations (high/unclear risk of bias) and one level for serious inconsistency.

6 We downgraded the quality of evidence one level for serious study limitations (high/unclear risk of bias).

7In this analysis, two studies tested two antioxidants compared with placebo control.

8 We downgraded the quality of evidence one level for serious study limitations (high/unclear risk of bias) and one level for serious inconsistency.

${ }^{9}$ We downgraded the quality of evidence three levels for very serious study limitations, in particular reflecting bias relating failure to record or report on adverse events by the majority of trials.

10Notably the antioxidant used was NAC (N-acetylcysteine), which is a prescription medicine with antioxidant properties. Listed side effects of NAC include nausea, vomiting and diarrhoea or constipation. 


\section{B A C K G R O U N D}

\section{Description of the condition}

Muscle soreness after exercise is commonly referred to as delayed onset muscle soreness (DOMS) (Cheung 2003). DOMS is common in individuals who engage in strenuous and unaccustomed exercise and physical activity. It is classified as a grade 1 muscle strain injury and is characterised by localised tenderness and soreness (Cheung 2003). DOMS typically peaks between 24 to 72 hours after a bout of exercise but eventually disappears after five to seven days (Armstrong 1984; Bieuzen 2013; Bleakley 2012; Byrnes 1986; Cleak 1992; Costello 2015).

DOMS is particularly associated with exercise involving eccentric muscle action, such as in downhill running. An eccentric action is where a muscle generates tension to control the rate it lengthens (Close 2005), and it can cause significant muscle damage. DOMS could be detrimental for athletes who are returning to training from a prolonged period of inactivity. In addition, DOMS could deter individuals from adhering to an exercise programme. For some individuals, DOMS could result from excessive physical activity associated with daily living, particularly if repeated eccentric movements or unaccustomed physical activity are involved.

Several theories have been proposed to explain the mechanisms underlying DOMS. These include lactate accumulation (Asmussen 1953), inflammation (Smith 1991), muscle spasm (De Vries 1966), muscle damage (Hough 1900), connective tissue damage (Weinstock 1997), and increased muscle temperature (Davies 1972). A common feature of several of these proposed mechanisms is an increased production of free radicals (Maughan 1989), and reactive oxygen species. Indeed, it has been shown that reactive oxygen species are produced in nearly every biological process and that they also play a crucial role as signalling molecules for translating the exercise signals to appropriate adaptations (Margaritelis 2016).

\section{Description of the intervention}

Taking dietary antioxidants in the form of supplements (e.g. tablets, capsules, powders) or antioxidant-enriched foods (e.g. food concentrates) in doses much higher than the recommended amounts (up to 10 times the recommended daily amounts) several days before and after exercise has been proposed as a way to prevent or reduce muscle soreness after exercise. Two sources of antioxidants exist: exogenous (i.e. from dietary sources) and endogenous (i.e. produced by the body) (Watson 2010). Exogenous antioxidants include vitamin C, vitamin $E$, polyphenols, glutathione, carotenoids and coenzyme $Q_{10}$. These are typically found in plant sources such as dark-coloured vegetables, citrus fruits, legumes, nuts, grains, seeds and oils. Endogenous antioxidants include plasma proteins, bilirubin, uric acid and the enzymes superoxide dismutase, glutathione peroxidase and catalase (Watson 2010).

\section{How the intervention might work}

It has been reported that although physical activity is beneficial to health, any type of exercise causes oxidative stress, partly due to increased oxygen consumption, and could deplete the body's antioxidant defences and increase the rate of free radical production (Powers 2008; Ramel 2004; Witt 1992). Moreover, unaccustomed, eccentric or exhaustive exercise may also induce inflammatory reactions that can contribute to increased reactive oxygen species production and reduced antioxidant defences (Tsai 2001), causing exercise-induced muscle damage and resulting in DOMS (Cheung 2003). Dietary antioxidants may counteract oxidative stress by reducing the concentration of free radicals and reactive oxygen species associated with exercise (Powers 2008). Reducing DOMS could be beneficial to athletes when returning to training from injury (i.e. after a period of inactivity), and it could help sedentary and older individuals recover from unaccustomed physical activity.

\section{Why it is important to do this review}

The ease of taking antioxidant supplements to prevent and reduce muscle soreness after exercise and enhance recovery makes this an attractive option for physically active individuals. Moreover, antioxidant supplements are available to buy from supermarkets and health food stores and some are marketed to enhance recovery. However, our initial look at the evidence based on a small sample of the trials testing antioxidants for reducing DOMS showed that the evidence to support these claims was mixed (Bryer 2006; Howatson 2010; Mastaloudis 2006). There is conflicting evidence, too, on the potential for adverse effects of taking antioxidant supplements including impairment of post-exercise adaptations both acutely (Gomez-Cabrera 2008; Ristow 2009) and chronically (Paulsen 2014). All these pointed to the need for a systematic review of all the available trials.

\section{O B JECT IVES}

To assess the effects (benefits and harms) of antioxidant supplements and antioxidant-enriched foods for preventing and reducing the severity and duration of delayed onset muscle soreness following exercise.

\section{METHODS}

\section{Criteria for considering studies for this review}

\section{Types of studies}

All randomised controlled trials and quasi-randomised controlled trials (a method of allocating participants to groups that is not truly random; e.g. allocation by date of birth, day of the week, medical record number) investigating the effects of dietary antioxidants on preventing or reducing delayed onset muscle soreness. Only studies that measured muscle soreness and/or muscle tenderness were included in this study.

\section{Types of participants}

People of any age and level of physical or sports activity, performing exercise (i.e. eccentric, high-intensity, unaccustomed exercise) that is likely to induce DOMS. We included studies that used any type of exercise protocol.

\section{Types of interventions}

All forms of antioxidant supplementation including specific antioxidant supplements (i.e. tablets, powders, concentrates) and antioxidant-enriched foods or diets. No restrictions were placed on timing (pre-exercise or post-exercise), frequency, dose or duration, or type of antioxidant supplementation. Interventions that used more than one antioxidant (e.g. a combination of vitamins $C$ and $E$ ) were also included. 
We set out two comparisons.

- Antioxidant supplementation versus placebo or no supplementation.

- High-dose versus low-dose, where the low-dose supplementation is within normal or recommended levels for the antioxidant involved.

\section{Types of outcome measures}

Trials that did not record muscle soreness (pain) were not included in the review.

\section{Primary outcomes}

1. Muscle soreness (pain) - typically measured by a visual analogue scale (i.e. subjective)

2. Subjective recovery (return to previous activities without signs or symptoms)

3. Adverse effects (e.g. intestinal discomfort, diarrhoea)

\section{Secondary outcomes}

1. Muscle tenderness - typically measured using a handheld algometer

2. Performance variables (e.g. vertical jump, speed, agility)

3. Muscle force production (objective measures of muscle strength or power)

4. Range of motion

\section{Timing of outcome measurement}

Where appropriate, we extracted outcome data for the following time periods: the day of exercise, and daily up to seven days postexercise.

\section{Search methods for identification of studies}

\section{Electronic searches}

We searched the Cochrane Bone, Joint and Muscle Trauma Group Specialised Register (6 February 2017), the Cochrane Central Register of Controlled Trials (CENTRAL) (2017, Issue 2), MEDLINE (including Epub Ahead of Print, In-Process \& Other Non-Indexed Citations and Ovid MEDLINE Daily) (1946 to 3 February 2017), Embase (1980 to 2017 Week 5) and SPORTDiscus (1949 to 20 April 2017). We also searched ClinicalTrials.gov and the World Health Organization Clinical Trials Registry Platform for ongoing and recently completed studies (to 6 February 2017).

In MEDLINE, we combined a subject-specific search with the sensitivity-maximising version of the Cochrane Highly Sensitive Search Strategy for identifying randomised trials (Lefebvre 2011). The search strategies for MEDLINE, CENTRAL, Embase and SPORTDiscus are shown in Appendix 1.

We applied no language restrictions.

\section{Searching other resources}

We contacted experts in the field (identified by the lead authors in published studies) to find unpublished trials. We checked the bibliographies of included studies and relevant reviews for further references to relevant trials.

\section{Data collection and analysis}

\section{Selection of studies}

Two authors (MR and DR) independently screened the titles, abstracts and descriptors of the studies retrieved from the searches. Studies that appeared meet the inclusion criteria were selected and the above two authors independently reviewed the full-text articles. Any disagreements about study selection were resolved by consultation with the third and fourth author (HS and JC). If required, we contacted study authors for further information; this, however, did not include contacting authors to check whether DOMS had been measured where not stated in the trial reports.

\section{Data extraction and management}

Two authors (MR and DR) independently extracted data using a prepiloted data extraction form. We resolved any discrepancies that could not be settled by discussion by consultation with the third and fourth authors (HS and JC). Where necessary, we contacted primary authors of selected studies for additional information and data.

\section{Assessment of risk of bias in included studies}

Two authors (MR and DR) independently assessed the risk of bias in the included studies using the guidelines and criteria outlined in the Cochrane Handbook for Systematic Reviews of Interventions (Higgins 2011). We assessed the included studies for selection bias (random sequence generation and allocation concealment), performance bias (blinding of participants and personnel), detection bias (blinding of outcome assessment), attrition bias (incomplete outcome data), reporting bias (selective reporting) and any other sources of bias. We resolved any disagreement by discussion and, where necessary, consultation with the third author and forth author (HS and JC).

\section{Measures of treatment effect}

We calculated mean differences with $95 \%$ confidence intervals for continuous data. We calculated standardised mean differences and 95\% confidence intervals when combining results from studies using different ways of measuring a continuous outcome. Where possible, we used follow-up scores in preference to change scores. Should dichotomous data have been available, we planned to calculate risk ratios with $95 \%$ confidence intervals.

\section{Unit of analysis issues}

The unit of randomisation in the included trials was the individual participant. Some trials reported the same outcomes at more than one time point (e.g. soreness measured immediately after exercise, one day post-exercise, two days post-exercise, three days postexercise and so on). As planned, we extracted and presented data for the above listed time points up to seven days post-exercise. We consulted a statistician to discuss the appropriate use and processing of data from cross-over trials that were included in the review. For these, we extracted data at each time point and analysed the data as if a parallel design was employed (Deeks 2011). We judged that there was an adequate washout period in each of the trials.

\section{Dealing with missing data}

Where there were missing data for an included study, we contacted the primary study author via email. We ignored data missing at 
random and focused only on the available data. Where appropriate, we conducted intention-to-treat analyses in which all randomised participants are analysed in the groups to which they were originally assigned. While planned, there were insufficient data (often missing denominators) to conduct worst-case and best-case scenario sensitivity analyses to examine the potential effects of dropouts and exclusions. We contacted authors for missing mean and standard deviations. Where data were not available in the manuscript and the authors did not respond we extracted data from graphs using Graphclick 2010.

\section{Assessment of heterogeneity}

We visually evaluated heterogeneity between comparable trials using forest plots, and the $\mathrm{Chi}^{2}$ test and $\mathrm{I}^{2}$ statistic, with the level of significance for the $\mathrm{Chi}^{2}$ test being set at $\mathrm{P}=0.1$ (Deeks 2011). Thus, we considered a $\mathrm{P}$ value for $\mathrm{Chi}^{2}$ of $<0.1$ to indicate statistically significant heterogeneity between studies. We interpreted values of $\mathrm{I}^{2}$ as follows: $0 \%$ to $40 \%$ might not be important; $30 \%$ to $60 \%$ may represent moderate heterogeneity; $50 \%$ to $90 \%$ may represent substantial heterogeneity; and $75 \%$ to $100 \%$ may represent considerable heterogeneity.

\section{Assessment of reporting biases}

In view of the difficulty of detecting and correcting for publication bias and other reporting biases, we aimed to minimise their potential impact by ensuring a comprehensive search for eligible studies and by being alert for duplication of data. Where there were 10 or more studies in an analysis, we planned to use a funnel plot to explore the possibility of small-study effects (a tendency for estimates of the intervention effect to be more beneficial in smaller studies). (We restricted these to DOMS at 24 and 48 hours given these were the time periods for which the majority of data were available.)

\section{Data synthesis}

If considered appropriate, we pooled the results of comparable groups of trials. Initially we used the fixed-effect model and 95\% confidence intervals but then selected the random-effects model, again with $95 \%$ confidence intervals, because of the substantial clinical and statistically significant heterogeneity.

\section{Subgroup analysis and investigation of heterogeneity}

As described in Differences between protocol and review, we modified our list of planned subgroup analyses, which involved the removal of one (antioxidant supplement versus antioxidantenriched food) and the merging of two subgroups relating to type of exercise (normal sporting activities versus laboratoryinduced DOMS; exercise that requires high oxygen consumption (e.g. running, cycling) versus exercise that requires low oxygen consumption (e.g. eccentric exercise in one arm). We also added in a subgroup analysis relating to source of funding.

Our revised list of planned subgroup analyses is as follows.

- Treatment intervention

- Timing of administration (pre-exercise or post-exercise)

- Type of exercise
- Mechanically induced damage (e.g. resistance exercise) versus whole body aerobic exercise (e.g. running)

- Funding source

- Trials funded by food company or provider of antioxidant supplements versus those not funded by food company or provider of antioxidant supplements

To test whether subgroups were statistically significantly different from one another, we used the test for subgroup differences available in the Review Manager 5 software (RevMan 2014).

\section{Sensitivity analysis}

Where sufficient data were available, we performed sensitivity analyses to investigate the effects of various aspects of trial and review methodology. We performed limited sensitivity analyses to explore the effects of inclusion of trials at high or unclear risk of selection bias, principally from lack of or unclear allocation concealment, the effects of including cross-over trials, and from the choice of model for data synthesis (fixed-effect compared with random-effects). We did not conduct our other planned sensitivity analyses to explore the effects of inclusion of trials at high risk of selection bias specifically because of lack of allocation concealment, or for which only abstracts were obtained, or the effects of missing data.

\section{'Summary of findings' table}

We prepared a 'Summary of findings' table for the main comparison (antioxidant supplementation versus a placebo intervention) (Schünemann 2011). We summarised the quality of evidence by applying the principles of the GRADE framework and following the recommendations and worksheets of the Cochrane Effective Practice and Organisation of Care Group for creating 'Summary of findings' tables (EPOC 2013). We assessed the quality of the evidence according to four levels (high, moderate, low and very low). We selected muscle soreness up to 6 hours after exercise, 24, 48, 72 and 96 hours; subjective recovery and adverse events for presentation in a 'Summary of findings' table.

\section{RESULTS}

\section{Description of studies}

\section{Results of the search}

The search was completed in February 2017. We screened a total of 1558 records from the following databases: Cochrane Bone, Joint and Muscle Trauma Group Specialised Register (25 records), CENTRAL (194), MEDLINE (302), Embase (476), SPORTDiscus (117), ClinicalTrials.gov (162) and the WHO International Clinical Trials Registry Platform (282). We also identified 12 potentially eligible studies from ongoing searches and through contacting experts in the field.

The search resulted in the identification of 128 potentially eligible studies, for which we obtained full reports. Upon study selection, we included 50 (see Included studies) and excluded 77 (see Excluded studies). One study is ongoing (NCT02281981). A flow diagram summarising the study selection process is presented in Figure 1. 


\section{Figure 1. Study flow diagram}

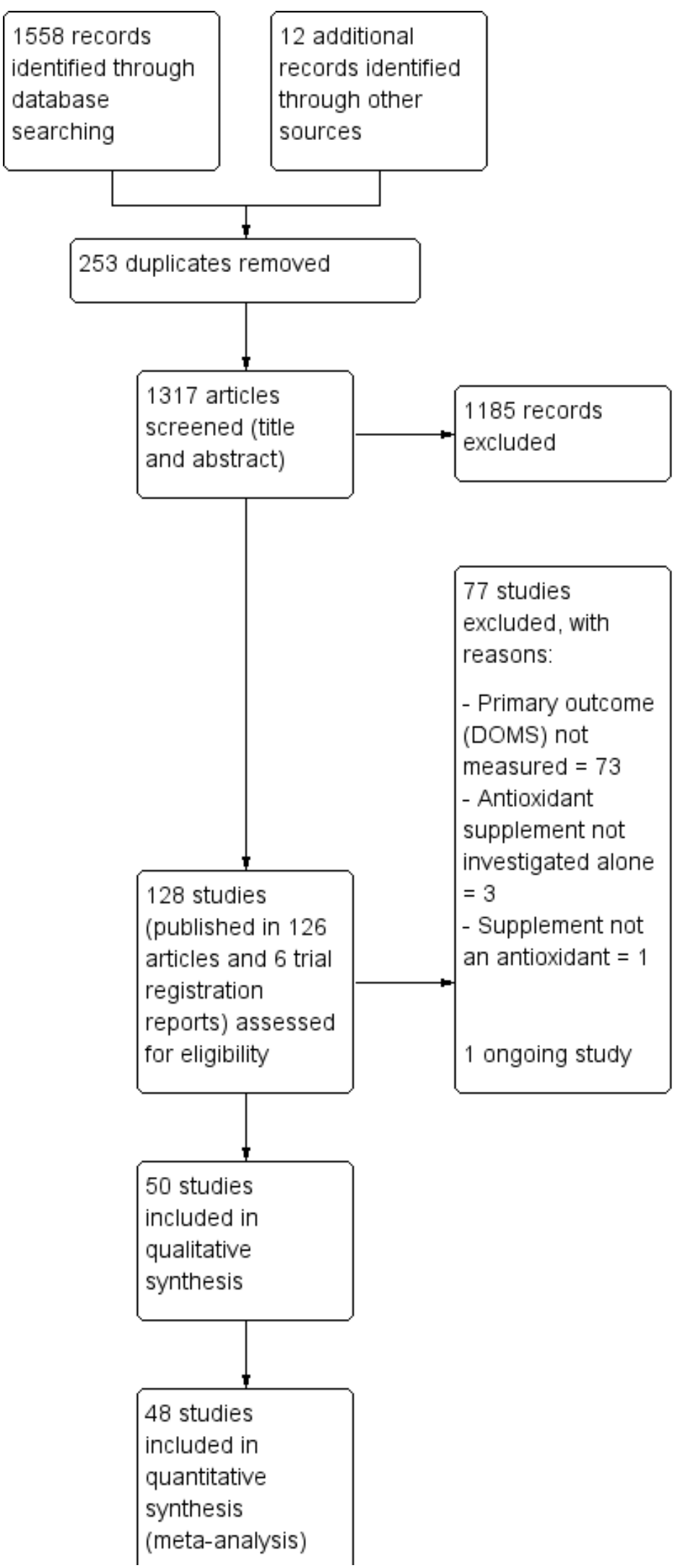


Figure 1. (Continued)

$$
\text { (meta-analysis) }
$$

\section{Included studies}

We included 50 studies with a total of 1089 participants of which 48 studies with 1043 participants were included in the quantitative synthesis (meta-analysis) for muscle soreness. All the studies were reported in English in peer-reviewed journals, in articles published between 1992 to 2016. Details of the individual studies are provided in Characteristics of included studies.

We contacted the authors of 33 studies to request for raw data for delayed onset muscle soreness (DOMS), maximal voluntary isometric contraction (MVIC), range of motion (ROM) and performance measures. Nineteen authors responded to our request (Bell 2015; Bell 2016; Bloomer 2004; Bloomer 2005; Bloomer 2007; Close 2006; Cobley 2011; Drobnic 2014; He 2015; Howatson 2009; Kaminski 1992; Kerksick 2009; Laupheimer 2014; Nicol 2015; O'Fallon 2012; Tanabe 2015; Thompson 2004; Trombold 2010; Trombold 2011); and 14 did not (Arent 2010; Avery 2003; Beaton 2002a; Bryer 2006; Connolly 2006; Connolly 2006a; Goldfarb 2011; Herrlinger 2015; Krotkiewski 1994; McFarlin 2016; Michailidis 2013; Phillips 2003; Peschek 2014; Su 2008). With the exception of Herrlinger 2015, we successfully extracted data from graphs for the other 13 studies in the second category using GraphClick, Arizona (version 3.0.2, 2010)

The two studies not included in the quantitative analyses for DOMS were Herrlinger 2015 and McCormick 2016. This resulted in the loss of 37 participants for whom DOMS data were missing for Herrlinger 2015 and of nine participants for McCormick 2016. We only included the data for McCormick 2016 in the qualitative analysis because the exercise paradigm was completely different to all the other studies included in this review. The other studies used an exercise paradigm where mechanical or whole body aerobic exercise was used to cause muscle damage and then a range of outcomes such as muscle soreness, muscle function, range of motion and performance were measured at various time points up to several days after exercise. However, participants in McCormick 2016 had a fixed daily training regimen for five continuous days performance, with outcomes being measured at the start and then throughout the trial. Thus the severity of muscle damage caused by the daily training regimen was not controlled.

\section{Design}

All 50 studies were randomised controlled trials; no quasirandomised controlled trials met the inclusion criteria. Thirty-eight trials (with a total of 901 participants) employed a parallel design. The other 12 trials (with a total of 188 participants) employed a cross-over design (Arent 2010; Connolly 2006a; Kaminski 1992; McCormick 2016; McLeay 2012; Michailidis 2013; Nicol 2015; Peschek 2014; Tanabe 2015; Thompson 2001; Trombold 2010; Trombold 2011). The time between intervention arms in the crossover trials was five days in Arent 2010; 14 days in Connolly 2006a, Nicol 2015, Thompson 2001, Trombold 2010 and Trombold 2011; 21 days in Kaminski 1992 and Peschek 2014; 28 days in Tanabe 2015; 30 days in McLeay 2012; 35 days in McCormick 2016 and 42 days in Michailidis 2013.
Three studies had three groups: Herrlinger 2015 compared low-dose phenolic blend (12 participants) versus high-dose phenolic blend (12 participants) versus placebo (13 participants); Kerksick 2009 compared epigallocatechin gallate supplementation (10 participants) versus $\mathrm{N}$-acetyl cysteine supplementation (10 participants) versus placebo (10 participants); and Silva 2008 compared $\mathrm{N}$-acetyl cysteine (nine participants) versus $\mathrm{N}$-acetyl cysteine plus placebo (eight participants) versus placebo (eight participants).

\section{Sample sizes}

The 50 trials included a total of 1089 participants with 901 participants in the parallel-group trials (range 7 to 54) and 188 participants in the cross-over trials (range 8 to 24).

\section{Setting}

Twenty-four studies were conducted in the USA (Arent 2010; Avery 2003; Beaton 2002a; Bloomer 2004; Bloomer 2005; Bloomer 2007; Bryer 2006; Connolly 2006; Connolly 2006a; Goldfarb 2011; He 2015; Herrlinger 2015; Hutchinson 2016; Kaminski 1992; Kerksick 2009; Kuehl 2010; McBride 1997; McFarlin 2016; O'Connor 2013; O'Fallon 2012; Peschek 2014; Phillips 2003; Trombold 2010; Trombold 2011); 12 studies were carried out in the UK (Bailey 2011; Bell 2015; Bell 2016; Close 2006; Cobley 2011; Howatson 2009; Laupheimer 2014; Lynn 2015; Thompson 2001; Thompson 2001a; Thompson 2003; Thompson 2004); two studies were conducted in Australia (McCormick 2016; Nicol 2015); two studies in Brazil (Silva 2008; Silva 2010); two studies in China (Nie 2004; Su 2008); two studies in Greece (Michailidis 2013; Theodorou 2011); one study in Iran (Meamarbashi 2011); one study in Ireland (Shafat 2004); one study in Japan (Tanabe 2015); one study in New Zealand (McLeay 2012); one study in Poland (Krotkiewski 1994); and one study in Spain (Drobnic 2014).

Seven trials were designed to produce DOMS under field-based conditions (Bailey 2011; Cobley 2011; Howatson 2009; Kuehl 2010; Laupheimer 2014; Lynn 2015; McCormick 2016), and the other 43 studies were designed to produce DOMS under laboratory-based conditions.

\section{Funding source}

Details of the funding of individual studies are given in Characteristics of included studies. In all, 21 studies were industry funded either by a food company or a provider of antioxidant supplements (Arent 2010; Bailey 2011; Beaton 2002a; Bell 2015; Bell 2016; Bloomer 2005; Bloomer 2007; Connolly 2006a; Herrlinger 2015; Kerksick 2009; Kuehl 2010; McFarlin 2016; O'Connor 2013; Peschek 2014; Phillips 2003; Tanabe 2015; Thompson 2001; Thompson 2001a; Thompson 2003; Trombold 2010; Trombold 2011). Of the 28 other studies reporting on funding, 15 declared "none" in their report (Avery 2003; Bloomer 2004; Bryer 2006; Close 2006; Cobley 2011; Connolly 2006; Drobnic 2014; Hutchinson 2016; Kaminski 1992; Laupheimer 2014; McBride 1997; Nie 2004; Shafat 2004; Theodorou 2011; Thompson 2004); the other 13 referring to various sources of university and public body research funding sources (Goldfarb 2011; He 2015; Howatson 2009; Krotkiewski 1994; 
Lynn 2015; McCormick 2016; McLeay 2012; Meamarbashi 2011; Michailidis 2013; Nicol 2015; O'Fallon 2012; Silva 2008; Silva 2010). We were unsuccessful in obtaining information on funding from the only trial that did not report on this (Su 2008).

\section{Participants}

Of the 1089 participants, 961 (88.2\%) were male and 128 (11.8\%) were female. Two studies recruited females only (Bloomer 2004; McLeay 2012). The age range of participants was between 16 (Nie 2004) and 55 years (Laupheimer 2014). The majority of the studies recruited recreationally active or moderately trained participants with the exception of seven studies (Bryer 2006; Kerksick 2009; Meamarbashi 2011; O'Connor 2013; O'Fallon 2012; Phillips 2003; Tanabe 2015), which included a total of 193 sedentary participants. One study had a sample of 16 semi-professional soccer players (Bell 2016) and one study (Laupheimer 2014) had seven well-trained distance runners. Only McCormick 2016 had participants (nine in all) who were classed as highly-trained elite athletes.

\section{Details of exercise}

There was a range of different exercise models used to induce muscle damage. Twenty-eight studies used mechanically induced exercise (i.e. resistance-based exercise) and 22 studies used whole body aerobic exercise (i.e. running, cycling, bench stepping). The majority of the studies that used mechanically induced exercise employed some form of resistance training protocol using weights or an isokinetic dynamometer to induce delayed onset muscle damage and soreness with large variances on number of repetitions, sets and percentage of load used. One study used a circuit training session where participants rotated round a circuit of cycling and stepping exercises (Krotkiewski 1994). Two studies used a repeated maximal sprint protocol on a cycle ergometer (Arent 2010; Bell 2016), one study used a repeated bench stepping protocol (Meamarbashi 2011), and one study used a repeated squat jump protocol using a weighted jacket (Nie 2004). Sixteen studies used a running model: seven trials used a downhill running protocol on a treadmill (Close 2006; Drobnic 2014; He 2015; Herrlinger 2015 Peschek 2014; Su 2008; Thompson 2004); four trials used the 90 minute Loughborough Intermittent Shuttle Running Test (LIST) (Bailey 2011; Thompson 2001; Thompson 2001a; Thompson 2003); one study used the YoYo IR 1 repeated sprint test (Cobley 2011), and three trials used a competitive running race to induce damage. Howatson 2009 and Laupheimer 2014 used the London marathon, one study used the ultra-endurance Hood Coast Relay, which is based in the United States (Kuehl 2010), and one study used a half marathon run (Lynn 2015).

The majority of the studies asked the participants to refrain from strenuous exercise, refrain from taking any form of antiinflammatory medication or other supplements, and not use any other form of analgesic activity that would reduce or relieve soreness, such as an ice bath or massage, for the duration of the study. Participants were typically excluded if they took any form of supplementation regularly or had any type of chronic inflammatory condition.

\section{Interventions}

In all trials, an antioxidant supplement was compared with a placebo. A summary of the antioxidant supplement regimens tested in the individual trials is presented in Table 1.
In all, 13 trials used antioxidants from a whole natural food source (Bell 2015; Bell 2016; Connolly 2006a; Howatson 2009; Hutchinson 2016; Kuehl 2010; Lynn 2015; McCormick 2016; McLeay 2012; O'Connor 2013; Peschek 2014; Trombold 2010; Trombold 2011), 19 used an antioxidant extract or mixed antioxidants (Arent 2010; Bailey 2011; Bloomer 2005; Cobley 2011; Drobnic 2014; Goldfarb 2011; Herrlinger 2015; Kerksick 2009; Krotkiewski 1994; Laupheimer 2014; McFarlin 2016; Meamarbashi 2011; Michailidis 2013; Nicol 2015; O'Fallon 2012; Phillips 2003; Silva 2008; Su 2008; Tanabe 2015), and 18 provided either vitamin C or vitamin E or both together (Avery 2003; Beaton 2002a; Bloomer 2004; Bloomer 2007; Bryer 2006; Close 2006; Connolly 2006; He 2015; Kaminski 1992; McBride 1997; Nie 2004; Shafat 2004; Silva 2010; Theodorou 2011; Thompson 2001; Thompson 2001a; Thompson 2003; Thompson 2004). All studies used a placebo either as a powder, capsule or drink; however, three studies did not provide details of what the placebo comprised (Arent 2010; McBride 1997; Nie 2004).

No trials compared high-dose versus low-dose antioxidant supplements, where the low-dose supplementation is within normal or recommended levels for the antioxidant involved.

\section{Antioxidants used}

Whole foods tested were:

- Bilberry juice ( $n=19)$ (Lynn 2015)

- Blackcurrant nectar $(n=16)$ (Hutchinson 2016)

- Blueberry smoothie $(n=10)$ (McLeay 2012)

- Cherry ( $n=127$ ) (Bell 2015, $n=16$; Bell 2016, $n=16$; Connolly 2006a, $n=16$; Howatson 2009, $n=16$; Kuehl 2010, $n=54$; McCormick 2016, n = 9)

- Cocoa $(n=8)$ (Peschek 2014)

- Mixed grape drink $(n=40)\left(O^{\prime} C o n n o r ~ 2013\right)$

- Pomegranate juice $(n=33$ ) (Trombold 2010, $n=16$; Trombold $2011, \mathrm{n}=17$ )

Antioxidant extract or mixed or other antioxidants tested were:

- Allicin ( $n=16)($ Su 2008)

- Astaxanthin extract $(n=20)$ (Bloomer 2005)

- Black tea extract $(n=18)$ (Arent 2010)

- Curcumin ( $n=79$ ) (Drobnic 2014, $n=20$; McFarlin 2016, $n=28$; Nicol 2015, $n=17$; Tanabe 2015, $n=14$ )

- Fruit and vegetable powder (Juice Plus) ( $N=44)$ (Goldfarb 2011)

- Green and black tea extract $(n=37)$ (Herrlinger 2015)

- Mixed antioxidants (vitamin C, E, B6, B9, B12 and zinc) ( $n=38$ ) (Bailey 2011)

- Mixed flavanoid antioxidants ( $N=40)$ (Phillips 2003)

- $\mathrm{N}$-acetylcysteine (NAC) with epigallocatechin gallate (EGCG) $(\mathrm{n}=$ 30) (Kerksick 2009)

- N-acetylcysteine (NAC) ( $n=53$ ) (Cobley 2011, $n=14$; Michailidis 2013, $n=10 ;$ Silva 2008, $n=29)$

- Pollen extract $(n=50)$ (Krotkiewski 1994)

- Purslane extract $(n=20)$ (Meamarbashi 2011)

- Quercetin ( $n=30)$ (O'Fallon 2012)

- Resveratrol $(n=7)$ (Laupheimer 2014)

Vitamin C or E or both combined were: 
- Vitamin C ( $\mathrm{n}=158)$ (Bryer 2006, $\mathrm{n}=18$; Close 2006, $\mathrm{n}=20$ Connolly 2006, $n=24$; Kaminski 1992, $n=25$; Nie 2004, $n=16$; Thompson 2001, $\mathrm{n}=9$; Thompson 2001a, $\mathrm{n}=16$; Thompson 2003, $\mathrm{n}=16$; Thompson 2004, $\mathrm{n}=14$ )

- Vitamin C and E co-ingestion ( $\mathrm{n}=134$ ) (Beaton 2002a, $\mathrm{n}=18$; Bloomer 2004, $n=18$; Bloomer 2007, $n=36$; He 2015, $n=22$; Shafat 2004, $n=12$; Theodorou 2011, $n=28$ )

- Vitamin E ( $n=57$ ) (Avery 2003, $n=18$; McBride 1997, $n=12$; Silva $2010, n=27)$

There was a large variation across the studies regarding the duration of supplementation: the shortest period was under one day (Tanabe 2015; Thompson 2001) and the longest period was 91 days (Herrlinger 2015). Although the form of supplement was varied, including capsules, powders and drinks, every study used an antioxidant dosage higher than the recommended daily amount. Every study required the participant to ingest the supplement orally either once daily or up to three times per day.

Supplementation was taken before, the day of and after exercise for up to several days in all the studies except for three studies where supplements were post-exercise only (Michailidis 2013; Peschek 2014; Thompson 2003).

\section{Outcomes}

Primary outcomes

\section{Muscle pain}

All 50 trials included muscle soreness as an outcome measure, the recording of which was an inclusion criterion of this review. Details of the measurement of muscle soreness in the individual trials are presented in Table 2.

Thirty-three trials measured muscle soreness using a 0 to 10 $\mathrm{cm}$ (or 0 to $100 \mathrm{~mm}$ ) visual analogue scale (VAS). Of the 17 other trials, seven measured soreness using a 1 to $10 \mathrm{~cm}$ scale (Bailey 2011; Bryer 2006; Goldfarb 2011; Kaminski 1992; Michailidis 2013;Thompson 2001; Thompson 2003); four trials used the 0 to 20 cm (or 0 to $200 \mathrm{~mm}$ ) scale (Bell 2015; Bell 2016; Howatson 2009; Lynn 2015); two studies (He 2015; Meamarbashi 2011) used a 0- to 6-point scale, Herrlinger 2015 used a 0 to 7 Likert scale, Drobnic 2014 used a 0- to 4-point scale; Cobley 2011 used a 0 to $12 \mathrm{~cm}$ scale and Su 2008 used the Borg CR-10 scale (Borg 1998). The Borg CR-10 scale ranges from 0 (no soreness) to 10 (maximal soreness). In the included studies, participants were asked to rate a muscle soreness on the soreness scales by either carrying out a squat using body weight, self palpitation of muscle or based on muscle soreness at rest.

There was considerable variation on the timing of the soreness measurement after the damaging exercise occurred. Whilst all the trials measured soreness at baseline, 18 studies measured muscle soreness immediately after exercise, two studies measured soreness two hours after exercise (Trombold 2010; Trombold 2011), and one study measured soreness six hours after exercise (Kerksick 2009). Due to this variation, we grouped these studies into the 'up to 6 hours post-exercise' category. In addition to measuring soreness immediately after exercise, a few trials also measured soreness 2, 4, 6 or 10 hours post-exercise although the earliest follow-up time point to immediately post-exercise was used. Fortyone trials measured muscle soreness at 24 hours, 45 trials at 48 hours, 28 trials at 72 hours and 17 trials at 96 hours post-exercise.
Only six trials measured muscle soreness subsequently: four trials measured soreness at 120 hours post-exercise (Krotkiewski 1994; Michailidis 2013; O'Fallon 2012; Theodorou 2011), one study at 144 hours (Michailidis 2013), and three studies at 168 hours after exercise (Michailidis 2013; Phillips 2003; Silva 2008).

\section{Subjective recovery}

None of the 50 included trials measured the primary outcome of subjective recovery.

\section{Adverse effects}

Only nine studies reported information on adverse effects, seven of which reported no adverse effects of antioxidant supplementation (Kerksick 2009; Laupheimer 2014; Lynn 2015; McLeay 2012; Michailidis 2013; O'Connor 2013; Phillips 2003), and two which reported specific adverse effects (Cobley 2011; Kuehl 2010). The remaining 41 studies failed to report adverse effects.

\section{Secondary outcomes}

\section{Muscle tenderness}

Muscle tenderness (or pressure pain threshold, PPT) was measured in four trials using a handheld algometer where the cylindrical metal probe was placed on the belly of the muscle and the investigator applied pressure gradually to the point where the participant felt discomfort (Close 2006; Connolly 2006; Connolly 2006a; Peschek 2014).

\section{Performance variables}

Performance variables were measured in five trials: Arent 2010 used the 30-second Wingate to measure power output in Watts per $\mathrm{kg}$ of body weight (W/kg); Bell 2015 measured cycling efficiency; Bell 2016 used a battery of tests including the $20 \mathrm{~m}$ sprint, 505 Agility test and counter-movement jump; Cobley 2011 used the 20 m sprint and Yo-Yo test; and O'Connor 2013 examined the effects of antioxidant supplementation on maximal oxygen consumption.

\section{Muscle force}

Muscle force production was measured in 30 trials using a dynamometer or an isokinetic dynamometer in the muscle where damage was caused (Bailey 2011; Beaton 2002a; Bell 2015; Bell 2016; Bloomer 2004; Bloomer 2005; Bloomer 2007; Bryer 2006; Close 2006; Cobley 2011; Connolly 2006; Connolly 2006a; Goldfarb 2011; Herrlinger 2015; Howatson 2009; Kerksick 2009; McLeay 2012; Meamarbashi 2011; Michailidis 2013; O'Connor 2013; O'Fallon 2012; Peschek 2014; Shafat 2004; Tanabe 2015; Theodorou 2011; Thompson 2001; Thompson 2001a; Thompson 2003; Trombold 2010; Trombold 2011). The main variable measured in these trials was peak isometric force.

\section{Range of motion}

Range of motion was assessed in 13 trials using a goniometer and units were reported in degrees (Bailey 2011; Beaton 2002a; Bloomer 2004; Bryer 2006; Connolly 2006; Goldfarb 2011; Howatson 2009; McLeay 2012; Meamarbashi 2011; O'Connor 2013; O'Fallon 2012; Tanabe 2015; Theodorou 2011). Flexion range was determined either in the elbow or the knee by using universal landmarks to ensure consistency on subsequent measures. 


\section{Excluded studies}

We excluded 77 studies, 73 because delayed onset muscle soreness was not measured (Characteristics of excluded studies). One study was excluded because the supplement used is not classed as an antioxidant (Kingsley 2006). We excluded one study because the antioxidant supplement was co-ingested with a fish oil supplement and therefore the effect of antioxidant-only supplementation was not examined (Lenn 2002). We excluded one study because the antioxidant was combined with a protein supplement (RomanoEly 2006), and we excluded one study because antioxidants were combined with ibuprofen, cold water immersion and whey protein at the same time (Al-Nawaiseh 2016).

\section{Studies awaiting classification}

There are no studies awaiting classification.

\section{Ongoing trials}

Details of one ongoing trial testing curcumin supplementation are available in the Characteristics of ongoing studies table (NCT02281981).

\section{Risk of bias in included studies}

Details of the 'Risk of bias' assessment, including methods of randomisation, for individual trials are provided in Characteristics of included studies and the assessments are summarised in Figure 2 and Figure 3. 
Figure 2. 'Risk of bias' summary: review authors' judgements about each risk of bias item for each included study.

\begin{tabular}{|c|c|c|c|c|c|c|c|}
\hline & 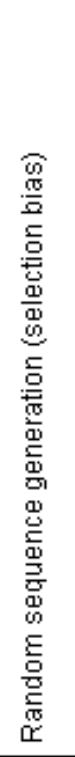 & 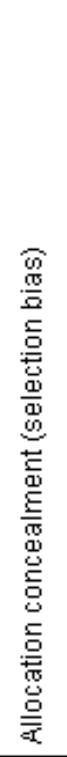 & 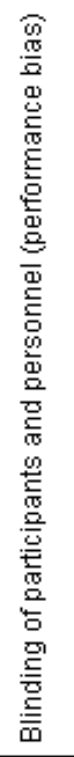 & 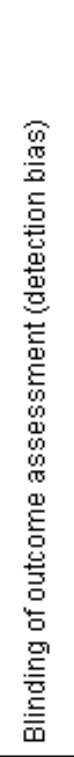 & 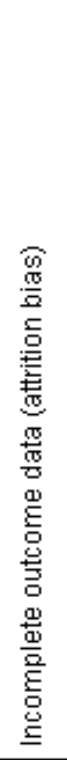 & 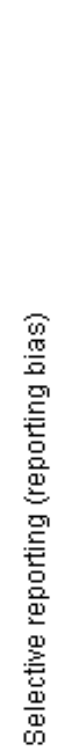 & 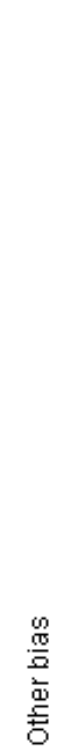 \\
\hline Arent 2010 & $?$ & $?$ & $\odot$ & $\odot$ & $\Theta$ & - & $\odot$ \\
\hline Avery 2003 & + & $?$ & + & + & + & $\theta$ & + \\
\hline Bailey 2011 & + & $\odot$ & + & $\odot$ & $\odot$ & - & $?$ \\
\hline Beaton 2002a & $?$ & $?$ & $\odot$ & $\odot$ & $\odot$ & - & $\odot$ \\
\hline Bell 2015 & $\odot$ & $\odot$ & + & $\odot$ & $\odot$ & - & $\odot$ \\
\hline Bell 2016 & $\odot$ & $\odot$ & $\odot$ & $\odot$ & $\odot$ & 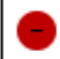 & $?$ \\
\hline Bloomer 2004 & $\odot$ & $\odot$ & + & $\odot$ & $\odot$ & 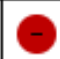 & + \\
\hline Bloomer 2005 & + & 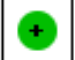 & + & 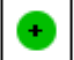 & $\odot$ & 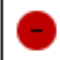 & $?$ \\
\hline Bloomer 2007 & + & 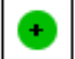 & + & $\bullet$ & $\Theta$ & 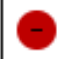 & 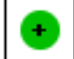 \\
\hline Bryer 2006 & $?$ & $?$ & $?$ & $?$ & $\odot$ & 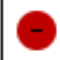 & 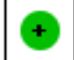 \\
\hline Close 2006 & + & + & + & + & $\odot$ & 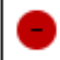 & + \\
\hline Cobley 2011 & + & + & + & + & $\odot$ & + & + \\
\hline Connolly 2006 & $?$ & $?$ & + & + & $\odot$ & - & + \\
\hline Connolly 2006a & $?$ & $?$ & $?$ & $?$ & $\Theta$ & O & $\odot$ \\
\hline Drobnic 2014 & + & $?$ & $\odot$ & $?$ & $\odot$ & O & + \\
\hline Goldfarb 2011 & $?$ & $?$ & + & + & + & $\theta$ & + \\
\hline He 2015 & $\odot$ & + & $\odot$ & + & $\odot$ & $\Theta$ & + \\
\hline Herrlinger 2015 & + & + & $?$ & $?$ & $\odot$ & $\odot$ & + \\
\hline Howatson 2009 & $\odot$ & $?$ & $\odot$ & $\odot$ & $\odot$ & $\theta$ & + \\
\hline Hutchinson 2016 & + & $?$ & $\odot$ & $\odot$ & 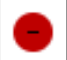 & $\odot$ & $\odot$ \\
\hline
\end{tabular}


Figure 2. (Continued)

\begin{tabular}{|c|c|c|c|c|c|c|c|}
\hline Hutchinson 2016 & $\odot$ & $?$ & $\odot$ & $\odot$ & $\Theta$ & $\Theta$ & + \\
\hline Kaminski 1992 & $\odot$ & $?$ & $\odot$ & 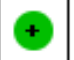 & $\odot$ & $\Theta$ & + \\
\hline Kerksick 2009 & $\odot$ & $\odot$ & + & + & + & $\odot$ & + \\
\hline Krotkiewski 1994 & $?$ & $?$ & $\odot$ & + & $?$ & $\Theta$ & $?$ \\
\hline Kuehl 2010 & $?$ & $?$ & $\odot$ & + & + & $\odot$ & + \\
\hline Laupheimer 2014 & + & + & + & $\odot$ & $\odot$ & $\odot$ & + \\
\hline Lynn 2015 & $\oplus$ & $?$ & - & $?$ & 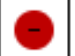 & $\odot$ & $\odot$ \\
\hline McBride 1997 & $?$ & $?$ & $?$ & $?$ & + & $\ominus$ & $?$ \\
\hline McCormick 2016 & + & + & + & + & + & $\Theta$ & $?$ \\
\hline McFarlin 2016 & $\oplus$ & $?$ & + & + & $\odot$ & $\Theta$ & + \\
\hline McLeay 2012 & 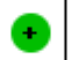 & $\odot$ & 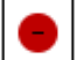 & - & + & $\odot$ & $?$ \\
\hline Meamarbashi 2011 & + & $\odot$ & + & $\odot$ & + & $\odot$ & + \\
\hline Michailidis 2013 & $?$ & $?$ & + & + & $\Theta$ & $\odot$ & $?$ \\
\hline Nicol 2015 & $?$ & $\odot$ & $\odot$ & $\odot$ & $\odot$ & $\Theta$ & $?$ \\
\hline Nie 2004 & $?$ & $?$ & + & $\odot$ & $\odot$ & $\Theta$ & $?$ \\
\hline O'Connor 2013 & $\oplus$ & $\odot$ & + & $\oplus$ & + & + & + \\
\hline O'Fallon 2012 & + & $?$ & + & $\odot$ & $\odot$ & $\odot$ & + \\
\hline Peschek 2014 & $\oplus$ & $\odot$ & 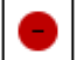 & $\odot$ & $\odot$ & $\Theta$ & + \\
\hline Phillips 2003 & $?$ & $?$ & $\odot$ & $\odot$ & $\Theta$ & $\odot$ & + \\
\hline Shafat 2004 & + & $?$ & $\odot$ & $?$ & + & $\Theta$ & $?$ \\
\hline Silva 2008 & $\odot$ & $\odot$ & - & $\odot$ & - & $\theta$ & $?$ \\
\hline Silva 2010 & $\oplus$ & $\odot$ & $\oplus$ & $\odot$ & O & $\Theta$ & $?$ \\
\hline Su 2008 & $\odot$ & $?$ & $?$ & $?$ & $\odot$ & $\Theta$ & $\odot$ \\
\hline Tanabe 2015 & $?$ & $?$ & $\odot$ & $?$ & + & $\Theta$ & + \\
\hline Theodorou 2011 & $\Theta$ & + & + & $\odot$ & + & $?$ & $?$ \\
\hline Thompson 2001 & + & $?$ & + & + & + & $\ominus$ & $?$ \\
\hline Thompson 2001a & + & $?$ & + & + & + & $\Theta$ & + \\
\hline Thompson 2003 & + & $?$ & + & $\odot$ & $\odot$ & $\Theta$ & + \\
\hline Thompson 2004 & + & $?$ & + & + & + & $\odot$ & $?$ \\
\hline Trombold 2010 & $?$ & $?$ & $\odot$ & $\odot$ & $\odot$ & $\theta$ & + \\
\hline Trombold 2011 & $?$ & $?$ & $\odot$ & $\odot$ & + & $\Theta$ & + \\
\hline
\end{tabular}


Figure 3. 'Risk of bias' graph: review authors' judgements about each risk of bias item presented as percentages across all included studies

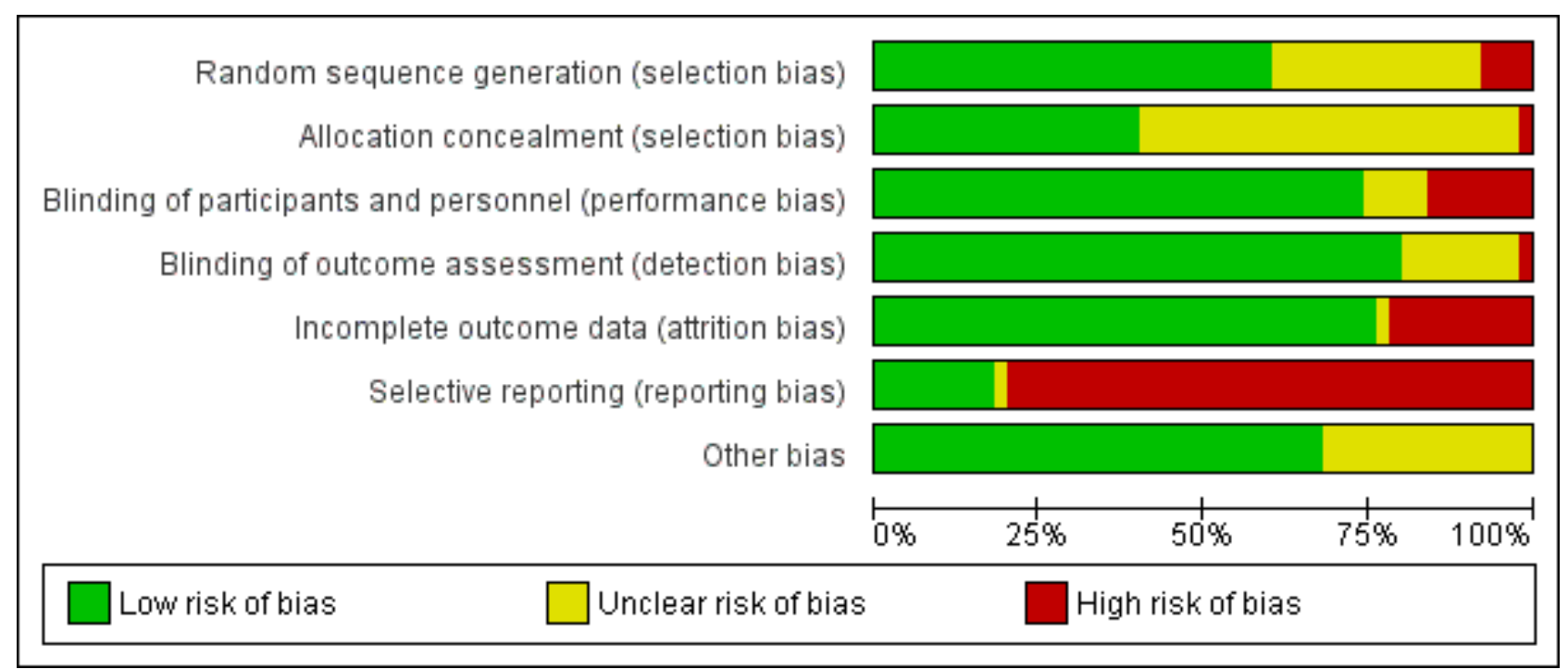

\section{Allocation}

\section{Random sequence generation}

We judged 30 studies, all of which gave details of random sequence generation, at low risk of bias. We rated 15 studies at unclear risk of bias because they did not specify how the random sequence was generated and attempts obtain clarification from authors were unsuccessful. Clarification received from the authors of Tanabe 2015 did not confirm effective random sequence generation and so we judged this at unclear risk of bias too.

Four studies were at high risk of bias (Howatson 2009; Kerksick 2009; Su 2008; Theodorou 2011). Howatson 2009 matched on sex and predicted finishing time. Participants were matched in clusters according to age and body weight for assignment in Kerksick 2009. Su 2008 randomly assigned participants into an allicin or control group according to sex and sports participation and in Theodorou 2011, participants were allocated based on age, body mass index (BMI) and maximum isometric torque into equal groups then a computer generator was used for the assignment into groups.

\section{Concealment of treatment allocation}

We deemed that 20 studies had a low risk of bias because allocation concealment was very likely (Bailey 2011; Bell 2015; Bell 2016; Bloomer 2004; Bloomer 2005; Bloomer 2007; Close 2006; Cobley 2011; He 2015; Herrlinger 2015; Kerksick 2009; Laupheimer 2014; McCormick 2016; Meamarbashi 2011; Nicol 2015; O'Connor 2013; Peschek 2014; Silva 2008; Silva 2010; Theodorou 2011). We rated 23 studies at unclear risk as there were no details specified in the manuscripts and authors did not respond to our request for clarification. The authors of a further six studies responded to our query but their response was unclear thus they were assessed also at unclear risk of bias (Drobnic 2014; Howatson 2009; Lynn 2015; Nie 2004; Shafat 2004; Tanabe 2015). We considered McLeay 2012 at high risk of bias because safeguards to ensure allocation concealment were absent and the treatment for the second stage of this cross-over trial would have been predictable.

\section{Blinding}

Overall, 36 studies were double-blind or blinding was reported and therefore we assessed them at low risk of performance and detection bias.

We assessed eight studies at high risk of performance bias because of the lack of blinding of personnel (Drobnic 2014; Howatson 2009; Lynn 2015; McLeay 2012; Peschek 2014; Shafat 2004; Silva 2008; Tanabe 2015). We rated five studies at unclear risk of performance bias as there were no details specified in the trial reports and the authors did not respond to our request for clarification (Bryer 2006; Connolly 2006a; Herrlinger 2015; McBride 1997; Su 2008). We assessed only one study at high risk of detection bias, with a clear possibility of a lack of participant blinding (McLeay 2012). Of the nine six studies assessed at unclear risk of detection bias, six provided no details of whether there was blinding (Bryer 2006; Connolly 2006a; Herrlinger 2015; McBride 1997; Su 2008; Tanabe 2015), and there were reasons for some doubts about whether blinding was assured in three others (Drobnic 2014; Lynn 2015; Shafat 2004).

\section{Incomplete outcome data}

We judged 38 studies at low risk of attrition bias. We assessed one study at unclear risk of attrition bias since there were no details on participant flow and the authors did not reply to our request for data (Krotkiewski 1994). We rated 11 studies at high risk of attrition bias as dropouts ranged between $12.5 \%$ to $50 \%$ either overall or in a trial arm (Arent 2010; Bloomer 2007; Connolly 2006a; Hutchinson 2016; Kaminski 1992; Lynn 2015; McFarlin 2016; Michailidis 2013; Phillips 2003; Silva 2008; Silva 2010). In Arent 2010, out of the six participants who dropped out, five withdrew of their own volition due to the inability to tolerate the physical demands of the testing protocol. Six participants did not complete all aspects of the study for personal reasons in Bloomer 2007. Two participants withdrew from another cross-over study for personal reasons (Connolly 2006a). In Hutchinson 2016, eight participants withdrew due to illness and injury unrelated to the study protocol. In Kaminski 1992, six participants withdrew for a variety of reasons (loss of capsule 
integrity, failure to properly maintain records, non-compliance with the experimental protocol), and one was removed for failure to develop DOMS in either stage of the cross-over trial. In Lynn 2015, data were missing from two participants of the intervention group; however, as this was a cross-over trial, attrition was balanced across groups. McFarlin 2016 had a 30\% attrition/non-compliance rate, probably with an uneven dropout rate between the two groups. One cross-over study stated in a published protocol that 20 individuals were enrolled and 12 completed although the manuscript stated that 10 males completed the study (Michailidis 2013). Phillips 2003 excluded five participants due to complications with blood-drawing procedures; however, it is unclear which group they were from. Four participants withdrew from Silva 2008 and six participants from Silva 2010 for personal reasons not associated with the exercise or the supplementation; it was not specified to which group the loses applied in either study.

\section{Selective reporting}

Three studies were registered with ClinicalTrials.gov and as all the outcomes were reported in the published studies we initially judged these at low risk of selective reporting (Kuehl 2010; Michailidis 2013; Theodorou 2011). However, Theodorou 2011 did not record adverse effects and we thus judged it at unclear risk of bias. We also judged all nine studies that reported on adverse effects from antioxidant supplementation, as well as fully reporting outcomes listed in their methods sections, at low risk of selective reporting bias (Cobley 2011; Kerksick 2009; Kuehl 2010; Laupheimer 2014; Lynn 2015; McLeay 2012; Michailidis 2013; O'Connor 2013; Phillips 2003). We rated the remaining 40 studies at high risk of selective reporting. As well as the lack of reporting of adverse effects, this reflected the lack of response from the authors of 16 studies to requests for mean and standard deviation data. Three studies rated at high risk of selective reporting bias because of other deficiencies in reporting were Bell 2015, Bell 2016 and Thompson 2003: the first two studies did not report muscle soreness data immediately post-exercise and Thompson 2003 did not report data for all the time points.

\section{Other potential sources of bias}

We deemed 16 studies at unclear risk of other potential sources of bias such as dietary control or avoiding medication or supplements that could reduce muscle soreness. Of these, we judged seven studies at unclear risk of other bias because no details regarding dietary control or instructing participants to avoid non-steroidal anti-inflammatory drugs (NSAIDs) or other supplements were provided in the trial report (Bailey 2011; Bloomer 2005; McBride 1997; Nicol 2015; Shafat 2004; Silva 2008; Silva 2010). The nine other studies controlled the participants' diets but provided no details regarding dietary control or instructing participants to avoid NSAIDs or other supplements and we therefore judged them at unclear risk of bias (Bell 2016; Krotkiewski 1994; McCormick 2016; McLeay 2012; Michailidis 2013; Nie 2004; Theodorou 2011; Thompson 2001; Thompson 2004). We rated 34 studies at low risk of other bias as diet, intake of supplements and medication were controlled.

\section{Effects of interventions}

See: Summary of findings for the main comparison Summary of findings: antioxidants versus placebo

Evidence from the 50 trials included in this review applied to only one comparison: antioxidant supplements versus control (placebo).

\section{Antioxidant supplementation versus placebo or no supplementation}

All 50 included studies made this comparison. Muscle soreness data were not available for pooling from one trial (Herrlinger 2015), and no data were pooled from McCormick 2016 because of its protracted exercise regimen.

\section{Primary outcomes}

Delayed onset muscle soreness (DOMS) (visual analogue scale, various scales or scores; highest values = worst pain)

Forty-eight studies presented data on muscle soreness at various different time points based on various visual analogue scale (VAS) scores. Results are presented at eight follow-up times after exercise: up to 6 hours, and at 24, 48,73,96,120, 144 and 168 hours. As there was considerable clinical heterogeneity we used the random-effects model. Both Kerksick 2009 and Silva 2008 tested two antioxidants: in the analyses, Kerksick 2009 appears twice for the first four follow-up times and Silva 2008 appears twice at 48, 96 and 168 hours.

Antioxidant supplementation reduced muscle soreness in comparison with placebo intervention when measured up to 6 hours post-exercise (standardised mean difference (SMD) -0.30 , $95 \%$ confidence interval $(\mathrm{Cl})-0.56$ to -0.04 ; participants $=525$; studies = 21; $\left.\right|^{2}=53 \%$; low-quality evidence); Analysis 1.1 ); at 24 hours after exercise $(\mathrm{SMD}-0.13,95 \% \mathrm{Cl}-0.27$ to 0.00 ; participants = 936; studies $=41 ; 1^{2}=5 \%$; moderate-quality evidence; Analysis 1.2; Figure 4); at 48 hours after exercise (SMD - $0.24,95 \% \mathrm{Cl}-0.42$ to -0.07 ; participants $=1047$; studies $=45 ; 1^{2}=47 \%$; low-quality evidence; Analysis 1.3; Figure 5) and at 72 hours after exercise (SMD - $0.19,95 \%$ $\mathrm{Cl}-0.38$ to -0.00 ; participants $=657$; studies $=28 ; \mathrm{I}^{2}=27 \%$; moderatequality evidence; Analysis 1.4). (It is notable that the heterogeneity in this analysis is solely related to the inclusion of Michailidis 2013). There was little effect of antioxidants on muscle soreness at 96 hours after exercise (SMD $-0.05,95 \% \mathrm{Cl}-0.29$ to 0.19 ; participants = 436; studies $=17 ; 1^{2}=31 \%$; low-quality evidence; Analysis 1.5$)$. Far fewer trials provided data at five days or subsequently. There was very low-quality evidence of little effect of antioxidants on muscle soreness at 120 hours (SMD $0.21,95 \% \mathrm{Cl}-0.26$ to 0.69 ; participants $=128$; studies $=4 ; \mathrm{I}^{2}=39 \%$ ), at 144 hours (SMD $-0.23,95 \% \mathrm{Cl}-1.11$ to 0.65 ; participants $=20$; studies $=1$ ) or at 168 hours (SMD $-0.04,95 \%$ $\mathrm{Cl}-0.48$ to 0.41 ; participants $=80$; studies $\left.=4 ; 1^{2}=0 \%\right)$; Analysis 1.6 ). 
Figure 4. Forest plot of comparison: 1 Antioxidant supplementation vs. placebo for delayed onset muscle soreness (all studies), outcome: 1.2 Muscle soreness at 24 hours; random-effects model.

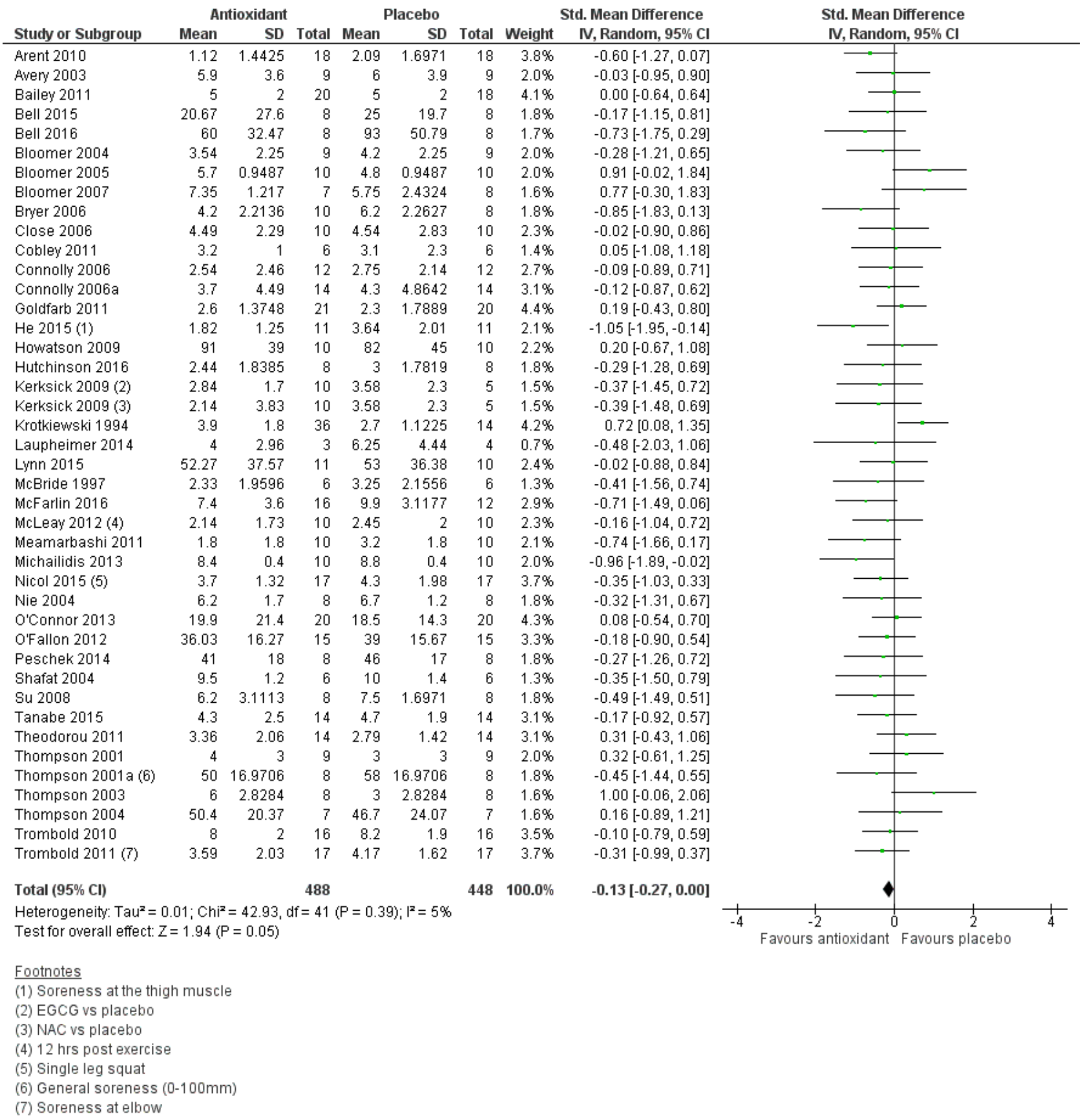


Figure 5. Forest plot of comparison: 1 Antioxidant supplementation vs. placebo for delayed onset muscle soreness (all studies), outcome: 1.3 Muscle soreness at 48 hours; random-effects model.

\begin{tabular}{|c|c|c|c|c|c|c|c|c|c|c|c|c|}
\hline \multirow[b]{2}{*}{ Study or Subgroup } & \multicolumn{3}{|c|}{ Antioxidant } & \multicolumn{3}{|c|}{ Placebo } & \multicolumn{2}{|r|}{ Std. Mean Difference } & \multirow{2}{*}{\multicolumn{4}{|c|}{$\begin{array}{c}\text { Std. Mean Difference } \\
\text { IV, Random, } 95 \% \mathrm{Cl}\end{array}$}} \\
\hline & Mean & SD & Total & Mean & SD & Total & Weight & IV, Random, 95\% Cl & & & & \\
\hline Arent 2010 & 0.88 & 1.3576 & 18 & 1.94 & 1.9516 & 18 & $2.8 \%$ & $-0.62[-1.29,0.05]$ & & & & \\
\hline Avery 2003 & 4.9 & 3.3 & 9 & 5.1 & 4.2 & 9 & $2.1 \%$ & $-0.05[-0.97,0.87]$ & & & & \\
\hline Bailey 2011 & 5 & 2 & 20 & 5 & 2 & 18 & $2.9 \%$ & $0.00[-0.64,0.64]$ & & & & \\
\hline Beaton 2002a & 8.8 & 3.1 & 9 & 7.5 & 2 & 7 & $1.9 \%$ & $0.46[-0.55,1.46]$ & & & & \\
\hline Bell 2015 & 14.92 & 22.51 & 8 & 21.8 & 18.72 & 8 & $1.9 \%$ & $-0.31[-1.30,0.67]$ & & & & \\
\hline Bell 2016 & 45 & 27.82 & 8 & 91 & 56.08 & 8 & $1.8 \%$ & $-0.98[-2.04,0.07]$ & & & & \\
\hline Bloomer 2004 & 3.04 & 2.4 & 9 & 5.46 & 3 & 9 & $1.9 \%$ & $-0.85[-1.82,0.13]$ & & & & \\
\hline Bloomer 2005 & 5.8 & 2.5298 & 10 & 4.8 & 1.8974 & 10 & $2.2 \%$ & $0.43[-0.46,1.32]$ & & & & \\
\hline Bloomer 2007 & 7.07 & 0.926 & 7 & 6.25 & 2.7436 & 8 & $1.8 \%$ & $0.37[-0.66,1.39]$ & & & & \\
\hline Bryer 2006 & 6.1 & 2.2136 & 10 & 7.5 & 2.2627 & 8 & $2.0 \%$ & $-0.60[-1.55,0.36]$ & & & - & \\
\hline Close 2006 & 4.34 & 2.74 & 10 & 5.59 & 2.6 & 10 & $2.1 \%$ & $-0.45[-1.34,0.44]$ & & & 一 & \\
\hline Cobley 2011 & 2.9 & 1.1 & 6 & 2.4 & 0.8 & 6 & $1.6 \%$ & $0.48[-0.68,1.64]$ & & & & \\
\hline Connolly 2006 & 2.25 & 1.92 & 12 & 2.75 & 2.07 & 12 & $2.4 \%$ & $-0.24[-1.05,0.56]$ & & & & \\
\hline Connolly $2006 a$ & 3.3 & 4.1158 & 14 & 5 & 4.49 & 14 & $2.6 \%$ & $-0.38[-1.13,0.37]$ & & & & \\
\hline Drobnic 2014 & 23.3 & 7.9 & 9 & 30.6 & 7.9 & 10 & $2.0 \%$ & $-0.88[-1.84,0.07]$ & & & & \\
\hline Goldfarb 2011 & 2.8 & 2.7495 & 21 & 3 & 1.3416 & 20 & $3.0 \%$ & $-0.09[-0.70,0.52]$ & & & & \\
\hline He 2015 (1) & 1.91 & 1.14 & 11 & 3.09 & 1.58 & 11 & $2.2 \%$ & $-0.82[-1.70,0.05]$ & & & & \\
\hline Howatson 2009 & 58 & 39 & 10 & 46 & 28 & 10 & $2.2 \%$ & $0.34[-0.55,1.22]$ & & & & \\
\hline Hutchinson 2016 & 2.75 & 2.4324 & 8 & 3.38 & 2.1213 & 8 & $1.9 \%$ & $-0.26[-1.25,0.72]$ & & & & \\
\hline Kaminski 1992 & 3.7 & 2.6 & 19 & 5.4 & 2.2 & 19 & $2.9 \%$ & $-0.69[-1.35,-0.03]$ & & & & \\
\hline Kerksick 2009 (2) & 3.49 & 2.15 & 10 & 5.51 & 1.64 & 5 & $1.6 \%$ & $-0.95[-2.09,0.20]$ & & & & \\
\hline Kerksick 2009 (3) & 3.3 & 2.08 & 10 & 5.51 & 1.64 & 5 & $1.6 \%$ & $-1.06[-2.23,0.10]$ & & & & \\
\hline Krotkiewski 1994 & 2.95 & 1.8 & 36 & 1.1 & 0.7483 & 14 & $2.8 \%$ & $1.15[0.49,1.81]$ & & & & \\
\hline Lynn 2015 & 24.6 & 22.53 & 10 & 17.7 & 12.99 & 10 & $2.2 \%$ & $0.36[-0.53,1.24]$ & & & & \\
\hline McBride 1997 & 2 & 2.1311 & 6 & 2.75 & 2.278 & 6 & $1.6 \%$ & $-0.31[-1.46,0.83]$ & & & & \\
\hline McFarlin 2016 & 11.4 & 3.2 & 16 & 12.5 & 2.7713 & 12 & $2.5 \%$ & $-0.35[-1.11,0.40]$ & & & - & \\
\hline McLeay 2012 (4) & 3.79 & 1.88 & 10 & 3.35 & 2.25 & 10 & $2.2 \%$ & $0.20[-0.68,1.08]$ & & & & \\
\hline Meamarbashi 2011 & 1.2 & 0.7 & 10 & 3.3 & 1.6 & 10 & $1.8 \%$ & $-1.63[-2.67,-0.59]$ & & & & \\
\hline Michailidis 2013 & 8.9 & 0.2 & 10 & 9.5 & 0.2 & 10 & $1.3 \%$ & $-2.87[-4.20,-1.55]$ & & & & \\
\hline Nicol $2015(5)$ & 3.32 & 1.15 & 17 & 4 & 2.14 & 17 & $2.8 \%$ & $-0.39[-1.07,0.29]$ & & & - & \\
\hline Nie 2004 & 5.1 & 1.2 & 8 & 4.9 & 1.3 & 8 & $1.9 \%$ & $0.15[-0.83,1.13]$ & & & & \\
\hline O'Connor 2013 & 18.6 & 18.7 & 20 & 17.7 & 13.9 & 20 & $3.0 \%$ & $0.05[-0.57,0.67]$ & & & & \\
\hline O'Fallon 2012 & 39.6 & 21.86 & 15 & 43.43 & 17.7 & 15 & $2.7 \%$ & $-0.19[-0.90,0.53]$ & & & & \\
\hline Peschek 2014 & 45 & 20 & 8 & 34 & 24 & 8 & $1.9 \%$ & $0.47[-0.53,1.47]$ & & & & \\
\hline Shafat 2004 & 10 & 1.5 & 6 & 10.3 & 1.4 & 6 & $1.6 \%$ & $-0.19[-1.33,0.94]$ & & & & \\
\hline Silva 2008 (6) & 5.83 & 1 & 8 & 5.43 & 0.8 & 4 & $1.5 \%$ & $0.39[-0.82,1.61]$ & & & & \\
\hline Silva $2008(7)$ & 3.86 & 0.7 & 9 & 5.43 & 0.8 & 4 & $1.1 \%$ & $-2.00[-3.50,-0.51]$ & & & & \\
\hline Silva 2010 & 3.8 & 2.6533 & 11 & 6.2 & 1.5811 & 10 & $2.1 \%$ & $-1.04[-1.97,-0.12]$ & & & & \\
\hline Su 2008 & 6.2 & 4.5255 & 8 & 8 & 4.2426 & 8 & $1.9 \%$ & $-0.39[-1.38,0.60]$ & & & & \\
\hline Tanabe 2015 & 5.5 & 2.1 & 14 & 6 & 2.2 & 14 & $2.6 \%$ & $-0.23[-0.97,0.52]$ & & & & \\
\hline Theodorou 2011 & 6.07 & 2.4 & 14 & 5.57 & 1.5 & 14 & $2.6 \%$ & $0.24[-0.50,0.99]$ & & & & \\
\hline Thompson 2001 & 3 & 3 & 9 & 3 & 3 & 9 & $2.1 \%$ & $0.00[-0.92,0.92]$ & & & & \\
\hline Thompson 2001 a (8) & 33 & 11.3137 & 8 & 47 & 22.6274 & 8 & $1.8 \%$ & $-0.74[-1.76,0.28]$ & & & - & \\
\hline Thompson 2003 & 4 & 2.8284 & 8 & 3 & 2.8284 & 8 & $1.9 \%$ & $0.33[-0.65,1.32]$ & & & & \\
\hline Thompson 2004 & 64.3 & 16.4 & 7 & 48.6 & 27.24 & 7 & $1.7 \%$ & $0.65[-0.43,1.74]$ & & & & \\
\hline Trombold 2010 & 8.1 & 1.6 & 16 & 8 & 2.2 & 16 & $2.7 \%$ & $0.05[-0.64,0.74]$ & & & & \\
\hline Trombold 2011 (9) & 2.71 & 2.11 & 17 & 3.76 & 1.68 & 17 & $2.8 \%$ & $-0.54[-1.22,0.15]$ & & & & \\
\hline Total $(95 \% \mathrm{Cl})$ & & & 549 & & & 498 & $100.0 \%$ & $-0.24[-0.42,-0.07]$ & & & & \\
\hline \multicolumn{7}{|c|}{$\begin{array}{l}\text { Heterogeneity: } \mathrm{Tau}^{2}=0.17 ; \mathrm{Chi}^{2}=86.34, \mathrm{df}=46(\mathrm{P}=0.0003) ; \mathrm{I}^{2}=47 \% \\
\text { Test for overall effect: } Z=2.72(\mathrm{P}=0.007)\end{array}$} & & & $\frac{1}{-4}$ & $\begin{array}{cc}-2 & 1 \\
\text { Favours antioxidant }\end{array}$ & Favours placebo & 4 \\
\hline \multicolumn{13}{|l|}{ Footnotes } \\
\hline \multicolumn{13}{|c|}{ (1) Soreness at the thigh muscle } \\
\hline \multicolumn{13}{|c|}{ (2) NAC vs placebo } \\
\hline \multicolumn{13}{|l|}{ (3) EGCG vs placebo } \\
\hline \multicolumn{13}{|c|}{ (4) 36 hours post exercise } \\
\hline \multicolumn{13}{|c|}{ (5) Single leg squat } \\
\hline (6) 14 days suppleme & ation & & & & & & & & & & & \\
\hline (7) 21 days suppleme & ation & & & & & & & & & & & \\
\hline (8) General soreness & $-100 \mathrm{mt}$ & & & & & & & & & & & \\
\hline (9) Soreness at elbow & & & & & & & & & & & & \\
\hline
\end{tabular}

As there was considerable variation in the units used to measured muscle soreness, we rescaled all trials to the 0 to 10 scale at the first five time points in order to explore the actual difference between groups on a standard scale. The results are as follows: up to 6 hours (mean difference (MD) $-0.52,95 \% \mathrm{Cl}-0.95$ to -0.08 ; participants =
$525 ;$ studies $=21 ;\left.\right|^{2}=66 \%$; Analysis 1.7$) ;$ at 24 hours (MD - $0.17,95 \%$ $\mathrm{Cl}-0.42$ to 0.07 ; participants $=936$; studies $=41 ; 1^{2}=29 \%$; Analysis 1.8 ); at 48 hours (MD $-0.41,95 \% \mathrm{Cl}-0.69$ to -0.12 ; participants $=1047$; studies $=45 ; \mathrm{I}^{2}=64 \%$; Analysis 1.9 ); at 72 hours (MD $-0.29,95 \% \mathrm{Cl}$ -0.59 to $0.02 ;$ participants $=657$; studies $=28 ;\left.\right|^{2}=27 \%$; Analysis 
1.10); and at 96 hours (MD $-0.03,95 \% \mathrm{Cl}-0.43$ to 0.37 ; participants = 436; studies $=17 ; 1^{2}=51 \%$; Analysis 1.11$)$. This rescaling also allows us to examine whether the antioxidant supplement produces a clinically important difference. For consistency with Bleakley 2012, we considered $1.4 \mathrm{~cm}$ as the minimal important difference (MID) for pain reduction on a $10 \mathrm{~cm}$ visual analogue scale; this was based on an estimated MID for musculoskeletal conditions of the shoulder by Tashjian 2009. It is notable that all of the upper limits of the $95 \% \mathrm{Cls}$ of these five analyses are lower that this MID and hence all quantitative differences do not appear to represent personrelevant differences in muscle soreness.

\section{Subgroup and sensitivity analyses}

We performed only a few subgroup and sensitivity analyses. We selected the 24 and 48 hours analyses for subgroup analyses given that these were the categories with the largest number of trials. We did not use the up to 6 hours time period because of the variation in the timing of measurement: i.e. some studies measured this outcome immediately after exercise whereas other studies measured this up to 2 hours or up to 6 hours after exercise.

A sensitivity analysis exploring the use of the fixed-effect model for all eight follow-up times produced similar results to that of randomeffects model (Table 3; analysis not shown).

A subgroup analysis could not be performed on timing of administration (i.e. pre-exercise and post-exercise versus postexercise only) because there were very few trials (one or two studies depending on the time of follow-up) in the post-exercise group.

We performed a subgroup analysis on the type of exercise, that is, mechanically induced versus whole body aerobic exercise for the 24 and 48 hour follow-up times (see Analysis 1.12; Analysis 1.13). There is no evidence of subgroup differences for muscle soreness for type of exercise at 24 hours $\left(\mathrm{Chi}^{2}=0.44, \mathrm{df}=1 ; \mathrm{P}=0.51, \mathrm{I}^{2}=0 \%\right)$ or at 48 hours $\left(\mathrm{Chi}^{2}=0.88, \mathrm{df}=1 ; \mathrm{P}=0.35, \mathrm{I}^{2}=0 \%\right)$.

Our second subgroup analysis was based on source of funding where we compared studies that were funded by a food company or provider of antioxidant supplements versus studies that there were not (see Analysis 1.14; Analysis 1.15). There is no evidence of subgroup differences for muscle soreness according to source of funding at 24 hours $\left(\mathrm{Chi}^{2}=0.03, \mathrm{df}=1, \mathrm{P}=0.87, \mathrm{I}^{2}=0 \%\right)$ or 48 hours $\left(\mathrm{Chi}^{2}=0.10, \mathrm{df}=1, \mathrm{P}=0.875 \mathrm{I}^{2}=0 \%\right) ;$ no information on funding was available for Su 2008.

We conducted a sensitivity analysis testing trials at unclear risk of bias, relating to random sequence generation, allocation concealment or both, which included 19 trials (Bailey 2011; Bell 2015; Bell 2016; Bloomer 2004; Bloomer 2005; Bloomer 2007; Close 2006; Cobley 2011; He 2015; Herrlinger 2015; Howatson 2009; Laupheimer 2014; McCormick 2016; Meamarbashi 2011; O'Connor 2013; Peschek 2014; Silva 2008; Silva 2010; Tanabe 2015). This analysis made little difference to the overall effect at either 24 hours post-exercise (SMD $-0.10,95 \% \mathrm{Cl}-0.37$ to 0.17 ; participants $=280$; studies $=14 ; 1^{2}=19 \%$ ) or at 48 hours (SMD $-0.31,95 \% \mathrm{Cl}-0.66$ to 0.04 ; participants $=327$; studies $=16 ; 12=57 \%)$.

Also presented are sensitivity analyses testing the effects of excluding cross-over studies; these provide reassurance that the inclusion of such trials did not have an important effect on the results (Table 4).

\section{Subjective recovery}

No study measured subjective recovery (return to previous activities without signs or symptoms).

\section{Adverse effects}

Nine studies, reporting on a total of 216 participants, reported on this outcome (very low-quality evidence). One study reported that all six participants in the NAC ( $\mathrm{N}$-acetylcysteine) supplementation group had diarrhoea, which was mild in five participants and severe diarrhoea in one (Cobley 2011). The same study reported mild indigestion in four participants $(67 \%)$ in the NAC group and one of six participants in the placebo group. Another study reported that tart cherry juice caused mild gastrointestinal distress in one of 26 participants taking the antioxidant supplement (Kuehl 2010). Seven studies reported no adverse effects of taking the antioxidant supplementation (Kerksick 2009; Laupheimer 2014; Lynn 2015; McLeay 2012; Michailidis 2013; O'Connor 2013; Phillips 2003). The remaining 41 studies failed to report adverse effects.

\section{Secondary outcomes}

\section{Muscle tenderness}

Only four studies measured muscle tenderness using a handheld algometer (Close 2006; Connolly 2006; Connolly 2006a; Peschek 2014) (and Analysis 1.17). Two studies measured tenderness using pressure algometry and reported the results in Newtons (Connolly 2006; Connolly 2006a), and two studies measured tenderness and reported in $\mathrm{kg}$ (Close 2006; Peschek 2014). There was very low-quality evidence of little difference between antioxidant supplementation versus placebo in tenderness (a greater pressure exerted means less tenderness) at the four time points $(24,48$, 72 and 96 hours) for the pooled data from the two studies (52 participants) reporting the results in Newtons (Analysis 1.16); nor for five time points (up to 6 hours, 24, 48, 72 and 96 hours) for the data from the two studies (36 participants) reporting the results in $\mathrm{kg}$ (Analysis 1.17).

\section{Performance variables}

The quality of the evidence for all performance variables was very low; each variable presented here being reported by only one of the five studies reporting these outcomes (Arent 2010; Bell 2015; Bell 2016; Cobley 2011; O'Connor 2013). Arent 2010 (18 participants; cross-over trial) found no effect of antioxidant supplementation on the 30-second Wingate performed on a cycle ergometer (the DOMS-provoking exercise) seven days after supplementation (MD $0.30 \mathrm{~W} / \mathrm{kg}, 95 \% \mathrm{Cl}-2.74$ to 3.34; Analysis 1.18). Cobley 2011 (12 participants) found antioxidant supplementation (NAC) enhanced sprint time over 20 metres at three follow-up times (lower values $=$ better performance): 24 hours (MD -0.41 seconds, $95 \% \mathrm{Cl}-0.63$ to -0.19 ), 48 hours (MD -0.30 seconds, $95 \% \mathrm{Cl}-0.52$ to -0.08 ) and 120 hours (MD - $0.30,95 \% \mathrm{Cl}-0.54$ to -0.06 ; Analysis 1.19 ). O'Connor 2013 (40 participants) found no improvements in maximal oxygen consumption when measured after 42 days after antioxidant supplementation (higher values $=$ better performance) $(\mathrm{MD} 0.20$ $\mathrm{mL} / \mathrm{kg} / \mathrm{min}, 95 \% \mathrm{Cl}-5.66$ to 6.06 ; Analysis 1.20). Bell 2016 (16 participants) found no effect of antioxidant supplementation on agility (5-0-5 agility: lower values = better performance) at any of the three time points measured: 24 hours (MD 0.01 seconds, $95 \%$ $\mathrm{Cl}-0.16$ to 0.18 ), 48 hours (MD -0.05 seconds, $95 \% \mathrm{Cl}-0.19$ to 0.09 ) or 72 hours (MD -0.02 seconds, $95 \% \mathrm{Cl}-0.17$ to 0.13 ) (Analysis 1.21). Bell 2015 (16 participants) found no effect of antioxidant 
supplementation on six-second sprint power (higher values $=$ better performance) at any of the three time points measured: 24 hours (MD 39.00 W, $95 \% \mathrm{Cl}-182.33$ to 260.33 ), 48 hours (MD $50.00 \mathrm{~W}, 95 \% \mathrm{Cl}$ -195.44 to 295.44) or 72 hours (MD 53.00 W, $95 \% \mathrm{Cl}-174.56$ to 280.56 ) (Analysis 1.22).

\section{Muscle force production (maximal voluntary contraction)}

Thirty studies measured muscle function at various different time points. Muscle force production was measured in different ways and we pooled results only from studies using the same outcome measure: 15 trials reported the percentage change in force production from baseline; six reported Newton metres, six reported Newtons, two reported Newton metres per kg of body mass and one reported $\mathrm{kg}$. We rated the quality of evidence as very low for all findings. When muscle force production was measured as a percentage change from baseline, antioxidant supplementation appeared to increase force production to a small extent (all under $6 \%$ ) in comparison with placebo across the first five time points: up to 6 hours after exercise (MD 5.86\%, 95\% $\mathrm{Cl} 3.29$ to 8.42; participants $=255$; studies $=11 ; 1^{2}=3 \%$ ), at 24 hours (MD 2.51\%, 95\% Cl 0.99 to 4.04; participants $=375$; studies $\left.=15 ;\left.\right|^{2}=75 \%\right)$, at 48 hours (MD $4.46 \%, 95 \% \mathrm{Cl} 2.94$ to 5.98 ; participants $=375$; studies $=15 ; 1^{2}=$ $59 \%$ ), at 72 hours (MD 3.92\%, $95 \% \mathrm{Cl} 0.88$ to 6.96 ; participants $=277$; studies $\left.=11 ;\left.\right|^{2}=51 \%\right)$, and at 96 hours after exercise (MD 5.29, 95\% $\mathrm{Cl} 3.65$ to 6.92 ; participants $=252$; studies $=9 ; 1^{2}=72 \%$ ) (Analysis 1.23). (Although in the results for 168 hours after exercise, the antioxidant showed a harmful effect on muscle force production, only two studies measured this outcome at this time point and the results were statistically heterogeneous (MD $-7.96,95 \% \mathrm{Cl}-15.96$ to 0.05 ; participants $=36$; studies $\left.=2 ; 1^{2}=68 \%\right)$. Where data were pooled, for up to six studies for force production measured in Newton metres, or for up to five studies for force production measured in Newtons, there were no differences found between the antioxidant supplementation and placebo groups across all of the time points measured (see Analysis 1.24 and Analysis 1.25). For completeness, the non-pooled results for the two trials reporting the strength in Newton metres per kg of body mass are shown in Analysis 1.26 and those for the trial reporting strength in $\mathrm{kg}$ in Analysis 1.27 . The former are dominated by those of Michailidis 2013, which favour antioxidants in the first five follow-ups but placebo in the last two follow-ups.

\section{Range of motion}

There was very low-quality evidence that range of motion, which was measured in 10 studies (Bailey 2011; Bloomer 2004; Bryer 2006 Connolly 2006a; Goldfarb 2011; Meamarbashi 2011; O'Connor 2013; Phillips 2003; Tanabe 2015; Theodorou 2011), did not differ importantly between the two groups (antioxidant versus placebo) at any of the follow-up times (see Analysis 1.28). All differences (higher values $=$ better range of motion) were small and unlikely to relate to a clinically important difference at either the elbow or knee. The first five follow-up time results are presented here: up to 6 hours after exercise (MD -0.25 degrees, $95 \% \mathrm{Cl}-3.31$ to 2.81; participants $=163$; studies $=6 ;\left.\right|^{2}=0 \%$ ), at 24 hours (MD 1.03 degrees, $95 \% \mathrm{Cl}-0.91$ to 2.96; participants $=259$; studies $=9 ; \mathrm{I}^{2}=$ $0 \%$ ), at 48 hours (MD 2.71 degrees, $95 \% \mathrm{Cl} 0.39$ to 5.04; participants $=259$; studies $=9 ; \mathrm{I}^{2}=61 \%$ ), at 72 hours (MD 2.93 degrees, $95 \% \mathrm{Cl}$ -0.02 to 5.87 ; participants $=196$; studies $=7 ; 1^{2}=0 \%$ ) and at 96 hours (MD 0.79 degrees, $95 \% \mathrm{Cl}-1.26$ to 2.84 ; participants = 158; studies $=6 ; 1^{2}=0 \%$ ).

\section{High-dose versus low-dose, where the low-dose supplementation is within normal or recommended levels for the antioxidant involved}

None of the included studies made this comparison.

\section{DISCUSSION}

\section{Summary of main results}

This review examined the effectiveness of antioxidants for preventing and treating muscle soreness after exercise. Fifty randomised placebo-controlled studies were included, 12 of which used a cross-over design. The 50 studies involved a total of 1089 participants (961 male; 128 female; age range 16 to 55 years). The studies were heterogeneous, including the timing (pre-exercise or post-exercise), frequency, dose or duration, and type of antioxidant supplementation, and the type of preceding delayed onset muscle soreness (DOMS)-producing exercise. All studies used an antioxidant dosage higher than the recommended daily amount. No studies compared high-dose versus low-dose, where the lowdose supplementation was within normal or recommended levels for the antioxidant involved.

The included studies made only one comparison: antioxidant supplements versus control (placebo). Our main outcomes were muscle soreness (up to 6 hours post-exercise and at 24, 48, 72 and 96 hours), subjective recovery and adverse events.

\section{Antioxidant supplementation versus placebo or no supplementation}

A summary of the evidence available for the main outcomes for this comparison is presented in Summary of findings for the main comparison. The assessment of the quality of the evidence varied between moderate quality, where the effect is probably true but there is a possibility that it could be substantially different, low quality, where the effect may be true but it may also be substantially different from what was found, and very low quality, where we are very uncertain about the estimate.

Pooled standardised mean difference (SMD) results for muscle soreness indicated a small difference in favour of antioxidant supplementation after DOMS-inducing exercise at all main followups: up to 6 hours (525 participants; 21 studies; low-quality evidence); at 24 hours (936 participants; 41 studies; moderatequality evidence), at 48 hours (1047 participants; 45 studies; low-quality evidence); at 72 hours (657 participants; 28 studies; moderate-quality evidence), and little difference at 96 hours (436 participants; 17 studies; low-quality evidence). When, however, we rescaled all the trial results to the 0 to $10 \mathrm{~cm}$ scale in order to compare the actual difference between groups, we found that the 95\% confidence intervals ( $\mathrm{Cls}$ ) for all five follow-up times were all below $1.0 \mathrm{~cm}$, and thus all below the minimal important difference of $1.4 \mathrm{~cm}$ that we used in this review. Thus, all statistical differences in DOMS favouring antioxidant supplementation were unlikely to equate to meaningful or important differences in practice. Neither of our subgroup analyses to examine for differences in effect according to type of DOMS-inducing exercise (mechanical versus whole body aerobic) or according to funding source confirmed subgroup differences. Sensitivity analyses to test the selection of the statistical model for pooling (fixed-effect instead of randomeffects) and the exclusion of cross-over studies all showed similar results to the main analyses. 
None of the 50 studies reported on subjective recovery (return to previous activities without signs or symptoms).

Only nine studies (216 participants) reported on adverse effects, with actual events reported in two studies. One study (12 participants) reported that all six participants in the NAC (Nacetylcysteine) supplementation group had diarrhoea, which was mild in five participants and severe in one (Cobley 2011). The same study reported mild indigestion in four participants (67\%) in the NAC group and one of six participants in the placebo group. It should be noted that NAC supplementation is usually prescribed and it has been found to cause uncomfortable side effects including nausea and diarrhoea in other studies. Another study reported that tart cherry juice caused mild gastrointestinal distress in one of 26 participants taking the antioxidant supplement (Kuehl 2010). The other seven studies reported no adverse effects of taking the antioxidant supplementation; this included 10 participants having NAC supplementation in one study. Overall, the available evidence for adverse events is very low-quality.

\section{Overall completeness and applicability of evidence}

Data for muscle soreness, the primary outcome, were available from 48 of the 50 small placebo-controlled randomised trials, with pooled data available at 24 hours after the exercise from 41 trials (one of which tested two antioxidants), involving 936 participants and from 45 (two of which tested two antioxidants), involving 1047 participants. In contrast there were no data for subjective recovery and few data for adverse effects.

We consider the applicability of the evidence in terms of the population characteristics, the exercise used to induce muscle damage and trial settings, the antioxidants used and outcomes. In particular, the 50 trials included in this review varied regarding dosages of antioxidants, the muscle damage model and adequate control of extraneous variables.

The majority of the 1089 participants included in this review were male $(961 ; 88.2 \%)$ and so arguably the findings of the review are mainly applicable to males but there is no biological basis for why antioxidants should have a different effect in the two sexes. These sex differences are typical of what is observed in the athletic recovery literature (Bieuzen 2013; Bleakley 2012; Costello 2014). More noteworthy is that no data from highly-trained elite athletes were included in the analyses; the data pertaining to nine elite athletes tested in McCormick 2016 were not included in the metaanalyses because the exercise paradigm was completely different to all the other studies included in this review. As the majority of the participants were either college students or relatively young and active, these findings cannot be generalised in the elite athlete population who have a different physiological and training status. Some reservations in terms of applicability also apply to older individuals due to their anatomical and physiological characteristics as there were no older participants included in this review (age range of participants: 16 to 55 years).

There were large variations regarding the mode of exercise used to induce muscle damage in the studies, with some studies using exhaustive high-intensity exercise such as downhill running (i.e. whole body aerobic exercise) and other studies using a resistance training protocol (i.e. mechanically induced exercise). Thus the level of muscle damage experienced by the participants will have varied. In addition, the intensity of the exercise used to illicit muscle damage also varied greatly amongst studies: some studies used an extremely demanding and intense exercise protocol such as 10 sets of 10 repetitions knee extensions performed at $80 \%$ of one repetition maximum or a marathon run, whereas others used less exhaustive protocols such as a bench stepping exercise. The amount of muscle damage and oxidative stress caused depends on the type, intensity and duration of physical exercise performed (Castrogiovanni 2012). Paulsen 2012 found exercise that has a greater eccentric component that involves a greater range of motion and high force generation is more likely to cause greater levels of damage. Moreover, Bleakley 2012 reported that resistance exercises performed under laboratory conditions are associated with high levels of muscle damage and soreness, particularly in the untrained population. Our subgroup analysis that compared type of exercise at 24 and 48 hours did not show subgroup differences between whole body aerobic exercise and mechanically induced exercise. Despite the variation, the key point for this review is that the exercise protocols, whether in the laboratory or field setting, were all sufficient to induce muscle damage that would result in DOMS in people undergoing sport activities.

There was large variation in the dose and duration of the antioxidants used, with three trials testing supplements started only after exercise. The variation was too great to enable meaningful indirect comparisons (subgroup analyses) and no trial compared high-versus low-dose supplementation, where the lowdose supplementation was within normal or recommended levels for the antioxidant involved. Nonetheless, all studies used an antioxidant dosage higher than the recommended daily amount.

The timing for assessment of muscle soreness, with the majority of evidence available for 24 and 48 hours after exercise, was appropriate. However, the timing of measurement for up to 6 hours varied greatly amongst the studies where some studies measured muscle soreness immediately after exercise and some studies measured this several hours after exercise. There was considerable variation in the measurement of muscle soreness, which meant that we pooled SMDs for the main analyses. Exploratory analyses, where all results were on a $10 \mathrm{~cm}$ scale, allowed an assessment of whether the between-group differences were clinically relevant. Crucially, the upper limits of the $95 \% \mathrm{Cls}$ at all five time points were much less than a typical minimal important difference (MID) for pain.

\section{Quality of the evidence}

We assessed the quality of evidence using the GRADE framework, which combines considerations of risk of bias,indirectness,inconsistency (heterogeneity),imprecision and publication bias. The findings for the main outcomes are shown in Summary of findings for the main comparison. We downgraded all outcomes one level for serious risk of bias, due mainly to selective reporting bias (the majority of the trials failed to report on adverse effects) and, to a lesser degree, attrition biases. We did not downgrade for indirectness in relation to muscle soreness. We downgraded two outcomes for serious inconsistency reflecting heterogeneity that could not be traced to the inclusion of just one outlier trial. Pooled evidence did not support downgrading for imprecision. Our tests for publication bias did not reveal a serious concern (Figure 6; Figure 7), although all were small studies. Thus, we did not downgrade for publication bias. We concluded that the quality of the evidence ranged from moderate to very low. 
Figure 6. Funnel plot of comparison: 1 Antioxidant supplementation vs. placebo for delayed onset muscle soreness (all studies), outcome: 1.2 Muscle soreness at 24 hours; random-effects model.

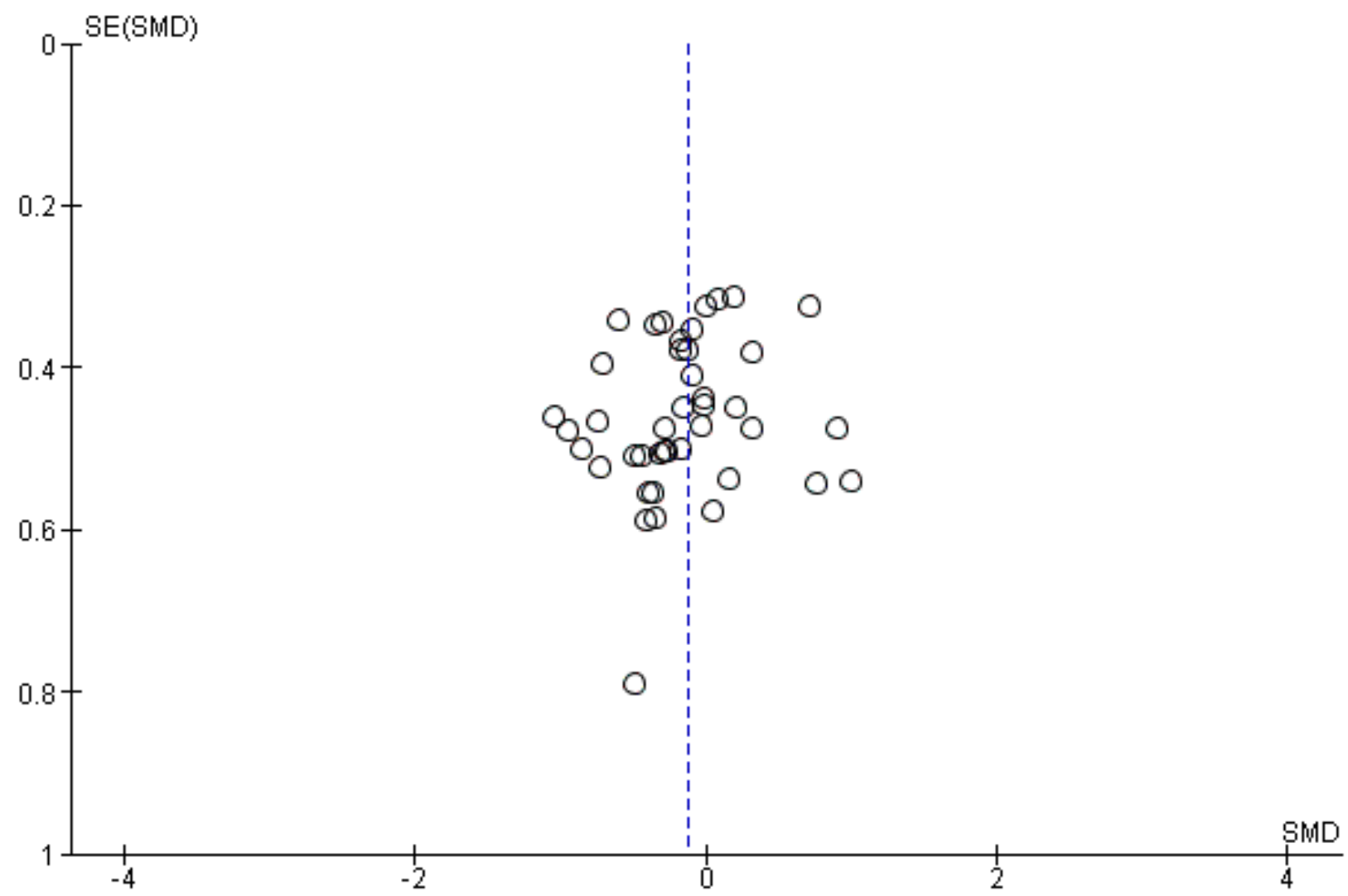


Figure 7. Funnel plot of comparison: 1 Antioxidant supplementation vs. placebo for delayed onset muscle soreness (all studies), outcome: 1.3 Muscle soreness at 48 hours; random-effects model.

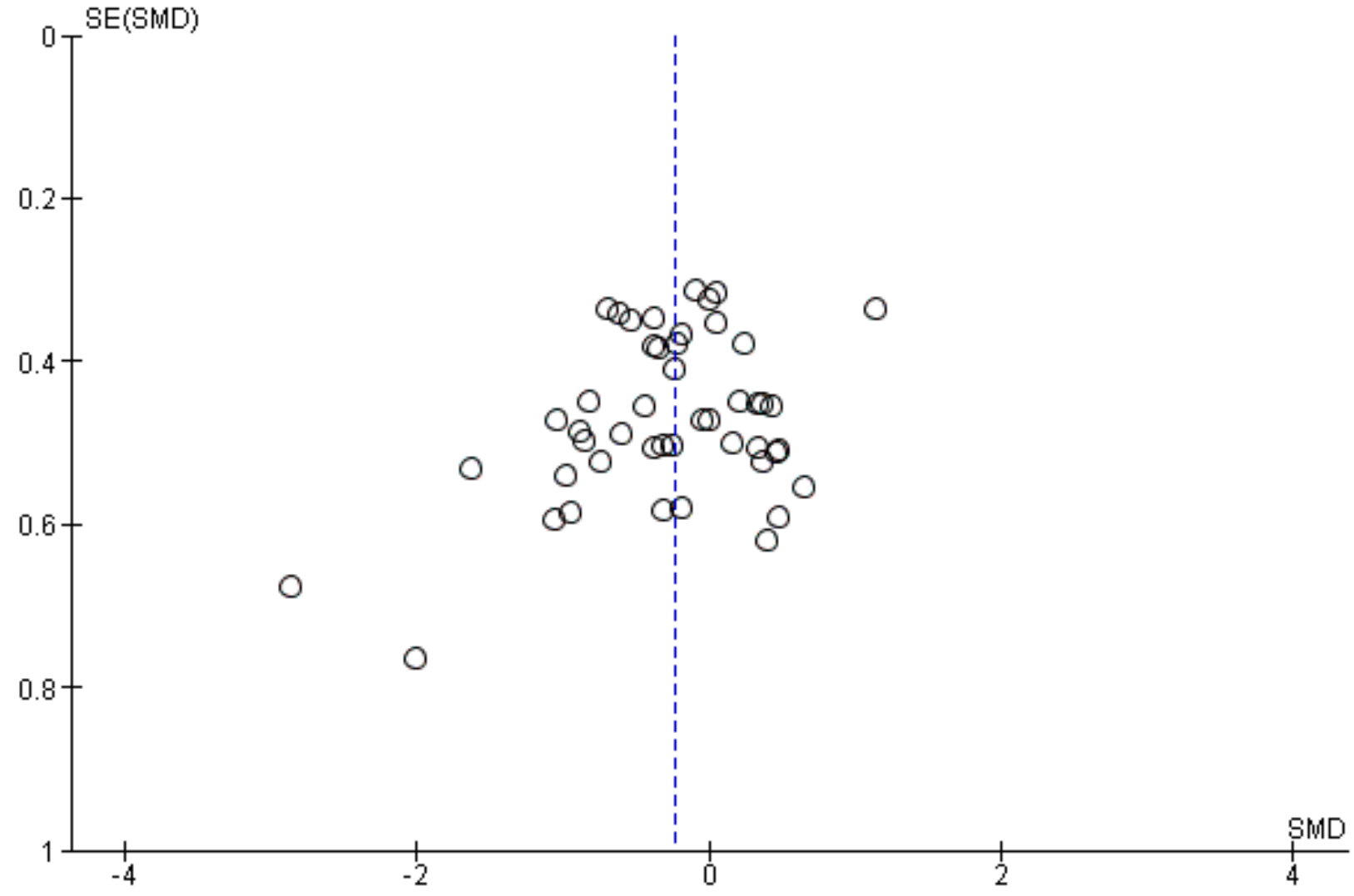

\section{Potential biases in the review process}

We used the standard methods described in the Cochrane Handbook for Systematic Reviews of Interventions (Higgins 2011). Although our search was extensive, we cannot exclude the possibility that we have missed relevant evidence. For studies where we required the raw data, we contacted authors via email. The authors of 14 studies did not respond to several emails requesting mean and standard deviation data (Avery 2003; Beaton 2002a; Bryer 2006; Connolly 2006; Connolly 2006a; Goldfarb 2011; Krotkiewski 1994; McFarlin 2016; Michailidis 2013; Peschek 2014; Phillips 2003; Su 2008; Trombold 2010; Trombold 2011). We therefore extracted these data from graphs using Graphclick 2010 Arizona (version 3.0.2, 2010). Whilst this is not ideal, we tried to minimise error by having two review authors (MR and DR) independently extract the data, with any discrepancies resolved by consultation with the third and fourth authors (HS and JC).

One potential source of bias is the post-hoc exclusion of trials not reporting our primary outcomes (see Types of outcome measures). However, none of the excluded studies were aimed at the prevention, reduction or treatment of DOMS.

We set out "to assess the effects (benefits and harms) of antioxidant supplements and antioxidant-enriched foods for preventing and reducing the severity and duration of delayed onset muscle soreness following exercise" (Objectives). To achieve this, we decided to pool data from clearly heterogeneous trials; for instance varying in their study design, populations, the exercise protocols, the antioxidant dosage, start and length of supplementation, their accounting for extraneous variables that could affect recovery and to a lesser degree in their timing of measuring muscle soreness (DOMS). In the light of this clinical heterogeneity, the statistical heterogeneity was not extreme and sometimes the heterogeneity could be sourced to a very few outliers (e.g. Michailidis 2013 for muscle soreness at 72 hours (Analysis 1.4)). Subgroup analysis by type of exercise proved reassuring. Keeping the focus on the main characteristic of the intervention (i.e. oral antioxidant supplementation at dosage above the recommended daily dosage) appears justified.

Publication bias is a threat to any systematic review or metaanalysis and publication bias among nutrition-related scientific articles remains a problem. Lesser 2007 investigated financial sponsorship of scientific articles addressing the health effects of three commonly consumed beverages to determine how sponsorship affects published conclusions and found that industry funding of nutrition-related studies may bias conclusions in favour of sponsors' products. However, funnel plots for the outcomes of muscle soreness at 24 hours and 48 hours were not suggestive of publication bias (Figure 6; Figure 7). Moreover, we performed a subgroup analysis on studies that were funded by a food company or provider of antioxidant supplements and compared them with studies that were not funded by a food company or provider of antioxidant supplements and we found no evidence of subgroup differences and thus sponsorship bias (Analysis 1.14; Analysis 1.15). 
Our inclusion of cross-over studies and our analysis of their data as if from a parallel group trial, thus without adjustment for the cross-over design, are other potential sources of bias. With one exception, the cross-over studies included in this review used a washout period of two to six weeks, which is sufficient to allow the muscles to recover. The exception used a washout period of only five days between treatments and therefore carries some risk of a carry-over effect (Arent 2010); sensitivity analysis to check on the effect of excluding the data from this trial did not result in important changes. Further sensitivity analyses checking the effects of excluding the cross-over trials from the muscle soreness analyses showed that our inclusion and handling of the cross-over studies did not have an important impact on the review results.

\section{Agreements and disagreements with other studies or reviews}

Several narrative reviews have been written on antioxidant supplementation and recovery (e.g. Gross 2011; Howatson 2008b; McGinley 2009; Peternelj 2011). However, to our knowledge this is the first systematic review that has examined the effects of antioxidant supplements for preventing and reducing muscle soreness after exercise. Our review also includes more recently published evidence. For example, of the 45 trials contributing evidence to the 48 hours muscle soreness analysis (Analysis 1.3), 14 were published in 2012 or subsequently, and 14 more were published between 2009 and 2011.

The observations by Howatson 2008b on the large variations in type of, dosage used and duration of antioxidant and exercise modality are consistent with our findings. McGinley 2009, which reviewed the effects of vitamin C, vitamin E and both combined on muscle damage and oxidative stress, also attributed the mixed findings to variations in dosage, timing and duration of antioxidant and exercise modality. McGinley 2009 suggested that there was some evidence to show that both vitamin $C$ and vitamin $E$ antioxidants can reduce oxidative stress but there was poor evidence to show any positive effects on protecting against muscle damage and soreness. It is also notable that there has been some indication that long-term antioxidant supplementation in high doses, in particular vitamin E, may increase mortality (Bjelakovic 2007). Peternelj 2011 concluded that antioxidant supplementation attenuates exercise-induced oxidative stress but had no effects on exerciseinduced muscle damage, soreness and performance. Although Peternelj 2011 did not perform a meta-analysis, they suggested that there is a growing body of evidence indicating that antioxidant supplements may have a detrimental effect as they may interfere with the beneficial effects of exercise training. Gross 2011 in their narrative review on antioxidant supplementation and endurance training noted that the use of antioxidants in sport by amateur and professional athletes was common and that some studies had suggested that these may actually be counterproductive (in particular vitamin C and E supplements) as they may impair and weaken some of the desired signalling roles played by free radicals during training adaptations. The latter, however, was not investigated by Gross 2011. Nonetheless, over the last few years there has been an emergence of studies showing that chronic antioxidant supplementation may actually be counterproductive, particularly in interfering with exercise-induced cell-signalling in skeletal muscle thus having an overall detrimental effect of exercise training on both performance and health (Gomez-Cabrera 2008; Paulsen 2014; Ristow 2009). More specifically, several studies have shown that antioxidant supplements promote exercise-induced oxidative stress (Avery 2003; Bailey 2011; Beaton 2002; Childs 2001; Knez 2007; Lamprecht 2009; Malm 1996; Nieman 2004), hinder cell adaptation to exercise-induced oxidative stress (GomezCabrera 2008; Ristow 2009; Paulsen 2014), and delay healing and recovery from exercise (Close 2006; Teixeira 2009), and long-term antioxidant supplementation in high doses may increase mortality (Bjelakovic 2014; Slatore 2008).

The risk of adverse effects is likely to be dependent of the type of antioxidant. One of the two trials in the review reporting on adverse effects was testing NAC supplementation and reported that all six participants in the antioxidant group had diarrhoea (Cobley 2011). As well as being a listed side effect of this prescription drug, uncomfortable side effects such as nausea and diarrhoea from NAC supplementation have also been reported elsewhere (Ferreira 2011).

As well as random errors relating to small trials and bias, there are numerous factors that can explain why there are differences between trials and in the antioxidant literature on whether antioxidants are beneficial or not for recovery. The recovery process is complex, and there are many extraneous variables that could interfere or accelerate the recovery process. Factors such as differences in antioxidant dosage, length of supplementation, and accounting for extraneous variables that could affect recovery could explain differences between trials (Close 2014). Second, there are large variations in the type of participants with most studies recruiting untrained, sedentary and relatively young and healthy individuals and far fewer studies recruiting well-trained athletes. Participants will vary in size, body weight, body composition and they may respond differently to antioxidant supplementation due to metabolic differences; these may also be some reasons that can explain the differences in findings. Nonetheless, as argued above, retaining the focus on the broad question asked in this review has helped to us to examine and summarise the evidence for the overall question of whether antioxidants prevent or reduce muscle soreness after exercise.

\section{AUTHORS' CONCLUSIONS}

\section{Implications for practice}

There is moderate- to low-quality evidence that antioxidant supplementation does not result in a clinically relevant reduction of muscle soreness after exercise at any of the five follow-up times: up to 6 hours and at 24, 48, 72 and 96 hours after exercise. There is no evidence available on subjective recovery and only limited evidence on adverse effects of taking antioxidant supplements. Some antioxidant supplements such as $\mathrm{N}$-acetylcysteine may cause unwanted side effects including gastrointestinal discomfort and diarrhoea.

\section{Implications for research}

The findings of, and messages from, this review provide an opportunity for researchers and other stakeholders to come together and consider what are the priorities, and underlying justifications, for future research in this area. Should there be a continuing focus on antioxidants, in preference to other interventions used for reducing muscle soreness, the area would benefit from standardisation of methods and antioxidant protocols. Future randomised controlled trials should ensure that 
the rationale for the antioxidant protocol is considered and specified, and attention given to dietary control and other factors that may affect recovery as these are important confounders when investigating the impact of antioxidant supplementation on exercise performance and recovery. The rationale for selection of populations different from those covered in the review should also be given. We suggest that a case could be made for elite athletes, not included in this review, as this particular group have a different physiological and training status. As recently noted, future studies should employ a parallel design with larger sample sizes as when investigating muscle recovery cross-over trials may have a risk regarding carry-over effects between treatment periods (Bleakley 2012; Costello 2015).

\section{ACKNOWLEDGEMENTS}

We would like to thank Joanne Elliott for her assistance with developing and running the search strategies. We would also like to thank Helen Handoll, Joanne Elliott, Lindsey Elstub and Zipporah Iheozor-Ejiofor for their comments and feedback on drafts of the review. We thank the external referee, Michalis Nikolaidis, for his feedback.

We thank the Cochrane Editorial Unit for feedback received during editorial screening, including the preparation by Newton Opiyo of an additional table documenting sensitivity analyses testing the effects of excluding cross-over studies.

This project was supported by the National Institute for Health Research via Cochrane Infrastructure funding to the Cochrane Bone, Joint and Muscle Trauma Group. The views and opinions expressed therein are those of the authors and do not necessarily reflect those of the Systematic Reviews Programme, NIHR, NHS or the Department of Health. 


\section{RE F E R E N C E S}

\section{References to studies included in this review}

Arent 2010 \{published data only (unpublished sought but not used)\}

Arent SM, Senso M, Golem DL, McKeever KH. The effects of theaflavin-enriched black tea extract on muscle soreness, oxidative stress, inflammation, and endocrine responses to acute anaerobic interval training: a randomized, double-blind, crossover study. Journal of the International Society of Sports Nutrition 2010;7(1):7.

Avery 2003 \{published data only\}

Avery NG, Kaiser JL, Sharman MJ, Scheett TP, Barnes DM, Gómez AL, et al. Effects of vitamin $\mathrm{E}$ supplementation on recovery from repeated bouts of resistance exercise. Journal of Strength and Conditioning Research 2003;17(4):801-9.

\section{Bailey 2011 \{published data only\}}

Bailey DM, Williams C, Betts JA, Thompson D, Hurst TL. Oxidative stress, inflammation and recovery of muscle function after damaging exercise: effect of 6-week mixed antioxidant supplementation. European Journal of Applied Physiology 2011;111(6):925-36.

\section{Beaton 2002a \{published data only\}}

Beaton LJ, Allan DA, Tarnopolsky MA, Tiidus PM, Phillips SM. Contraction-induced muscle damage is unaffected by vitamin E supplementation. Medicine and Science in Sports and Exercise 2002;34(5):798-805.

Bell 2015 \{published and unpublished data\}

* Bell PG, Walshe IH, Davison GW, Stevenson EJ, Howatson G. Recovery facilitation with Montmorency cherries following high-intensity, metabolically challenging exercise. Applied Physiology, Nutrition, and Metabolism 2016;40(4):414-23.

Ranchordas MK. Raw data for DOMS and MVIC [personal communication]. Email to: P Bell 3 February 2017.

Bell 2016 \{published and unpublished data\}

* Bell PG, Stevenson E, Davison GW, Howatson G. The effects of Montmorency tart cherry concentrate supplementation on recovery following prolonged, intermittent exercise. Nutrients 2016;8(7):441. [PUBMED: 27455316]

Ranchordas MK. Request for raw data for DOMS and MVIC [personal communication]. Email to: P Bell 3 February 2017.

Bloomer 2004 \{published and unpublished data\}

* Bloomer RJ, Goldfarb AH, McKenzie MJ, You T, Nguyen L. Effects of antioxidant therapy in women exposed to eccentric exercise. International Journal of Sport Nutrition and Exercise Metabolism 2004;14(4):377-88.

Ranchordas MK. Raw data for DOMS and MVIC [personal communication]. Email to: AH Goldfarb 3 October 2013.

Bloomer 2005 \{published and unpublished data\}

* Bloomer RJ, Fry A, Schilling B, Chiu L, Hori N, Weiss L. Astaxanthin supplementation does not attenuate muscle injury following eccentric exercise in resistance-trained men. International Journal of Sport Nutrition and Exercise Metabolism 2005;15(4):401-12.

Ranchordas MK. Raw data for DOMS and MVIC [personal communication]. Email to: RJ Bloomer 3 October 2013.

Bloomer 2007 \{published and unpublished data\}

* Bloomer RJ, Falvo MJ, Schilling BK, Smith WA. Prior exercise and antioxidant supplementation: effect on oxidative stress and muscle injury. Journal of the International Society of Sports Nutrition 2007;3(10):1-10.

Ranchordas MK. Raw data for DOMS and MVIC [personal communication]. Email to: RJ Bloomer 3 October 2013.

\section{Bryer 2006 \{published data only\}}

Bryer SC, Goldfarb AH. Effect of high dose vitamin C supplementation on muscle soreness, damage, function, and oxidative stress to eccentric exercise. International Journal of Sport Nutrition and Exercise Metabolism 2006;16(3):270-80.

\section{Close 2006 \{published and unpublished data\}}

* Close GL, Ashton T, Cable T, Doran D, Holloway C, McArdle F, et al. Ascorbic acid supplementation does not attenuate postexercise muscle soreness following muscle-damaging exercise but may delay the recovery process. British Journal of Nutrition 2006;95(5):976-81. [PUBMED: 16611389]

Ranchordas MK. Raw data for PPT, DOMS and MVIC [personal communication]. Email to: CL Close 3 October 2013.

Cobley 2011 \{published and unpublished data\}

* Cobley JN, McGlory C, Morton JP, Close GL. N-acetylcysteine's attenuation of fatigue after repeated bouts of intermittent exercise: practical implications for tournament situations. International Journal of Sport Nutrition and Exercise Metabolism 2011;21(6):451-61.

Ranchordas MK. Raw data for DOMS, performance variables and MVIC [personal communication]. Email to: J Cobley 3 December 2013.

\section{Connolly 2006 \{published data only\}}

Connolly DA, Lauzon C, Agnew J, Dunn M, Reed B. The effects of vitamin $C$ supplementation on symptoms of delayed onset muscle soreness. Sports Medicine and Physical Fitness 2006;46(3):462-7.

\section{Connolly 2006a $\{$ published data only\}}

Connolly DA, McHugh MP, Padilla-Zakour OI, Carlson L, Sayers SP. Efficacy of a tart cherry juice blend in preventing the symptoms of muscle damage. British Journal of Sports Medicine 2006;40(8):679-83.

Drobnic 2014 \{published and unpublished data\}

* Drobnic F, Riera J, Appendino G, Togni S, Franceschi F, Valle X, et al. Reduction of delayed onset muscle soreness by a novel curcumin delivery system (Meriva): a randomised placebo 
controlled trial. Journal of the International Society of Sport Nutrition 2014;11(31):1-10.

Ranchordas MK. Raw data for DOMS [personal communication]. Email to: F Drobnic 18 February 2016.

Goldfarb 2011 \{published data only\}

Goldfarb AH, Garten RS, Cho C, Chee PD, Chambers LA. Effects of a fruit/berry/vegetable supplement on muscle function and oxidative stress. Medicine and Science in Sports and Exercise 2011;43(3):501-8.

\section{He 2015 \{published and unpublished data\}}

* He F, Hockemeyer AK, Sedlock D. Does combined antioxidant vitamin supplementation blunt repeated bout effect?

International Journal of Sports Medicine 2015;36:407-13.

Ranchordas MK. Raw data for DOMS [personal communication]. Email to: F He 24 February 2016.

\section{Herrlinger 2015 \{published data only\}}

Herrlinger KA, Chirouzes DM, Ceddia MA. Supplementation with a polyphenolic blend improves post-exercise strength recovery and muscle soreness. Food and Nutrition Research 2015;59:30034.

\section{Howatson 2009 \{published data only\}}

Howatson G, McHugh MP, Hill JA, Brouner J, Jewell AP, van Someren KA, et al. Influence of tart cherry juice on indices of recovery following marathon running. Scandinavian Journal of Medicine and Science in Sports 2010;20(6):843-52.

\section{Hutchinson 2016 \{published data only\}}

Hutchinson AT, Flieller EB, Dillon KJ, Leverett BD. Black currant nectar reduces muscle damage and inflammation following a bout of high-intensity eccentric contractions. Journal of Dietary Supplements 2016;13(1):1-15.

\section{Kaminski 1992 \{published and unpublished data\}}

* Kaminski M, Boal R. An effect of ascorbic acid on delayedonset muscle soreness. Pain 1992;50(3):317-21.

Ranchordas MK. Raw data for DOMS [personal communication]. Email to: M Kaminski 3 December 2013.

Kerksick 2009 \{published and unpublished data\}

* Kerksick CM, Kreider RB, Willoughby DS. Intramuscular adaptations to eccentric exercise and antioxidant supplementation. Amino Acids 2010;39(1):219-32.

Ranchordas MK. Raw data for DOMS and MVIC [personal communication]. Email to DS Willoughby 2 November 2013.

\section{Krotkiewski 1994 \{published data only\}}

Krotkiewski M, Brzezinska Z, Liu B, Grimby G, Palm S. Prevention of muscle soreness by pretreatment with antioxidants. Scandinavian Journal of Science Medicine and Sport 1994;4(3):191-9.
Kuehl 2010 \{published data only\}

Kuehl KS. Hood to coast injury study. https://clinicaltrials.gov/ ct2/show/NCT00733395?term=NCT00733395\&rank=1 (accessed 20 April 2017).

* Kuehl KS, Perrier ET, Elliot DL, Chesnutt JC. Efficacy of tart cherry juice in reducing muscle pain during running: a randomized controlled trial. Journal if the International Society of Sports Nutrition 2010;7(7):17.

Laupheimer 2014 \{published and unpublished data\} * Laupheimer MW, Perry M, Benton S, Malliaras P, Maffulli N. Resveratrol exerts no effect on inflammatory response and delayed onset muscle soreness after a marathon in male athletes. Translational Medicine 2014;10(8):38-42.

Ranchordas MK. Raw data for DOMS [personal communication]. Email to: MW Laupheimer 18 February 2016.

Lynn 2015 \{published data only\}

Lynn A, Garner S, Nelson N, Simper T, Hall A, Ranchordas MK. Effect of bilberry juice on muscle damage and inflammation in runners completing a half marathon. Proceedings of the Nutrition Society 2015;74(OCE5):E287.

McBride 1997 \{published data only\}

McBride JM, Kraemer WJ, Triplett-McBride T, Sebastianelli W. Effect of resistance exercise on free radical production. Medicine and Science in Sports and Exercise 1998;30(1):67-72.

McCormick 2016 \{published data only\}

McCormick R, Peeling P, Binnie M, Dawson B, Sim M. Effect of tart cherry juice on recovery and next day performance in welltrained Water Polo players. Journal of the International Society of Sports Nutrition 2016;13:41.

McFarlin 2016 \{published data only\}

McFarlin BK, Venable AS, Henning AL, Sampson JNB, Pennel K, Vingren $\mathrm{J}$, et al. Reduced inflammatory and muscle damage biomarkers following oral supplementation with bioavailable curcumin. BBA Clinical 2016;5:72-8.

\section{McLeay 2012 \{published data only\}}

McLeay Y, Barnes MJ, Mundel T, Hurst SM, Hurst RD, Stannard SR. Effect of New Zealand blueberry consumption on recovery from eccentric exercise-induced muscle damage. Journal of the International Society of Sports Nutrition 2012;9(1):9-19.

Meamarbashi 2011 \{published data only\}

Meamarbashi A, Abedini F. Preventative effects of purslane extract on delayed onset muscle soreness induced by one session bench stepping exercise. Isokinetics and Exercise Science 2011;19(3):199-206.

Michailidis 2013 \{published data only\}

Fatouros IF. NAC supplementation and skeletal muscle performance. https://clinicaltrials.gov/ct2/show/NCT01778309 (accessed 20 April 2017).

* Michailidis Y, Karagounis LG, Terzis G, Jamurtas AZ, Spengos K, Tsoukas D, et al. Thiol-based antioxidant 
supplementation alters human skeletal muscle signaling and attenuates its inflammatory response and recovery after intense eccentric exercise. American Journal of Clinical Nutrition 2013;98(1):233-45.

\section{Nicol 2015 \{published and unpublished data\}}

* Nicol LM, Rowlands DS, Fazakerly R, Kellet J. Curcumin supplementation likely attenuates delayed onset muscle soreness (DOMS). European Journal of Applied Physiology 2015;115(8):1769-77.

Ranchordas MK. Raw data for DOMS and CMJ [personal communication]. Email to: DS Rowlands 15 March 2016.

\section{Nie 2004 \{published data only\}}

Nie J, Lin H. Effects of vitamin C supplementation on recovery from eccentric exercise-induced muscle soreness and damage in junior athletes. Journal of Exercise Science and Fitness 2004;2(2):94-8.

\section{O'Connor 2013 \{published data only\}}

O'Connor PJ, Caravalho AL, Freese EC, Cureton KJ. Grape consumption's effects on fitness, muscle injury, mood, and perceived health. International Journal of Sport Nutrition and Exercise Metabolism 2013;23(1):57-64.

\section{O'Fallon 2012 \{published and unpublished data\}}

* O'Fallon KS, Kaushik D, Michniak-Kohn B, Dunne CP, Zambraski EJ, Clarkson PM. Effects of quercetin supplementation on markers of muscle damage and inflammation after eccentric exercise. International Journal of Sport Nutrition and Exercise Metabolism 2012;22(6):430-7.

Ranchordas MK. Raw data for DOMS, ROM and MVIC [personal communication]. Email to: KS O'Fallon 3 November 2013.

\section{Peschek 2014 \{published data only\}}

Peschek K, Pritchett R, Bergman E, Pritchett K. The effects of acute post exercise consumption of two cocoa-based beverages with varying flavanol content on indices of muscle recovery following downhill treadmill running. Nutrients 2013;6:50-62.

\section{Phillips 2003 \{published data only\}}

Phillips T, Childs AC, Dreon DM, Phinney S, Leeuwenburgh C. A dietary supplement attenuates IL- 6 and CRP after eccentric exercise in untrained males. Medicine and Science in Sports and Exercise 2003;35(12):2032-7.

\section{Shafat 2004 \{published data only\}}

Shafat A, Butler P, Jensen RL, Donnelly AE. Effects of dietary supplementation with vitamins $C$ and $E$ on muscle function during and after eccentric contractions in humans. European Journal of Applied Physiology 2004;93(1-2):196-202.

\section{Silva 2008 \{published data only\}}

Silva LA, Silveira PC, Pinho CA, Tuon T, Dal Pizzol F, Pinho RA. $\mathrm{N}$-acetylcysteine supplementation and oxidative damage and inflammatory response after eccentric exercise. International Journal of Sport Nutrition and Exercise Metabolism 2008;18(4):379-88.

\section{Silva 2010 \{published data only\}}

Silva LA, Pinho CA, Silveira PC, Tuon T, De Souza CT, Dal-Pizzol F, et al. Vitamin E supplementation decreases muscular and oxidative damage but not inflammatory response induced by eccentric contraction. Journal of Physiological Sciences 2010;60(1):51-7.

\section{Su 2008 \{published data only\}}

Su QS, Tian Y, Zhang JG, Zhang H. Effects of allicin supplementation on plasma markers of exercise-induced muscle damage, IL-6 and antioxidant capacity. European Journal of Applied Physiology 2008;103(3):275-83.

Tanabe 2015 \{published and unpublished data\}

Ranchordas MK. Raw data for DOMS, ROM and MVIC [personal communication]. Email to: N Akazawa 8 December 2016.

* Tanabe Y, Maeda S, Akazawa N, Zempo-Miyaki A, Choi Y, Ra S, et al. Attenuation of indirect markers of eccentric exerciseinduced muscle damage by curcumin. European Journal of Applied Physiology 2015;115(9):1949-57.

Theodorou 2011 \{published data only\}

Jamurtas AZ. The effect of antioxidant vitamin supplementation on muscle performance and redox status after eccentric training. https://clinicaltrials.gov/ct2/show/NCT01290458 (accessed 20 April 2017).

* Theodorou AA, Nikolaidis MG, Paschalis V, Koutsias S, Panayiotou G, Fatouros IG, et al. No effect of antioxidant supplementation on muscle performance and blood redox status adaptations to eccentric training. American Journal of Clinical Nutrition 2011;93(6):1373-83.

Thompson 2001 \{published data only\}

Thompson D, Williams C, Kingsley M, Nicholas CW, Lakomy HK, McArdle $F$, et al. Muscle soreness and damage parameters after prolonged intermittent shuttle-running following acute vitamin C supplementation. International Journal of Sports Medicine 2001;22(1):68-75

\section{Thompson 2001a \{published data only\}}

Thompson D, Williams C, McGregor SJ, Nicholas CW, McArdle F, Jackson MJ, et al. Prolonged vitamin C supplementation and recovery from demanding exercise. International Journal of Sport Nutrition and Exercise Metabolism 2001;11(4):466-81.

Thompson 2003 \{published data only\}

Thompson D, Williams C, Garcia-Roves P, McGregor SJ, McArdle F, Jackson MJ. Post-exercise vitamin C supplementation and recovery from demanding exercise. European Journal of Applied Physiology 2003;89(3-4):393-400.

Thompson 2004 \{published and unpublished data\}

Ranchordas MK. Raw data for DOMS [personal communication]. Email to: D Thompson 3 November 2013.

* Thompson D, Bailey DM, Hill J, Hurst T, Powell JR, Williams C. Prolonged vitamin $\mathrm{C}$ supplementation and recovery from eccentric exercise. European Journal of Applied Physiology 2004;92(1-2):133-8. 
Trombold 2010 \{published and unpublished data\}

Ranchordas MK. Raw data for DOMS and MVIC [personal communication]. Email to: JR Trombold 2 November 2013.

* Trombold JR, Barnes JN, Critchley L, Coyle EF. Ellagitannin consumption improves strength recovery 2-3 d after eccentric exercise. Medicine Science in Sports Exercise 2010;42(3):493-8.

Trombold 2011 \{published and unpublished data\}

Ranchordas MK. Raw data for DOMS and MVIC [personal communication]. Email to: JR Trombold 2 November 2013.

* Trombold JR, Reinfeld AS, Casler JR, Coyle EF. The effect of pomegranate juice supplementation on strength and soreness after eccentric exercise. Journal of Strength and Conditioning Research 2011;25(7):1782-8.

\section{References to studies excluded from this review}

\section{Aalizadeh 2016 \{published data only\}}

Aalizadeh A, Vispour Z, Changizi-Ashtiyani S, Hashemi G, Alvani J, Fatemikia H. Effects of oral administration of thyme (Thymus vulgaris) aqueous extract on delayed muscle soreness in inactive women. De Pharma Chemica 2016;8(3):225-30.

\section{Al-Nawaiseh 2016 \{published data only\}}

Al-Nawaiseh AM, Pritchett RC, Bishop PA. Enhancing short-term recovery after high-intensity anaerobic exercise. Journal of Strength and Conditioning Research 2016;30(2):320-5. [PUBMED: 26815173]

\section{Ammar 2016 \{published data only\}}

Ammar A. Pomegranate improve biological recovery kinetics in elite weightlifter. https://clinicaltrials.gov/ct2/show/ NCT02697903?term=NCT02697903\&rank=1 (accessed 20 April 2017).

* Ammar A, Turki M, Chtourou H, Hammouda O, Trabelsi K, Kallel C, et al. Pomegranate supplementation accelerates recovery of muscle damage and soreness and inflammatory markers after a weightlifting training session. PLoS One 2016;11(10):e0160305.

\section{Arent 2010a \{published data only\}}

Arent SM, Pellegrino JK, Williams CA, Difabio DA, Greenwood JC. Nutritional supplementation, performance, and oxidative stress in college soccer players. Journal of Strength and Conditioning Research 2010;24(4):1117-24. [PUBMED: 20300015]

\section{Askari 2012 \{published data only\}}

Askari G, Ghiasvand R, Karimian J, Feizi A, Paknahad Z, Sharifirad G, et al. Does quercetin and vitamin C improve exercise performance, muscle damage, and body composition in male athletes?. Journal of Research in Medical Sciences 2012;17(4):328-31. [PUBMED: 23267392]

\section{Askari 2013 \{published data only\}}

Askari G, Ghiasvand R, Paknahad Z, Karimian J, Rabiee K, Sharifirad $G$. The effects of quercetin supplementation on body composition, exercise performance and muscle damage indices in athletes. International Journal of Preventive Medicine 2013;4(1):21-6.

Babaei 2009 \{published data only\}

Babaei P, Rahmani-Nia F, Nakhostin B, Bohloolo SH. The effect of vitamin $C$ on immunoendocrine and oxidative stress responses to exercise. Journal of Clinical and Diagnotic Research 2009;3:1627-32.

Bell 2014 \{published data only\}

Bell PG, Walshe IH, Davison GW, Stevenson E, Howatson G. Montmorency cherries reduce the oxidative stress and inflammatory responses to repeated days high-intensity stochastic cycling. Nutrients 2014;6(2):829-43.

Bloomer 2006 \{published data only\}

Bloomer RJ, Goldfarb AH, McKenzie MJ. Oxidative stress response to aerobic exercise: comparison of antioxidant supplements. Medicine and Science in Sports and Exercise 2006;38(6):1098-105. [PUBMED: 16775552]

Bowtell 2011 \{published data only\}

Bowtell JL, Sumners DP, Dyer A, Fox P, Mileva KN. Montmorency cherry juice reduces muscle damage caused by intensive strength exercise. Medicine and Science in Sports and Exercise 2011;43(8):1544-51. [PUBMED: 21233776]

Braakhuis 2014 \{published data only\}

Braakhuis AJ, Hopkins WG, Lowe TE. Effects of dietary antioxidants on training and performance in female runners. European Journal of Sport Science 2014;14(2):160-8.

Bunpo 2016 \{published data only\}

Bunpo P, Anthony TG. Ascorbic acid supplementation does not alter oxidative stress markers in healthy volunteers engaged in a supervised exercise program. Applied Physiology, Nutrition, and Metabolism 2016;41(2):175-80. [PUBMED: 26789096]

Carvalho-Peixoto 2015 \{published data only\}

Carvalho-Peixoto J, Moura MR, Cunha FA, Lollo PC, Monteiro WD, Carvalho LM, et al. Consumption of acai (Euterpe oleracea Mart.) functional beverage reduces muscle stress and improves effort tolerance in elite athletes: a randomized controlled intervention study. Applied Physiology, Nutrition, and Metabolism 2015;40(7):725-33. [PUBMED: 26140415]

Cavas 2004 \{published data only\}

Cavas L, Tarhan L. Effects of vitamin-mineral supplementation on cardiac marker and radical scavenging enzymes, and MDA levels in young swimmers. International Journal of Sport Nutrition and Exercise Metabolism 2004;14(2):133-46. [PUBMED: 15118188]

Childs 2001a \{published data only\}

Childs A, Jacobs C, Kaminski T, Halliwell B, Leeuwenburgh C. Supplementation with vitamin $\mathrm{C}$ and $\mathrm{N}$-acetyl-cysteine increases oxidative stress in humans after an acute muscle injury induced by eccentric exercise. Free Radical Biology and Medicine 2001;31(6):745-53. [PUBMED: 11557312] 


\section{Clifford 2017 \{published data only\}}

Clifford T, Bell O, West DJ, Howatson G, Stevenson EJ. Antioxidant-rich beetroot juice does not adversely affect acute neuromuscular adaptation following eccentric exercise. Journal of Sports Sciences 2017;35(8):812-9. [PUBMED: 27267689]

Daneshvar 2013 \{published data only\} Daneshvar P, Hariri M, Ghiasvand R, Askari G, Darvishi L, Mashhadi NS, et al. Effect of eight weeks of quercetin supplementation on exercise performance, muscle damage and body muscle in male badminton players. International Journal of Preventative Medicine 2013;4(Suppl 1):S53-7.

\section{Dawson 2002 \{published data only\}}

Dawson B, Henry GJ, Goodman C, Gillam I, Beilby JR, Ching S, et al. Effect of vitamin C and E supplementation on biochemical and ultrastructural indices of muscle damage after a $21 \mathrm{~km}$ run. International Journal of Sports Medicine 2002;23(1):10-5. [PUBMED: 11774060]

\section{Eichenberger 2010 \{published data only\}}

Eichenberger P, Mettler S, Arnold M, Colombani PC. No effects of three-week consumption of a green tea extract on time trial performance in endurance-trained men. International Journal for Vitamin and Nutrition Research 2010;80(1):54-64. [PUBMED: 20533245]

\section{Fuster-Munoz 2016 \{published data only\}}

Fuster-Munoz E, Roche E, Funes L, Martinez-Peinado P, Sempere JM, Vicente-Salar N. Effects of pomegranate juice in circulating parameters, cytokines, and oxidative stress markers in endurance-based athletes: a randomized controlled trial. Nutrition 2016;32(5):539-45. [PUBMED: 26778544]

\section{Gaeini 2006 \{published data only\}}

Gaeini AA, Rahnama N, Hamedinia MR. Effects of vitamin E supplementation on oxidative stress at rest and after exercise to exhaustion in athletic students. Journal of Sports Medicine and Physical Fitness 2006;46(3):458-61. [PUBMED: 16998452]

\section{Gomez-Cabrera 2003 \{published data only\}}

Gomez-Cabrera MC, Pallardo FV, Sastre J, Vina J, Garcia-delMoral L. Allopurinol and markers of muscle damage among participants in the Tour de France. JAMA 2003;289(19):2503-4. [PUBMED: 12759321]

\section{Hillman 2017 \{published data only\}}

Hillman AR, Taylor BCR, Thompkins D. The effects of tart cherry juice with whey protein on the signs and symptoms of exerciseinduced muscle damage following plyometric exercise. Journal of Functional Foods 2017;29:185-92.

\section{Itoh 2000 \{published data only\}}

Itoh H, Ohkuwa T, Yamazaki Y, Shimoda T, Wakayama A, Tamura S, et al. Vitamin E supplementation attenuates leakage of enzymes following 6 successive days of running training. International Journal of Sports Medicine 2000;21(5):369-74. [PUBMED: 10950448]
Jakeman 1993 \{published data only\}

Jakeman P, Maxwell S. Effect of antioxidant vitamin supplementation on muscle function after eccentric exercise. European Journal of Applied Physiology and Occupational Physiology 1993;67(5):426-30. [PUBMED: 8299614]

Jowko 2011 \{published data only\}

Jowko E, Sacharuk J, Balasinska B, Ostaszewski P, Charmas M, Charmas R. Green tea extract supplementation gives protection against exercise-induced oxidative damage in healthy men. Nutrition Research 2011;31(11):813-21. [PUBMED: 22118751]

Jowko 2012 \{published data only\}

Jowko E, Sacharuk J, Balasinska B, Wilczak J, Charmas M, Ostaszewski $P$, et al. Effect of a single dose of green tea polyphenols on the blood markers of exercise-induced oxidative stress in soccer players. International Journal of Sport Nutrition and Exercise Metabolism 2012;22(6):486-96. [PUBMED: 22805286]

Jowko 2015 \{published data only\}

Jowko E, Dlugolecka B, Makaruk B, Cieslinski I. The effect of green tea extract supplementation on exercise-induced oxidative stress parameters in male sprinters. European Journal of Nutrition 2015;54(5):783-91. [PUBMED: 25120110]

\section{Kaikkonen 1998 \{published data only\}}

Kaikkonen J, Kosonen L, Nyyssonen K, Porkkala-Sarataho E, Salonen R, Korpela $\mathrm{H}$, et al. Effect of combined coenzyme Q10 and d-alpha-tocopheryl acetate supplementation on exerciseinduced lipid peroxidation and muscular damage: a placebocontrolled double-blind study in marathon runners. Free Radical Research 1998;29(1):85-92. [PUBMED: 9733025]

\section{Keong 2006 \{published data only\}}

Keong CC, Singh HJ, Singh R. Effects of palm vitamin E supplementation on exercise-induced oxidative stress and endurance performance in the heat. Journal of Sport Science and Medicine 2006;5(4):629-39.

\section{Kim 2013 \{published data only\}}

Kim H, Suzuki T, Saito K, Yoshida H, Kojima N, Kim M, et al. Effects of exercise and tea catechins on muscle mass, strength and walking ability in community-dwelling elderly Japanese sarcopenic women: a randomized controlled trial. Geriatrics Gerontology International 2013;13(2):458-65.

\section{Kingsley 2006 \{published data only\}}

Kingsley MI, Kilduff LP, McEneny J, Dietzig RE, Benton D. Phosphatidylserine supplementation and recovery following downhill running. Medicine and Science in Sports and Exercise 2006;38(9):1617-25. [PUBMED: 16960523]

\section{Kizaki 2015 \{published data only\}}

Kizaki K, Terada T, Arikawa H, Tajima T, Imai H, Takahashi T, et al. Effect of reduced coenzyme Q10 (ubiquinol) supplementation on blood pressure and muscle damage during kendo training camp: a double-blind, randomized controlled study. Journal of Sports Medicine and Physical Fitness 2015;55(7-8):797-804. [PUBMED: 25369277] 
Kon 2008 \{published data only\}

Kon M, Tanabe K, Akimoto T, Kimura F, Tanimura Y, Shimizu K, et al. Reducing exercise-induced muscular injury in kendo athletes with supplementation of coenzyme Q10. British Journal of Nutrition 2008;100(4):903-9. [PUBMED: 18284711]

\section{Kraemer 2007 \{published data only\}}

Kraemer WJ, Hatfield DL, Spiering BA, Vingren JL, Fragala MS, Ho JY, et al. Effects of a multi-nutrient supplement on exercise performance and hormonal responses to resistance exercise. European Journal of Applied Physiology 2007;101(5):637-46. [PUBMED: 17701421]

\section{Lafay 2009 \{published data only\}}

Lafay S, Jan C, Nardon K, Lemaire B, Ibarra A, Roller M, et al. Grape extract improves antioxidant status and physical performance in elite male athletes. Journal of Sports Science and Medicine 2009;8(3):468-80. [PUBMED: 24150013]

\section{Lamprecht 2009a \{published data only\}}

Lamprecht M, Hofmann P, Greilberger JF, Schwaberger G. Increased lipid peroxidation in trained men after 2 weeks of antioxidant supplementation. International Journal of Sport Nutrition and Exercise Metabolism 2009;19(4):385-99. [PUBMED: 19827463]

\section{Leelarungrayub 2011 \{published data only\}}

Leelarungrayub D, Khansuwan R, Pothongsunun P, Klaphajone J. N-acetylcysteine supplementation controls total antioxidant capacity, creatine kinase, lactate, and tumor necrotic factor-alpha against oxidative stress induced by graded exercise in sedentary men. Oxidative Medicine and Cellular Longevity 2011;329643:1-6. [DOI: 10.1155/2011/329643]

\section{Lenn 2002 \{published data only\}}

Lenn J, Uhl T, Mattacola C, Boissonneault G, Yates J, Ibrahim W, et al. The effects of fish oil and isoflavones on delayed onset muscle soreness. Medicine and Science in Sports and Exercise 2002;34(10):1605-13. [PUBMED: 12370562]

\section{Levers 2015 \{published data only\}}

Levers K, Dalton R, Galvan E, Goodenough C, O'Connor A, Simbo S, et al. Effects of powdered Montmorency tart cherry supplementation on an acute bout of intense lower body strength exercise in resistance trained males. Journal of the International Society of Sports Nutrition 2015;12:41. [PUBMED: 26578852]

\section{Levers 2016 \{published data only\}}

Levers K, Dalton R, Galvan E, O'Connor A, Goodenough C, Simbo $S$, et al. Effects of powdered Montmorency tart cherry supplementation on acute endurance exercise performance in aerobically trained individuals. Journal of the International Society of Sports Nutrition 2016;13:22. [PUBMED: 27231439]

\section{Louis 2010 \{published data only\}}

Louis J, Hausswirth C, Bieuzen F, Brisswalter J. Vitamin and mineral supplementation effect on muscular activity and cycling efficiency in master athletes. Applied Physiology, Nutrition, and Metabolism 2010;35(3):251-60. [PUBMED: 20555368]

\section{Margaritis 2003 \{published data only\}}

Margaritis I, Palazzetti S, Rousseau AS, Richard MJ, Favier A. Antioxidant supplementation and tapering exercise improve exercise-induced antioxidant response. Journal of the American College of Nutrition 2003;22(2):147-56. [PUBMED: 12672711]

Mastaloudis 2006 \{published data only\}

Mastaloudis A, Traber MG, Carstensen K, Widrick JJ. Antioxidants did not prevent muscle damage in response to an ultramarathon run. Medicine and Science in Sports and Exercise 2006;38(1):72-80. [PUBMED: 16394956]

\section{Matsumoto 2005 \{published data only\}}

Matsumoto H, Takenami E, Iwasaki-Kurashige K, Osada T, Katsumura T, Hamaoka T. Effects of blackcurrant anthocyanin intake on peripheral muscle circulation during typing work in humans. European Journal of Applied Physiology 2005;94(1-2):36-45. [PUBMED: 15605279]

\section{McKenna 2006 \{published data only\}}

McKenna MJ, Medved I, Goodman CA, Brown MJ, Bjorksten AR, Murphy KT, et al. $\mathrm{N}$-acetylcysteine attenuates the decline in muscle $\mathrm{Na}+, \mathrm{K}+-$ pump activity and delays fatigue during prolonged exercise in humans. Journal of Physiology 2006;576(Pt 1):279-88. [PUBMED: 16840514]

\section{Meamarbashi 2014 \{published data only\}}

Meamarbashi A, Tavakoli AM. Ergogenic effect of a traditional natural powder: ghavoot. Journal of Dietary Supplements 2014;11(3):241-7. [PUBMED: 25025852]

\section{Meamarbashi 2016 \{published data only\}}

Meamarbashi A, Rajabi A. Potential ergogenic effects of saffron. Journal of Dietary Supplements 2016;13(5):522-9. [PUBMED: 26811090]

\section{Medved 2004 \{published data only\}}

Medved I, Brown MJ, Bjorksten AR, Murphy KT, Petersen AC, Sostaric $\mathrm{S}$, et al. $\mathrm{N}$-acetylcysteine enhances muscle cysteine and glutathione availability and attenuates fatigue during prolonged exercise in endurance-trained individuals. Journal of Applied Physiology 2004;97(4):1477-85. [PUBMED: 15194675]

\section{Meydani 1993 \{published data only\}}

Meydani M, Evans WJ, Handelman G, Biddle L, Fielding RA, Meydani SN, et al. Protective effect of vitamin E on exerciseinduced oxidative damage in young and older adults. American Journal of Physiology 1993;264(5 Pt 2):R992-8. [PUBMED: 8498608]

\section{Mizuno 1997 \{published data only\}}

Mizuno M, Quistorff B, Theorell H, Theorell M, Chance B. Effects of oral supplementation of coenzyme Q10 on 31P-NMR detected skeletal muscle energy metabolism in middle-aged post-polio subjects and normal volunteers. Molecular Aspects of Medicine 1997;18 Suppl:S291-8. [PUBMED: 9266539]

\section{Morillas-Ruiz 2005 \{published data only\}}

Morillas-Ruiz J, Zafrilla P, Almar M, Cuevas MJ, Lopez FJ, Abellan $\mathrm{P}$, et al. The effects of an antioxidant-supplemented beverage on exercise-induced oxidative stress: results from a 
placebo-controlled double-blind study in cyclists. European Journal of Applied Physiology 2005;95(5-6):543-9. [PUBMED: 16132121]

\section{NCT01555775 \{published data only\}}

Sousa MV. Compared effect of a fruit milk shake with a proteincarbohydrate supplement on recovery after resistance exercise. https://clinicaltrials.gov/ct2/show/NCT01555775? term=NCT01555775\&rank=1 (accessed 20 April 2017).

\section{Nieman 2010 \{published data only\}}

Nieman DC, Williams AS, Shanely RA, Jin F, McAnulty SR, Triplett NT, et al. Quercetin's influence on exercise performance and muscle mitochondrial biogenesis. Medicine and Science in Sports and Exercise 2010;42(2):338-45. [PUBMED: 19927026]

\section{Olesen 2013 \{published data only\}}

Olesen J, Gliemann L, Bienso RS, Schmidt J, Hellsten Y, Pilegaard $\mathrm{H}$. Exercise - but not resveratrol - increases performance and oxidative proteins in elderly human skeletal muscle. European Association for the Study of Diabetes (EASD) 49th Annual Meeting; 2013 Sep 23-7; Barcelona, Spain. 2013.

\section{Ostman 2012 \{published data only\}}

Ostman B, Sjodin A, Michaelsson K, Byberg L. Coenzyme Q10 supplementation and exercise-induced oxidative stress in humans. Nutrition 2012;28(4):403-17. [PUBMED: 22079391]

\section{Panza 2016 \{published data only\}}

Panza VP, Diefenthaeler F, Tamborindeguy AC, Camargo $\mathrm{C}$ de Q, De Moura BM, Brunetta HS, et al. Effects of mate tea consumption on muscle strength and oxidative stress markers after eccentric exercise. British Journal of Nutrition 2016;115(8):1370-8. [PUBMED: 26917157]

\section{Passerieux 2015 \{published data only\}}

Passerieux E, Hayot M, Jaussent A, Carnac G, Gouzi F, Pillard F, et al. Effects of vitamin C, vitamin E, zinc gluconate, and selenomethionine supplementation on muscle function and oxidative stress biomarkers in patients with facioscapulohumeral dystrophy: a double-blind randomized controlled clinical trial. Free Radical Biology \& Medicine 2015;81:158-69. [PUBMED: 25246239]

\section{Paulsen 2014a \{published data only\}}

Paulsen G, Cumming KT, Holden G, Hallén J, Rønnestad BR, Sveen $O$, et al. Vitamin $C$ and $E$ supplementation hampers cellular adaptation to endurance training in humans: a doubleblind, randomised, controlled trial. Journal of Physiology 2014;592(8):1887-901.

\section{Petersen 2001 \{published data only\}}

Petersen EW, Ostrowski K, Ibfelt T, Richelle M, Offord E, HalkjaerKristensen J, et al. Effect of vitamin supplementation on cytokine response and on muscle damage after strenuous exercise. American Journal of Physiology. Cell Physiology 2001;280(6):C1570-5. [PUBMED: 11350752]

\section{Pilaczynska-Szczesniak 2005 \{published data only\}}

Pilaczynska-Szczesniak L, Skarpanska-Steinborn A, Deskur E, Basta P, Horoszkiewicz-Hassan M. The influence of chokeberry juice supplementation on the reduction of oxidative stress resulting from an incremental rowing ergometer exercise. International Journal of Sport Nutrition and Exercise Metabolism 2005;15(1):48-58. [PUBMED: 15902989]

\section{Roengrit 2014 \{published data only\}}

Roengrit T, Wannanon P, Prasertsri P, Kanpetta Y, Sripanidkulchai BO, Leelayuwat N. Antioxidant and antinociceptive effects of Phyllanthus amarus on improving exercise recovery in sedentary men: a randomized crossover (double-blind) design. Journal of the International Society of Sports Nutrition 2014;11(1):9. [PUBMED: 24636198]

\section{Roengrit 2015 \{published data only\}}

Roengrit T, Wannanon P, Prasertsri P, Kanpetta $Y$, Sripanidkulchai BO, Wattanathorn J, et al. Antioxidant effect of Phyllanthus amarus after moderate-intensity exercise in sedentary males: a randomized crossover (double-blind) study. Journal of Physical Therapy Science 2015;27(4):1181-6. [PUBMED: 25995584]

\section{Romano-Ely 2006 \{published data only\}}

Romano-Ely BC, Todd MK, Saunders MJ, Laurent TS. Effect of an isocaloric carbohydrate-protein-antioxidant drink on cycling performance. Medicine and Science in Sports and Exercise 2006;38(9):1608-16. [PUBMED: 16960522]

\section{Sacheck 2003 \{published data only\}}

Sacheck JM, Milbury PE, Cannon JG, Roubenoff R, Blumberg JB. Effect of vitamin $E$ and eccentric exercise on selected biomarkers of oxidative stress in young and elderly men. Free Radical Biology \& Medicine 2003;34(12):1575-88. [PUBMED: 12788477]

\section{Sanchis-Gomar 2015 \{published data only\}}

Sanchis-Gomar F, Pareja-Galeano H, Gomez-Cabrera MC, Candel J, Lippi G, Salvagno GL, et al. Allopurinol prevents cardiac and skeletal muscle damage in professional soccer players. Scandinavian Journal of Medicine \& Science in Sports 2015;25(1):e110-5. [PUBMED: 24690021]

Santos 2016 \{published data only\}

Santos SA, Silva ET, Caris AV, Lira FS, Tufik S, Dos Santos RV. Vitamin E supplementation inhibits muscle damage and inflammation after moderate exercise in hypoxia. Journal of Human Nutrition and Dietetics 2016;29(4):516-22. [PUBMED: 27062041]

\section{Skarpanska-Stejnborn 2008 \{published data only\}}

Skarpanska-Stejnborn A, Pilaczynska-Szczesniak L, Basta P, Deskur-Smielcka E, Horoszkiewicz-Hassan M. The influence of supplementation with artichoke (Cynara scolymus L.) extract on selected redox parameters in rowers. International Journal of Sport Nutrition and Exercise Metabolism 2008;18(3):313-27. [PUBMED: 18562776]

\section{Suzuki 2015 \{published data only\}}

Suzuki K, Takahashi M, Li CY, Lin SP, Tomari M, Shing CM, et al. The acute effects of green tea and carbohydrate coingestion on systemic inflammation and oxidative stress during 
sprint cycling. Applied Physiology, Nutrition, and Metabolism 2015;40(10):997-1003. [PUBMED: 26319564]

Taub 2015 \{published data only\}

Taub PR, Patel M, Higginbotham E, Ramon L, Moreno-Ulloa A, Ramirez-Sanchez I, el al. Effects of Dark Chocolate (DC) on exercise capacity in sedentary older adults (a double blind placebo controlled trial. American College of Cardiology (ACC) 64th Annual Scientific Session \& Expo 2015 \& i2 Summit; 2015 Mar 14-16;San Diego, California. 2015.

Teixeira 2009a \{published data only\}

Teixeira VH, Valente HF, Casal SI, Marques AF, Moreira PA. Antioxidants do not prevent postexercise peroxidation and may delay muscle recovery. Medicine and Science in Sports and Exercise 2009;41(9):1752-60. [PUBMED: 19657294]

\section{Toscano 2015 \{published data only\}}

Toscano LT, Tavares RL, Toscano LT, Silva CS, Almeida AE, Biasoto AC, et al. Potential ergogenic activity of grape juice in runners. Applied Physiology, Nutrition, and Metabolism 2015;40(9):899-906. [PUBMED: 26288392]

\section{Yarahmadi 2014 \{published data only\}}

Yarahmadi M, Askari G, Kargarfard M, Ghiasvand R, Hoseini M, Mohamadi $\mathrm{H}$, et al. The effect of anthocyanin supplementation on body composition, exercise performance and muscle damage indices. International Journal of Preventative Medicine 2014;5(12):1594-600.

\section{Yarahmadi 2014a \{published data only\}}

Yarahmadi M, Askari G, Kargarfard M, Ghiasvand R, Hoseini M, Mohamadi $\mathrm{H}$, et al. The effect of anthocyanin supplementation on body composition, exercise performance and muscle damage indices in athletes. International Journal of Preventive Medicine 2014;5(12):1594-600. [PUBMED: 25709796]

\section{Yfanti 2010 \{published data only\}}

Yfanti C, Akerstrom T, Nielsen S, Nielsen AR, Mounier R, Mortensen $\mathrm{OH}$, et al. Antioxidant supplementation does not alter endurance training adaptation. Medicine and Science in Sports and Exercise 2010;42(7):1388-95. [PUBMED: 20019626]

\section{Yfanti 2012 \{published data only\}}

Yfanti C, Fischer CP, Nielsen S, Akerström T, Nielsen AR, Veskoukis AS, et al. Role of vitamin $\mathrm{C}$ and $\mathrm{E}$ supplementation on IL-6 in response to training. Journal of Applied Physiology 2012;112(6):990-1000.

\section{Zoppi 2006 \{published data only\}}

Zoppi CC, Hohl R, Silva FC, Lazarim FL, Neto JM, Stancanneli M, et al. Vitamin $\mathrm{C}$ and $\mathrm{E}$ supplementation effects in professional soccer players under regular training. Journal of the International Society of Sports Nutrition 2006;3:37-44. [PUBMED: 18500971]

\section{References to ongoing studies \\ NCT02281981 \{published data only\}}

Burr J. The effects of repeated bouts of downhill running and curcumin supplementation on arterial stiffness during recovery. https://clinicaltrials.gov/ct2/show/NCT02281981? term=NCT02281981\&rank=1 (accessed 20 April 2017).

\section{Additional references}

\section{Armstrong 1984}

Armstrong RB. Mechanisms of exercise-induced delayed onset muscular soreness: a brief review. Medicine and Science in Sports and Exercise 1984;16(6):529-38. [PUBMED: 6392811]

\section{Asmussen 1953}

Asmussen E. Positive and negative muscular work. Acta Physiologica Scandinavica 1953;28(4):364-82. [PUBMED: 13091912]

\section{Beaton 2002}

Beaton LJ, Allan DA, Tarnopolsky MA, Tiidus PM, Phillips SM. Contraction-induced muscle damage is unaffected by vitamin E supplementation. Medicine and Science in Sports and Exercise 2002;34(5):798-805. [PUBMED: 11984298]

\section{Bieuzen 2013}

Bieuzen F, Bleakley CM, Costello JT. Contrast water therapy and exercise induced muscle damage: a systematic review and meta-analysis. PloS One 2013;8(4):e62356. [DOI: 10.1371/ journal.pone.0062356]

\section{Bjelakovic 2007}

Bjelakovic G, Nikolova D, Gluud LL, Simonetti RG, Gluud C. Mortality in randomized trials of antioxidant supplements for primary and secondary prevention: systematic review and meta-analysis. JAMA 2007;297(8):842-57. [PUBMED: 17327526]

\section{Bjelakovic 2014}

Bjelakovic G, Nikolova D, Gluud C. Antioxidant supplements and mortality. Current Opinion in Clinical Nutrition and Metabolic Care 2014;17(1):40-4. [PUBMED: 24241129]

\section{Bleakley 2012}

Bleakley C, McDonough S, Gardner E, Baxter GD, Hopkins JT, Davison GW. Cold-water immersion (cryotherapy) for preventing and treating muscle soreness after exercise. Cochrane Database of Systematic Reviews 2012, Issue 2. [DOI: 10.1002/14651858.CD008262.pub2]

\section{Borg 1998}

Borg G. Perceived Exertion and Pain Scale. Champaign, IL: Human Kinetics, 1998.

\section{Byrnes 1986}

Byrnes WC, Clarkson PM. Delayed onset muscle soreness and training. Clinics in Sports Medicine 1986;5(3):605-14. [PUBMED: 3521903]

\section{Castrogiovanni 2012}

Castrogiovanni P, Imbesi R. Oxidative stress and skeletal muscle in exercise. Italian Journal of Anatomy and Embryology 2012;117(2):107-17. [PUBMED: 23420998] 


\section{Cheung 2003}

Cheung K, Hume P, Maxwell L. Delayed onset muscle soreness: treatment strategies and performance factors. Sports Medicine 2003;33(2):145-64. [PUBMED: 12617692]

\section{Childs 2001}

Childs A, Jacobs C, Kaminski T, Halliwell B, Leeuwenburgh C. Supplementation with vitamin $\mathrm{C}$ and $\mathrm{N}$-acetyl-cysteine increases oxidative stress in humans after an acute muscle injury induced by eccentric exercise. Free Radical Biology and Medicine 2001;31(6):745-53. [PUBMED: 11557312]

\section{Cleak 1992}

Cleak MJ, Eston RG. Delayed onset muscle soreness: mechanisms and management. Journal of Sports Sciences 1992;10(4):325-41. [PUBMED: 1518094]

\section{Close 2005}

Close GL, Ashton T, McArdle A, Maclaren DP. The emerging role of free radicals in delayed onset muscle soreness and contraction-induced muscle injury. Comparative Biochemistry and Physiology. Part A, Molecular \& Integrative Physiology 2005;142(3):257-66. [PUBMED: 16153865]

\section{Close 2014}

Close GL, Jackson MJ. Antioxidants and exercise: a tale of the complexities of relating signalling processes to physiological function?. Journal of Physiology 2014;592(8):1721-2. [PUBMED: 24737894]

\section{Costello 2014}

Costello JT, Bieuzen F, Bleakley CM. Where are all the female participants in Sports and Exercise Medicine research?. European Journal of Sport Science 2014;14(8):847-51. [DOI: 10.1080/17461391.2014.911354]

\section{Costello 2015}

Costello JT, Baker PRA, Minett GM, Bieuzen F, Stewart IB, Bleakley C. Whole-body cryotherapy (extreme cold air exposure) for preventing and treating muscle soreness after exercise in adults. Cochrane Database of Systematic Reviews 2015, Issue 9. [DOI: 10.1002/14651858.CD010789.pub2]

\section{Davies 1972}

Davies CT, Barnes C. Negative (eccentric) work. II. Physiological responses to walking uphill and downhill on a motor-driven treadmill. Ergonomics 1972;15(2):121-31. [PUBMED: 5036082]

\section{De Vries 1966}

De Vries HA. Quantitative electromyographic investigation of the spasm theory of muscle pain. American Journal of Physical Medicine 1966;45(3):119-34. [PUBMED: 5938206]

\section{Deeks 2011}

Deeks JJ, Higgins JPT, Altman DG (editors). Chapter 9: Analysing data and undertaking meta-analyses. In: Higgins JPT, Green $\mathrm{S}$ (editors). Cochrane Handbook for Systematic Reviews of Interventions Version 5.1.0 (updated March 2011). The Cochrane Collaboration, 2011. Available from www.cochranehandbook.org.

\section{EPOC 2013}

Cochrane Effective Practice, Organisation of Care. EPOC Worksheets for preparing a Summary of Findings (SoF) table using GRADE 2013. http://epoc.cochrane.org/epoc-specificresources-review-authors (accessed 28 June 2016).

\section{Ferreira 2011}

Ferreira LF, Campbell KS, Reid MB. N-acetylcysteine in handgrip exercise: plasma thiols and adverse reactions. International Journal of Sport Nutrition and Exercise Metabolism 2011;21(2):146-54. [PUBMED: 21558576]

\section{Gomez-Cabrera 2008}

Gomez-Cabrera MC, Domenech E, Romagnoli M, Arduini A, Borras C, Pallardo FV, et al. Oral administration of vitamin C decreases muscle mitochondrial biogenesis and hampers training-induced adaptations in endurance performance. American Journal of Clinical Nutrition 2008;87(1):142-9. [PUBMED: 18175748]

\section{Graphclick 2010 [Computer program]}

Bovet J, Bovet S. Graphclick version 3.0.2. http://www.arizonasoftware.ch/graphclick: Arizona, 2010.

\section{Gross 2011}

Gross M, Baum O, Hoppeler H. Antioxidant supplementation and endurance training: win or loss?. European Journal of Sport Science 2011;11(1):27-32.

\section{Higgins 2011}

Higgins JPT, Altman DG, Sterne JAC (editors). Chapter 8: Assessing risk of bias in included studies. In: Higgins JPT, Green S (editors). Cochrane Handbook for Systematic Reviews of Interventions Version 5.1.0 (updated March 2011). The Cochrane Collaboration, 2011. Available from www.cochranehandbook.org.

\section{Hough 1900}

Hough T. Ergographic studies in muscular fatigue and soreness. Journal of the Boston Society of Medical Sciences 1900;5(3):81-92. [PUBMED: 19971340]

\section{Howatson 2008b}

Howatson G, van Someren KA. The prevention and treatment of exercise-induced muscle damage. Sports Medicine 2008;38(6):483-503. [PUBMED: 18489195]

\section{Howatson 2010}

Howatson G, McHugh MP, Hill JA, Brouner J, Jewell AP, van Someren KA, et al. Influence of tart cherry juice on indices of recovery following marathon running. Scandinavian Journal of Medicine \& Science in Sports 2010;20(6):843-52. [PUBMED: 19883392]

\section{Knez 2007}

Knez WL, Jenkins DG, Coombes JS. Oxidative stress in half and full Ironman triathletes. Medicine and Science in Sports and Exercise 2007;39(2):283-8. [PUBMED: 17277592] 


\section{Lamprecht 2009}

Lamprecht M, Hofmann P, Greilberger JF, Schwaberger G. Increased lipid peroxidation in trained men after 2 weeks of antioxidant supplementation. International Journal of Sport Nutrition and Exercise Metabolism 2009;19(4):385-99. [PUBMED: 19827463]

\section{Lefebvre 2011}

Lefebvre C, Manheimer E, Glanville J. Chapter 6: Searching for studies. In: Higgins JPT, Green S (editors). Cochrane Handbook for Systematic Reviews of Interventions Version 5.1.0 (updated March 2011). The Cochrane Collaboration, 2011. Available from www.cochrane-handbook.org.

\section{Lesser 2007}

Lesser LI, Ebbeling CB, Goozner M, Wypij D, Ludwig DS. Relationship between funding source and conclusion among nutrition-related scientific articles. PLoS Medicine 2007;4(1):e5. [PUBMED: 17214504]

\section{Malm 1996}

Malm C, Svensson M, Sjoberg B, Ekblom B, Sjodin B. Supplementation with ubiquinone-10 causes cellular damage during intense exercise. Acta Physiologica Scandinavica 1996;157(4):511-2. [PUBMED: 8869734]

\section{Margaritelis 2016}

Margaritelis NV, Cobley JN, Paschalis V, Veskoukis AS, Theodorou AA, Kyparos A, et al. Principles for integrating reactive species into in vivo biological processes: examples from exercise physiology. Cellular Signalling 2016;28(4):256-71. [PUBMED: 26721187]

\section{Maughan 1989}

Maughan RJ, Donnelly AE, Gleeson M, Whiting PH, Walker KA, Clough PJ. Delayed-onset muscle damage and lipid peroxidation in man after a downhill run. Muscle \& Nerve 1989;12(4):332-6. [PUBMED: 2770784]

\section{McGinley 2009}

McGinley C, Shafat A, Donnelly AE. Does antioxidant vitamin supplementation protect against muscle damage?. Sports Medicine 2009;39(12):1011-32. [PUBMED: 19902983]

\section{Nieman 2004}

Nieman DC, Henson DA, McAnulty SR, McAnulty LS, Morrow JD, Ahmed A, et al. Vitamin E and immunity after the Kona Triathlon World Championship. Medicine and Science in Sports and Exercise 2004; Vol. 36, issue 8:1328-35. [PUBMED: 15292740]

\section{Paulsen 2012}

Paulsen G, Mikkelsen UR, Raastad T, Peake JM. Leucocytes, cytokines and satellite cells: what role do they play in muscle damage and regeneration following eccentric exercise?. Exercise Immunology Review 2012;18:42-97. [PUBMED: 22876722]

\section{Paulsen 2014}

Paulsen G, Cumming KT, Holden G, Hallen J, Ronnestad BR, Sveen $\mathrm{O}$, et al. Vitamin $\mathrm{C}$ and $\mathrm{E}$ supplementation hampers cellular adaptation to endurance training in humans: a double- blind, randomised, controlled trial. Journal of Physiology 2014;592(8):1887-901. [PUBMED: 24492839]

\section{Peternelj 2011}

Peternelj TT, Coombes JS. Antioxidant supplementation during exercise training: beneficial or detrimental?. Sports Medicine 2011;41(12):1043-69. [PUBMED: 22060178]

\section{Powers 2008}

Powers SK, Jackson MJ. Exercise-induced oxidative stress: cellular mechanisms and impact on muscle force production. Physiological Reviews 2008;88(4):1243-76. [PUBMED: 18923182]

\section{Ramel 2004}

Ramel A, Wagner KH, Elmadfa I. Plasma antioxidants and lipid oxidation after submaximal resistance exercise in men. European Journal of Nutrition 2004;43(1):2-6. [PUBMED: 14991263]

\section{RevMan 2014 [Computer program]}

The Nordic Cochrane Centre, The Cochrane Collaboration. Review Manager (RevMan). Version 5.3. Copenhagen: The Nordic Cochrane Centre, The Cochrane Collaboration, 2014.

\section{Ristow 2009}

Ristow M, Zarse K, Oberbach A, Kloting N, Birringer M, Kiehntopf M, et al. Antioxidants prevent health-promoting effects of physical exercise in humans. Proceedings of the National Academy of Sciences of the United States of America 2009;106(21):8665-70.

\section{Schünemann 2011}

Schünemann HJ, Oxman AD, Vist GE, Higgins JPT, Deeks JJ, Glasziou P, et al. Chapter 11: Presenting results and 'Summary of findings' tables. In: Higgins JPT, Green S (editors), Cochrane Handbook for Systematic Reviews of Interventions Version 5.1.0 (updated March 2011). The Cochrane Collaboration, 2011. Available from www.cochrane-handbook.org.

\section{Slatore 2008}

Slatore CG, Littman AJ, Au DH, Satia JA, White E. Long-term use of supplemental multivitamins, vitamin C, vitamin E, and folate does not reduce the risk of lung cancer. American Journal of Respiratory and Critical Care Medicine 2008;177(5):524-30. [PUBMED: 17989343]

\section{Smith 1991}

Smith LL. Acute inflammation: the underlying mechanism in delayed onset muscle soreness?. Medicine and Science in Sports and Exercise 1991;23(5):542-51. [PUBMED: 2072832]

\section{Tashjian 2009}

Tashjian RZ, Deloach J, Porucznik CA, Powell AP. Minimal clinically important differences (MCID) and patient acceptable symptomatic state (PASS) for visual analog scales (VAS) measuring pain in patients treated for rotator cuff disease. Journal of Shoulder and Elbow Surgery 2009;18(6):927-32.

\section{Teixeira 2009}

Teixeira VH, Valente HF, Casal SI, Marques AF, Moreira PA. Antioxidants do not prevent postexercise peroxidation and 
may delay muscle recovery. Medicine and Science in Sports and Exercise 2009;41(9):1752-60. [PUBMED: 19657294]

\section{Tsai 2001}

Tsai K, Hsu TG, Hsu KM, Cheng H, Liu TY, Hsu CF, et al. Oxidative DNA damage in human peripheral leukocytes induced by massive aerobic exercise. Free Radical Biology \& Medicine 2001;31(11):1465-72. [PUBMED: 11728819]

\section{Watson 2010}

Watson T. The science of antioxidants and exercise performance. In: Burke L, Deakin V editor(s). Clinical Sports Nutrition. 4th Edition. Sydney: McGraw-Hill, 2010:295-303.

\section{Weinstock 1997}

Weinstock C, Konig D, Harnischmacher R, Keul J, Berg A, Northoff $\mathrm{H}$. Effect of exhaustive exercise stress on the cytokine response. Medicine and Science in Sports and Exercise 1997;29(3):345-54. [PUBMED: 9139173]

\section{CHARACTERISTICS OF STUDIES}

Characteristics of included studies [ordered by study ID]

\section{Witt 1992}

Witt EH, Reznick AZ, Viguie CA, Starke-Reed P, Packer L. Exercise, oxidative damage and effects of antioxidant manipulation. Journal of Nutrition 1992;122(3 Suppl):766-73. [PUBMED: 1514950]

\section{References to other published versions of this review Ranchordas 2012}

Ranchordas MK, Rogerson D, Soltani H. Antioxidants for preventing and reducing muscle soreness after exercise. Cochrane Database of Systematic Reviews 2012, Issue 4. [DOI: 10.1002/14651858.CD009789]

* Indicates the major publication for the study

Arent 2010

Methods Randomised controlled trial (cross-over design)

Separated by a 5-day washout

\section{Participants}

Setting: laboratory; USA

$n=24$ college-aged males with at least 1 year of weightlifting experience; mean age 21.3 (SE 0.4) years

18 participants completed the study; 1 participant dropped out due to training conflicts with his sport and the other 5 participants withdrew of their own volition due to the inability to tolerate the physical demands of the testing protocol.

\section{Inclusion/exclusion criteria}

This study was limited to males in order to control for fluctuations in cortisol that occur during the menstrual cycle. At initial enrolment, all participants self-reported to be free from current injuries limiting their ability to train and complete physiological testing.

Interventions

\section{Intervention}

Black tea extract: each 2-capsule serving contained $880 \mathrm{mg}$ black tea extract and was standardised for $350 \mathrm{mg}$ theaflavin

4 capsules per day - 2 in the morning and 2 in the afternoon

\section{Placebo}

Not specified

\section{Duration}

Supplements were taken 9 days before and 2 days after exercise (11 days)

\section{Outcomes}

\section{PRIMARY}

Muscle soreness was assessed using a $10 \mathrm{~cm}$ visual analogue scale (VAS). The anchor at 0 corresponds to "no soreness" and at 10 to "too sore to move muscles". Participants were asked to perform one squat with hands on hips and then draw a line on the scale corresponding to their level of soreness. 
Arent 2010 (Continued)

\section{SECONDARY}

Wingate 30-second sprint was performed on a Monark 894E Anaerobic Test Ergometer (Monark Exercise $A B$, Sweden). The load was set according to each participant's mass. The test was 30 seconds of all out cycling followed by 5 minutes of rest and then $8 \times 10$-second intervals of all out cycling. Each interval was separated by 2 minutes of rest. The resistance for the Wingate and intervals was set at $0.10 \mathrm{kP} / \mathrm{kg}$ body mass.

\begin{tabular}{ll}
\hline Exercise type & $\begin{array}{l}\text { 30-second Wingate with } 5 \text { minutes rest followed by } 8 \times 10 \text {-second maximal sprints with } 2 \text { minutes re- } \\
\text { covery }\end{array}$ \\
\hline Sources of funding & The study was funded by WellGen, Inc USA through an unrestricted research \\
\hline Notes & $\begin{array}{l}\text { Author was contacted via email on } 27 \text { May } 2016 \text { to request data for delayed onset muscle soreness but } \\
\text { did not respond }\end{array}$ \\
\hline
\end{tabular}

\section{Risk of bias}

\begin{tabular}{|c|c|c|}
\hline Bias & Authors' judgement & Support for judgement \\
\hline $\begin{array}{l}\text { Random sequence genera- } \\
\text { tion (selection bias) }\end{array}$ & Unclear risk & $\begin{array}{l}\text { No details specified in manuscript } \\
\text { Author was contacted via email on } 27 \text { May } 2016 \text { but did not respond }\end{array}$ \\
\hline $\begin{array}{l}\text { Allocation concealment } \\
\text { (selection bias) }\end{array}$ & Unclear risk & $\begin{array}{l}\text { No details specified in manuscript } \\
\text { Author was contacted via email on } 27 \text { May } 2016 \text { but did not respond }\end{array}$ \\
\hline $\begin{array}{l}\text { Blinding of participants } \\
\text { and personnel (perfor- } \\
\text { mance bias) } \\
\text { All outcomes }\end{array}$ & Low risk & Double-blind \\
\hline $\begin{array}{l}\text { Blinding of outcome as- } \\
\text { sessment (detection bias) } \\
\text { All outcomes }\end{array}$ & Low risk & Double-blind \\
\hline $\begin{array}{l}\text { Incomplete outcome data } \\
\text { (attrition bias) } \\
\text { All outcomes }\end{array}$ & High risk & $\begin{array}{l}6 \text { participants withdrew from the study } \\
\text { Attrition rate }=25 \%\end{array}$ \\
\hline $\begin{array}{l}\text { Selective reporting (re- } \\
\text { porting bias) }\end{array}$ & High risk & $\begin{array}{l}\text { No published protocol available } \\
\text { All outcomes reported at all time points } \\
\text { Adverse effects of antioxidant supplementation were not reported }\end{array}$ \\
\hline Other bias & Low risk & $\begin{array}{l}\text { Participants were asked to refrain from using anti-inflammatory medication } \\
\text { and other supplements for the duration of the study } \\
\text { Participants were also asked to keep food records }\end{array}$ \\
\hline
\end{tabular}

Avery 2003

\begin{tabular}{ll}
\hline Methods & Randomised controlled trial (parallel design) \\
\hline Participants & Setting: laboratory; USA
\end{tabular}


Avery 2003 (Continued)

$\mathrm{n}=18$ healthy men who were active in endurance sports but not resistance trained ( 9 in each group)

Mean age vitamin group: $22.7 \pm 4.1$ years

Mean age placebo group: $22.3 \pm 3.6$ years

\section{Inclusion/exclusion criteria}

Participants were normally actively participating in endurance and sports activities but not resistance training to ensure the whole-body resistance exercise protocol resulted in detectable muscle soreness and muscle disruption. The participants had not lost or gained weight in the previous year, were not adhering to special diets and were not regular consumers of nutritional supplements including vitamin $\mathrm{E}$. All participants were non-smokers and not currently taking any medication known to affect any of the dependant variables in the study.

\begin{tabular}{|c|c|c|}
\hline \multirow[t]{6}{*}{ Interventions } & \multicolumn{2}{|l|}{ Intervention } \\
\hline & \multicolumn{2}{|c|}{ Vitamin E supplementation 992 mg per day (1200 IU) } \\
\hline & \multicolumn{2}{|c|}{ Number of capsules per day not specified } \\
\hline & \multicolumn{2}{|l|}{ Placebo } \\
\hline & \multicolumn{2}{|c|}{$\begin{array}{l}\text { Microcrystalline cellulose } \\
\text { Duration }\end{array}$} \\
\hline & \multicolumn{2}{|l|}{31 days } \\
\hline \multirow[t]{2}{*}{ Outcomes } & \multicolumn{2}{|l|}{ PRIMARY } \\
\hline & \multicolumn{2}{|c|}{$\begin{array}{l}\text { Delayed onset muscle soreness of the shoulders, chest, quadriceps and hamstrings was evaluated us- } \\
\text { ing a visual analogue scale }(0 \text { to } 10 \mathrm{~cm} \text { ) where } 0 \text { is "no pain" and } 10 \text { is "extreme pain" after performing } \\
\text { shoulder abduction, shoulder horizontal adduction and hip flexion (unloaded squat). }\end{array}$} \\
\hline Exercise type & \multicolumn{2}{|c|}{ Whole body resistance exercise training protocol; 3 sets of 10 repetitions of $30 \%$ to $60 \% 1 \mathrm{RM}$} \\
\hline Sources of funding & \multicolumn{2}{|l|}{ None } \\
\hline Notes & \multicolumn{2}{|c|}{$\begin{array}{l}\text { Authors were contacted on } 25 \text { May } 2016 \text { to request data for delayed onset muscle soreness with no re- } \\
\text { ply. }\end{array}$} \\
\hline \multicolumn{3}{|l|}{ Risk of bias } \\
\hline Bias & Authors' judgement & Support for judgement \\
\hline $\begin{array}{l}\text { Random sequence genera- } \\
\text { tion (selection bias) }\end{array}$ & Low risk & $\begin{array}{l}\text { Participants were matched according to physical characteristics and training } \\
\text { history and then randomly assigned using a computer program }\end{array}$ \\
\hline Allocation concealment & Unclear risk & No details in the manuscript \\
\hline 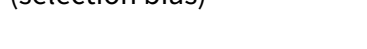 & & Authors were contacted on 25 May 2016 with no reply \\
\hline $\begin{array}{l}\text { Blinding of participants } \\
\text { and personnel (perfor- } \\
\text { mance bias) } \\
\text { All outcomes }\end{array}$ & Low risk & Double-blind \\
\hline $\begin{array}{l}\text { Blinding of outcome as- } \\
\text { sessment (detection bias) } \\
\text { All outcomes }\end{array}$ & Low risk & Double-blind \\
\hline
\end{tabular}


Avery 2003 (Continued)
Incomplete outcome data
Low risk
All participants completed the study
(attrition bias)

All outcomes

\begin{tabular}{lll}
\hline $\begin{array}{l}\text { Selective reporting (re- } \\
\text { porting bias) }\end{array}$ & High risk & $\begin{array}{l}\text { No published protocol available } \\
\text { All outcomes reported at all time points } \\
\text { Adverse effects of antioxidant supplement were not reported }\end{array}$ \\
\hline Other bias & Low risk & $\begin{array}{l}\text { Participants were asked to refrain from using anti-inflammatory medication } \\
\text { and other supplements for the duration of the study as well as any form of } \\
\text { therapeutic intervention such as massage and ice }\end{array}$ \\
& $\begin{array}{l}\text { Participants who were exposed to any form of resistance training were also ex- } \\
\text { cluded }\end{array}$
\end{tabular}

Bailey 2011

\begin{tabular}{ll}
\hline Methods & Randomised controlled trial (parallel design) \\
\hline Participants & Setting: field and laboratory; UK \\
$\mathrm{n}=38$ healthy young men (18 in the antioxidant group and 20 in the placebo group); mean age 22 (SD 1) \\
years \\
Inclusion/exclusion criteria \\
All participants were non-smokers and habitually active in a variety of sports but were unfamiliar with \\
the specific exercise protocol involved in the study
\end{tabular}

\begin{tabular}{ll}
\hline Interventions & Intervention \\
& Mixed antioxidant supplement. $400 \mathrm{mg}$ vitamin C, $268 \mathrm{mg}$ vitamin E, 2 mg vitamin B6, $200 \mu \mathrm{g}$ vitamin \\
B9, $5 \mu \mathrm{g}$ zinc sulphate, $1 \mu \mathrm{g}$ vitamin B12 capsules \\
1 capsule daily \\
Placebo \\
Lactose capsules \\
Duration \\
6 weeks
\end{tabular}

Outcomes PRIMARY

Delayed onset muscle soreness using a visual analogue scale 1 to 10 with anchor terms ranging from 1 being "not sore" to 10 being "very very sore"

\section{SECONDARY}

Peak isometric torque of knee flexors

Range of motion at the knee

\begin{tabular}{ll}
\hline Exercise type & 90 -minute intermittent shuttle running \\
\hline Sources of funding & The study received financial support from Unilever R\&D \\
\hline
\end{tabular}


Bailey 2011 (Continued)

Notes

\title{
Risk of bias
}

\begin{tabular}{|c|c|c|}
\hline Bias & Authors' judgement & Support for judgement \\
\hline $\begin{array}{l}\text { Random sequence genera- } \\
\text { tion (selection bias) }\end{array}$ & Low risk & Randomised using a computer generator \\
\hline $\begin{array}{l}\text { Allocation concealment } \\
\text { (selection bias) }\end{array}$ & Low risk & Identical capsules ingested twice daily with meals \\
\hline $\begin{array}{l}\text { Blinding of participants } \\
\text { and personnel (perfor- } \\
\text { mance bias) } \\
\text { All outcomes }\end{array}$ & Low risk & Double-blind \\
\hline $\begin{array}{l}\text { Blinding of outcome as- } \\
\text { sessment (detection bias) } \\
\text { All outcomes }\end{array}$ & Low risk & Double-blind \\
\hline $\begin{array}{l}\text { Incomplete outcome data } \\
\text { (attrition bias) } \\
\text { All outcomes }\end{array}$ & Low risk & All participants completed the study \\
\hline $\begin{array}{l}\text { Selective reporting (re- } \\
\text { porting bias) }\end{array}$ & High risk & $\begin{array}{l}\text { No published protocol available } \\
\text { All outcomes reported at all time points } \\
\text { Adverse effects of antioxidant supplementation were not reported }\end{array}$ \\
\hline Other bias & Unclear risk & $\begin{array}{l}\text { No details on whether participants were asked to refrain from using other sup- } \\
\text { plements or anti-inflammatory medication }\end{array}$ \\
\hline
\end{tabular}

Beaton 2002a

Methods Randomised controlled trial (parallel design)

Participants

\author{
Setting: laboratory; USA \\ $\mathrm{n}=18$ healthy men, mean age $20.3(\mathrm{SD} 1.70)$ years
}

\section{Inclusion/exclusion criteria}

Non-smokers, not taking vitamin E supplements(or any other antioxidant or related supplements) and had not participated in resistance training, or any other form of structured exercise for at least 6 months

\section{Intervention}

1200 IU vitamin E supplementation

\section{Placebo}

\section{Safflower oil}

\section{Duration}


Beaton 2002a (Continued)

30 days

$\begin{array}{ll}\text { Outcomes } & \text { PRIMARY } \\ \text { Muscle soreness was assessed using the Descriptor Differential Scale (DDS) at the quadriceps where } 0 \text { is } \\ \text { "no pain" and } 10 \text { is "extreme pain" }\end{array}$

\section{SECONDARY}

Peak isometric torque of knee flexors performed on the Biodex. Participants performed 3 maximal voluntary contraction repetitions each being of 5 seconds duration with 60 seconds rest in between

\begin{tabular}{ll}
\hline Exercise type & 24 sets of 10 repetitions of eccentric knee flexion and extension contractions \\
\hline Sources of funding & $\begin{array}{l}\text { The authors acknowledged Quest vitamins (Vancouver, BC) for the gracious donation of the vitamin E } \\
\text { used in the study. "This work was supported by NSERC (SMP). SMP is the recipient of a PREA and grate- } \\
\text { fully acknowledges that source of support in aiding in the completion of this research." }\end{array}$ \\
\hline Notes & $\begin{array}{l}\text { Supplements were given in the form of a capsule } \\
\text { Authors were contacted on numerous occasions to request data for delayed onset muscle soreness, } \\
\text { maximal voluntary isometric contraction and range of motion with the final email sent } 25 \text { May } 2016 \\
\text { with no reply }\end{array}$ \\
\hline
\end{tabular}

\section{Risk of bias}

\begin{tabular}{|c|c|c|}
\hline Bias & Authors' judgement & Support for judgement \\
\hline $\begin{array}{l}\text { Random sequence genera- } \\
\text { tion (selection bias) }\end{array}$ & Unclear risk & $\begin{array}{l}\text { No details in the manuscript } \\
\text { Authors were contacted on numerous occasions with final email sent } 25 \text { May } \\
2016 \text { with no reply }\end{array}$ \\
\hline $\begin{array}{l}\text { Allocation concealment } \\
\text { (selection bias) }\end{array}$ & Unclear risk & $\begin{array}{l}\text { No details in the manuscript } \\
\text { Authors were contacted on numerous occasions with final email sent } 25 \text { May } \\
2016 \text { with no reply }\end{array}$ \\
\hline $\begin{array}{l}\text { Blinding of participants } \\
\text { and personnel (perfor- } \\
\text { mance bias) } \\
\text { All outcomes }\end{array}$ & Low risk & Double-blind \\
\hline $\begin{array}{l}\text { Blinding of outcome as- } \\
\text { sessment (detection bias) } \\
\text { All outcomes }\end{array}$ & Low risk & Double-blind \\
\hline $\begin{array}{l}\text { Incomplete outcome data } \\
\text { (attrition bias) } \\
\text { All outcomes }\end{array}$ & Low risk & All participants completed the study \\
\hline $\begin{array}{l}\text { Selective reporting (re- } \\
\text { porting bias) }\end{array}$ & High risk & $\begin{array}{l}\text { No published protocol available } \\
\text { All outcomes reported at all time points } \\
\text { Adverse effects of antioxidant supplementation were not reported }\end{array}$ \\
\hline Other bias & Low risk & $\begin{array}{l}\text { Participants were non-resistance trained and were asked to refrain from using } \\
\text { other supplements or anti-inflammatory medication }\end{array}$ \\
\hline
\end{tabular}


Bell 2015

\begin{tabular}{|c|c|}
\hline Methods & Double-blind randomised controlled trial (parallel design) \\
\hline \multirow[t]{5}{*}{ Participants } & Setting: laboratory; England \\
\hline & $\mathrm{n}=16$ healthy men ( 8 in the experimental group; 8 in the placebo group) \\
\hline & Mean age $30($ SD 8$)$ years \\
\hline & Inclusion/exclusion criteria \\
\hline & $\begin{array}{l}\text { Exclusion criteria for the study included }>45 \text { years of age, female, allergy to specific fruit products, cur- } \\
\text { rently taking any nutritional supplements or medication, and history of gastrointestinal, renal or car- } \\
\text { diovascular disease }\end{array}$ \\
\hline \multirow[t]{2}{*}{ Interventions } & Intervention \\
\hline & $\begin{array}{l}\text { Participants were instructed to consume } 30 \mathrm{~mL} \text { of the supplement twice per day ( } 0800 \text { and } 1800 \text { hours) } \\
\text { for } 8 \text { consecutive days ( } 4 \text { days pretrial, on the day of, and } 3 \text { days post-trial). Manuscript states "manu- } \\
\text { facturer's specification (Cherry Active Ltd, Hanworth, UK), each } 30 \mathrm{~mL} \text { dose of MC contained } 90-110 \\
\text { Montmorency tart cherries; independent laboratory analysis shows the juice to provide } 9.2 \mathrm{mg} \cdot \mathrm{mL}-1 \text { of } \\
\text { anthocyanins and } 669.4 \mathrm{mg} \cdot \mathrm{mL}-1 \text { of carbohydrate (Atlas Biosciences, Tuscon, Ariz., USA)" }\end{array}$ \\
\hline
\end{tabular}

\section{Placebo}

A commercially available mixed berry cordial (less than $5 \%$ fruit in concentrate form), mixed with 100 $\mathrm{mL}$ water and maltodextrin (MyProtein Ltd., Northwich, UK) until matched for carbohydrate content

\section{Duration}

8 days

Outcomes PRIMARY

Muscle soreness was assessed using a 0 to $200 \mathrm{~mm}$ visual analogue scale where 0 is "no pain" and 200 is "pain/soreness as bad as it could be". Participants rated their soreness after completing a squat to approximately a $90^{\circ}$ knee flexion before standing and immediately marked upon the scale to indicate their level of soreness

\section{SECONDARY}

Maximum voluntary isometric contraction of the dominant knee extensors was determined using a strain gauge (MIE Medical Research Ltd., Leeds, UK). Participants were seated on a platform and the strain gauge was attached to the dominant ankle at an internal joint angle of $80^{\circ}$ (verified by a goniometer). Participants were given standardised verbal encouragement for the duration of each of the 3 maximum 3-second contraction. Each contraction was separated by 1 minute.

Power: 6-second peak cycle power

Cycling efficiency

Exercise type

Sources of funding
A 109-minute cycling trial designed to replicate road race demands on an electromagnetically braked, cycle ergometer (Velotron Racer-Mate, Seattle, Wash., USA)
Manuscript states: "The Cherry Marketing Institute (a not for profit organisation) provided financial support for the analysis of inflammatory indices"

Notes
Authors were contacted on 3 February 2017 to request raw data for delayed onset muscle soreness and maximal voluntary isometric contraction and responded on 3 February 2017

\section{Risk of bias}


Bell 2015 (Continued)

\begin{tabular}{lll} 
Bias $\quad$ Authors' judgement Support for judgement \\
\hline
\end{tabular}

Random sequence genera- Low risk No details in manuscript

tion (selection bias)

Authors confirmed via email on 3 February 2017 that stratified randomisation based on aerobic fitness and coin toss was employed

\begin{tabular}{ll}
\hline $\begin{array}{l}\text { Allocation concealment } \\
\text { (selection bias) }\end{array}$ & Low risk \\
& $\begin{array}{l}\text { No details in manuscript } \\
\text { drinking bottles and this was prepared by an independent member of the de- } \\
\text { partment }\end{array}$
\end{tabular}

Blinding of participants $\quad$ Low risk $\quad$ Double-blind
and personnel (perfor-
mance bias)

\begin{tabular}{ll}
\hline Blinding of outcome as- & Low risk \\
sessment (detection bias) & \\
All outcomes & \\
\hline
\end{tabular}

\begin{tabular}{lll}
\hline $\begin{array}{l}\text { Incomplete outcome data } \\
\text { (attrition bias) } \\
\text { All outcomes }\end{array}$ & Low risk & All participants completed the study \\
\hline $\begin{array}{l}\text { Selective reporting (re- } \\
\text { porting bias) }\end{array}$ & High risk & $\begin{array}{l}\text { Delayed onset muscle soreness data immediately post-exercise not recorded } \\
\text { or reported } \\
\text { Adverse effects of antioxidant supplementation were not reported }\end{array}$ \\
\hline Other bias & Low risk & $\begin{array}{l}\text { Participants did not complete any other exercise or take supplements/medica- } \\
\text { tion over the course of the study }\end{array}$ \\
\hline
\end{tabular}

Bell 2016

\begin{tabular}{ll}
\hline Methods & Double-blind randomised controlled trial (parallel design) \\
\hline Participants & Setting: laboratory; England \\
$\mathrm{n}=16$ semi professional male soccer players (8 in the experimental group; 8 in the placebo group) \\
Mean age 25 (SD 4) years \\
Inclusion/exclusion criteria \\
Inclusion criteria required participants to have trained in soccer consistently across the preceding 3 \\
years and be free of any lower limb injury for the preceding 6 months
\end{tabular}

Interventions

\section{Intervention}

Participants were instructed to consume $30 \mathrm{~mL}$ of the supplement twice per day (0800 and 1800 hours) for 7 consecutive days ( 4 days pretrial and on each trial day). The supplement was a commercially available Montmorency cherry concentrate (CherryActive, Sunbury, UK); containing a total anthocyanin content of $73.5 \mathrm{mg} \cdot \mathrm{L}^{-1}$ of cyanidin-3-glucoside, a total phenolic content of 178.8 gallic acid equivalent $\cdot \mathrm{L}^{-1}$ and an antioxidant capacity (TEAC) of 0.58 trolox equivalents $\cdot \mathrm{L}^{-1}$

\section{Placebo}


Bell 2016 (Continued)

A commercially available, less than $5 \%$ fruit, cordial, mixed with water and maltodextrin (MyProtein Ltd, Northwich, UK) until matched for energy content of the intervention (102 kcal)

\section{Duration}

7 days

PRIMARY
Muscle soreness was assessed using a 0 to $200 \mathrm{~mm}$ visual analogue scale where 0 is "no pain" and 200
is "unbearably painful". Participants rated their soreness after completing a squat to approximately a
$90^{\circ}$ knee flexion before standing and immediately marked upon the scale to indicate their level of sore-
ness

\section{SECONDARY}

Maximum voluntary isometric contraction of the dominant knee extensors was determined using a strain gauge (MIE Medical Research Ltd., Leeds, UK). Participants were given standardised verbal encouragement for the duration of each of the 3 maximum 3-second contractions. Each contraction was separated by 1 minute

Sprint performance (20 $\mathrm{m}$ - infrared timing gates)

Agility: 5-0-5 agility test (infrared timing gates)

Power: counter movement jump (jump mat)

Exercise type

Sources of funding

$12 \times 20 \mathrm{~m}$ run sprints, departing every 60 seconds followed by an adapted version of the Loughborough Intermittent Shuttle Test (LIST) (6 x 15-minute sections)

The Cherry Marketing Institute (a not for profit organisation) provided financial support for the analysis of inflammatory indices

\section{Notes}

Authors were contacted on 3 February 2017 to request raw data for delayed onset muscle soreness and maximal voluntary isometric contraction and responded on 3 February 2017

\section{Risk of bias}

\begin{tabular}{lll}
\hline Bias & Authors' judgement & Support for judgement \\
\hline $\begin{array}{l}\text { Random sequence genera- } \\
\text { tion (selection bias) }\end{array}$ & Low risk & No details in manuscript \\
& $\begin{array}{l}\text { Authors confirmed via email on 3 February 2017 that stratified randomisation } \\
\text { based on aerobic fitness and coin toss was employed }\end{array}$
\end{tabular}

\begin{tabular}{ll}
\hline $\begin{array}{l}\text { Allocation concealment } \\
\text { (selection bias) }\end{array}$ & Low risk \\
& $\begin{array}{l}\text { Manuscript states: "All supplements were prepared by an independent mem- } \\
\text { ber of the department prepared in opaque bottles in order to maintain the } \\
\text { double blind design" }\end{array}$
\end{tabular}

Blinding of participants Low risk Double-blind
and personnel (performance bias)

All outcomes

\begin{tabular}{lll}
\hline $\begin{array}{l}\text { Blinding of outcome as- } \\
\text { sessment (detection bias) }\end{array}$ & Low risk & \\
All outcomes & & \\
\hline $\begin{array}{l}\text { Incomplete outcome data } \\
\text { (attrition bias) }\end{array}$ & Low risk & No details in manuscript \\
All outcomes & &
\end{tabular}


Bell 2016 (Continued)

Authors confirmed via email on 3 February 2017 that all participants completed the study

\begin{tabular}{|c|c|c|}
\hline $\begin{array}{l}\text { Selective reporting (re- } \\
\text { porting bias) }\end{array}$ & High risk & $\begin{array}{l}\text { Delayed onset muscle soreness data immediately post-exercise not recorded } \\
\text { or reported } \\
\text { Adverse effects of antioxidant supplementation were not reported }\end{array}$ \\
\hline Other bias & Unclear risk & $\begin{array}{l}\text { Manuscript states that participants "were also provided with a diet record di- } \\
\text { ary and a list of foods to avoid throughout the } 4 \text { days prior to and during the } \\
\text { trial period" }\end{array}$ \\
\hline & & No information on NSAIDs or medication \\
\hline
\end{tabular}

\title{
Bloomer 2004
}

\begin{tabular}{ll}
\hline Methods & Randomised controlled trial (parallel design) \\
\hline Participants & Setting: laboratory; USA \\
$\mathrm{n}=18$ healthy women age range 19 to 31 years (9 in each group) \\
Inclusion/exclusion criteria \\
Participants provided a medical history and completed physical activity and diet and supplementation \\
questionnaires to determine eligibility. None had orthopaedic or metabolic conditions that could have \\
affected the variables of measurement. All participants were non-smokers, did not use oral contracep- \\
tives, anti-inflammatory drugs or dietary supplements (i.e. antioxidants for at least the past 3 months), \\
and all were classified as non-resistance trained (i.e. had not performed resistance training in the past \\
12 months).
\end{tabular}

Interventions

\section{Intervention}

$268 \mathrm{mg}$ vitamin E, $1 \mathrm{~g}$ vitamin C, $90 \mu \mathrm{g}$ selenium

\author{
Placebo \\ Lactose placebo pill \\ 3 capsules per day \\ Duration \\ 18 days
}

Outcomes PRIMARY

Delayed onset muscle soreness in both arms using a visual analogue scale $(0$ to $10 \mathrm{~cm})$ where 0 is "no pain" and 10 is "unbearable pain"

Soreness was measured following active movement of elbow flexion or extension, as well as following light palpitation by the investigators

\section{SECONDARY}

Maximum isometric force was performed on the Biodex isokinetic dynamometer (Biodex Medical Systems, Ronkonkoma, NY). Participants were secured in the Biodex chair by shoulder and lap belts. Participants were asked to perform 3 maximal isometric unilateral contractions with their elbow flexors each lasting 3 seconds with 60 seconds rest in between each effort. 
Bloomer 2004 (Continued)

Range of motion was measured both relaxed and flexed at the elbow. Range of motion was calculated as relaxed minus flexed.

\begin{tabular}{ll}
\hline Exercise type & 4 sets of 12 repetitions of non-dominant elbow flexors at an angular velocity of $20 \%$ second \\
\hline Sources of funding & None \\
\hline Notes & $\begin{array}{l}\text { Authors were contacted on } 3 \text { October } 2013 \text { to request raw data for delayed onset muscle soreness and } \\
\text { maximal voluntary isometric contraction and responded on } 1 \text { November } 2013\end{array}$
\end{tabular}

\section{Risk of bias}

\begin{tabular}{|c|c|c|}
\hline Bias & Authors' judgement & Support for judgement \\
\hline \multirow{2}{*}{$\begin{array}{l}\text { Random sequence genera- } \\
\text { tion (selection bias) }\end{array}$} & Low risk & No details in manuscript \\
\hline & & $\begin{array}{l}\text { Authors were contacted on } 24 \text { May 2016; response: "Likely via coin flip or ran- } \\
\text { dom number selection" }\end{array}$ \\
\hline $\begin{array}{l}\text { Allocation concealment } \\
\text { (selection bias) }\end{array}$ & Low risk & $\begin{array}{l}\text { Response: "Blinding code retained by person not associated with research } \\
\text { and/or provided in sealed envelope" }\end{array}$ \\
\hline $\begin{array}{l}\text { Blinding of participants } \\
\text { and personnel (perfor- } \\
\text { mance bias) } \\
\text { All outcomes }\end{array}$ & Low risk & Double-blind \\
\hline
\end{tabular}

\begin{tabular}{ll}
\hline Blinding of outcome as- & Low risk \\
sessment (detection bias) & \\
All outcomes &
\end{tabular}

\begin{tabular}{lll}
\hline $\begin{array}{l}\text { Incomplete outcome data } \\
\text { (attrition bias) } \\
\text { All outcomes }\end{array}$ & Low risk & All participants completed the study with 100\% compliance \\
\hline $\begin{array}{l}\text { Selective reporting (re- } \\
\text { porting bias) }\end{array}$ & High risk & No published protocol available \\
& All outcomes reported at all time points \\
& Adverse effects of antioxidant supplementation were not reported \\
\hline Other bias & Low risk & $\begin{array}{l}\text { Participants were non-resistance trained and relatively inactive } \\
\text { flammatory medication and oral contraceptives }\end{array}$ \\
&
\end{tabular}

\section{Bloomer 2005}

\begin{tabular}{ll}
\hline Methods & Randomised controlled trial (parallel design) \\
\hline Participants & Setting: laboratory; USA \\
$\mathrm{n}=20$ weight-trained men (10 in the experimental group; 10 in the placebo group) \\
Antioxidant group: mean age 24 (SEM 1.1) years \\
Placebo group: mean age 26.2 (SEM 2.0) years
\end{tabular}




\section{Inclusion/exclusion criteria}

All participants had been weight training their lower body for a minimum of 12 months prior to testing and demonstrated a minimum strength of 1.5 times their body weight in the barbell back squat exercise. All participants were free of the orthopaedic and metabolic conditions that would have affected the variables of measurement.

\section{Intervention}

Astaxanthin - BioAstin; $1732 \mathrm{mg}$ safflower oil; haematococcus algae extract (contains $4 \mathrm{mg}$ astaxanthin and $480 \mathrm{mg}$ lutein)

\section{Placebo}

$1732 \mathrm{mg}$ safflower oil

2 capsules per day

\section{Duration}

3 weeks before and 96 hours after

\section{Outcomes}

\section{PRIMARY}

Delayed onset muscle soreness in the dominant leg during knee extension using a $10 \mathrm{~cm}$ visual analogue scale where 0 is "no pain" and 10 is "unbearable pain"

\section{SECONDARY}

Muscle performance $1 \mathrm{RM}$ concentric strength in the knee extension

Isometric knee extensor action was performed using the modified York barbell (York, P.A. knee extension/flexion machine. The cable length was adjusted so that the knee was at 90 degrees flexion.

Mean dynamic force was determined in the knee extension exercise using a Body-Solid knee extension machine interfaced with a Fitrodyne dynamometer (Fitronic, Bratislava, Slovakia).

\begin{tabular}{|c|c|c|}
\hline Exercise type & \multicolumn{2}{|c|}{ York knee extension machine 10 sets of 10 repetitions at $85 \%$ of $1 \mathrm{RM}$} \\
\hline Sources of funding & \multicolumn{2}{|c|}{$\begin{array}{l}\text { The study was supported by Cyanotech Corp. Kailua-Kona, HI, and IMAGINNutrition, Inc. Laguna } \\
\text { Niguel, CA }\end{array}$} \\
\hline Notes & \multicolumn{2}{|c|}{$\begin{array}{l}\text { Authors were contacted on } 3 \text { October } 2013 \text { to request raw data for delayed onset muscle soreness and } \\
\text { maximal voluntary isometric contraction and responded on } 1 \text { November } 2013\end{array}$} \\
\hline \multicolumn{3}{|l|}{ Risk of bias } \\
\hline Bias & Authors' judgement & Support for judgement \\
\hline \multirow{2}{*}{$\begin{array}{l}\text { Random sequence genera- } \\
\text { tion (selection bias) }\end{array}$} & Low risk & No details in manuscript \\
\hline & & $\begin{array}{l}\text { Authors were contacted on } 24 \text { May 2016; response: "Likely via coin flip or ran- } \\
\text { dom number selection" }\end{array}$ \\
\hline \multirow{2}{*}{$\begin{array}{l}\text { Allocation concealment } \\
\text { (selection bias) }\end{array}$} & Low risk & No details in manuscript \\
\hline & & $\begin{array}{l}\text { Authors were contacted on } 24 \text { May 2016; response: "Blinding code retained by } \\
\text { person not associated with research and/or provided in sealed envelope" }\end{array}$ \\
\hline $\begin{array}{l}\text { Blinding of participants } \\
\text { and personnel (perfor- } \\
\text { mance bias) }\end{array}$ & Low risk & Double-blind \\
\hline
\end{tabular}


Bloomer 2005 (Continued)

All outcomes

Blinding of outcome as- $\quad$ Low risk Double-blind
sessment (detection bias)
All outcomes

Incomplete outcome data Low risk $\quad$ All participants successfully completed testing with 100\% compliance
(attrition bias)

All outcomes

\begin{tabular}{lll}
\hline $\begin{array}{l}\text { Selective reporting (re- } \\
\text { porting bias) }\end{array}$ & High risk & $\begin{array}{l}\text { No published protocol available } \\
\text { All outcomes reported at all time points } \\
\end{array}$ \\
\hline Other bias & Unclear risk & $\begin{array}{l}\text { No details on whether participants were asked to refrain from using other sup- } \\
\text { plements or anti-inflammatory medication }\end{array}$ \\
\hline
\end{tabular}

\section{Bloomer 2007}

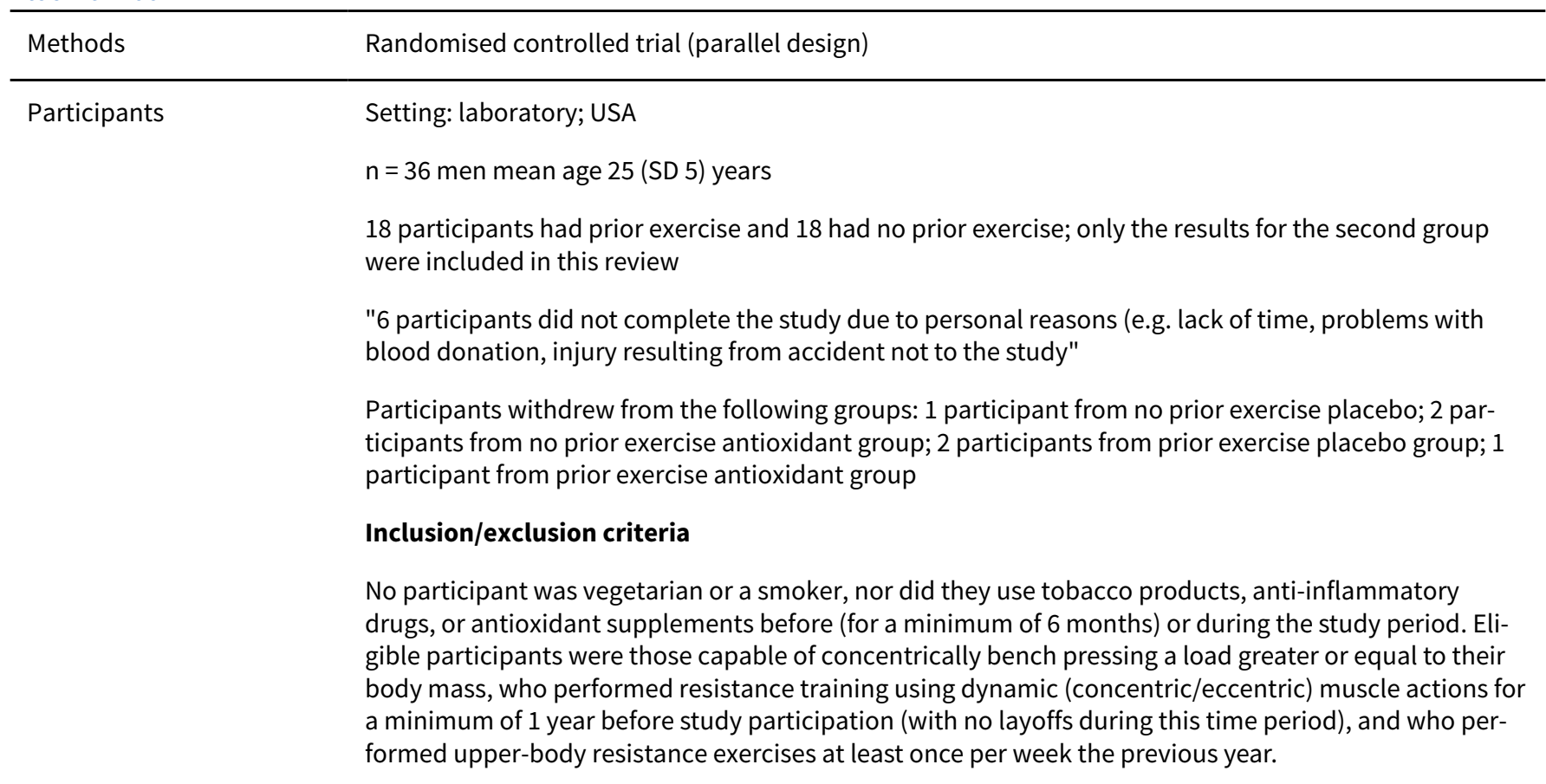

Interventions

\section{Intervention}

Mixed antioxidant $1000 \mathrm{mg}$ of vitamin C $+378 \mathrm{mg}$ mixed tocopherols $-41 \mathrm{mg}$ alpha, $3 \mathrm{mg}$ beta, $84 \mathrm{mg}$ delta, $250 \mathrm{mg}$ gamma; and $39.5 \mathrm{mg}$ mixed tocotrienols $-11 \mathrm{mg}$ alpha, $1.5 \mathrm{mg}$ beta, $5 \mathrm{mg}$ delta, $22 \mathrm{mg}$ gamma

\section{Placebo}

Soft gel (soybean oil) and powder (cellulose) placebos were identical in appearance to the antioxidants

2 capsules per day

\section{Duration}


Bloomer 2007 (Continued)

14 days

Outcomes PRIMARY

Delayed onset muscle soreness, visual analogue scale $(0$ to $10 \mathrm{~cm}$ ) following performance of 2 (concentric-eccentric) repetitions of the barbell bench press exercise using a standard $20 \mathrm{~kg}$ barbell. 0 represents "no pain" and 10 represents "intense pain"

\section{SECONDARY}

Maximal isometric force in a bench press position measured using a customised force plate and power rack design. The upper arm was fixed parallel to the floor with a 90 degree angle about the elbow joint and the bar was in line with the mid-sternum

\begin{tabular}{ll}
\hline Exercise type & Barbell bench press 10 sets, 10 reps of 70\% 1 RM \\
\hline Sources of funding & $\begin{array}{l}\text { Supported in part by Jarrow Formulas and The National Strength and Conditioning Association Gradu- } \\
\text { ate Student Research Grant }\end{array}$ \\
\hline Notes & $\begin{array}{l}\text { Authors were contacted on } 3 \text { October } 2013 \text { to request raw data for delayed onset muscle soreness and } \\
\text { maximal voluntary isometric contraction and responded on } 1 \text { November } 2013\end{array}$ \\
In our review, only the data from the no prior exercise group were used
\end{tabular}

\section{Risk of bias}

\begin{tabular}{lll}
\hline Bias & Authors' judgement & Support for judgement \\
\hline $\begin{array}{l}\text { Random sequence genera- } \\
\text { tion (selection bias) }\end{array}$ & Low risk & $\begin{array}{l}\text { No details in manuscript } \\
\text { Authors were contacted on 24 May 2016; response: "Likely via coin flip or ran- } \\
\text { dom number selection" }\end{array}$ \\
\hline $\begin{array}{l}\text { Allocation concealment } \\
\text { (selection bias) }\end{array}$ & Low risk & No details in manuscript \\
\hline $\begin{array}{l}\text { Blinding of participants } \\
\begin{array}{l}\text { and personnel (perfor- } \\
\text { mance bias) }\end{array}\end{array}$ & $\begin{array}{l}\text { Authors were contacted on 24 May 2016; response: "Blinding code retained by } \\
\text { All outcomes }\end{array}$ & Lerson not associated with research and/or provided in sealed envelope" \\
\hline
\end{tabular}

\begin{tabular}{lll}
\hline $\begin{array}{l}\text { Blinding of outcome as- } \\
\text { sessment (detection bias) } \\
\text { All outcomes }\end{array}$ & Low risk & Double-blind \\
\hline $\begin{array}{l}\text { Incomplete outcome data } \\
\text { (attrition bias) }\end{array}$ & High risk & 6 participants did not complete all aspects of the study for personal reasons \\
All outcomes & Attrition rate: $17 \%$
\end{tabular}

\begin{tabular}{lll}
\hline $\begin{array}{l}\text { Selective reporting (re- } \\
\text { porting bias) }\end{array}$ & High risk & $\begin{array}{l}\text { No published protocol available } \\
\text { All outcomes reported at all time points } \\
\text { Adverse effects of antioxidant supplementation were not reported }\end{array}$ \\
\hline Other bias & Low risk & $\begin{array}{l}\text { Participants were asked to refrain from using anti-inflammatory medication } \\
\text { and other supplements for the duration of the study }\end{array}$ \\
\hline
\end{tabular}


Bryer 2006

\begin{tabular}{ll}
\hline Methods & Randomised controlled trial (parallel design) \\
\hline Participants & Setting: laboratory, USA \\
& $\mathrm{n}=18$ young, untrained males who did not weight train for 6 months, mean age 24.4 (SEM 1.7) years \\
& Inclusion/exclusion criteria \\
& All participants were prescreened, in good health, abstained from vitamin or herbal supplements for at \\
& least 6 months and were free of any muscular injuries
\end{tabular}

Intervention
Vitamin C supplementation (3 g per day)
Placebo
Starch pills
3 capsules per day and participants were asked to keep food records
Duration
Supplementation given 2 weeks prior and 4 days after exercise

\section{Outcomes}

\section{PRIMARY}

Delayed onset muscle soreness was assessed by means of a linear scale from 1 to 10 in a rested position and in response to palpation on the arms of the muscle where 1 is "no pain" and 10 is "extreme pain"

\section{SECONDARY}

Isometric force was conducted on an isokinetic dynamometer (Biodex System 3 Isokinetic Dynamometer, Biodex Medical Systems, Shirely, NY). Participants performed 3 concentric maximum voluntary contractions (MVC) and the forces were recorded for both the dominant and non-dominant arms through a full range of motion at a speed of $1.75 \mathrm{rad} / \mathrm{second}$. The highest force obtained with no movement of the lever arm was accepted as the maximum isometric force.

Range of motion was assessed on both arms using a goniometer placed on markings from the medial aspect of th elbow of the humerus.

\begin{tabular}{ll}
\hline Exercise type & 70 eccentric actions using the elbow flexors \\
\hline Sources of funding & None \\
\hline Notes & $\begin{array}{l}\text { Authors were contacted via email on } 25 \text { November } 2013 \text { to request data for delayed onset muscle sore- } \\
\text { ness, maximal voluntary isometric contraction and range of motion, but did not respond }\end{array}$
\end{tabular}

\section{Risk of bias}

\begin{tabular}{lll}
\hline Bias & Authors' judgement & Support for judgement \\
\hline $\begin{array}{l}\text { Random sequence genera- } \\
\text { tion (selection bias) }\end{array}$ & Unclear risk & No details in manuscript \\
& $\begin{array}{l}\text { Authors were contacted via email on 25 November 2013 but no information } \\
\text { was provided }\end{array}$ \\
\hline $\begin{array}{l}\text { Allocation concealment } \\
\text { (selection bias) }\end{array}$ & Unclear risk & Participants were given numbered containers for the 3 capsules per day \\
\hline
\end{tabular}




\begin{tabular}{|c|c|c|}
\hline $\begin{array}{l}\text { Blinding of participants } \\
\text { and personnel (perfor- } \\
\text { mance bias) } \\
\text { All outcomes }\end{array}$ & Unclear risk & $\begin{array}{l}\text { No details provided in the manuscript } \\
\text { Authors were contacted via email on } 25 \text { November } 2013 \text { but no information } \\
\text { was provided }\end{array}$ \\
\hline
\end{tabular}

\begin{tabular}{lll}
\hline $\begin{array}{l}\text { Blinding of outcome as- } \\
\text { sessment (detection bias) } \\
\text { All outcomes }\end{array}$ & Unclear risk & No details provided \\
\hline $\begin{array}{l}\text { Incomplete outcome data } \\
\text { (attrition bias) } \\
\text { All outcomes }\end{array}$ & Low risk & All participants completed the study with no adverse outcomes \\
\hline $\begin{array}{l}\text { Selective reporting (re- } \\
\text { porting bias) }\end{array}$ & High risk & No published protocol available \\
& All outcomes reported at all time points \\
\hline Other bias & Adverse effects of antioxidant supplementation were not reported \\
\hline
\end{tabular}

\section{Close 2006}

\begin{tabular}{ll}
\hline Methods & Randomised controlled trial (parallel design) \\
\hline Participants & Setting: laboratory; UK \\
$\mathrm{n}=20$ physically active males naive to downhill running \\
Placebo group mean age 22.1 (SEM 0.4) years $(\mathrm{n}=10)$ \\
Vitamin C group mean age 24.2 (SEM 1.5) years $(\mathrm{n}=10)$ \\
Inclusion/exclusion criteria \\
All participants were non-smokers and free from any known illness as ascertained by questionnaire \\
Participants taking any form of vitamin supplementation were excluded
\end{tabular}

Interventions

\section{Intervention}

$1 \mathrm{~g}$ of vitamin $\mathrm{C}$ supplementation

\section{Placebo}

Lactose placebo

\section{Duration}

14 days

Outcomes PRIMARY

Delayed onset muscle soreness was measured at the gastrocnemius, anterior tibialis, hamstrings, quadriceps, gluteals (both sides) and lower back muscles using a 10-point visual analogue scale where 0 is "no pain" and 10 is "extreme pain" 
Close 2006 (Continued)

\section{SECONDARY}

Muscle function was performed an isokinetic dynamometer. The test involved concentric quadriceps muscle torque assessment at 1.06 and $5.20 \mathrm{rad} / \mathrm{second}$ as well as eccentric quadriceps assessment at $2.6 \mathrm{rad} / \mathrm{second}$

Muscle tenderness was measurement using pressure algometry at the gastrocnemius, anterior tibialis, hamstrings, quadriceps, gluteals (both sides) and lower back muscles

\begin{tabular}{ll}
\hline Exercise type & 30 minutes of downhill running on a treadmill at a grade of $-15 \%$ at $60 \%$ VO2max \\
\hline Sources of funding & None \\
\hline Notes & No details on whether supplement was administered as a drink or a capsule or a powder \\
& $\begin{array}{l}\text { Authors were contacted to request raw data for PPT, delayed onset muscle soreness and maximal vol- } \\
\text { untary isometric contraction on } 3 \text { October } 2013 \text { and responded on } 3 \text { December } 2013\end{array}$ \\
\hline
\end{tabular}

\section{Risk of bias}

\begin{tabular}{|c|c|c|}
\hline Bias & Authors' judgement & Support for judgement \\
\hline $\begin{array}{l}\text { Random sequence genera- } \\
\text { tion (selection bias) }\end{array}$ & Low risk & $\begin{array}{l}\text { No details in manuscript } \\
\text { Authors were contacted via email } 17 \text { May } 2016 \\
\text { Author response: "A random number generator to allocate into groups and } \\
\text { from memory they were block randomised according to their VO2max" }\end{array}$ \\
\hline $\begin{array}{l}\text { Allocation concealment } \\
\text { (selection bias) }\end{array}$ & Low risk & $\begin{array}{l}\text { No details in manuscript } \\
\text { Authors were contacted via email } 17 \text { May } 2016 \\
\text { Author response: "All supplements were given in visually identical capsules } \\
\text { double blind" }\end{array}$ \\
\hline $\begin{array}{l}\text { Blinding of participants } \\
\text { and personnel (perfor- } \\
\text { mance bias) } \\
\text { All outcomes }\end{array}$ & Low risk & Double-blind \\
\hline
\end{tabular}

\begin{tabular}{ll}
\hline Blinding of outcome as- & Low risk \\
sessment (detection bias) & \\
All outcomes & \\
\hline
\end{tabular}

Incomplete outcome data Low risk $\quad$ All participants completed the study with no adverse effects
(attrition bias)

(attrition bias)
All outcomes

\begin{tabular}{lll}
\hline $\begin{array}{l}\text { Selective reporting (re- } \\
\text { porting bias) }\end{array}$ & High risk & $\begin{array}{l}\text { No published protocol available } \\
\text { All outcomes reported at all time points } \\
\text { Adverse effects of antioxidant supplementation were not reported }\end{array}$ \\
\hline Other bias & Low risk & $\begin{array}{l}\text { Participants were asked to refrain from using anti-inflammatory medication } \\
\text { and other supplements for the duration of the study as well as any form of } \\
\text { therapeutic intervention such as massage and ice }\end{array}$ \\
\hline
\end{tabular}


Cobley 2011

\begin{tabular}{|c|c|}
\hline Methods & Randomised controlled trial (parallel design) \\
\hline \multirow[t]{5}{*}{ Participants } & Setting: Laboratory and Field; UK \\
\hline & $\mathrm{n}=14$ recreationally trained males mean age 24.7 (SD 4.2) years (6 in each group) \\
\hline & 2 participants dropped out for personal reasons \\
\hline & Inclusion/exclusion criteria \\
\hline & $\begin{array}{l}\text { Recreationally trained was defined as participating in physical activity of an intermittent nature at least } \\
3 \text { times per week for at least } 12 \text { months. Prospective participants were excluded if they smoked or en- } \\
\text { gaged in any course of supplementation or medication (e.g. antioxidant supplementation) that may } \\
\text { have interfered with the study's results. }\end{array}$ \\
\hline \multirow[t]{6}{*}{ Interventions } & Intervention \\
\hline & $\mathrm{N}$-acetylcysteine supplementation $50 \mathrm{mg} / \mathrm{kg}$ \\
\hline & Placebo \\
\hline & Water and cordial \\
\hline & Duration \\
\hline & 6 days \\
\hline
\end{tabular}

\section{Outcomes}

\section{PRIMARY}

Delayed onset muscle soreness was assessed by a 12-point visual analogue scale where 0 is "no pain" and 12 is "intolerable pain". Participants were required to mark a point on the VAS that corresponded to their perception of total muscle soreness after performing a 90 degree squat.

\section{SECONDARY}

Absolute muscle torque was determined in the dominant limb concentric quadriceps using a Isokinetic Dynamomter (Biodex Medical Systems, Shirely, NY). Concentric quadriceps torque was determined at 60,180 and $300 \mathrm{rad} / \mathrm{second} .3$ maximal repetitions were performed at each speed with the greatest value attained being recorded.

Yo-Yo Intermittent Recovery Test Level 1. Involves the performance of consecutive $2 \times 20$ m shuttles separated by 10 seconds recovery intervals. Running velocity is dictated by audio beeps and increased by $0.5 \mathrm{~km} /$ hour throughout the test until volitional exhaustion ensues.

Loughborough intermittent Shuttle Test was completed in a well-ventilated indoor runway. This consists of successive cycles of cruising at 95\% VO2max (60 m), jogging at 55\% VO2max (60 m), walking (60 $\mathrm{m}$ ) and maximally sprinting $(20 \mathrm{~m}$ ) between 2 pairs of timing lights placed $20 \mathrm{~m}$ apart in time with audio beeps for 15 minutes

Side effects on a scale of 0 to 10

\begin{tabular}{ll}
\hline Exercise type & Loughborough intermittent Shuttle Test and Yo-Yo Intermittent Recovery Test Level 1 \\
\hline Sources of funding & None \\
\hline Notes & N-acetylcysteine and placebo supplementation mixed in water \\
& $\begin{array}{l}\text { Authors were contacted to request raw data for delayed onset muscle soreness, maximal voluntary iso- } \\
\text { metric contraction and performance data on } 3 \text { December } 2013 \text { and responded on } 5 \text { December } 2013\end{array}$
\end{tabular}

\section{Risk of bias}


Cobley 2011 (Continued)

\begin{tabular}{|c|c|c|}
\hline Bias & Authors' judgement & Support for judgement \\
\hline $\begin{array}{l}\text { Random sequence genera- } \\
\text { tion (selection bias) }\end{array}$ & Low risk & Pair-matched based on performance on the baseline test \\
\hline $\begin{array}{l}\text { Allocation concealment } \\
\text { (selection bias) }\end{array}$ & Low risk & $\begin{array}{l}\text { Not specified in manuscript } \\
\text { Authors were contacted on } 21 \text { February } 2017 \text { and replied "treatment alloca- } \\
\text { tion was done in sealed opaque containers" }\end{array}$ \\
\hline $\begin{array}{l}\text { Blinding of participants } \\
\text { and personnel (perfor- } \\
\text { mance bias) } \\
\text { All outcomes }\end{array}$ & Low risk & Double-blind \\
\hline
\end{tabular}

\begin{tabular}{ll}
\hline $\begin{array}{l}\text { Incomplete outcome data } \\
\text { (attrition bias) }\end{array}$ & Low risk \\
All outcomes & Attrition rate: $14.3 \%$ \\
\hline
\end{tabular}

\begin{tabular}{lll}
\hline $\begin{array}{l}\text { Selective reporting (re- } \\
\text { porting bias) }\end{array}$ & Low risk & $\begin{array}{l}\text { No published protocol available } \\
\text { All outcomes reported at all time points }\end{array}$ \\
\hline Other bias & Low risk & $\begin{array}{l}\text { Participants were asked to refrain from using anti-inflammatory medication } \\
\text { and other supplements for the duration of the study as well as any form of } \\
\text { therapeutic intervention such as massage and ice }\end{array}$ \\
\hline
\end{tabular}

Connolly 2006

\begin{tabular}{ll}
\hline Methods & Randomised controlled trial (parallel design) \\
\hline Participants & Setting: 2006, USA \\
$\mathrm{n}=24$ healthy college males and females mean age 22 (SD 4) years \\
Inclusion/exclusion criteria \\
Without upper extremity injury, or previous known history of injury. Potential participants who indicat- \\
ed arm discomfort during any baseline assessments were excluded. Participants who reported habitu- \\
ally participating in a strenuous resistance-training programme involving elbow flexors, or unusual up- \\
per extremity activity were also excluded.
\end{tabular}

Interventions

Intervention

Vitamin C supplementation $1000 \mathrm{mg} 3$ times per day

\section{Placebo}

$3 \times 50 \mathrm{mg}$ per day of glucose

\section{Duration}

Supplements given 3 days before and 5 days after damaging exercise 
Delayed onset muscle soreness assessed at the quadriceps by a 0 to 10 visual analogue scale where 0 is "no discomfort whatsoever" and 10 is "indicated extreme pain and discomfort"

\section{SECONDARY}

Maximal isometric strength

Muscle tenderness scores were assessed using a standard manual muscle myometer. Measurements were made just proximal to the distal tendon of the biceps. Force was applied via the probe through a 1 $\mathrm{cm}$ diameter head until the participant indicated pain or discomfort.

\begin{tabular}{ll}
\hline Exercise type & 40 maximal eccentric contractions of the elbow flexors $(2 \times 20)$ \\
\hline Sources of funding & None \\
\hline Notes & $\begin{array}{l}\text { Authors were contacted on } 30 \text { October } 2013 \text { to request data for delayed onset muscle soreness and } \\
\text { maximal voluntary isometric contraction but did not respond }\end{array}$
\end{tabular}

\section{Risk of bias}

\begin{tabular}{|c|c|c|}
\hline Bias & Authors' judgement & Support for judgement \\
\hline $\begin{array}{l}\text { Random sequence genera- } \\
\text { tion (selection bias) }\end{array}$ & Unclear risk & $\begin{array}{l}\text { Randomly assigned (no details specified in the manuscript) } \\
\text { Authors have been contacted with no response (19 May 2016) }\end{array}$ \\
\hline $\begin{array}{l}\text { Allocation concealment } \\
\text { (selection bias) }\end{array}$ & Unclear risk & $\begin{array}{l}\text { No details specified in manuscript } \\
\text { Authors have been contacted with no response (19 May 2016) }\end{array}$ \\
\hline $\begin{array}{l}\text { Blinding of participants } \\
\text { and personnel (perfor- } \\
\text { mance bias) } \\
\text { All outcomes }\end{array}$ & Low risk & Double-blind \\
\hline $\begin{array}{l}\text { Blinding of outcome as- } \\
\text { sessment (detection bias) } \\
\text { All outcomes }\end{array}$ & Low risk & Double-blind \\
\hline $\begin{array}{l}\text { Incomplete outcome data } \\
\text { (attrition bias) } \\
\text { All outcomes }\end{array}$ & Low risk & All participants completed the study \\
\hline $\begin{array}{l}\text { Selective reporting (re- } \\
\text { porting bias) }\end{array}$ & High risk & $\begin{array}{l}\text { No published protocol available } \\
\text { All outcomes reported at all time points } \\
\text { Adverse effects of antioxidant supplementation were not reported }\end{array}$ \\
\hline Other bias & Low risk & $\begin{array}{l}\text { Participants were asked to refrain from using anti-inflammatory medication } \\
\text { and other supplements for the duration of the study as well as any form of } \\
\text { therapeutic intervention such as massage and ice. Participants who were ex- } \\
\text { posed to any form of resistance training were also excluded }\end{array}$ \\
\hline
\end{tabular}

Methods Randomised controlled trial (cross-over design)


Connolly 2006a (Continued)

Separated by a 14-day washout

Setting: laboratory; USA
$\mathrm{n}=16$ men (training status not specified)
Mean age vitamin C group 22.3 (SD 3.90) years
Mean age placebo group 22.6 (SD 4.6) years
Inclusion/exclusion criteria
Not specified
Authors were contacted via email on 30 October 2013 and again on 26 May 2016

Interventions

Intervention

Freshly prepared tart cherry juice with commercially available apple juice. One 12 oz bottle of juice provided at least $600 \mathrm{mg}$ phenolic compounds and at least $40 \mathrm{mg}$ of anthocyanins. Each bottle contained approximately 50 to 60 cherries. $2 \times 12$ oz bottles consumed daily

\section{Placebo}

Unsweetened black cherry Kool-Aid with added sugar

\section{Duration}

8 days with a 2-week washout

\section{Outcomes}

\section{PRIMARY}

Pain scores were obtained by asking participants to verbally rate their overall discomfort during active elbow flexion and extension with activities of daily living on a scale of 0 to 10 where 0 is "no discomfort whatsoever" and 10 is "extreme pain and discomfort"

\section{SECONDARY}

Maximal isometric strength was tested on a modified seated arm curl bench (preacher) with the upper arm supported by a padded bench in about 45 degrees shoulder flexion. Isometric strength was tested at 3 different elbow flexion angles: 130, 90 and 30 degrees.

Muscle tenderness scores were assessed using a standard manual muscle myometer. Measurements were made just proximal to the distal tendon of the biceps. Force was applied via the probe through a 1 $\mathrm{cm}$ diameter head until the participant indicated pain or discomfort.

\begin{tabular}{|c|c|c|}
\hline Exercise type & \multicolumn{2}{|c|}{$40(2 \times 20)$ maximal eccentric contraction of the elbow flexors using a modified preacher curl } \\
\hline \multirow[t]{2}{*}{ Sources of funding } & \multicolumn{2}{|c|}{ The study was funded by Cherrypharm Inc (West Hartford, Connecticut, USA) } \\
\hline & \multicolumn{2}{|c|}{ The authors of the study each have $2.5 \%$ equity in Cherrypharm Inc. } \\
\hline Notes & \multicolumn{2}{|c|}{$\begin{array}{l}\text { Authors were contacted on } 30 \text { October } 2013 \text { to request data for delayed onset muscle soreness and } \\
\text { maximal voluntary isometric contraction but did not respond }\end{array}$} \\
\hline \multicolumn{3}{|l|}{ Risk of bias } \\
\hline Bias & Authors' judgement & Support for judgement \\
\hline \multirow{2}{*}{$\begin{array}{l}\text { Random sequence genera- } \\
\text { tion (selection bias) }\end{array}$} & \multirow[t]{2}{*}{ Unclear risk } & No details specified in the manuscript \\
\hline & & $\begin{array}{l}\text { Authors were contacted via email on } 30 \text { October } 2013 \text { and again on } 26 \text { May } \\
2016\end{array}$ \\
\hline
\end{tabular}


Connolly 2006a (Continued)
Allocation concealment
Unclear risk
No details specified in the manuscript
(selection bias)
Authors were contacted via email on 30 October 2013 and again on 26 May 2016

\begin{tabular}{|c|c|c|}
\hline $\begin{array}{l}\text { Blinding of participants } \\
\text { and personnel (perfor- } \\
\text { mance bias) } \\
\text { All outcomes }\end{array}$ & Unclear risk & $\begin{array}{l}\text { No details specified in the manuscript } \\
\text { Authors were contacted via email on } 30 \text { October } 2013 \text { and again on } 26 \text { May } \\
2016\end{array}$ \\
\hline
\end{tabular}

\begin{tabular}{lll}
\hline $\begin{array}{l}\text { Blinding of outcome as- } \\
\text { sessment (detection bias) } \\
\text { All outcomes }\end{array}$ & Unclear risk & No details provided \\
\hline $\begin{array}{l}\text { Incomplete outcome data } \\
\text { (attrition bias) } \\
\text { All outcomes }\end{array}$ & High risk & 2 participants withdrew before completion; unclear which group they were in \\
\hline $\begin{array}{l}\text { Selective reporting (re- } \\
\text { porting bias) }\end{array}$ & High risk & Attrition rate: $12.5 \%$ \\
& No published protocol available \\
& All outcomes reported at all time points \\
\hline Other bias & Low risk & $\begin{array}{l}\text { Participants were asked to refrain from using anti-inflammatory medication } \\
\text { and other supplements for the duration of the study as well as any form of } \\
\text { therapeutic intervention such as massage and ice. Participants who were ex- } \\
\text { posed to any form of resistance training were also excluded }\end{array}$ \\
\hline
\end{tabular}

Drobnic 2014

\begin{tabular}{ll}
\hline Methods & Randomised controlled trial (parallel design) \\
\hline Participants & Setting: laboratory, Spain \\
& $\mathrm{n}=20$ male, healthy, moderately exercising (regular aerobic exercise for at least 4 hours per week), \\
non-smoking with no injury \\
Mean age 38.1 (SD 11.1) years in placebo group $(\mathrm{n}=10)$ \\
Mean age 32.7 (SD 12.3) years in curcumin group $(\mathrm{n}=9)$
\end{tabular}

\section{Intervention}

Curcumin given as the Phytosome delivery system (Meriva) $1 \mathrm{~g}$ twice daily corresponding to $200 \mathrm{mg}$ curcumin twice daily

\section{Placebo}

Matched capsules

\section{Duration}

5 days - supplements taken 2 days prior to running

Outcomes PRIMARY

Delayed onset muscle soreness lower limbs when descending and climbing stairs (4-point visual analogue scale: 0 is "no pain" and 4 is "disabling pain"). Scores were a sum of 8 sites (anterior right thigh, 
Drobnic 2014 (Continued)

posterior right thigh, anterior right leg, posterior right leg, anterior left thigh, posterior left thigh, anterior left leg, posterior left leg)

\begin{tabular}{ll}
\hline Exercise type & $\begin{array}{l}\text { Downhill running test on a treadmill at grade -10\% at a constant speed (anaerobic threshold) for } 45 \\
\text { minutes }\end{array}$ \\
\hline Sources of funding & $\begin{array}{l}\text { Authors Stefano Togni and Fedrico are employees of Indena SpA the manufacturer of Meriva, Giovanni } \\
\text { Appendino is a consultant to Indena SpA } \\
\text { Statistical analysis assistance was funded by Indena }\end{array}$ \\
\hline Notes & $\begin{array}{l}\text { Authors were contacted to request raw data for delayed onset muscle soreness on } 18 \text { February } 2016 \\
\text { and responded on 18 February } 2016\end{array}$ \\
\hline
\end{tabular}

\section{Risk of bias}

\begin{tabular}{lll}
\hline Bias & Authors' judgement & Support for judgement \\
\hline $\begin{array}{l}\text { Random sequence genera- } \\
\text { tion (selection bias) }\end{array}$ & Low risk & Randomised used computer software \\
\hline $\begin{array}{l}\text { Allocation concealment } \\
\text { (selection bias) }\end{array}$ & Unclear risk & $\begin{array}{l}\text { No details of safeguards. Although placebo-controlled, the sports medicine } \\
\text { physicians performing the exercise test beforehand were not blinded }\end{array}$ \\
\hline $\begin{array}{l}\text { Blinding of participants } \\
\text { and personnel (perfor- } \\
\text { mance bias) } \\
\text { All outcomes }\end{array}$ & High risk & $\begin{array}{l}\text { "Study subjects and physicians performing the radiologic and laboratory as- } \\
\text { sessments were blinded to treatment, whereas the sports medicine physicians } \\
\text { involved in exercise testing were not." }\end{array}$ \\
& & \begin{tabular}{l} 
It is not explained why the lattermost were not blinded \\
\hline
\end{tabular}
\end{tabular}

\begin{tabular}{|c|c|c|}
\hline $\begin{array}{l}\text { Blinding of outcome as- } \\
\text { sessment (detection bias) } \\
\text { All outcomes }\end{array}$ & Unclear risk & $\begin{array}{l}\text { "Study subjects and physicians performing the radiologic and laboratory as- } \\
\text { sessments were blinded to treatment, whereas the sports medicine physicians } \\
\text { involved in exercise testing were not." }\end{array}$ \\
\hline & & $\begin{array}{l}\text { It is likely that the participants reporting DOMS were blinded but some uncer- } \\
\text { tainty remains }\end{array}$ \\
\hline
\end{tabular}

Incomplete outcome data Low risk 1 dropout by personal decision; $5 \%$ dropout rate
(attrition bias)
All outcomes

\begin{tabular}{lll}
\hline $\begin{array}{l}\text { Selective reporting (re- } \\
\text { porting bias) }\end{array}$ & High risk & $\begin{array}{l}\text { No published protocol available } \\
\text { All outcomes reported at all time points } \\
\text { Adverse effects of antioxidant supplementation were not reported }\end{array}$ \\
\hline Other bias & Low risk & $\begin{array}{l}\text { Participants were asked to refrain from using anti-inflammatory medication } \\
\text { and other supplements for the duration of the study }\end{array}$ \\
& Participants were familiarised with the protocol and diet was standardised \\
\hline
\end{tabular}

Goldfarb 2011

\begin{tabular}{ll}
\hline Methods & Randomised controlled trial (parallel design) \\
\hline Participants & Setting: laboratory; USA
\end{tabular}


$\mathrm{n}=44$ healthy college aged men age range 18 to 35 years

Mean age in the antioxidant group 23.8 (SEM 3.6) years $(n=21)$

Mean age in the placebo group $22.8($ SEM 0.7) years $(n=20)$

\title{
Inclusion/exclusion criteria
}

All participants completed a medical history, diet, supplement and fitness questionnaire to determine eligibility. Participants were non-smokers, were not on anti-inflammatory drugs or on dietary supplements for at least 3 months and refrained from these substances throughout the study.

$\begin{array}{ll}\text { Interventions } & \text { Intervention } \\ \text { Fruit, vegetable and berry juice powder (7.5 mg beta-carotene, } 276 \mathrm{mg} \text { vitamin C and } 108 \text { IU of vitamin } \\ \text { E) (Juice Plus+, NSA, LLC, Collierville, TN) }\end{array}$

\section{Placebo}

Microcrystalline cellulose capsules

Participants were given a sealed container and were asked to take 6 capsules per day, 3 in the morning and 3 in the afternoon

\section{Duration}

28 days

\begin{abstract}
Outcomes
PRIMARY

Delayed onset muscle soreness was measured at the elbow flexor with the arm rested using a visual linear scale ranging from 1 to 10 where 1 is "no pain" and 10 is "extreme pain"

\section{SECONDARY}

Maximal isometric strength was measured on a Biodex isokinetic dynamometer. Each participant performed 3 maximal isometric force contractions with their non-dominant and dominant arm elbow flexors each lasting 3 seconds with 60 seconds rest in between each effort.

Range of motion was assessed using a goniometer assessing the elbow flexors on both arms by asking participants to flex and extend their arms at the elbows.
\end{abstract}

\begin{tabular}{ll}
\hline Exercise type & 4 sets of 12 repetitions of eccentric actions of the elbow flexors \\
\hline Sources of funding & $\begin{array}{l}\text { The research study was partially supported by the NSA LLC and the University of North Carolina } \\
\text { Greensboro }\end{array}$ \\
\hline Notes & $\begin{array}{l}\text { Authors were contacted on } 25 \text { November } 2013 \text { to request data for delayed onset muscle soreness, max- } \\
\text { imal voluntary isometric contraction and range of motion but did not respond }\end{array}$ \\
\hline
\end{tabular}

\section{Risk of bias}

\begin{tabular}{lll}
\hline Bias & Authors' judgement & Support for judgement \\
\hline $\begin{array}{l}\text { Random sequence genera- } \\
\text { tion (selection bias) }\end{array}$ & Unclear risk & $\begin{array}{l}\text { Participants were randomised but no details provided in the manuscript on } \\
\text { how this was done } \\
\text { Authors were contacted on } 25 \text { November } 2013 \text { with no reply }\end{array}$ \\
\hline $\begin{array}{l}\text { Allocation concealment } \\
\text { (selection bias) }\end{array}$ & Unclear risk & No details in the manuscript \\
\hline
\end{tabular}


Goldfarb 2011 (Continued)

Blinding of participants Low risk Double-blind
and personnel (perfor-
mance bias)
All outcomes

\begin{tabular}{lll}
\hline $\begin{array}{l}\text { Blinding of outcome as- } \\
\text { sessment (detection bias) } \\
\text { All outcomes }\end{array}$ & Low risk & Double-blind \\
\hline $\begin{array}{l}\text { Incomplete outcome data } \\
\text { (attrition bias) }\end{array}$ & Low risk & $\begin{array}{l}\text { 3 participants did not complete the study: } 2 \text { participants were from the place- } \\
\text { bo group and } 1 \text { participant was from the supplementation group }\end{array}$ \\
$\begin{array}{ll}\text { All outcomes } & \text { Attrition rate: } 6.8 \%\end{array}$
\end{tabular}

\begin{tabular}{lll}
\hline $\begin{array}{l}\text { Selective reporting (re- } \\
\text { porting bias) }\end{array}$ & High risk & $\begin{array}{l}\text { No published protocol available } \\
\text { All outcomes reported at all time points } \\
\text { Adverse effects of antioxidant supplementation were not reported }\end{array}$ \\
\hline Other bias & Low risk & $\begin{array}{l}\text { Participants were asked to refrain from using anti-inflammatory medication } \\
\text { and other supplements for the duration of the study as well as any form of } \\
\text { therapeutic intervention such as massage and ice. Participants who were ex- } \\
\text { posed to any form of resistance training were also excluded }\end{array}$ \\
\hline
\end{tabular}

\section{He 2015}

\begin{tabular}{ll}
\hline Methods & Randomised controlled trial (parallel design) \\
\hline Participants & Setting: laboratory, USA \\
$\mathrm{n}=22$ moderately trained males age range 18 to 25 years \\
Mean age supplement group 20.5 (SD 2.3) years $\mathrm{n}=11$ \\
Mean age placebo group 21.3 (SD 4.0) years $\mathrm{n}=11$ \\
Inclusion/exclusion criteria \\
$\begin{array}{l}\text { Exclusion criteria included people who smoke, take any medication that would alter cardiovascular or } \\
\text { metabolic function, have musculoskeletal limitations or use anti-inflammatory drugs. People who sup- } \\
\text { plemented with vitamin C and vitamin E or other antioxidants within } 3 \text { months prior to the study were } \\
\text { excluded. }\end{array}$
\end{tabular}

Interventions

Intervention

Capsules $100 \mathrm{mg}$ vitamin C and $400 \mathrm{IU}$ vitamin E ingested daily for 2 weeks

\section{Placebo}

Maltodextrin capsules identical to supplement group

\section{Duration}

17 days to 14 days before and 2 days after the downhill run

\section{Outcomes}

\section{PRIMARY}


He 2015 (Continued)

Delayed onset muscle soreness of the quadriceps, hamstrings, gluteus, gastrocnemius and tibialis anterior using a visual analogue scale of 0 "no pain" to 6 "unbearable pain"

\begin{tabular}{|c|c|c|}
\hline Exercise type & \multicolumn{2}{|c|}{40 minutes downhill running $-10 \%$ grade at $65 \%$ to $70 \%$ VO 2 max } \\
\hline Sources of funding & \multicolumn{2}{|c|}{$\begin{array}{l}\text { Funded by Wastl Human Performance Laboratory, Donald L. Corrigan Professional Development Grant } \\
\text { and Purdue Bilsland Strategic Initiative Fellowship }\end{array}$} \\
\hline Notes & \multirow{2}{*}{\multicolumn{2}{|c|}{$\begin{array}{l}\text { Compliance with supplementation was } 99.4 \% \text { as assessed by random capsule count } \\
\text { Authors were contacted to request raw data for delayed onset muscle soreness on } 24 \text { February } 2016 \\
\text { and responded on } 25 \text { February } 2016\end{array}$}} \\
\hline & & \\
\hline \multicolumn{3}{|l|}{ Risk of bias } \\
\hline Bias & Authors' judgement & Support for judgement \\
\hline $\begin{array}{l}\text { Random sequence genera- } \\
\text { tion (selection bias) }\end{array}$ & Low risk & Computer generator \\
\hline $\begin{array}{l}\text { Allocation concealment } \\
\text { (selection bias) }\end{array}$ & Low risk & Double-blind \\
\hline $\begin{array}{l}\text { Blinding of participants } \\
\text { and personnel (perfor- } \\
\text { mance bias) } \\
\text { All outcomes }\end{array}$ & Low risk & Double-blind \\
\hline $\begin{array}{l}\text { Blinding of outcome as- } \\
\text { sessment (detection bias) } \\
\text { All outcomes }\end{array}$ & Low risk & Double-blind \\
\hline $\begin{array}{l}\text { Incomplete outcome data } \\
\text { (attrition bias) } \\
\text { All outcomes }\end{array}$ & Low risk & All participants completed the study \\
\hline \multirow{3}{*}{$\begin{array}{l}\text { Selective reporting (re- } \\
\text { porting bias) }\end{array}$} & High risk & No published protocol available \\
\hline & & All outcomes reported at all time points \\
\hline & & Adverse effects of antioxidant supplementation were not reported \\
\hline Other bias & Low risk & $\begin{array}{l}\text { Participants were asked to refrain from using anti-inflammatory medication } \\
\text { and other supplements }\end{array}$ \\
\hline
\end{tabular}

Herrlinger 2015

\begin{tabular}{ll}
\hline Methods & Randomised controlled trial (parallel design) \\
\hline Participants & Setting: laboratory; USA \\
& $\mathrm{n}=37$ men between the ages of 18 and 35 years who were recreationally active \\
& High-dose $(\mathrm{n}=12)$ mean age 24.33 (SEM 1.54) years \\
& Low-dose $(\mathrm{n}=12)$ mean age 21.67 (SEM 1.12) years \\
& Placebo $(\mathrm{n}=13)$ mean age 22.69 (SEM 1) years
\end{tabular}


Herrlinger 2015 (Continued)

\section{Inclusion/exclusion criteria}

Men who were recreationally active in both resistance and cardiovascular training yet not exercising for more that 6 hours per week were included. The training criteria required that participants be actively performing aerobic exercise and partaking in resistance training at least twice per week for a minimum of 3 months.

Participants were excluded who were actively engaged in eccentric muscle training, downhill running, running more that 15 miles per week or presented with certain diseases or conditions such as HIV, hepatitis $\mathrm{B}$ and $\mathrm{C}$, uncontrolled cardiovascular arrhythmias, chronic obstructive pulmonary disease, emphysema, diabetes, or unresolved orthopaedic concerns. Additional exclusion criteria included a body mass index of $<18$ or $>30 \mathrm{~kg} / \mathrm{m}^{2}$, use of tobacco products within the previous 12 months, and regular consumption of medications or over-the-counter therapies that might affect inflammation such as: green or black tea, green or black tea supplements, cherry juice, vitamin E, vitamin C, aspirin, corticosteroids, anabolic steroids or NSAIDs

Interventions

\section{Intervention}

A blend of water-extracted black and green tea (Camellia sinensis) containing a minimum of $40 \%$ total polyphenols, $1.3 \%$ theaflavins, $5 \%$ to $8 \%$ epigallocatechin-3-gallate, $7 \%$ to $13 \%$ caffeine, and $600 \mathrm{ppm}$ manganese. There were 3 groups in this study:

Group 1: high-dose (2000 mg per day polyphenolic blend) $n=12$

Group 2: low-dose (1000 mg per day polyphenolic blend) $n=12$

Group 3: placebo $n=13$

2 capsules twice per day were consumed

\section{Placebo}

4 capsules per day of $500 \mathrm{mg}$ microcrystalline cellulose excipient as 2 capsules twice per day were consumed

\section{Duration}

13 weeks

\section{Outcomes}

\section{Primary}

Muscle soreness was assessed using a 7-point Likert scale questionnaire for a variety of muscle groups including the gastrocnemius, hamstrings, quadriceps, gluteus maximus, lower back, abdominals and the whole body where 1 is "no pain" and 7 is "severe pain"

\section{Secondary}

Muscle strength

All muscle strength tests were performed on a Biodex System 3 dynamometer (Biodex Medical Systems, Shirley, NY, USA). Participants performed 3 sets of quadriceps leg extensions on their dominant leg for 12 repetitions at 120 degrees per second.

Exercise type

Sources of funding Downhill running on a treadmill consisted of running at a $10 \%$ decline for 40 minutes at a speed associated with $65 \%$ of $\mathrm{VO} 2 \mathrm{max}$

Source of funding for the study was Kemin Foods, L.C. All authors were employed by the sponsor company and manufacturer of the polyphenol blend at the time of the clinical trial.

Notes

The authors of Herrlinger 2015 were contacted on 3 February 2017 and again on 18 February 2017 for missing data (delayed onset muscle soreness and maximal voluntary isometric contraction maximal voluntary isometric contraction) as these were not available in the manuscript and could not be ex- 
Herrlinger 2015 (Continued)

tracted from graphs. No response was received and this study was therefore included in the qualitative analysis but not the quantitative analysis.

\section{Risk of bias}

\begin{tabular}{lll}
\hline Bias & Authors' judgement & Support for judgement \\
\hline $\begin{array}{ll}\text { Random sequence genera- } \\
\text { tion (selection bias) }\end{array}$ & Low risk & $\begin{array}{l}\text { Authors indicate random assignment to one of 3 groups (placebo, low-dose, } \\
\text { high-dose), however methods to achieve randomisation were not indicated in } \\
\text { the manuscript }\end{array}$ \\
& Authors contacted 3 February 2017 but no response was received
\end{tabular}

\begin{tabular}{lll}
\hline $\begin{array}{l}\text { Allocation concealment } \\
\text { (selection bias) }\end{array}$ & Low risk & $\begin{array}{l}\text { No details in manuscript } \\
\text { Authors contacted 3 February 2017 via email but no response was received }\end{array}$ \\
\hline $\begin{array}{l}\text { Blinding of participants } \\
\text { and personnel (perfor- } \\
\text { mance bias) }\end{array}$ & Unclear risk & No details in manuscript \\
All outcomes & Authors contacted 3 February 2017 via email but no response was received
\end{tabular}

\begin{tabular}{|c|c|c|}
\hline $\begin{array}{l}\text { Blinding of outcome as- } \\
\text { sessment (detection bias) } \\
\text { All outcomes }\end{array}$ & Unclear risk & No details provided \\
\hline $\begin{array}{l}\text { Incomplete outcome data } \\
\text { (attrition bias) } \\
\text { All outcomes }\end{array}$ & Low risk & $\begin{array}{l}\text { From } 39 \text { participants randomised } 37 \text { completed the intervention ( } 12 \text { each for } \\
\text { low and high; } 13 \text { for placebo); } 1 \text { participant was withdrawn due to elevated } \\
\text { creatine kinase during follow-up testing (high-dose group) and } 1 \text { participant } \\
\text { was excluded due to }<80 \% \text { compliance (low-dose group) }\end{array}$ \\
\hline $\begin{array}{l}\text { Selective reporting (re- } \\
\text { porting bias) }\end{array}$ & High risk & $\begin{array}{l}\text { All outcomes reported at all time points } \\
\text { Manuscripts states that participants were "contacted on a weekly basis by } \\
\text { phone or email to ask about any adverse events..." although adverse effects of } \\
\text { antioxidant supplementation were not reported }\end{array}$ \\
\hline Other bias & Low risk & $\begin{array}{l}\text { Diet diaries performed prior to and during baseline testing, however diet was } \\
\text { not monitored during or post-intervention. Pre-test meals not standardised for } \\
\text { all participants however advice provided. }\end{array}$ \\
\hline
\end{tabular}

Howatson 2009

\begin{tabular}{ll}
\hline Methods & Randomised controlled trial (parallel design) \\
\hline Participants & Setting: Field; UK \\
$\mathrm{n}=20$ moderately trained male (13) and female (7) runners \\
Mean age cherry juice group 37 (SD 13) years \\
Mean age placebo group 38 (SD 5) years \\
Inclusion/exclusion criteria \\
$\begin{array}{l}18 \text { of the participants were accepted for, and completed, the 2008 London Marathon. All participants } \\
\text { completed a health screening questionnaire and a written informed consent. }\end{array}$
\end{tabular}


Howatson 2009 (Continued)

Interventions

\section{Intervention}

Tart cherry juice blend; $2 \times 8 \mathrm{fl}$ oz bottles per day. One bottle of the juice contained the equivalent of 50 to 60 cherries and provided at least $600 \mathrm{mg}$ phenolic compounds, expressed as gallic acid equivalents, $32 \mathrm{~g}$ of carbohydrate and at least $40 \mathrm{mg}$ of anthocyanins. One bottle in the morning and one in the afternoon

Placebo

Fruit flavoured concentrate mixed with $8 \mathrm{fl} \mathrm{oz} \mathrm{of} \mathrm{water}$

\section{Duration}

5 days before and 2 days after

\section{Outcomes \\ PRIMARY \\ Delayed onset muscle soreness was determined using a $200 \mathrm{~mm}$ visual analogue scale where 0 is "no soreness" and 200 is "unbearably painful." The participant stood with the hands on hips and feet ap- proximately shoulder width apart. The participant was then asked to squat down to 90 degrees (inter- nal joint angle) rise to the start position and then indicate on the visual analogue scale the soreness felt in the lower limbs. \\ SECONDARY \\ Maximum voluntary isometric contraction of the non-dominant knee extensors was determined using a strain gauge (MIE Medical Research Ltd, Leeds, UK). Participants were seated on a platform and the non-dominant ankle was attached to the strain gauge at an internal joint angle of 80 degrees (verified by a goniometer). Participants were given 3 submaximal trials, each separated by 1 minute. Each con- traction lasted approximately 3 seconds and all participants were given standardised verbal encour- agement throughout.}

Exercise type

Participants completed the 2008 London marathon. The environmental conditions on the day were barometric pressure: $758 \mathrm{mmHg}$; temperature: 7 degrees Celsius; wind speed: $4 \mathrm{~km} / \mathrm{h}$; relative humidity: 56\%; there were intermittent showers throughout the day.

2 volunteers completed the marathon distance on similar terrain 14 days after the London Marathon

Sources of funding The authors thanked Dr Marco Cardinale from the British Olympic Association for procuring technical support and St Mary's University College Scholarship and Research Support Fund for financial support of the project

Notes -

\section{Risk of bias}

\begin{tabular}{lll}
\hline Bias & Authors' judgement & Support for judgement \\
\hline $\begin{array}{l}\text { Random sequence genera- } \\
\text { tion (selection bias) }\end{array}$ & High risk & $\begin{array}{l}\text { Pseudo-randomised based on predicted finishing time. "We also attempted to } \\
\text { balance the number of male and female participants in each group to account } \\
\text { for possible sex differences" }\end{array}$ \\
\hline $\begin{array}{l}\text { Allocation concealment } \\
\text { (selection bias) }\end{array}$ & Unclear risk & No details in manuscript \\
& $\begin{array}{l}\text { Authors were contacted via email on } 27 \text { May 2016 } \\
\text { Author reply: "allocation was based on sex and predicted finish time. So ran- } \\
\text { domised, but stratified. ABBA style and treatments were given in identical con- } \\
\text { tainers" }\end{array}$ \\
\hline
\end{tabular}


Howatson 2009 (Continued)

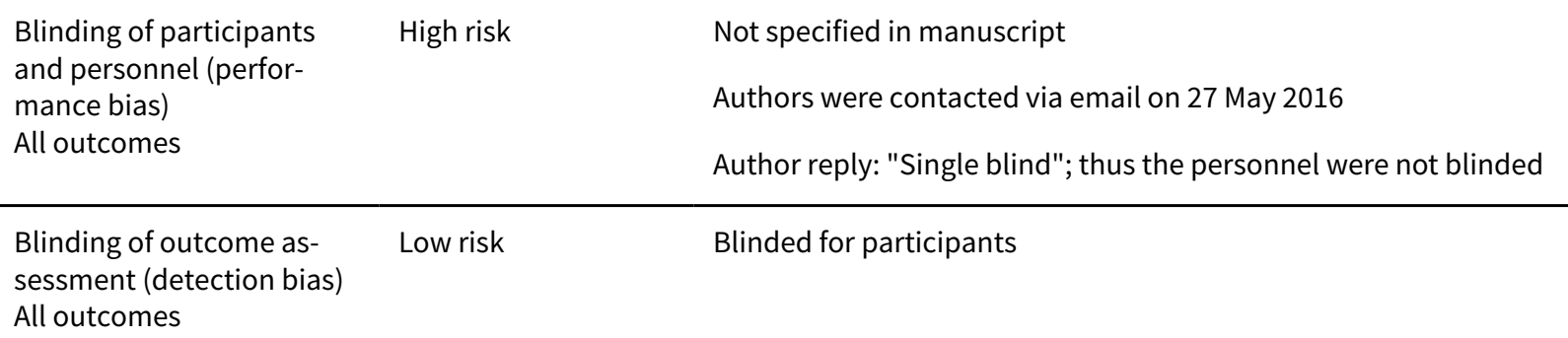

Incomplete outcome data Low risk All the participants completed the study
(attrition bias)

All outcomes

\begin{tabular}{lll}
\hline $\begin{array}{l}\text { Selective reporting (re- } \\
\text { porting bias) }\end{array}$ & High risk & $\begin{array}{l}\text { No published protocol available } \\
\text { All outcomes reported at all time points } \\
\text { Adverse effects of antioxidant supplementation were not reported }\end{array}$ \\
\hline Other bias & Low risk & $\begin{array}{l}\text { Participants were asked to keep a food diary and to refrain from taking supple- } \\
\text { ments or taking part in strenuous exercise other than the marathon }\end{array}$ \\
\hline
\end{tabular}

Hutchinson 2016

\begin{tabular}{ll}
\hline Methods & Randomised controlled trial (parallel design) \\
\hline Participants & Setting: laboratory; USA \\
$\mathrm{n}=16$ college students ( 24 were originally recruited) \\
Mean age blackcurrant group ( $\mathrm{n}=9,7$ female) 19.5 (SEM 0.3) years \\
Mean age placebo group ( $\mathrm{n}=8,6$ female) 20.9 (SEM 0.9) years \\
Inclusion/exclusion criteria \\
Inclusion criteria included being untrained, moderately active, between the ages of 18 and 40 years. Ex- \\
clusion criteria included a recent history of ankle, knee, hip or back pain that precluded squatting exer- \\
cises, and the use of anti-inflammatory or analgesic drugs that would reduce pain.
\end{tabular}

\section{Intervention}

Commercially available blackcurrant nectar (CurrantC) was provided by CorpPharms (Staatsburg, NY). Each $16 \mathrm{oz}$ bottle contained approximately $100 \mathrm{~g}$ of fruit, malvidin glucosides $193.25 \mathrm{mg}$, cyanidin glucosides $175.69 \mathrm{mg}$

\section{Placebo}

The placebo drink was produced by mixing black cherry Kool-Aid powder (Kraft, Ryrerbrook, NY, USA) with water

\section{Duration}

8 days

Outcomes Primary


Hutchinson 2016 (Continued)

Muscle soreness was assessed during a full range squat with no external weight using a 0 to 10 scale where 0 is "no soreness" and 10 is "extreme discomfort"

\begin{tabular}{ll}
\hline Exercise type & $\begin{array}{l}\text { Eccentric squatting session consisted of } 3 \text { sets of } 10 \text { repetitions of eccentric contractions using a bar } \\
\text { weighted with } 115 \% \text { of the respective } 1 \text { repetition maximum }\end{array}$ \\
\hline Sources of funding & None \\
\hline Notes & -
\end{tabular}

\section{Risk of bias}

\begin{tabular}{lll}
\hline Bias & Authors' judgement & Support for judgement \\
\hline $\begin{array}{l}\text { Random sequence genera- } \\
\text { tion (selection bias) }\end{array}$ & Low risk & $\begin{array}{l}\text { Independent 3rd party completed randomisation using random number gener- } \\
\text { ation in Excel }\end{array}$ \\
\hline $\begin{array}{l}\text { Allocation concealment } \\
\text { (selection bias) }\end{array}$ & Unclear risk & $\begin{array}{l}\text { Not indicated in the manuscript } \\
\text { Authors contacted on 3 February 2017 but no response was received }\end{array}$ \\
\hline $\begin{array}{l}\text { Blinding of participants } \\
\text { and personnel (perfor- } \\
\text { mance bias) } \\
\text { All outcomes }\end{array}$ & Low risk & $\begin{array}{l}\text { Double-blind; labels removed from bottles; neither personnel norticipants } \\
\text { aware of contents }\end{array}$ \\
\hline
\end{tabular}

\begin{tabular}{ll}
\hline Blinding of outcome as- & Low risk \\
sessment (detection bias) & \\
All outcomes &
\end{tabular}

\begin{tabular}{|c|c|c|}
\hline $\begin{array}{l}\text { Incomplete outcome data } \\
\text { (attrition bias) } \\
\text { All outcomes }\end{array}$ & High risk & $\begin{array}{l}24 \text { recruited, } 16 \text { completed the study ( } 4 \text { illness; } 3 \text { injury; } 1 \text { removed due to un- } \\
\text { dertaking resistance training prior to study) }\end{array}$ \\
\hline
\end{tabular}

\begin{tabular}{lll}
\hline $\begin{array}{l}\text { Selective reporting (re- } \\
\text { porting bias) }\end{array}$ & High risk & $\begin{array}{l}\text { All outcomes reported at all time points } \\
\text { Adverse effects of antioxidant supplementation were not reported }\end{array}$ \\
\hline Other bias & Low risk & $\begin{array}{l}\text { Diet not standardised during the trial however participants advised to main- } \\
\text { tain normal diet and avoid anti-inflammatory foods and drugs }\end{array}$ \\
\hline
\end{tabular}

Kaminski 1992

\begin{tabular}{ll}
\hline Methods & Randomised controlled trial (cross-over design) \\
\hline Participants & Setting: laboratory; USA \\
& $\mathrm{n}=25$ healthy college students and college employees. Of the 25 original participants, 2 dropped out \\
of the experiment, 3 were excluded for a variety of reasons (loss of capsule integrity, failure to proper- \\
ly maintain records, non-compliance with the experimental protocol), and 1 was removed for failure to \\
develop delayed onset muscle soreness in either trial. Left with 19 participants (6 women and 13 men). \\
Age rage 24 to 48 years
\end{tabular}

\section{Inclusion/exclusion criteria}

Participants were excluded from the study if they were older than 50 years, had a sensitivity to lactose, took analgesic or anti-inflammatory agents during the trials, participated in rigorous athletic training, 
Kaminski 1992 (Continued)

had a current musculoskeletal ailment in the legs, or took ascorbic acid or riboflavin supplements within 3 weeks of the study

\begin{tabular}{ll}
\hline Interventions & Intervention \\
& Vitamin C $1000 \mathrm{mg}$ as 3 capsules per day \\
& Placebo \\
Lactose capsules & Duration \\
& Vitamin C taken 3 days before and 7 days after exercise with a 3-week washout period \\
& PRIMARY \\
Delayed onset muscle soreness was monitored by self-reporting using a 10 cm continuous unmarked \\
line as a visual analogue scale anchored with 1 "have no soreness" at one end and 10 "my soreness \\
could not be any worse" at the other
\end{tabular}

\begin{tabular}{ll}
\hline Exercise type & Strenuous eccentric work of the plantar flexors of the calf \\
\hline Sources of funding & None \\
\hline Notes & $\begin{array}{l}\text { Participants were asked to refrain from using anti-inflammatory medication and other supplements for } \\
\text { the duration of the study }\end{array}$ \\
& $\begin{array}{l}\text { Authors were contacted to request raw data for delayed onset muscle soreness } 3 \text { December } 2013 \\
\text { and responded on } 9 \text { December } 2013\end{array}$
\end{tabular}

\section{Risk of bias}

\begin{tabular}{|c|c|c|}
\hline Bias & Authors' judgement & Support for judgement \\
\hline $\begin{array}{l}\text { Random sequence genera- } \\
\text { tion (selection bias) }\end{array}$ & Low risk & Randomised using a computer program \\
\hline $\begin{array}{l}\text { Allocation concealment } \\
\text { (selection bias) }\end{array}$ & Unclear risk & $\begin{array}{l}\text { No details provided in manuscript } \\
\text { Authors were contacted via email on } 14 \text { May } 2016 \text { with no response }\end{array}$ \\
\hline $\begin{array}{l}\text { Blinding of participants } \\
\text { and personnel (perfor- } \\
\text { mance bias) } \\
\text { All outcomes }\end{array}$ & Low risk & Double-blind \\
\hline $\begin{array}{l}\text { Blinding of outcome as- } \\
\text { sessment (detection bias) } \\
\text { All outcomes }\end{array}$ & Low risk & Double-blind \\
\hline $\begin{array}{l}\text { Incomplete outcome data } \\
\text { (attrition bias) } \\
\text { All outcomes }\end{array}$ & High risk & $\begin{array}{l}6 \text { participants dropped out and were excluded for a variety of reasons } \\
\text { Attrition rate: } 24 \%\end{array}$ \\
\hline $\begin{array}{l}\text { Selective reporting (re- } \\
\text { porting bias) }\end{array}$ & High risk & $\begin{array}{l}\text { No published protocol available } \\
\text { All outcomes reported at all time points } \\
\text { Adverse effects of antioxidant supplementation were not reported }\end{array}$ \\
\hline
\end{tabular}


Kaminski 1992 (Continued)

Other bias Low risk Participants were asked to refrain from using anti-inflammatory medication and other supplements for the duration of the study

Kerksick 2009

\begin{tabular}{ll}
\hline Methods & Randomised controlled trial (parallel design) \\
\hline Participants & Setting: laboratory; USA \\
$\mathrm{n}=30$ healthy non-resistance trained men mean age 20 (SD 1.8) years \\
Inclusion/exclusion criteria \\
Non-resistance trained men defined as less than 1 workout per month over the last 6 months. All par- \\
ticipants were classified as low risk for cardiovascular disease with no contraindications to exercise ac- \\
cording to the American College of Sports Medicine. No nutritional supplements (including multivita- \\
mins) were consumed at least 3 months prior to the study
\end{tabular}

Interventions

\section{Interventions}

1. $1800 \mathrm{mg} \mathrm{N}$-acetyl-cysteine (NAC)

2. $1800 \mathrm{mg}$ epigallocatechin gallate (EGCG)

\section{Placebo}

1000 mg glucomannan

Supplements were taken in the morning on an empty stomach and compliance was monitored by making phone calls and participants bringing back empty bottles during next visit

\section{Duration}

14 days

Outcomes PRIMARY

Delayed onset muscle soreness was assessed at the quadriceps along a $10 \mathrm{~cm}$ visual analogue scale where 0 is "no soreness" and 10 is "extreme soreness"

\section{SECONDARY}

Peak isometric torque was assessed using a Biodex System-3 isokinetic dynamometer 9 Biodex Medical Systems, Inc, NY, USA). Prior to testing participants warmed up on a cycle ergometer for 10 minutes. Changes in dynamic strength of the knee extensors was assessed by having participants complete 10 maximal repetitions in a concentric and eccentric fashion.

Peak dynamic torque was measured in the dominant knee extensors, a total of 3 maximal voluntary contractions over 5 seconds duration were completed with 60 seconds rest in between each repetition. Participants were verbally encouraged to produce maximal effort throughout the entire 5-second period. The peak torque exerted throughout all 3 repetitions was regarded as peak isometric torque. All isometric repetitions were completed at an angle of 90 degrees flexion.

\begin{tabular}{ll}
\hline Exercise type & 10 sets of 10 repetitions at an isokinetic dynamometer; 1 minute rest between sets \\
\hline Sources of funding & $\begin{array}{l}\text { Partial funding for the study was provided by the National Strength and Conditioning Association } \\
\text { through GNC Nutritional Research Grant, a Baylor University Faculty Research Award for Darryn } \\
\text { Willoughby, PhD and HHPR a graduate student research award and indirect costs provided by grants } \\
\text { awarded to Richard Kreider, PhD through the Exercise and Sports Nutrition Laboratory while at Baylor } \\
\text { university }\end{array}$
\end{tabular}


Kerksick 2009 (Continued)

Notes

Authors were contacted on 2 November 2013 to request raw data for delayed onset muscle soreness and maximal voluntary isometric contraction and responded on 3 December 2013

\section{Risk of bias}

\begin{tabular}{|c|c|c|}
\hline Bias & Authors' judgement & Support for judgement \\
\hline $\begin{array}{l}\text { Random sequence genera- } \\
\text { tion (selection bias) }\end{array}$ & High risk & $\begin{array}{l}\text { Participants were matched in clusters according to age and body weight for } \\
\text { assignment }\end{array}$ \\
\hline $\begin{array}{l}\text { Allocation concealment } \\
\text { (selection bias) }\end{array}$ & Low risk & Clear capsules provided \\
\hline $\begin{array}{l}\text { Blinding of participants } \\
\text { and personnel (perfor- } \\
\text { mance bias) } \\
\text { All outcomes }\end{array}$ & Low risk & Double-blind \\
\hline $\begin{array}{l}\text { Blinding of outcome as- } \\
\text { sessment (detection bias) } \\
\text { All outcomes }\end{array}$ & Low risk & Double-blind \\
\hline $\begin{array}{l}\text { Incomplete outcome data } \\
\text { (attrition bias) } \\
\text { All outcomes }\end{array}$ & Low risk & $\begin{array}{l}\text { A total of } 3 \text { participants did not complete the study; } 2 \text { participants withdrew } \\
\text { from the study and } 1 \text { was excluded due to non-compliance } \\
\text { Attrition rate: } 10 \%\end{array}$ \\
\hline $\begin{array}{l}\text { Selective reporting (re- } \\
\text { porting bias) }\end{array}$ & Low risk & $\begin{array}{l}\text { No published protocol available } \\
\text { All outcomes reported at all time points } \\
\text { "No adverse outcomes were reported to the supplementation protocol" }\end{array}$ \\
\hline Other bias & Low risk & $\begin{array}{l}\text { Food records were obtained, participants were instructed to minimise foods } \\
\text { high in quercetin and were asked to refrain from taking any other supplements } \\
\text { or anti-inflammatory medication or to engage in any other modality that could } \\
\text { enhance recovery }\end{array}$ \\
\hline
\end{tabular}

Krotkiewski 1994

\begin{tabular}{ll}
\hline Methods & Randomised controlled trial (parallel design) \\
\hline Participants & Setting: laboratory; Poland \\
$\mathrm{n}=50$ male volunteers recruited from local paper \\
36 to the pollen group; mean age pollen extract group 35.1 (SEM 2.62) years \\
$\begin{array}{l}14 \text { to the placebo group; mean age placebo group 35.1 (SEM 2.62) years } \\
\text { Inclusion/exclusion criteria } \\
\text { Inclusion criteria were absence of hypertension, diabetes, cardiovascular disease, organic brain dis- } \\
\text { ease, alcohol or drug dependence and any other deviation from good health, no physical training or } \\
\text { permanent or intensive basis and the lack of any ongoing medication }\end{array}$ \\
\hline
\end{tabular}


Krotkiewski 1994 (Continued)

Pollen extract; superoxide dismutase activity of approximately 30,000 units per gram/Polbax (Allegon, Sweden)

Placebo

Placebo not specified

\section{Duration}

4 weeks

\begin{tabular}{ll}
\hline Outcomes & PRIMARY \\
& $\begin{array}{l}\text { Delayed onset muscle soreness, visual analogue scale }(0 \text { to } 10 \mathrm{~cm}) \text { where } 0 \text { is "no pain and discomfort" } \\
\text { and } 10 \text { is "intense pain and discomfort." }\end{array}$ \\
\hline Exercise type & $\begin{array}{l}\text { A circuit exercise test which consisted of } 10 \text { minutes on the step up test, } 30 \text { minutes cycling at } 70 \% \\
\text { VO2max followed by } 10 \text { minutes on the step test. } 30 \text { minutes of cycling at } 60 \% \text { VO2max followed by } 10 \\
\text { minutes on the step test repeated twice. }\end{array}$
\end{tabular}

\begin{tabular}{|c|c|}
\hline Sources of funding & The study was supported by the Swedish Sports Council and Askers Foundation \\
\hline \multirow[t]{2}{*}{ Notes } & $\begin{array}{l}\text { All the authors were contacted several times via email with no response. Maximal voluntary strength } \\
\text { data were not reported in the manuscript either in a graph or a table and delayed onset muscle sore- } \\
\text { ness data were reported as a difference between the starting values therefore data could not be ex- } \\
\text { tracted }\end{array}$ \\
\hline & $\begin{array}{l}\text { Authors were contacted on } 3 \text { November } 2016 \text { to request data for delayed onset muscle soreness but } \\
\text { did not respond }\end{array}$ \\
\hline
\end{tabular}

\section{Risk of bias}

\begin{tabular}{lll}
\hline Bias & Authors' judgement & Support for judgement \\
\hline $\begin{array}{ll}\text { Random sequence genera- } \\
\text { tion (selection bias) }\end{array}$ & Unclear risk & No details in manuscript \\
& 36 participants in experimental group and 14 in the placebo \\
& Authors contacted several times but did not respond \\
\hline
\end{tabular}

\begin{tabular}{|c|c|c|}
\hline $\begin{array}{l}\text { Allocation concealment } \\
\text { (selection bias) }\end{array}$ & Unclear risk & $\begin{array}{l}\text { No details in manuscript } \\
\text { Authors contacted several times but did not respond }\end{array}$ \\
\hline
\end{tabular}

Blinding of participants Low risk Manuscript states: "tablets were given in a double blind manner"
and personnel (performance bias)

All outcomes

$\begin{array}{ll}\text { Blinding of outcome as- } & \text { Low risk } \quad \text { Double-blind } \\ \text { sessment (detection bias) } & \end{array}$

All outcomes

\begin{tabular}{|c|c|c|}
\hline $\begin{array}{l}\text { Incomplete outcome data } \\
\text { (attrition bias) } \\
\text { All outcomes }\end{array}$ & Unclear risk & $\begin{array}{l}\text { No details in manuscript } \\
\text { It appears as if all participants completed the study } \\
\text { Authors contacted several times but did not respond. }\end{array}$ \\
\hline
\end{tabular}

\begin{tabular}{ll}
\hline $\begin{array}{l}\text { Selective reporting (re- } \\
\text { porting bias) }\end{array}$ & High risk \\
& No protocol available \\
\hline
\end{tabular}




Other bias Unclear risk

Manuscript states: "All participants explicitly asked to follow their habitual style of life, particularly with regards to diet and physical activity", but no details on whether participants were asked to refrain from NSAIDs or any other supplements

Kuehl 2010

\begin{tabular}{ll}
\hline Methods & Randomised controlled trial (parallel design) \\
\hline Participants & Setting: field; USA \\
$\mathrm{n}=54$ male (36) and female (18) runners participating in the Hood Coast Relay; mean age 35.8 (SD 9.6) \\
years; 25 participant in the placebo group and 26 participants in the Cherry group \\
Inclusion/exclusion criteria \\
Inclusion criteria included an ability and willingness to abstain from anti-inflammatory or pain relieving \\
drugs, and willingness to refrain from seeking any other treatment for symptoms of muscle damage un- \\
til the competition of the study \\
Exclusion criteria included recent use of pain management methods (including acupuncture, transcu- \\
taneous electrical nerve stimulation, topical medications/aesthetics, muscle relaxants, injections or \\
systematic steroids). Women capable of becoming pregnant completed a pregnancy test to rule out \\
pregnancy prior to participation.
\end{tabular}

\section{Intervention}

Cherry juice $10.5 \mathrm{oz}$ : $600 \mathrm{mg}$ phenolic compounds, $40 \mathrm{mg}$ anthocyanins, 40 to 50 cherries

\section{Placebo}

Unsweetened fruit punch with added sugar to match the cherry juice

\section{Duration}

7 days before the race and 8 days during the race; total 15 days

\begin{tabular}{ll}
\hline PRIMARY & \\
Delayed onset muscle soreness was assessed using a standard 100 mm visual analogue scale where 0 \\
is "no pain" and 100 is "most severe pain." After finishing the race, participants completed the pain VAS \\
for general soreness.
\end{tabular}

Exercise type Hood Coast Relay - $315 \mathrm{~km}$. Each participant completed 3 running segments during the race with individual segments ranging from 5.6 (SD 2.5) km and an average total running distance of 26.3 (SD 2.5) km.
Sources of funding No external funding was provided for this study. Cherrish Corporation (Seattle. WA) provided the cherry juice in the study

Notes $2 \times 335$ bottles daily prior to race

\section{Risk of bias}


Kuehl 2010 (Continued)

$\begin{array}{ll}\begin{array}{l}\text { Random sequence genera- } \\ \text { tion (selection bias) }\end{array} & \text { Unclear risk }\end{array} \quad \begin{aligned} & \text { No details in manuscript } \\ & \text { Authors were contacted via email on } 27 \text { May } 2016\end{aligned}$

\begin{tabular}{|c|c|c|}
\hline $\begin{array}{l}\text { Allocation concealment } \\
\text { (selection bias) }\end{array}$ & Unclear risk & $\begin{array}{l}\text { No details in manuscript } \\
\text { Authors were contacted via email on } 27 \text { May } 2016\end{array}$ \\
\hline
\end{tabular}

Blinding of participants Low risk $\quad$ Double-blind
and personnel (perfor-
mance bias)
All outcomes

\begin{tabular}{lll}
\hline $\begin{array}{l}\text { Blinding of outcome as- } \\
\text { sessment (detection bias) } \\
\text { All outcomes }\end{array}$ & Low risk & Double-blind \\
\hline $\begin{array}{l}\text { Incomplete outcome data } \\
\text { (attrition bias) }\end{array}$ & Low risk & $\begin{array}{l}3 \text { participants dropped out (2 from experimental group and } 1 \text { from placebo } \\
\text { due to NSAID use) }\end{array}$ \\
$\begin{array}{ll}\text { All outcomes } & \text { Attrition rate: } 6 \%\end{array}$ \\
\hline
\end{tabular}

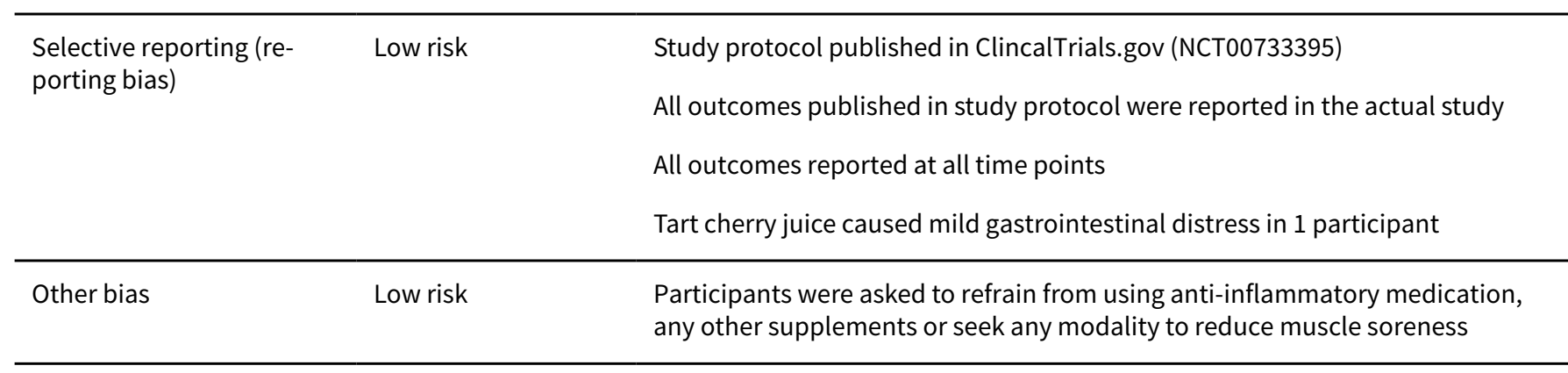

Laupheimer 2014

\begin{tabular}{|c|c|}
\hline Methods & Randomised controlled trial (parallel design) \\
\hline \multirow[t]{6}{*}{ Participants } & Setting: field; UK \\
\hline & $\begin{array}{l}n=7 \text { (experimental group of } 3 \text {, placebo group of } 4 \text { ) well trained distance runners, age range } 40 \text { to } 55 \\
\text { years }\end{array}$ \\
\hline & $\begin{array}{l}\text { Originally } 8 \text { (all males) were recruited but } 1 \text { participant in the experimental group was excluded be- } \\
\text { cause of a viral infection during the study }\end{array}$ \\
\hline & Inclusion/exclusion criteria \\
\hline & $\begin{array}{l}\text { Inclusion criteria were male gender and age } 20 \text { to } 55 \text { years. The male gender and age were chosen to } \\
\text { ensure a homogenous cohort and to optimise the safety of the use of resveratrol }\end{array}$ \\
\hline & $\begin{array}{l}\text { Exclusion criteria included a past medical history of chronic inflammatory medical conditions, muscle } \\
\text { disorders or heart conditions, and a drug history of immune suppressants or anti-inflammatories }\end{array}$ \\
\hline
\end{tabular}

\section{Intervention}

$600 \mathrm{mg}$ of resveratrol daily for 7 days and immediately before the marathon

$2 \times 100 \mathrm{mg}$ tablets were taken 3 times daily

\section{Placebo}


Laupheimer 2014 (Continued)

Not specified

\section{Duration}

9 days

\begin{tabular}{ll}
\hline Outcomes & $\begin{array}{l}\text { PRIMARY } \\
\text { General soreness on both legs; delayed onset muscle soreness, 10-point visual analogue scale: } 0 \text { "com- } \\
\text { plete absence of pain" to } 10 \text { "indicating extreme soreness with noticeable pain and stiffness at all } \\
\text { times" }\end{array}$ \\
\hline Exercise type & Running the London marathon race in 2010 \\
\hline Sources of funding & None declared \\
\hline Notes & $\begin{array}{l}\text { Participants were asked not to alter their diet in any way and were not given any nutrition or hydration } \\
\text { advice prior to the race }\end{array}$ \\
& $\begin{array}{l}\text { Authors were contacted to request raw data for delayed onset muscle soreness on } 18 \text { February } 2016 \\
\text { and responded on } 18 \text { February } 2016\end{array}$
\end{tabular}

\section{Risk of bias}

\begin{tabular}{|c|c|c|}
\hline Bias & Authors' judgement & Support for judgement \\
\hline $\begin{array}{l}\text { Random sequence genera- } \\
\text { tion (selection bias) }\end{array}$ & Low risk & Computer block randomisation \\
\hline \multirow{2}{*}{$\begin{array}{l}\text { Allocation concealment } \\
\text { (selection bias) }\end{array}$} & \multirow[t]{2}{*}{ Low risk } & Double-blind \\
\hline & & $\begin{array}{l}\text { Before randomisation } 2 \text { different sets of envelopes had been prepared by an } \\
\text { independent person not associated with the study }\end{array}$ \\
\hline $\begin{array}{l}\text { Blinding of participants } \\
\text { and personnel (perfor- } \\
\text { mance bias) } \\
\text { All outcomes }\end{array}$ & Low risk & Double-blind \\
\hline $\begin{array}{l}\text { Blinding of outcome as- } \\
\text { sessment (detection bias) } \\
\text { All outcomes }\end{array}$ & Low risk & Double-blind \\
\hline $\begin{array}{l}\text { Incomplete outcome data } \\
\text { (attrition bias) } \\
\text { All outcomes }\end{array}$ & Low risk & All outcomes reported at all time points \\
\hline \multirow{2}{*}{$\begin{array}{l}\text { Selective reporting (re- } \\
\text { porting bias) }\end{array}$} & \multirow[t]{2}{*}{ Low risk } & All outcomes reported at all time points \\
\hline & & $\begin{array}{l}\text { "None of the seven participants reported any adverse effects during the study } \\
\text { period or during the marathon itself" }\end{array}$ \\
\hline \multirow[t]{2}{*}{ Other bias } & \multirow[t]{2}{*}{ Low risk } & $\begin{array}{l}\text { Participants were asked not to alter their diet in any way and were not given } \\
\text { any nutrition or hydration advice prior to the race }\end{array}$ \\
\hline & & Participants were instructed to avoid anti-inflammatory medication \\
\hline
\end{tabular}


Lynn 2015

\begin{tabular}{|c|c|}
\hline Methods & Randomised controlled trial (single-blind, parallel design) \\
\hline \multirow[t]{4}{*}{ Participants } & Setting: field; UK \\
\hline & $\begin{array}{l}\mathrm{n}=21 \text { (experimental group of } 11 \text {, placebo group of } 10 ; 2 \text { participants were excluded from the bilberry } \\
\text { group as they failed to report to the lab to provide follow-up data), recreationally trained runners, age } \\
\text { range } 18 \text { to } 55 \text { years }\end{array}$ \\
\hline & Inclusion/exclusion criteria \\
\hline & $\begin{array}{l}\text { Individuals with cardiovascular disease, diabetes, hypertension, gastrointestinal problems, renal dis- } \\
\text { ease, musculoskeletal problems, regular antioxidant or NSAIDs use, and any food allergies were exclud- } \\
\text { ed from the study }\end{array}$ \\
\hline
\end{tabular}

\section{Intervention}

$2 \times 200 \mathrm{~mL}$ of bilberry juice daily for 5 days before completing the Sheffield Half Marathon, on race day and for 2 days post-race

Total phenol content per $200 \mathrm{~mL}$ serving was $744.14 \pm 81.75 \mathrm{mg}(\mathrm{n}=3)$. and $80.04 \pm 3.51 \mathrm{mg}(\mathrm{n}=3)$ of total anthocyanins

\section{Placebo}

Energy matched control drink

\section{Duration}

8 days

\begin{tabular}{ll}
\hline Outcomes & PRIMARY \\
& $\begin{array}{l}\text { Delayed onset muscle soreness, } 200 \mathrm{~mm} \text { visual analogue scale, rated after a squat to a } 90 \text { angle and re- } \\
\text { turning to a standing position: } 0 \text { "complete absence of pain" to } 200 \text { "indicating extreme soreness with } \\
\text { noticeable pain and stiffness at all times" }\end{array}$ \\
\hline Exercise type & Sheffield half marathon \\
\hline Sources of funding & The study was funded by Sheffield Hallam University \\
\hline Notes & $\begin{array}{l}2 \times 200 \mathrm{~mL} \text { of bilberry juice was consumed } 5 \text { days before the race, on the day of, and up to } 48 \text { hours post } \\
\text { race }\end{array}$ \\
\hline
\end{tabular}

\section{Risk of bias}

\begin{tabular}{lll}
\hline Bias & Authors' judgement & Support for judgement \\
\hline $\begin{array}{l}\text { Random sequence genera- } \\
\text { tion (selection bias) }\end{array}$ & Low risk & $\begin{array}{l}\text { No details in published abstract } \\
\text { Authors confirmed via email on 3 February 2017 that a "random numbers gen- } \\
\text { erator" was employed }\end{array}$ \\
\hline $\begin{array}{l}\text { Allocation concealment } \\
\text { (selection bias) }\end{array}$ & Unclear risk & $\begin{array}{l}\text { No details in published abstract } \\
\text { Authors described via email on 3 February 2017 that the "Study was single } \\
\text { blind so investigators knew which drink each participant got" and "drinks were } \\
\text { given in non-labelled container" }\end{array}$ \\
& \begin{tabular}{l} 
Adequate safeguards not reported \\
\hline
\end{tabular}
\end{tabular}


Lynn 2015 (Continued)

$\begin{array}{ll}\begin{array}{l}\text { Blinding of participants } \\ \text { and personnel (perfor- }\end{array} & \text { High risk } \\ \begin{array}{l}\text { mance bias) } \\ \text { All outcomes }\end{array} & \begin{array}{l}\text { Authors described via email on } 3 \text { February } 2017 \text { that the "Study was single } \\ \text { blind so investigators knew which drink each participant got" and "drinks were } \\ \text { given in non-labelled container" }\end{array} \\ & \text { Not blinded }\end{array}$

\begin{tabular}{lll}
\hline $\begin{array}{l}\text { Blinding of outcome as- } \\
\text { sessment (detection bias) } \\
\text { All outcomes }\end{array}$ & Unclear risk & Participants may have remained blinded but this is not confirmed \\
\hline $\begin{array}{l}\text { Incomplete outcome data } \\
\text { (attrition bias) }\end{array}$ & High risk & No details in published abstract \\
All outcomes & $\begin{array}{l}\text { Authors confirmed via email on } 3 \text { February } 2017 \text { that "Of the } 21 \text { participants, } \\
\text { we missed getting data from 2, one missed the post race sample, and on the } \\
\text { last day one other person was missed - both were in the bilberry group" }\end{array}$
\end{tabular}

\begin{tabular}{|c|c|c|}
\hline $\begin{array}{l}\text { Selective reporting (re- } \\
\text { porting bias) }\end{array}$ & Low risk & $\begin{array}{l}\text { No published protocol } \\
\text { All data available at all time points } \\
\text { Personal communication: "None of the participants reported any adverse ef- } \\
\text { fects from consuming the Bilberry juice or the placebo" }\end{array}$ \\
\hline Other bias & Low risk & $\begin{array}{l}\text { Participants were asked to complete a food diary and were asked to refrain } \\
\text { from using anti-inflammatory drugs or other supplements that could reduce } \\
\text { soreness }\end{array}$ \\
\hline
\end{tabular}

\section{McBride 1997}

\begin{tabular}{ll}
\hline Methods & Randomised controlled trial (parallel design) \\
\hline Participants & Setting: laboratory; USA \\
$\mathrm{n}=12$ males who were recreationally weight trained for at least 1 year \\
Mean age placebo group $22.0(\mathrm{SEM}) 0.85(\mathrm{n}=6)$ \\
Mean age vitamin E group $21.17(\mathrm{SEM}) 0.65(\mathrm{n}=6)$ \\
Inclusion/exclusion criteria \\
All participants were required to be recreationally weight trained with resistance training experience of \\
at least 1 year. Participants had no medical problems (e.g. orthopaedic, endocrine, cardiovascular) that \\
would confound the results of this investigation.
\end{tabular}

Interventions

\section{Intervention}

$992 \mathrm{mg}$ per day of vitamin E (1200 IU)

\section{Placebo}

Identical looking cellulose capsule - no detail on contents

\section{Duration}

2 weeks

\section{Outcomes}

\section{PRIMARY}


McBride 1997 (Continued)

Delayed onset muscle soreness, visual analogue scale $(0$ to $10 \mathrm{~cm}$ ) where 0 is "no soreness" and 10 is

"extremely sore"

\begin{tabular}{ll}
\hline Exercise type & Heavy resistance exercise protocol \\
\hline Sources of funding & None \\
\hline Notes & 1 capsule taken daily
\end{tabular}

\section{Risk of bias}

\begin{tabular}{|c|c|c|}
\hline Bias & Authors' judgement & Support for judgement \\
\hline $\begin{array}{l}\text { Random sequence genera- } \\
\text { tion (selection bias) }\end{array}$ & Unclear risk & $\begin{array}{l}\text { No details in the manuscript } \\
\text { Authors were contacted via email on } 14 \text { May } 2016 \text { but no response }\end{array}$ \\
\hline $\begin{array}{l}\text { Allocation concealment } \\
\text { (selection bias) }\end{array}$ & Unclear risk & $\begin{array}{l}\text { No details in the manuscript } \\
\text { Authors were contacted via email on } 14 \text { May } 2016 \text { but no response }\end{array}$ \\
\hline $\begin{array}{l}\text { Blinding of participants } \\
\text { and personnel (perfor- } \\
\text { mance bias) } \\
\text { All outcomes }\end{array}$ & Unclear risk & $\begin{array}{l}\text { No details in the manuscript } \\
\text { Authors were contacted via email on } 14 \text { May } 2016 \text { but no response }\end{array}$ \\
\hline $\begin{array}{l}\text { Blinding of outcome as- } \\
\text { sessment (detection bias) } \\
\text { All outcomes }\end{array}$ & Unclear risk & No details provided \\
\hline $\begin{array}{l}\text { Incomplete outcome data } \\
\text { (attrition bias) } \\
\text { All outcomes }\end{array}$ & Low risk & All participants completed the study \\
\hline $\begin{array}{l}\text { Selective reporting (re- } \\
\text { porting bias) }\end{array}$ & High risk & $\begin{array}{l}\text { No published protocol available } \\
\text { All outcomes reported at all time points } \\
\text { Adverse effects of antioxidant supplementation were not reported }\end{array}$ \\
\hline Other bias & Unclear risk & $\begin{array}{l}\text { Diet was controlled using food records, however no details on whether partici- } \\
\text { pants were asked to refrain from using anti-inflammatory medication, any oth- } \\
\text { er supplements or seeking any modality to reduce muscle soreness }\end{array}$ \\
\hline
\end{tabular}

\section{McCormick 2016}

\begin{tabular}{ll}
\hline Methods & Randomised, double-blind (cross-over design) \\
& 5-week washout period \\
\hline
\end{tabular}

\section{Participants}
Setting: field/laboratory; Australia
$\mathrm{n}=9$ highly-trained (elite) male water polo players from the Western Australian Institute of Sport
Mean age 18.6 (SD 1.4)

\section{Inclusion/exclusion criteria}


McCormick 2016 (Continued)

Not specified - authors contacted on 4 February 2017 and a reply received 8 February 2017: "Participants had to be a part of the West Australian Institute of Sport Men's High Performance Water polo squad that attend daily training sessions. Participants were not taking any vitamin supplements (as per WAIS supplements policy). Maintained daily contact with the research group to ensure consumption of the prescribed supplement."

Interventions

\section{Intervention}

$90 \mathrm{~mL}$ daily for 6 days of tart Montmorency Cherry Juice (Prunus cerasus) concentrate (Cherry Active, Sunbury, UK) diluted with water, such that each $30 \mathrm{~mL}$ serving was made up into a $200 \mathrm{~mL}$ beverage. Both the cherry juice and placebo were consumed in 2 doses each day; $200 \mathrm{~mL}$ before morning training, and $400 \mathrm{~mL}$ in the evening post training.

\section{Placebo}

3 different 'off the shelf' cordials: lime (Woolworths select lime cordial, Australia), cranberry (Bickford's cranberry juice cordial, Australia) and raspberry (Cottee's raspberry flavoured cordial, Australia). Cordials were mixed with food colouring and $480 \mathrm{~mL}$ of water in order to closely imitate the taste, colour and carbohydrate content.

\section{Duration}

6 days

Outcomes Primary

Delayed onset muscle soreness (delayed onset muscle soreness) was measured on a 0 to 10 scale in the upper body, upper legs, lower legs and overall body encompassing the anchor points of 0 (normal; without pain or stiffness) to 10 (very painful)

Total quality of recovery was also recorded on a 6- to 20-point scale for the upper body, upper legs, lower legs and overall body, which encompassed the anchor points 6 (very, very poor recovery) to 20 (very, very good recovery)

\section{Secondary}

Swimming-based tests comprised of the in-water vertical jump test, $10 \mathrm{~m}$ sprint test, a repeat sprint test and the Water Polo Intermittent Shuttle Test

\section{Exercise type}

A fixed training regimen for 6 days. All training (technical skill, weights, and swimming) performed during the 7-day trials was identical, and took place in the controlled environment of the indoor Water Polo pool or gymnasium.
Manuscript states: "Funds received from the Australian Institute of Sport and the Australian Sports Commission"
This study was only included in the qualitative analysis because the exercise paradigm was completely different to all the other studies included in this review. The other studies used an exercise paradigm where mechanical or whole body aerobic exercise was used to cause muscle damage and then a range of outcomes such as muscle soreness, muscle function, range of motion and performance were measured at various time points up to several days after exercise. However, participants in this study had a fixed daily training regimen for 5 continuous days performance, with outcomes being measured at the start and then throughout the trial. Thus the severity of muscle damage caused by the daily training regimen was not controlled

\section{Risk of bias}

\begin{tabular}{lll}
\hline Bias & Authors' judgement & Support for judgement \\
\hline $\begin{array}{l}\text { Random sequence genera- } \\
\text { tion (selection bias) }\end{array}$ & Low risk & $\begin{array}{l}\text { Manuscript states: "randomised, double-blind, repeated measures, crossover } \\
\text { design". No specific details provided on how randomisation was completed }\end{array}$
\end{tabular}


McCormick 2016 (Continued)

Authors contacted on 4 February 2017 and response was received on 8 February 2017: "Each participant was assigned a participant number and randomised by a number generator into two separate groups."

$\begin{aligned} & \text { Allocation concealment } \\ & \text { (selection bias) }\end{aligned} \quad$ Low risk specific details provided on how randomisation was completed

Authors contacted on 4 February 2017 and a response was received on 8 February 2017: "Fluids were prepared (by an independent researcher) in the absence of the athletes and researchers involved in the performance testing. PLA was made to look and taste the same as the $\mathrm{CJ}$ (specific product details within the manuscript). Bottles were then labelled with athlete names to ensure no mix-up."

$\begin{array}{ll}\text { Blinding of participants } & \text { Low risk } \\ \text { and personnel (perfor- } & \text { Manuscript states: "randomised, double-blind, repeated measures, crossover } \\ \text { design" }\end{array}$

mance bias)

All outcomes

Blinding of outcome as- $\quad$ Low risk Double-blind
sessment (detection bias)
All outcomes

\begin{tabular}{|c|c|c|}
\hline $\begin{array}{l}\text { Incomplete outcome data } \\
\text { (attrition bias) } \\
\text { All outcomes }\end{array}$ & Low risk & $\begin{array}{l}\text { No details in the manuscript } \\
\text { Authors contacted on } 4 \text { February } 2017 \text { and a response was received on } 8 \text { Feb- } \\
\text { ruary 2017: "Initial sample size was } n=11 \text { however, two participants withdrew } \\
\text { during the study due to injury. These participants were not included in the } \\
\text { manuscript, leaving us with n=9." }\end{array}$ \\
\hline
\end{tabular}

\begin{tabular}{lll}
\hline $\begin{array}{l}\text { Selective reporting (re- } \\
\text { porting bias) }\end{array}$ & High risk & $\begin{array}{l}\text { No published protocol available } \\
\text { All outcomes reported at all time points }\end{array}$ \\
\hline Other bias & Unclear risk & $\begin{array}{l}\text { Manuscript states: "A limitation of this investigation is that the anthocyanin } \\
\text { concentration of both the commercial and placebo supplement used was not } \\
\text { confirmed" }\end{array}$ \\
\hline
\end{tabular}

\section{McFarlin 2016}

\begin{tabular}{ll}
\hline Methods & Randomised controlled trial (parallel design) \\
\hline Participants & Setting: laboratory; USA \\
$\mathrm{n}=28$ participants ( 40 in all) \\
Mean age curcumin group ( $\mathrm{n}=16,11$ females) 20 (SD 1) years \\
Mean age placebo group ( $\mathrm{n}=12,7$ females) 19 (SD 2) years \\
"We experienced a $30 \%$ attrition/non-compliance"; it was not specified which group these participants \\
withdrew from. \\
Inclusion/exclusion criteria \\
Exclusion criteria included regular resistance training in the previous 6 months, leg muscle or or- \\
thopaedic condition, arthritis or other chronic inflammatory injury in the lower extremity, regular in- \\
gestion of curcumin containing foods, regular anti-inflammatory use, intake of curcumin supplementa-
\end{tabular}


McFarlin 2016 (Continued)

tion in the pas 6 months and any other condition that would prohibit the completion of the lower body resistance exercise protocol

\begin{tabular}{ll}
\hline Interventions & Intervention \\
& $\begin{array}{l}\text { Curcumin supplementation (Longvida; Verdure Sciences Corp, Noblesville, IN) } 400 \text { mg per dose; total } \\
\text { study dose } 2400 \mathrm{mg}\end{array}$
\end{tabular}

study dose $2400 \mathrm{mg}$

Placebo

$400 \mathrm{mg}$ rice flour

\section{Duration}

2 days prior to exercise, the day of and 3 days after exercise, total duration of 6 days

\begin{tabular}{ll}
\hline Outcomes & PRIMARY \\
& $\begin{array}{l}\text { Soreness was measured using a } 10 \mathrm{~cm} \text { visual analogue scale from } 0 \text { at one end "no pain" to } 10 \text { "severe } \\
\text { pain" at the other end. Measures of soreness were made on the thigh (i.e. quadriceps). A gauge was ap- } \\
\text { plied using standard fore }(20 \text { to } 30 \mathrm{~N}) \text { over the distal, middle and proximal thigh in a seated position } \\
\text { with the knee fully extended and relaxed. } \\
\text { The } 3 \text { ratings for each quadricep were added together }\end{array}$ \\
\hline Exercise type & $\begin{array}{l}6 \text { sets of } 10 \text { repetition of the leg press exercise with a start load set at } 110 \% \text { of the estimated } 1 \text { repeti- } \\
\text { tion maximum }\end{array}$ \\
\hline Sources of funding & $\begin{array}{l}\text { The study was partially funded by a grant from Verdure Sciences Corp (PI: McFarlin) and the National } \\
\text { Strength and Conditioning Association to the University of North Texas }\end{array}$ \\
\hline Notes & $\begin{array}{l}\text { Authors contacted on } 4 \text { February } 2017 \text { to request data for delayed onset muscle soreness but no reply } \\
\text { was received }\end{array}$ \\
\hline
\end{tabular}

\section{Risk of bias}

\begin{tabular}{lll}
\hline Bias & Authors' judgement & Support for judgement \\
\hline $\begin{array}{ll}\text { Random sequence genera- } \\
\text { tion (selection bias) }\end{array}$ & Low risk & $\begin{array}{l}\text { Manuscript states: "Stratified randomization (based on gender and initial } \\
\text { strength) was used to assign participants to the treatment conditions to en- } \\
\text { sure similar numbers of men and women and a balance based on initial mus- } \\
\text { cle strength between conditions" }\end{array}$ \\
& &
\end{tabular}

\begin{tabular}{|c|c|c|}
\hline $\begin{array}{l}\text { Allocation concealment } \\
\text { (selection bias) }\end{array}$ & Unclear risk & $\begin{array}{l}\text { No specific details provided on how randomisation was completed } \\
\text { Authors contacted on } 4 \text { February } 2017 \text { but no reply was received }\end{array}$ \\
\hline
\end{tabular}

\begin{tabular}{|c|c|c|}
\hline $\begin{array}{l}\text { Blinding of participants } \\
\text { and personnel (perfor- } \\
\text { mance bias) } \\
\text { All outcomes }\end{array}$ & Low risk & $\begin{array}{l}\text { Manuscript states: "Subjects were provided supplements using a double-blind } \\
\text { approach". However, no specific details were provided. } \\
\text { Authors contacted on } 4 \text { February } 2017 \text { but no reply was received }\end{array}$ \\
\hline $\begin{array}{l}\text { Blinding of outcome as- } \\
\text { sessment (detection bias) } \\
\text { All outcomes }\end{array}$ & Low risk & Double-blind \\
\hline $\begin{array}{l}\text { Incomplete outcome data } \\
\text { (attrition bias) } \\
\text { All outcomes }\end{array}$ & High risk & $\begin{array}{l}\text { Manuscript states: "we enrolled } 20 \text { subjects per group" and "In the case of the } \\
\text { present study, no subjects asked to drop (sic), thus the key source of attrition } \\
\text { was associated with lack of adherence to the study protocol or sample collec- }\end{array}$ \\
\hline
\end{tabular}




\begin{tabular}{lll}
\hline $\begin{array}{l}\text { Selective reporting (re- } \\
\text { porting bias) }\end{array}$ & High risk & $\begin{array}{l}\text { No published protocol available } \\
\text { All outcomes reported at all time points }\end{array}$ \\
& Adverse effects of antioxidant supplementation were not reported \\
\hline Other bias & $\begin{array}{l}\text { Manuscript states: "Exclusion criteria included: regular resistance training in } \\
\text { the previous } 6 \text { months, leg muscle or orthopedic condition, arthritis or oth- } \\
\text { er chronic inflammatory injury in the lower extremity, regular ingestion (N2 } \\
\text { times per week) of curcumin containing foods, regular NSAID use (at least } 3 \text { of } \\
7 \text { days), intake of a curcumin supplement (within the past } 6 \text { months), and any } \\
\text { other condition that would prohibit completion of the lower body resistance } \\
\text { exercise protocol" }\end{array}$
\end{tabular}

\section{McLeay 2012}

Methods Randomised controlled trial (balanced randomised cross-over design)

30 day washout

Petting: laboratory; New Zealand
$\mathrm{n}=10$ healthy active females mean age 22 (SD 1) years
Inclusion/exclusion criteria
All participants were physically active and participated in this study. All participants were physically
active and participated in recreational level resistance and aerobic-based exercise at least twice per
week. All participants had at least 1 years' experience in training in this manner. Participants complet-
ed a Health Screening Questionnaire to exclude those who were at risk physically, culturally or reli-
giously in following the protocol. Those who passed the questionnaire were asked to provide written
consent.

Interventions

\section{Intervention}

Blueberry smoothie $200 \mathrm{~g}$ blueberries $50 \mathrm{~g}$ banana $+200 \mathrm{~mL}$ apple juice. Per $100 \mathrm{~mL}$, total phenolics 168 $\mathrm{mg}$ /gallic acid equ.; anthocyanins $96.6 \mathrm{mg}$; phenolic acid $26 \mathrm{mg}$, flavonoids $10.2 \mathrm{mg}$; vitamin C $45 \mathrm{mg}$; vitamin E $3 \mathrm{mg}$

\section{Placebo}

Smoothie $25 \mathrm{~g}$ dextrose $50 \mathrm{~g}$ banana $+200 \mathrm{~mL}$ apple juice

\section{Duration}

4 days

Outcomes PRIMARY

Delayed onset muscle soreness was recorded using a subjective 10-point scale where 0 is "no soreness" and 10 is "very, very painful." Participants were asked to step up (concentric muscle action) onto a 40 $\mathrm{cm}$ box then step down (eccentric muscular contraction) and the soreness was rated.

\section{SECONDARY}

Muscle function was tested using an isokinetic dynamometer (Biodex Medical Systems Inc. 2004). Range of motion of the leg was set at 60 degrees for concentric and eccentric contractions and at 75 degrees for isometric contractions. The participants performed 5 maximal contractions of each type with 
McLeay 2012 (Continued)

each set separated by 2 minutes of recovery. Concentric and eccentric torque was measured at an angular velocity of 30 degrees per second.

\begin{tabular}{ll}
\hline Exercise type & 3 sets of 100 eccentric repetitions of the quadriceps \\
\hline Sources of funding & $\begin{array}{l}\text { Funded by an Institute of Food, Nutrition and Human Health Postgraduate Research Award, and the } \\
\text { New Zealand Ministry of Science and Innovation, contract C06X0807 awarded to Plant and Food re- } \\
\text { search Ltd. }\end{array}$ \\
\hline Notes & Drinks consumed on day of exercise the again at 12 hours and 36 hours post-exercise \\
\hline
\end{tabular}

\section{Risk of bias}

\begin{tabular}{lll}
\hline Bias & Authors' judgement & Support for judgement \\
\hline $\begin{array}{l}\text { Random sequence genera- } \\
\text { tion (selection bias) }\end{array}$ & Low risk & $\begin{array}{l}\text { Author response: "A table with vertically numbered cells 1-10 had either 'blue- } \\
\text { berries' or 'no blueberries' (4 of each) next to them. Names were then simply } \\
\text { pulled from a hat and typed into these cells in drawn order. A simple method, } \\
\text { yet allowed for randomised allocation of treatment." }\end{array}$ \\
\hline $\begin{array}{l}\text { Allocation concealment } \\
\text { (selection bias) }\end{array}$ & High risk & $\begin{array}{l}\text { No details in manuscript } \\
\text { Authors were contacted on 27 May 2016 via email }\end{array}$ \\
& $\begin{array}{l}\text { Author response: "Due to the form the treatment was given as (smoothie), we } \\
\text { were unable to blind the study. Both control and blueberry smoothies were } \\
\text { isocaloric however. The study was a cross-over design and both treatment and } \\
\text { leg of damage was randomised." }\end{array}$ \\
$\begin{array}{l}\text { Adequate safeguards not reported for the first phase; the second phase was } \\
\text { predictable }\end{array}$ \\
$\begin{array}{l}\text { Blinding of participants } \\
\begin{array}{l}\text { and personnel (perfor- } \\
\text { mance bias) }\end{array}\end{array}$ \\
$\begin{array}{ll}\text { All outcomes } \\
\text { High risk }\end{array}$
\end{tabular}

\begin{tabular}{|c|c|c|}
\hline $\begin{array}{l}\text { Blinding of outcome as- } \\
\text { sessment (detection bias) } \\
\text { All outcomes }\end{array}$ & High risk & Probably not blinded \\
\hline $\begin{array}{l}\text { Incomplete outcome data } \\
\text { (attrition bias) } \\
\text { All outcomes }\end{array}$ & Low risk & All participants completed the study with no adverse effects \\
\hline $\begin{array}{l}\text { Selective reporting (re- } \\
\text { porting bias) }\end{array}$ & Low risk & $\begin{array}{l}\text { No published protocol available } \\
\text { All outcomes reported at all time points } \\
\text { Manuscript states: "there were no reported adverse effects from the dietary in- } \\
\text { tervention" }\end{array}$ \\
\hline Other bias & Unclear risk & $\begin{array}{l}\text { Participants were asked to complete a food diary but no detail on whether par- } \\
\text { ticipants were asked to refrain from using anti-inflammatory drugs or other } \\
\text { supplements that could reduce soreness }\end{array}$ \\
\hline
\end{tabular}


Meamarbashi 2011

\begin{tabular}{ll}
\hline Methods & Randomised controlled trial (parallel design) \\
\hline Participants & Setting: laboratory, Iran \\
$\mathrm{n}=20$ male non-athletic university students mean age 18.2 (SD 0.4) years \\
Inclusion/exclusion criteria \\
Participants were selected based on fitness and health screening tests and recruited in a double-blind \\
trial. Participants with history of any type of muscle injury, chronic inflammation, coagulation disor- \\
ders, immune system impairment and cardiovascular problems were excluded. Participants were also \\
excluded if they regularly participated in vigorous exercise in the previous 3 months.
\end{tabular}

\begin{tabular}{|c|c|}
\hline \multirow[t]{6}{*}{ Interventions } & Intervention \\
\hline & Purslane extract $1200 \mathrm{mg}$ given as $2 \times 600 \mathrm{mg}$ capsules per day \\
\hline & Placebo \\
\hline & Lactose powder placebo capsules \\
\hline & Duration \\
\hline & 5 days \\
\hline \multirow[t]{2}{*}{ Outcomes } & PRIMARY \\
\hline & $\begin{array}{l}\text { A general rating of muscle soreness was assessed using a } 0 \text { - to } 6 \text {-point scale where } 0 \text { corresponded to } \\
\text { "no pain" and } 6 \text { to "unbearably painful". Participants were requested to rate the discomfort in only the } \\
\text { quadriceps and calf regions of the right leg. }\end{array}$ \\
\hline
\end{tabular}

\section{SECONDARY}

Knee range of motion - participants laid prone on an examination table with both knees fully extended. The knee joint angle was determined by using a goniometer and universal landmarks to ensure alignment. Knee flexion range was determined when the participant maximally and voluntary flexed the knee.

Maximal knee extension isometric force was evaluated using a computerised dynamometer attached to an adjustable steel chain. Participant was seated on a special chair with knee flexed at an angle of 90 degrees then the ankle was fixed by a special belt connected to a force transducer. During a 5-second test, force-time data were recorded on a memory card.

\begin{tabular}{|c|c|c|}
\hline Exercise type & \multicolumn{2}{|c|}{7 sets of 5 minutes of continuous bench stepping exercise with 1 minute rest; $50 \mathrm{~cm}$ bench height } \\
\hline Sources of funding & \multicolumn{2}{|c|}{$\begin{array}{l}\text { Financial support was received from the university postgraduate grant (no 11-4-899). University of Mo- } \\
\text { haghegh Ardabil, Iran }\end{array}$} \\
\hline Notes & \multicolumn{2}{|l|}{2 capsules daily } \\
\hline \multicolumn{3}{|l|}{ Risk of bias } \\
\hline Bias & Authors' judgement & Support for judgement \\
\hline \multirow{3}{*}{$\begin{array}{l}\text { Random sequence genera- } \\
\text { tion (selection bias) }\end{array}$} & \multirow[t]{3}{*}{ Low risk } & No details in the manuscript \\
\hline & & Authors were contacted by email on 25 May 2016 \\
\hline & & $\begin{array}{l}\text { Response: "two groups had selection criteria's and randomly selected by on- } \\
\text { line program from a bigger group of volunteers" }\end{array}$ \\
\hline
\end{tabular}


Meamarbashi 2011 (Continued)

$\begin{array}{ll}\begin{array}{l}\text { Allocation concealment } \\ \text { (selection bias) }\end{array} & \text { Now risk details in the manuscript } \\ & \text { Authors were contacted by email on } 25 \text { May } 2016 \\ & \text { Response: "placebo and purslane were capsulated" }\end{array}$

\begin{tabular}{lll}
\hline Blinding of participants Low risk $\quad$ Double-blind
\end{tabular}

and personnel (perfor-

mance bias)

All outcomes

\begin{tabular}{lll}
\hline $\begin{array}{l}\text { Blinding of outcome as- } \\
\text { sessment (detection bias) } \\
\text { All outcomes }\end{array}$ & Low risk & Double-blind \\
\hline $\begin{array}{l}\text { Incomplete outcome data } \\
\text { (attrition bias) } \\
\text { All outcomes }\end{array}$ & Low risk & All participants completed the study \\
\hline $\begin{array}{l}\text { Selective reporting (re- } \\
\text { porting bias) }\end{array}$ & High risk & No published protocol available \\
& All outcomes reported at all time points \\
\hline $\begin{array}{l}\text { Other bias } \\
\text { Adverse effects of antioxidant supplementation were not reported }\end{array}$ & $\begin{array}{l}\text { Participants were asked to refrain from using any supplements and anti-in- } \\
\text { flammatory drugs or other treatment that could reduce soreness. Diet not con- } \\
\text { trolled. }\end{array}$
\end{tabular}

Michailidis 2013

\begin{tabular}{ll}
\hline Methods & Randomised, double-blind (cross-over design) \\
& 6 weeks washout period \\
\hline
\end{tabular}

Participants

Setting: laboratory, Greece
$\mathrm{n}=10$ male recreationally active

Mean age 23.5 (SD 2.5) years

\section{Inclusion/exclusion criteria}

Participants were recreationally trained, as evidenced by their maximal oxygen consumption $\left(\mathrm{O}_{2}\right.$ max $)$ level (> $\left.45 \mathrm{~mL} \cdot \mathrm{kg}^{-1} \cdot \mathrm{min}^{-1}\right)$; had been engaged in systematic exercise $\geq 3$ times/week for $\geq 12$ months, and were non-smokers. Participants abstained from any vigorous physical activity and the consumption of caffeine, alcohol or performance-enhancing or antioxidant supplements and medications before ( 6 months) and during the exercise trials.

Exclusion criteria included a known NAC intolerance or allergy, a recent febrile illness and history of muscle lesion and lower limb trauma.

Interventions

\section{Intervention}

$20 \mathrm{mg} \mathrm{NAC/kg}$ per day was administered orally (Uni-Pharma) in 3 daily dosages. NAC was dissolved in a $500 \mathrm{~mL}$ drink that contained water $(375 \mathrm{~mL})$, a sugar-free cordial $(125 \mathrm{~mL})$ and a $2 \mathrm{~g} \mathrm{low}$-calorie glucose/dextrose powder to improve palatability

\section{Placebo}


Michailidis 2013 (Continued)

Placebo solution was formulated to be identical to the NAC solution, except for the NAC content

\section{Duration}

Supplement consumed immediately after muscle-damaging exercise and for 8 days post-exercise

PRIMARY
Outcomes
Delayed onset of muscle soreness (delayed onset muscle soreness) was determined by palpation of
the muscle belly and the distal region of the vastus medialis, vastus lateralis and rectus femoris after a
squat. Perceived soreness was rated on a scale ranging from 1 (normal) to 10 (very, very sore).

\section{SECONDARY}

Maximal knee extensor eccentric peak torque at $60^{\circ} /$ second on an isokinetic dynamometer (Isoforce)

Exercise type

Sources of funding
300 eccentric unilateral repetitions ( 20 sets, 15 repetitions/set, 30 -second rest between sets) with the quadriceps muscle group at a speed of $30 \%$ second on an Isoforce (TUR Gmbh) isokinetic dynamometer

Manuscript states: "Supported by departmental funding, a grant received by Bodosakis Foundation (Greece) for instrument purchase, and grant funding (CE-80739). APR was supported by a National Health and Medical Research Council Career Development Award, Australia."

Notes

Authors were contacted on 7 February 2017 to request data for delayed onset muscle soreness and maximal voluntary isometric contraction but did not respond

\section{Risk of bias}

\begin{tabular}{lll}
\hline Bias & Authors' judgement & Support for judgement \\
\hline $\begin{array}{l}\text { Random sequence genera- } \\
\text { tion (selection bias) }\end{array}$ & Unclear risk & No details in manuscript \\
& Authors were contacted on 7 February 2017 but did not respond \\
\hline $\begin{array}{l}\text { Allocation concealment } \\
\text { (selection bias) }\end{array}$ & Unclear risk & No details in manuscript \\
\hline $\begin{array}{l}\text { Blinding of participants } \\
\text { and personnel (perfor- } \\
\text { mance bias) } \\
\text { All outcomes }\end{array}$ & Low risk & Authors were contacted on 7 February 2017 but did not respond \\
\hline
\end{tabular}

\begin{tabular}{lll}
\hline $\begin{array}{l}\text { Blinding of outcome as- } \\
\text { sessment (detection bias) } \\
\text { All outcomes }\end{array}$ & Low risk & Double-blind \\
\hline $\begin{array}{l}\text { Incomplete outcome data } \\
\text { (attrition bias) }\end{array}$ & High risk & $\begin{array}{l}\text { Protocol states } 20 \text { individuals were enrolled and } 12 \text { completed. Manuscript } \\
\text { states that } 10 \text { males completed the study. }\end{array}$ \\
\hline
\end{tabular}

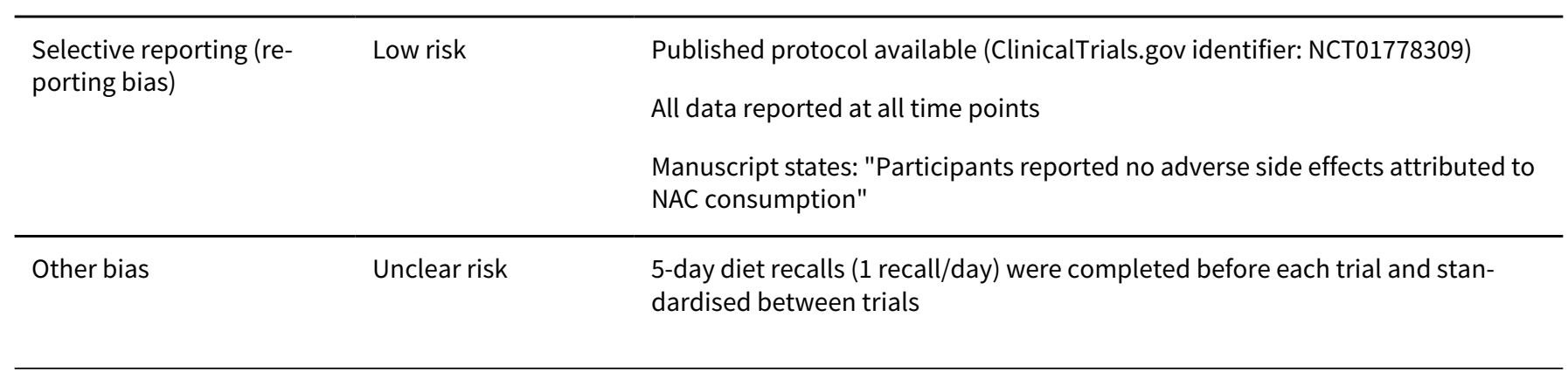


Nicol 2015

\begin{tabular}{ll}
\hline Methods & Randomised controlled trial (cross-over design) \\
14-day washout & Setting: laboratory; Australia \\
& $\mathrm{n}=17$ healthy men aged between 18 and 39 years \\
& 2 withdrew from the study following acceptance due to the inability to attend testing commitments \\
& Inclusion/exclusion criteria \\
& Participants were undertaking light to moderate regular physical activity including sports training but \\
& not doing lower limb resisted exercise
\end{tabular}

\begin{tabular}{ll}
\hline Interventions & Intervention \\
& $2.5 \mathrm{~g}$ of curcumin \\
& Placebo \\
& $2.5 \mathrm{~g}$ Avicel 105, an inert plant cellulose \\
& 5 capsules taken twice daily \\
& Duration \\
& 5 capsules were taken twice daily for 2.5 days prior to exercise, then 5 capsules twice daily for 2.5 days \\
& after exercise
\end{tabular}

Primary
Muscle soreness using a 0 to $10 \mathrm{~cm}$ visual analogue scale where 0 is "no pain" and 10 is "severe pain".
Pain was rated for a single leg squat, walking downstairs, passive strength of the gluteals and a single
leg vertical jump.
Muscle tenderness was assessed using a Somedic pressure algometer (Somedic, Sollentuna, Sweden)
at 4 standardised points

\section{Secondary}

Jump performance was measured by a single leg vertical squat jump. The jump and reach method using Vertec (Vertec, Vertec Sports Imports, Hilliard, OH).

Exercise type Eccentric exercise protocol consisted of 7 sets of 1 - eccentric single leg press repetitions on a leg press machine

\begin{tabular}{ll}
\hline Sources of funding & Manuscript states: "Funding from the Australian Institute of Sport" \\
\hline Notes & $\begin{array}{l}\text { Authors were contacted on } 15 \text { March } 2016 \text { to request raw data for delayed onset muscle soreness and } \\
\text { counter-movement jump and they responded on } 15 \text { March } 2016\end{array}$ \\
\hline
\end{tabular}

\section{Risk of bias}


Nicol 2015 (Continued)

Random sequence genera- Unclear risk Manuscript states that the "randomization sequence was generated using a tion (selection bias) random numbers table (http://www.ramdomizer.org)". Secondly: "Randomization was applied to both the order of treatment or placebo and to the sequence of right or left leg use within the unilateral crossover". It is known that the repeated bout effects can be observed in the non-exercised limb.

\begin{tabular}{|c|c|c|}
\hline $\begin{array}{l}\text { Allocation concealment } \\
\text { (selection bias) }\end{array}$ & Low risk & $\begin{array}{l}\text { Manuscript states: "Allocation was concealed using sequentially numbered } \\
\text { medication. Investigators and participants were blinded by provision of the } \\
\text { medications by AIS nursing staff according to the randomization protocol." }\end{array}$ \\
\hline $\begin{array}{l}\text { Blinding of participants } \\
\text { and personnel (perfor- } \\
\text { mance bias) } \\
\text { All outcomes }\end{array}$ & Low risk & $\begin{array}{l}\text { Manuscript states: "Investigators and participants were blinded by provision of } \\
\text { the medications by AIS nursing staff according to the randomization protocol" } \\
\text { and that "the participants reported that they could not distinguish between } \\
\text { the treatment and placebo" }\end{array}$ \\
\hline
\end{tabular}

\begin{tabular}{lll}
\hline $\begin{array}{l}\text { Blinding of outcome as- } \\
\text { sessment (detection bias) } \\
\text { All outcomes }\end{array}$ & Low risk & Participants were blinded \\
\hline $\begin{array}{l}\text { Incomplete outcome data } \\
\begin{array}{l}\text { (attrition bias) } \\
\text { All outcomes }\end{array}\end{array}$ & Low risk & $\begin{array}{l}\text { Manuscript states" "Two withdrew from the study following acceptance due to } \\
\text { the inability to attend testing commitments, and no replacements were added } \\
\text { due to resource constraints." This equates to } 11 \% \text { attrition. }\end{array}$ \\
\hline
\end{tabular}

\begin{tabular}{lll}
\hline $\begin{array}{l}\text { Selective reporting (re- } \\
\text { porting bias) }\end{array}$ & High risk & $\begin{array}{l}\text { No published protocol available } \\
\text { All outcomes reported at all time points } \\
\end{array}$ \\
\hline Other bias & Unclear risk & $\begin{array}{l}\text { No information in the manuscript regarding food or using anti-inflammatory } \\
\text { drugs or other supplements during the trial }\end{array}$ \\
\hline
\end{tabular}

Nie 2004

\begin{tabular}{|c|c|}
\hline Methods & Randomised controlled trial (parallel design) \\
\hline \multirow[t]{6}{*}{ Participants } & Setting: laboratory; China \\
\hline & $\mathrm{n}=16$ male junior basketball players ( 8 in each group) \\
\hline & Mean age vitamin C group 16.7 (SD 0.3) years \\
\hline & Mean age placebo group 16.5 (SD 0.2) years \\
\hline & Inclusion/exclusion criteria \\
\hline & $\begin{array}{l}\text { Participants completed } 4 \text { to } 5 \text { training sessions a week with an average weekly training of } 12.3 \text { (SD 1.3) } \\
\text { hours }\end{array}$ \\
\hline
\end{tabular}

Interventions

Intervention

$800 \mathrm{mg}$ of vitamin C

Placebo

No details provided other than it was identical in appearance

\section{Duration}


Nie 2004 (Continued)

Vitamin C taken 3 hours before exercise and 31 hours after exercise and outcomes measured for up to 2 days post-exercise

\begin{tabular}{ll}
\hline Outcomes & PRIMARY \\
& Delayed onset muscle soreness was evaluated in the leg extensors using a $10 \mathrm{~cm}$ visual analogue scale \\
where 0 is "complete absence of pain" and 10 is "extremely sore with noticeable pain and stiffness at \\
all times and the muscle and leg are difficult to use". Perceived soreness was done during quadriceps \\
extension.
\end{tabular}

\begin{tabular}{ll}
\hline Exercise type & 10 sets of 15 full-squat jumps with $10 \mathrm{~kg}$ weight imposed at the waist \\
\hline Sources of funding & None \\
\hline Notes & No detail on how the supplements were administered or whether it was a drink or capsule
\end{tabular}

\section{Risk of bias}

\begin{tabular}{|c|c|c|}
\hline Bias & Authors' judgement & Support for judgement \\
\hline $\begin{array}{l}\text { Random sequence genera- } \\
\text { tion (selection bias) }\end{array}$ & Unclear risk & $\begin{array}{l}\text { No details in manuscript } \\
\text { Authors were contacted via email on } 26 \text { May } 2016 \text { and responded on } 27 \text { May } \\
\text { 2016: "distribute subjects by lot" }\end{array}$ \\
\hline $\begin{array}{l}\text { Allocation concealment } \\
\text { (selection bias) }\end{array}$ & Unclear risk & $\begin{array}{l}\text { No details in manuscript } \\
\text { Authors were contacted via email on } 26 \text { May } 2016 \text { and responded on } 27 \text { May } \\
2016 \text { but did not understand the query }\end{array}$ \\
\hline $\begin{array}{l}\text { Blinding of participants } \\
\text { and personnel (perfor- } \\
\text { mance bias) } \\
\text { All outcomes }\end{array}$ & Low risk & Double-blind \\
\hline
\end{tabular}

\begin{tabular}{|c|c|c|}
\hline $\begin{array}{l}\text { Blinding of outcome as- } \\
\text { sessment (detection bias) } \\
\text { All outcomes }\end{array}$ & Low risk & Double-blind \\
\hline $\begin{array}{l}\text { Incomplete outcome data } \\
\text { (attrition bias) } \\
\text { All outcomes }\end{array}$ & Low risk & $\begin{array}{l}\text { No details in manuscript } \\
\text { Authors were contacted via email on } 26 \text { May } 2016 \text { and responded to say that } \\
\text { all participants completed the study }\end{array}$ \\
\hline $\begin{array}{l}\text { Selective reporting (re- } \\
\text { porting bias) }\end{array}$ & High risk & $\begin{array}{l}\text { No published protocol available } \\
\text { All outcomes reported at all time points } \\
\text { Adverse effects of antioxidant supplementation were not reported }\end{array}$ \\
\hline
\end{tabular}

\section{O'Connor 2013}

\begin{tabular}{ll}
\hline Methods $\quad$ Randomised controlled trial (parallel design) \\
\hline
\end{tabular}


O'Connor 2013 (Continued)
Participants
Setting: laboratory; USA
$\mathrm{n}=40$ untrained men (20) and women (20); age range 18 to 39
Placebo group ( $n=20 ; 10$ women) Antioxidant group ( $n=2 ; 9$ women)

\section{Inclusion/exclusion criteria}
Excluded were pregnant women, individuals engaged in vigorous activities on a regular basis (more than once per week on average during the prior month), those with contraindications to exercise, those taking pain or prescription drugs (except for oral contraceptives), and high consumers of 55 fruits, veg- etables, drinks or chocolate products known to contain polyphenols ( $>1$ serving per day during the pri- or month)

\begin{abstract}
Interventions
Intervention

Grape beverage - stilbenes (resveratrol $=1.75 \mathrm{mg} / \mathrm{kg}$ ), catechins (catechin $=19.7 \mathrm{mg} / \mathrm{kg}$, epicatechin = $12.6 \mathrm{mg} / \mathrm{kg}$ ), anthocyanins (peonidin $=31.7 \mathrm{mg} / \mathrm{kg}$, cyanidin $=125 \mathrm{mg} / \mathrm{kg}$, malvidin $=145.2 \mathrm{mg} / \mathrm{kg}$ ) and flavanols (quercetin $=32.6 \mathrm{mg} / \mathrm{kg}$, kaempferol $=5.6 \mathrm{mg} / \mathrm{kg}$, isorhamnetin $=6.8 \mathrm{mg} / \mathrm{kg}$ )
\end{abstract}

\title{
Placebo
}

A combination of starch, sugars, cellulose, acids, dipotassium phosphate, potassium citrate, grape flavouring and food dyes was used to create a placebo powder that matched the composition and caloric content of the grape powder as closely as possible but without any polyphenolic compounds

\section{Duration}

45 days

PRIMARY
Outcomes
Delayed onset muscle soreness in the arm was rated in response to isometric strength measurement
trials using a $100 \mathrm{~mm}$ visual analogue scale where 0 is "no pain" and 100 is "extreme pain"

\section{SECONDARY}

Range of motion

Isometric strength of the elbow flexors at 90 degrees

Maximal oxygen consumption performed on a treadmill

$\begin{array}{ll}\text { Exercise type } & \begin{array}{l}3 \text { sets of } 6 \text { repetitions were performed using the non-dominant elbow flexors with a weight of } 120 \% \text { of } \\ \text { concentric } 1 \text { RM }\end{array}\end{array}$
concentric 1 RM

\begin{tabular}{ll}
\hline Sources of funding & Financial support for the study was provided by the California table Grape Commission \\
\hline Notes & One serving of powder daily mixed with $236 \mathrm{~mL}$ of water
\end{tabular}

\section{Risk of bias}

\begin{tabular}{lll}
\hline Bias & Authors' judgement & Support for judgement \\
\hline $\begin{array}{l}\text { Random sequence genera- } \\
\text { tion (selection bias) }\end{array}$ & Low risk & $\begin{array}{l}\text { One investigator generated an allocation sequence using an online random } \\
\text { number generator that created blocks of } 2 \text { with an allocation ratio of } 1: 1 \text { to the } \\
\text { conditions. A different investigator randomly assigned participants in blocks } \\
\text { to their groups. }\end{array}$ \\
\hline
\end{tabular}

Allocation concealment $\quad$ Low risk $\quad$ Opaque containers and a clip was placed on the nose
(selection bias)


O'Connor 2013 (Continued)

Blinding of participants Low risk Double-blind: participants as well as researchers administering the intervenand personnel (perfortion, assessing the outcomes and conducting the statistical analyses were mance bias)

All outcomes

blinded

\begin{tabular}{|c|c|c|}
\hline $\begin{array}{l}\text { Blinding of outcome as- } \\
\text { sessment (detection bias) } \\
\text { All outcomes }\end{array}$ & Low risk & Double-blind \\
\hline $\begin{array}{l}\text { Incomplete outcome data } \\
\text { (attrition bias) } \\
\text { All outcomes }\end{array}$ & Low risk & All participants completed the study with no adverse effects \\
\hline $\begin{array}{l}\text { Selective reporting (re- } \\
\text { porting bias) }\end{array}$ & Low risk & $\begin{array}{l}\text { No published protocol available } \\
\text { All outcomes reported at all time points } \\
\text { Manuscript states: "No adverse events occurred in response to beverage con- } \\
\text { sumption" }\end{array}$ \\
\hline Other bias & Low risk & $\begin{array}{l}\text { Participants were asked to record food frequency and were asked to refrain } \\
\text { from using anti-inflammatory drugs or other supplements that could reduce } \\
\text { soreness }\end{array}$ \\
\hline
\end{tabular}

\section{O'Fallon 2012}

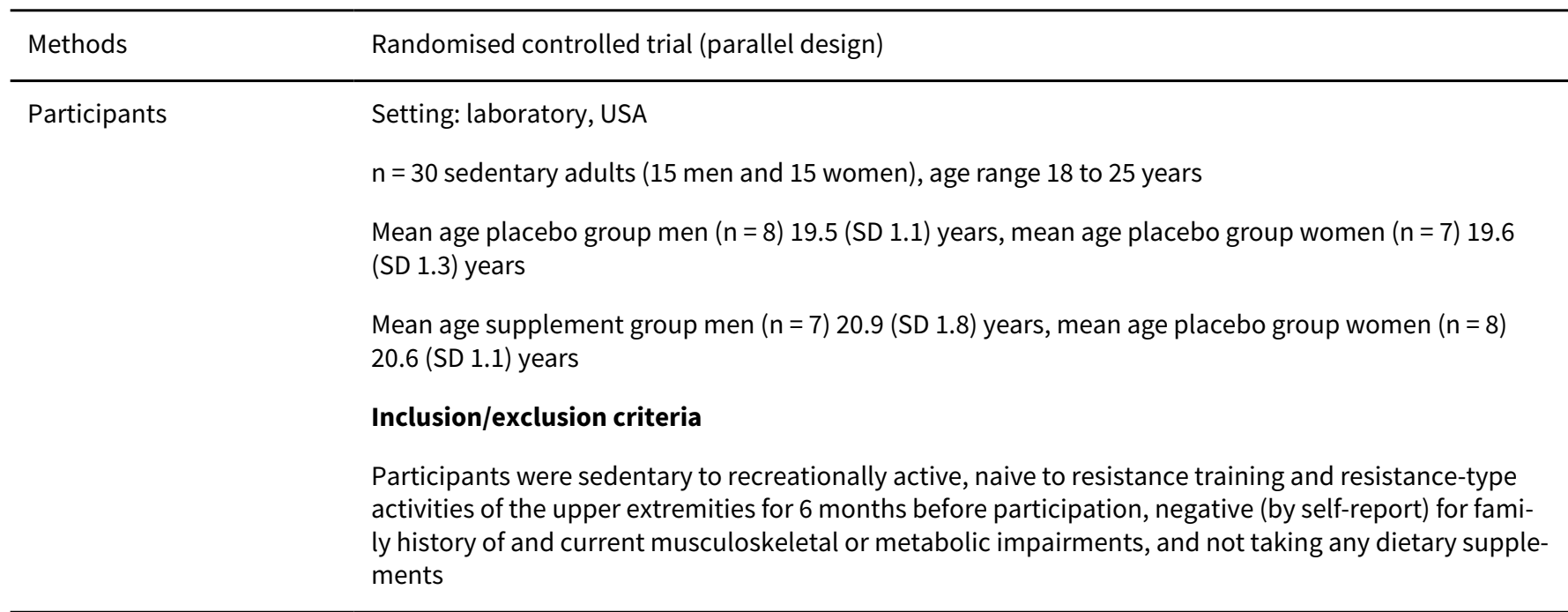

Interventions

Intervention

First Strike Nutrition (Natick Soldier Centre, Natick MA) Bars with 1000 mg of Quercitin (Merck, SA Brazil)

\section{Placebo}

Placebo First Strike Nutrition Bar (Natick Soldier Centre, Natick MA)

\section{Duration}

7 days 
O'Fallon 2012 (Continued)

Delayed onset muscle soreness was assessed using a $100 \mathrm{~mm}$ visual analogue scale where 0 is "no soreness" and 100 is "unbearable pain"

Elbow flexor

\section{SECONDARY}

Resting arm angle

Upper arm swelling

Isometric peak torque

\begin{tabular}{ll}
\hline Exercise type & 24 eccentric contractions of the elbow flexors \\
\hline Sources of funding & Funded by the US Army contract \# W911QY-07-C-0001 \\
\hline Notes & 1 bar twice daily for 7 days \\
& $\begin{array}{l}\text { Authors were contacted to request raw data for delayed onset muscle soreness, range of motion and } \\
\text { maximal voluntary isometric contraction on } 3 \text { November } 2013 \text { and responded on } 3 \text { December } 2013\end{array}$
\end{tabular}

\section{Risk of bias}

\begin{tabular}{|c|c|c|}
\hline Bias & Authors' judgement & Support for judgement \\
\hline $\begin{array}{l}\text { Random sequence genera- } \\
\text { tion (selection bias) }\end{array}$ & Low risk & Randomly assigned in a permuted block design \\
\hline $\begin{array}{l}\text { Allocation concealment } \\
\text { (selection bias) }\end{array}$ & Unclear risk & $\begin{array}{l}\text { No details in the manuscript } \\
\text { Authors were contacted but no reply received }\end{array}$ \\
\hline $\begin{array}{l}\text { Blinding of participants } \\
\text { and personnel (perfor- } \\
\text { mance bias) } \\
\text { All outcomes }\end{array}$ & Low risk & Double-blind \\
\hline $\begin{array}{l}\text { Blinding of outcome as- } \\
\text { sessment (detection bias) } \\
\text { All outcomes }\end{array}$ & Low risk & Double-blind \\
\hline $\begin{array}{l}\text { Incomplete outcome data } \\
\text { (attrition bias) } \\
\text { All outcomes }\end{array}$ & Low risk & All participants completed the study without any adverse effects \\
\hline $\begin{array}{l}\text { Selective reporting (re- } \\
\text { porting bias) }\end{array}$ & High risk & $\begin{array}{l}\text { No published protocol available } \\
\text { All outcomes reported at all time points } \\
\text { Adverse effects of antioxidant supplementation were not reported }\end{array}$ \\
\hline Other bias & Low risk & $\begin{array}{l}\text { Food records were obtained, participants were instructed to minimise foods } \\
\text { high in quercetin and were asked to refrain from taking any other supple- } \\
\text { ments, anti-inflammatory medication or engage in any other modality that } \\
\text { could enhance recovery }\end{array}$ \\
\hline
\end{tabular}


Peschek 2014

\begin{tabular}{ll}
\hline Methods & Randomised controlled trial (cross-over design) \\
& Separated by a 21-day washout \\
\hline Participants & Setting: laboratory, USA \\
$\mathrm{n}=8$ well-trained male runners and triathletes age range 18 to 44 years \\
Inclusion/exclusion criteria \\
Inclusion criteria - currently training for at least 6 or more hours per week \\
Exclusion criteria - lower body extremity injury in the past 6 months and/or were currently taking \\
chronic or daily doses of anti-inflammatory medication or nutritional supplements. Participants who \\
had a history of a recent illness were also excluded from the study.
\end{tabular}

\section{Intervention}

$240 \mathrm{~mL}$ serving of carbohydrate protein beverage plus natural cocoa (350 mg flavanols)

\section{Placebo}

Placebo cocoa-based (processed with alkali) carbohydrate protein beverage ( $0 \mathrm{mg}$ of flavanols)

\section{Duration}

Beverage consumed 1 and 2 hours into recovery after downhill running and primary and secondary outcomes measured for up to 2 days after exercise

\begin{tabular}{|c|c|c|}
\hline \multirow[t]{6}{*}{ Outcomes } & \multicolumn{2}{|l|}{ PRIMARY } \\
\hline & \multicolumn{2}{|c|}{$\begin{array}{l}\text { Delayed onset muscle soreness at the legs (10-point visual analogue scale: } 0 \text { is "no pain at all" and } 10 \text { is } \\
\text { "unbearable pain") }\end{array}$} \\
\hline & \multicolumn{2}{|l|}{$\underline{\text { SECONDARY }}$} \\
\hline & \multicolumn{2}{|c|}{ Muscle tenderness using a force algometer (Wagner Pain Test Model FPK Algometer) } \\
\hline & \multicolumn{2}{|c|}{ Muscle function - Quadricep Extension } \\
\hline & \multicolumn{2}{|c|}{ Performance $-5 \mathrm{~km}$ running time trial } \\
\hline Exercise type & \multicolumn{2}{|c|}{ Downhill running protocol at a $-10 \%$ grade for 30 minutes at a speed equal to $70 \%$ of $\mathrm{VO} 2 \mathrm{max}$} \\
\hline Sources of funding & \multicolumn{2}{|c|}{ Chocolate milk was provided by Darigold Co. } \\
\hline Notes & \multirow{2}{*}{\multicolumn{2}{|c|}{$\begin{array}{l}\text { Drinks were } 240 \mathrm{~mL} \text { per serving and consumed } 1 \text { hour post-exercise and } 2 \text { hours post-exercise. } \\
\text { Authors were contacted on } 18 \text { February } 2016 \text { to request data for delayed onset muscle soreness, maxi- } \\
\text { mal voluntary isometric contraction and } 5 \mathrm{~km} \text { time trial but did not respond }\end{array}$}} \\
\hline & & \\
\hline \multicolumn{3}{|l|}{ Risk of bias } \\
\hline Bias & Authors' judgement & Support for judgement \\
\hline $\begin{array}{l}\text { Random sequence genera- } \\
\text { tion (selection bias) }\end{array}$ & Low risk & Randomised using a computer program \\
\hline $\begin{array}{l}\text { Allocation concealment } \\
\text { (selection bias) }\end{array}$ & Low risk & Unmarked bottles \\
\hline
\end{tabular}


Peschek 2014 (Continued)

Blinding of participants High risk Single-blind design thus personnel were not blinded and personnel (performance bias)

All outcomes

\begin{tabular}{lll}
\hline $\begin{array}{l}\text { Blinding of outcome as- } \\
\text { sessment (detection bias) } \\
\text { All outcomes }\end{array}$ & Low risk & Participants were blinded \\
\hline $\begin{array}{l}\text { Incomplete outcome data } \\
\text { (attrition bias) } \\
\text { All outcomes }\end{array}$ & Low risk & All participants completed the study without any adverse effects \\
\hline $\begin{array}{l}\text { Selective reporting (re- } \\
\text { porting bias) }\end{array}$ & High risk & All outcomes reported at all time points \\
\hline $\begin{array}{l}\text { Other bias } \\
\text { Low risk }\end{array}$ & Adverse effects of antioxidant supplementation were not reported \\
\hline
\end{tabular}

Phillips 2003

\begin{tabular}{ll}
\hline Methods & Randomised controlled trial (parallel design) \\
\hline Participants & Setting: laboratory; USA \\
$\mathrm{n}=40$ healthy, untrained, non-smoking males who were regularly involved with weight training mean; \\
age 22.1 (SEM 3.9) years (16 in the antioxidant group and 19 in the placebo group) \\
Inclusion/exclusion criteria \\
During the screening process an extensive interview to clarify the extent and nature of each individual's \\
exercise habits was conducted, specifically to ascertain whether or not a regular weight-training pro- \\
gramme was a component thereof. Those participants not involved with a regular weight-training pro- \\
gramme and with no prior history of injury to the biceps brachii or elbow region were included in the \\
study.
\end{tabular}

\section{Intervention}

Mixed antioxidant supplement (300 mg tocopherols, $800 \mathrm{mg}$ docosahexaenoate, $300 \mathrm{mg}$ flavonoids, of which was $100 \mathrm{mg}$ hesperetin and $200 \mathrm{mg}$ quercetin)

\section{Placebo}

Sunflower oil and rice powder capsules

\section{Duration}

2 weeks of supplementation

\section{Outcomes}

\section{PRIMARY}

Muscle soreness was measured using a visual analogue scale $(0$ to $10 \mathrm{~cm})$ where 0 is "no pain" and 10 is "extreme pain". Soreness measures were subjectively evaluated through palpitation for oedema at the elbow and were performed by the same researcher throughout the study.

\section{SECONDARY}


Phillips 2003 (Continued)

Range of motion was measured as active arm flexion from full extension using standard goniometry.

Each range of motion value was obtained from an average of 3 measurements.

\begin{tabular}{ll}
\hline Exercise type & 3 sets of 10 repetitions at $80 \%$ of 1 RM of elbow flexor \\
\hline Sources of funding & This research was supported with funding from Galileo Laboratories, Inc. \\
\hline Notes & Supplements were taken in the form of capsules (number of capsules per day not specified) \\
& $\begin{array}{l}\text { Authors were contacted via email on } 2 \text { November } 2013 \text { and again on } 3 \text { December } 2013 \text { to request da- } \\
\text { ta for delayed onset muscle soreness and maximal voluntary isometric contraction but they did not re- } \\
\text { spond }\end{array}$
\end{tabular}

\section{Risk of bias}

\begin{tabular}{|c|c|c|}
\hline Bias & Authors' judgement & Support for judgement \\
\hline $\begin{array}{l}\text { Random sequence genera- } \\
\text { tion (selection bias) }\end{array}$ & Unclear risk & $\begin{array}{l}\text { Randomised; however, no details in the manuscript on how this was done } \\
\text { Authors were contacted via email on } 2 \text { November } 2013 \text { and again on } 3 \text { Decem- } \\
\text { ber } 2013 \text { with no reply }\end{array}$ \\
\hline $\begin{array}{l}\text { Allocation concealment } \\
\text { (selection bias) }\end{array}$ & Unclear risk & $\begin{array}{l}\text { No details in the manuscript } \\
\text { Authors were contacted via email on } 2 \text { November } 2013 \text { and again on } 3 \text { Decem- } \\
\text { ber } 2013 \text { with no reply }\end{array}$ \\
\hline $\begin{array}{l}\text { Blinding of participants } \\
\text { and personnel (perfor- } \\
\text { mance bias) } \\
\text { All outcomes }\end{array}$ & Low risk & Double-blind \\
\hline $\begin{array}{l}\text { Blinding of outcome as- } \\
\text { sessment (detection bias) } \\
\text { All outcomes }\end{array}$ & Low risk & Double-blind \\
\hline $\begin{array}{l}\text { Incomplete outcome data } \\
\text { (attrition bias) } \\
\text { All outcomes }\end{array}$ & High risk & $\begin{array}{l}5 \text { participants were excluded from the study due to complications with the } \\
\text { blood-drawing procedures, however it is unclear which group they were from } \\
\text { Attrition rate }=12.5 \%\end{array}$ \\
\hline $\begin{array}{l}\text { Selective reporting (re- } \\
\text { porting bias) }\end{array}$ & Low risk & $\begin{array}{l}\text { No published protocol available } \\
\text { All outcomes reported at all time points } \\
\text { Manuscript states: "During the period of supplementation, there were no re- } \\
\text { ported adverse events by any of the research subjects..." }\end{array}$ \\
\hline Other bias & Low risk & $\begin{array}{l}\text { Participants were asked to refrain from using any other supplements and med- } \\
\text { ication for the duration of the study }\end{array}$ \\
\hline
\end{tabular}

Shafat 2004

\begin{tabular}{ll}
\hline Methods & Randomised controlled trial (parallel design) \\
\hline Participants & Setting: laboratory; Ireland \\
& $\mathrm{n}=12$ moderately fit, active, non-smoking men
\end{tabular}


Shafat 2004 (Continued)

Mean age vitamin C group 25 (SD 7.5) years

Mean age placebo group 20.6 (SD 1.1) years

\section{Inclusion/exclusion criteria}

All volunteers were moderately active non-smokers who had not participated in any form of resistance training exercise in the previous 6 months. Volunteers who were currently taking supplements in the past 6 months were excluded from the study.

Intervention
Interventions $500 \mathrm{mg}$ vitamin C and $1200 \mathrm{IU}$ vitamin $\mathrm{E} ; 2 \times 250 \mathrm{mg}$ tablets of vitamin C +3 tablets 400 IU each vitamin
$\mathrm{E}$

Placebo

Glucose

Duration

37 days

Outcomes PRIMARY

Delayed onset muscle soreness was evaluated using a questionnaire employing a visual analogue scale for a total of 8 sites ( 6 sites on the anterior muscle of the upper leg and 2 sites on the posterior muscles of the upper leg). The participants were asked to palpate the relaxed muscle and rate soreness on a scale of 1 "normal" to 10 "very very sore". Results were summed for the 8 sites so that no soreness is indicated by a score of 8 and maximal muscle soreness by a score of 80 .

\section{SECONDARY}

Maximal voluntary concentric torque for the knee extensors was measured at an angular velocity of 0.5 $\mathrm{rad} / \mathrm{s} 3$ minutes to and 3 minutes following the eccentric contraction bout on the Con-Trex dynamometer.

Isometric maximum voluntary contraction force (MVC) and electrically simulated force of the knee extensors were measured using a custom made isometric test rig. Volunteers were seated in the upright position with their leg connected to a pre-calibrated load cell (Novatech, Hastings, UK). Analogue signals from the strain gauge were converted to digital information using an A:D convertor (Powerlab 1400 , ADInstruments, Oxfordshire, UK) and were recorded on a PC. The chair was adjusted to allow attachment of the strain gauge above the ankle with the knee at an angle of $1.57 \mathrm{rad}$ ( 90 degrees). For $M V C$, volunteers were instructed to contract maximally for 3 seconds and verbally encouraged during their effort. 3 repetitions were performed, separated by 1 minute. The highest peak force value of the 3 repetitions was recorded as the MVC.

\begin{tabular}{lll}
\hline Exercise type & 30 sets of 10 eccentric knee extensions at a velocity of 0.52 rad $\cdot \mathrm{s}^{-1}$ \\
\hline Sources of funding & None & \\
\hline Notes & - & \\
\hline Risk of bias & Authors' judgement & Support for judgement \\
\hline Bias & Low risk & No details in manuscript \\
\hline $\begin{array}{l}\text { Random sequence genera- } \\
\text { tion (selection bias) }\end{array}$ & $\begin{array}{l}\text { Authors were contacted via email on } 26 \text { May 2016 and responded on } 5 \text { June } \\
\text { 2016: "Numbers were drawn out of a hat to determine a set allocation order } \\
\text { which was balanced in numbers for treatment and placebo. As participants }\end{array}$
\end{tabular}


Shafat 2004 (Continued)

were recruited to the study, they were allocated to a group according to that random allocation order."

\begin{tabular}{|c|c|c|}
\hline $\begin{array}{l}\text { Allocation concealment } \\
\text { (selection bias) }\end{array}$ & Unclear risk & $\begin{array}{l}\text { No details in manuscript } \\
\text { Authors were contacted via email on } 26 \text { May } 2016 \text { and responded on } 5 \text { June } \\
\text { 2016: "All volunteers were informed that they were being supplemented. All } \\
\text { were supplied with identical labelled dispensers, containing capsules. Howev- } \\
\text { er, the capsules were not identical in colour or size. We checked, informally, at } \\
\text { the end of the testing to see if volunteers thought they were supplemented or } \\
\text { controlled and they really had no idea which was which" }\end{array}$ \\
\hline
\end{tabular}

Blinding of participants High risk Non-identical capsules; the personnel were not blinded

and personnel (perfor-

Non-identical capsules; the personnel were not blinded

mance bias)

All outcomes

\begin{tabular}{lll}
\hline $\begin{array}{l}\text { Blinding of outcome as- } \\
\text { sessment (detection bias) }\end{array}$ & Unclear risk & \\
All outcomes & \\
\hline $\begin{array}{l}\text { Incomplete outcome data } \\
\text { (attrition bias) }\end{array}$ & Low risk & All participants completed the study \\
All outcomes &
\end{tabular}

\begin{tabular}{lll}
\hline $\begin{array}{l}\text { Selective reporting (re- } \\
\text { porting bias) }\end{array}$ & High risk & $\begin{array}{l}\text { No published protocol available } \\
\text { All outcomes reported at all time points } \\
\text { Adverse effects of antioxidant supplementation were not reported }\end{array}$ \\
\hline Other bias & Unclear risk & $\begin{array}{l}\text { Participants that took supplements or smoked were excluded } \\
\text { No details on whether participants were asked to refrain from using anti-in- } \\
\text { flammatory drugs or other treatment modalities that could reduce soreness }\end{array}$ \\
\hline
\end{tabular}

Silva 2008

\begin{tabular}{ll}
\hline Methods & Randomised controlled trial (parallel design) \\
\hline Participants & Setting: laboratory; Brazil \\
$\mathrm{n}=29$ healthy, male university students mean age 21.3 (SD 4) years \\
Inclusion/exclusion criteria \\
$\begin{array}{l}\text { Participants were non-smokers, did not take NAC or related supplements, had not participated in resis- } \\
\text { tance training or any other form of structured exercise for at least } 6 \text { months, did not have a history of } \\
\text { muscle lesion, and were not carriers of any disease that might compromise the results or be aggravat- } \\
\text { ed by physical exercise }\end{array}$
\end{tabular}

Interventions

\section{Intervention}

$\mathrm{N}$-acetylcysteine (NAC) $10 \mathrm{mg} / \mathrm{kg}$ of body mass in 3 groups as follows:

Group 1: 21 days of $\mathrm{N}$-acetylcysteine (NAC) $10 \mathrm{mg} / \mathrm{kg}$ of body mass $\mathrm{n}=8$

Group 2: 14 days of $\mathrm{N}$-acetylcysteine (NAC) $10 \mathrm{mg} / \mathrm{kg}$ of body mass + placebo (14 days of NAC +7 days of placebo) $n=8$ 
Silva 2008 (Continued)

Group 3: 21 days of placebo $n=9$

\section{Placebo}

Starch capsules

\section{Duration}

21 days

\begin{tabular}{ll}
\hline Outcomes & $\begin{array}{l}\text { PRIMARY } \\
\text { Delayed onset muscle soreness at the elbow flexor using a visual analogue scale }(0 \text { to } 10 \mathrm{~cm}) . \text { Partici- } \\
\text { pants marked their subjective rating from } 0 \text { "without pain" to } 10 \text { "extreme pain" }\end{array}$ \\
\hline Exercise type & Elbow flexion and extension on the Scott bench at $80 \% 1$ RM until exhaustion \\
\hline Sources of funding & The study was supported by grants from UNESC, CNPq and CAPES (Brazil) \\
\hline Notes & 1 capsule per day for 14 days before the exercise protocol
\end{tabular}

\section{Risk of bias}

\begin{tabular}{|c|c|c|}
\hline Bias & Authors' judgement & Support for judgement \\
\hline \multirow[t]{2}{*}{$\begin{array}{l}\text { Random sequence genera- } \\
\text { tion (selection bias) }\end{array}$} & Low risk & $\begin{array}{l}\text { No details in the manuscript } \\
\text { Authors were contacted via email on } 24 \text { May } 2016\end{array}$ \\
\hline & & $\begin{array}{l}\text { Author response: "We selected the individual using a random number table. } \\
\text { The participants were selected and they received a number. According with } \\
\text { the random number tables all individuals were included in the experimental or } \\
\text { control groups." }\end{array}$ \\
\hline
\end{tabular}

$\begin{array}{ll}\begin{array}{l}\text { Allocation concealment } \\ \text { (selection bias) }\end{array} & \text { Now risk } \\ & \text { Authors were contacted via email on } 24 \text { May } 2016 \\ & \begin{array}{l}\text { Author response: "Allocation concealment was ensured by the use of sequen- } \\ \text { tially numbered, dark and sealed envelopes. An independent colleague, blind- } \\ \text { ed to the allocated treatment, did the selection and carried out the composi- } \\ \text { tion of groups." }\end{array}\end{array}$

\begin{tabular}{l}
\hline Blinding of participants High risk $\quad$ Single-blind; participants were blinded but the researchers were not \\
and personnel (perfor- \\
mance bias) \\
All outcomes
\end{tabular}

\begin{tabular}{lll}
\hline $\begin{array}{l}\text { Blinding of outcome as- } \\
\text { sessment (detection bias) } \\
\text { All outcomes }\end{array}$ & Low risk & Participants were blinded \\
\hline $\begin{array}{l}\text { Incomplete outcome data } \\
\text { (attrition bias) } \\
\text { All outcomes }\end{array}$ & High risk & 4 participants withdrew for personal reasons \\
\hline $\begin{array}{l}\text { Selective reporting (re- } \\
\text { porting bias) }\end{array}$ & High risk & Attrition rate: $14 \%$ \\
& No published protocol available \\
& All outcomes reported at all time points \\
\hline
\end{tabular}


Silva 2008 (Continued)

Other bias Unclear risk Participants were non-smokers, did not take any other supplements and had not participated in resistance training or any form of structured exercise for 6 months

No details on whether the participants used anti-inflammatory drugs for the duration of the study

Silva 2010

\begin{tabular}{ll}
\hline Methods & Randomised controlled trial (parallel design) \\
\hline Participants & Setting: laboratory; Brazil \\
$\mathrm{n}=27$ male university students mean age 25.5 (SD 4) years \\
Inclusion/exclusion criteria \\
All participants were non-smokers, were not taking vitamin E or any other antioxidant or related sup- \\
plements, had not participated in resistance training or any other form of structured exercise for at \\
least 6 months, did not have a history of muscular lesions, and were not carriers of any disease that \\
might compromise the results or be aggravated by physical exercise
\end{tabular}

Interventions

\section{Intervention}

800 IU per day of D-a-tocopherol acetate (vitamin E); 1 capsule per day

\section{Placebo}

Starch capsules

\section{Duration}

14 days before and 7 days after (total 21 days)

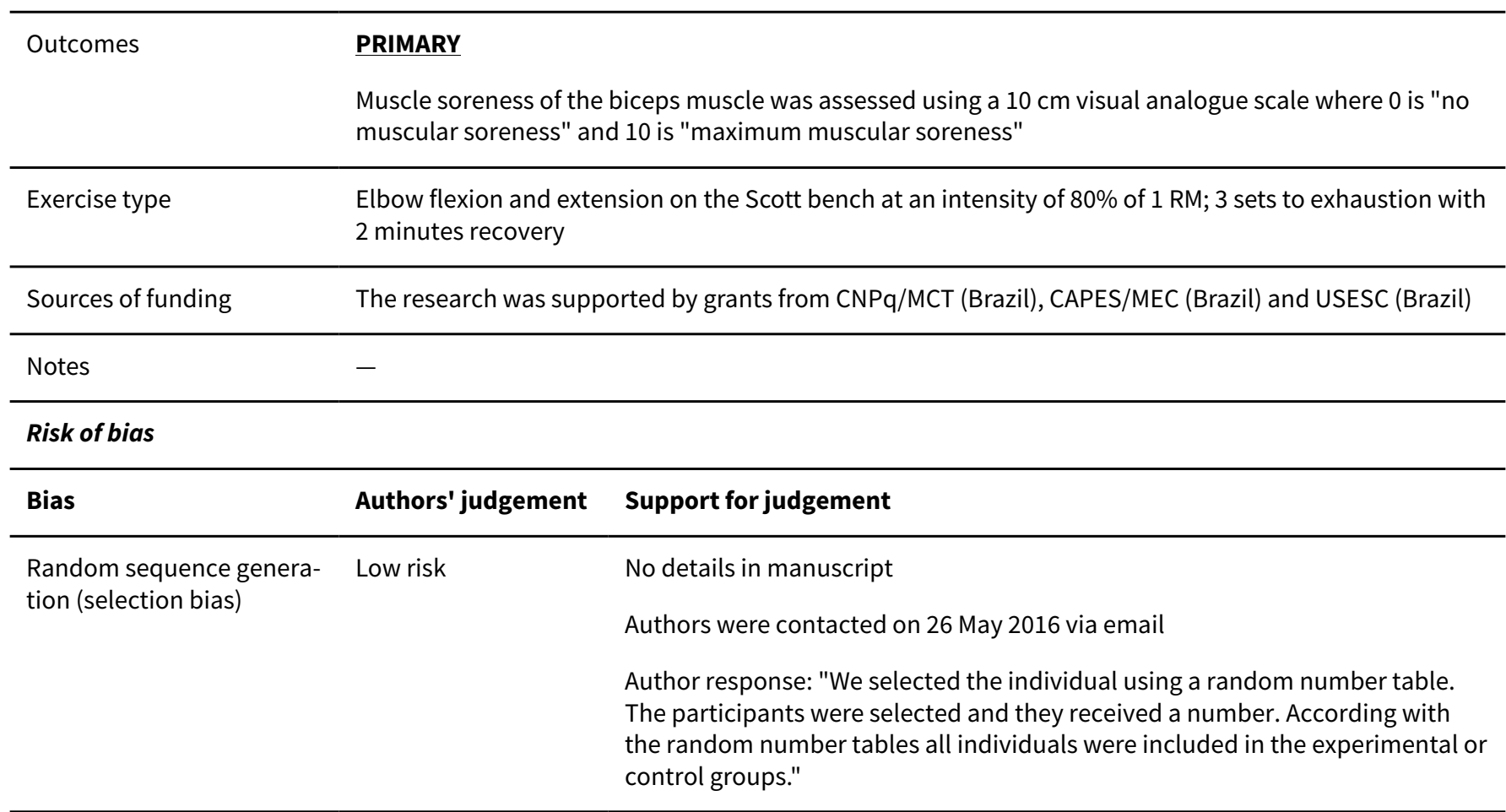


Silva 2010 (Continued)

$\begin{array}{ll}\begin{array}{l}\text { Allocation concealment } \\ \text { (selection bias) }\end{array} & \text { No details in manuscript } \\ & \text { Authors were contacted on } 26 \text { May } 2016 \text { via email } \\ & \begin{array}{l}\text { Author response: "Allocation concealment was ensured by the use of sequen- } \\ \text { tially numbered, dark and sealed envelopes. An independent colleague, blind- } \\ \text { ed to the allocated treatment, did the selection and carried out the composi- } \\ \text { tion of groups." }\end{array}\end{array}$

Blinding of participants Low risk $\quad$ Double-blind
and personnel (perfor-
mance bias)
All outcomes

\begin{tabular}{ll}
\hline Blinding of outcome as- & Low risk \\
sessment (detection bias) & \\
All outcomes & \\
\hline
\end{tabular}

\begin{tabular}{lll}
\hline $\begin{array}{l}\text { Incomplete outcome data } \\
\text { (attrition bias) } \\
\text { All outcomes }\end{array}$ & High risk & $\begin{array}{l}6 \text { participants withdrew from the study for personal reasons } \\
\text { Attrition rate: } 22 \%\end{array}$ \\
\hline $\begin{array}{l}\text { Selective reporting (re- } \\
\text { porting bias) }\end{array}$ & High risk & No published protocol available \\
& All outcomes reported at all time points \\
& Adverse effects of antioxidant supplementation were not reported \\
\hline Other bias & Unclear risk & No data on food records reported \\
& $\begin{array}{l}\text { Participants were instructed to refrain from taking supplements for the dura- } \\
\text { tion of the study but no details on anti-inflammatory medication }\end{array}$ \\
\hline
\end{tabular}

Su 2008

\begin{tabular}{ll}
\hline Methods & Randomised controlled trial (parallel design) \\
\hline Participants & Setting: laboratory; China \\
$\mathrm{n}=16$ athletes aged 18 to 20 years (8 males and 8 females) \\
Mean age 18.9 (SD 0.8) years \\
Inclusion/exclusion criteria \\
$\begin{array}{l}\text { A medical exam, including measurement of height, weight, blood pressure and electrocardiogram was } \\
\text { performed for each participant before the start of the study. No participants had infectious diseases or } \\
\text { were currently taking anti-inflammatory and anti-fatigue medicine during the study period. }\end{array}$
\end{tabular}

Interventions

Intervention

$80 \mathrm{mg}$ of allicin supplementation

Placebo

$80 \mathrm{mg}$ maltodextrin

\section{Duration}


Su 2008 (Continued)

2 weeks before and 2 days after running

\section{Outcomes \\ PRIMARY \\ Muscle soreness was assessed using the Borg CR-10 Scale where 0 is "no pain" and 10 is "maximal pain". At the beginning of the exercise test, participants were instructed to give CR-10 values.}

\begin{tabular}{ll}
\hline Exercise type & Downhill running on a treadmill at a grade of -10\% \\
\hline Sources of funding & No information in the manuscript \\
& Authors were contacted on 2 November 2013 and 3 December 2013 via email with no response \\
\hline Notes & Supplements taken as capsules daily \\
& $\begin{array}{l}\text { Authors were contacted on } 2 \text { November } 2013 \text { and } 3 \text { December } 2013 \text { via email to request data for de- } \\
\text { layed onset muscle soreness with no response }\end{array}$ \\
\hline
\end{tabular}

\section{Risk of bias}

\begin{tabular}{|c|c|c|}
\hline Bias & Authors' judgement & Support for judgement \\
\hline $\begin{array}{l}\text { Random sequence genera- } \\
\text { tion (selection bias) }\end{array}$ & High risk & $\begin{array}{l}\text { Participants were randomly assigned into an allicin or control group by sex } \\
\text { and sports participation }\end{array}$ \\
\hline $\begin{array}{l}\text { Allocation concealment } \\
\text { (selection bias) }\end{array}$ & Unclear risk & $\begin{array}{l}\text { Not specified in the manuscript } \\
\text { Authors were contacted on } 2 \text { November } 2013 \text { and } 3 \text { December } 2013 \text { via email } \\
\text { with no response }\end{array}$ \\
\hline $\begin{array}{l}\text { Blinding of participants } \\
\text { and personnel (perfor- } \\
\text { mance bias) } \\
\text { All outcomes }\end{array}$ & Unclear risk & $\begin{array}{l}\text { Not specified in the manuscript } \\
\text { Authors were contacted on } 2 \text { November } 2013 \text { and } 3 \text { December } 2013 \text { via email } \\
\text { with no response }\end{array}$ \\
\hline $\begin{array}{l}\text { Blinding of outcome as- } \\
\text { sessment (detection bias) } \\
\text { All outcomes }\end{array}$ & Unclear risk & No details provided \\
\hline $\begin{array}{l}\text { Incomplete outcome data } \\
\text { (attrition bias) } \\
\text { All outcomes }\end{array}$ & Low risk & All participants completed the study \\
\hline $\begin{array}{l}\text { Selective reporting (re- } \\
\text { porting bias) }\end{array}$ & High risk & $\begin{array}{l}\text { No published protocol available } \\
\text { All outcomes reported at all time points } \\
\text { Adverse effects of antioxidant supplementation were not reported }\end{array}$ \\
\hline Other bias & Low risk & $\begin{array}{l}\text { Participants were asked to maintain their normal dietary habits and avoid any } \\
\text { form of antioxidant supplementation }\end{array}$ \\
\hline
\end{tabular}

Tanabe 2015

$\begin{array}{ll}\text { Methods } & \text { Randomised controlled trial (cross-over design) } \\ \text { 4-week washout period }\end{array}$


Tanabe 2015 (Continued)

Participants

Setting: laboratory; Japan

$\mathrm{n}=14$ untrained young men mean age 23.5 (SD 2.4) years

\section{Inclusion/exclusion criteria}

Participants had not been involved in any regular resistance exercise training for the past year

Intervention
$150 \mathrm{mg}$ of curcumin in 6 capsules of $25 \mathrm{mg}$ each
Placebo
$150 \mathrm{mg}$ of starch in 6 capsules of $25 \mathrm{mg}$ each
Duration
1 hour before exercise and 12 hours after exercise separated by a 4-week washout
Primary
Muscle soreness was measured using a 100 mm visual analogue scale where 0 is "no pain" and 100 is
"extremely sore." Soreness was measured upon palpitation of the upper arm and passively extending
the elbow joint.
Secondary
Range of motion was measured by actively extending the elbow joint maximally (extended elbow joint)
and touching the shoulder of the same side with the hand (flexed elbow joint angle). The range of mo-
tion was defined by the difference between the 2 elbow joints. Each angle was measured by a goniome-
ter 3 times and the mean of the 3 measures was used.
Maximum voluntary contraction of the exercised elbow flexors was measured using the isokinetic dy-
namometer in the same positioning as the eccentric exercise and the elbow joint angle was set at 90
degrees. 3 maximal isometric contractions were performed with a 30 -second rest.

Exercise type

2 bouts of eccentric exercise of the elbow flexors on a Biodex dynamometer (Biodex System 3, USA) using 1 arm for each bout separated by 4 weeks. Each exercise bout consisted of 50 maximal eccentric contractions of the elbow flexors at a velocity of 120 degrees per second.

\begin{tabular}{ll}
\hline Sources of funding & The study was supported by Theravalues Corporation, Japan \\
\hline Notes & $\begin{array}{l}\text { Authors were contacted to request raw data for delayed onset muscle soreness, range of motion and } \\
\text { maximal voluntary isometric contraction on } 8 \text { December } 2017 \text { and responded on } 9 \text { December } 2017\end{array}$ \\
\hline
\end{tabular}

\section{Risk of bias}

\begin{tabular}{lll}
\hline Bias & Authors' judgement & Support for judgement \\
\hline $\begin{array}{l}\text { Random sequence genera- } \\
\text { tion (selection bias) }\end{array}$ & Unclear risk & $\begin{array}{l}\text { Manuscript states: "randomised, single-blinded" design was used; no addition- } \\
\text { al details in the manuscript }\end{array}$ \\
& $\begin{array}{l}\text { Authors were contacted via email on } 5 \text { February } 2017 \text { and responded on } 8 \text { Feb- } \\
\text { ruary 2017: "One investigator (YT) assigned and managed the order of domi- } \\
\text { nant-nondominant and active-placebo to be counterbalanced as described in } \\
\text { manuscript." }\end{array}$ \\
\hline
\end{tabular}

$\begin{aligned} & \text { Allocation concealment } \\ & \text { (selection bias) }\end{aligned} \quad$ Unclear risk $\quad$ No details in manuscript
.


Tanabe 2015 (Continued)

Authors were contacted via email on 5 February 2017 and responded on 8 February 2017: "The subjects were allocated before the authors got any subject information (e.g., height, weight, day of birth etc)."

\begin{tabular}{|c|c|c|}
\hline $\begin{array}{l}\text { Blinding of participants } \\
\text { and personnel (perfor- } \\
\text { mance bias) } \\
\text { All outcomes }\end{array}$ & High risk & The study was a single-blinded design \\
\hline $\begin{array}{l}\text { Blinding of outcome as- } \\
\text { sessment (detection bias) } \\
\text { All outcomes }\end{array}$ & Unclear risk & No details provided \\
\hline $\begin{array}{l}\text { Incomplete outcome data } \\
\text { (attrition bias) } \\
\text { All outcomes }\end{array}$ & Low risk & $\begin{array}{l}\text { Authors were contacted via email on } 5 \text { February } 2017 \text { and responded on } 8 \text { Feb- } \\
\text { ruary 2017: "all participants completed the study" }\end{array}$ \\
\hline $\begin{array}{l}\text { Selective reporting (re- } \\
\text { porting bias) }\end{array}$ & High risk & $\begin{array}{l}\text { No published protocol available } \\
\text { All outcomes reported at all time points } \\
\text { Adverse effects of antioxidant supplementation were not reported }\end{array}$ \\
\hline Other bias & Low risk & $\begin{array}{l}\text { Manuscript states: "Subjects maintained their normal food intake and lifestyle } \\
\text { habits, but abstained from strenuous physical activities, and did not take an- } \\
\text { ti-inflammatory drugs during the study period." }\end{array}$ \\
\hline
\end{tabular}

\section{Theodorou 2011}

\begin{tabular}{ll}
\hline Methods & Randomised controlled trial (parallel design) \\
\hline Participants & Setting: laboratory; Greece \\
$\mathrm{n}=28$ healthy, recreationally trained men \\
Mean age placebo group 25.6 (SEM 1.2) \\
Mean age vitamin C group 26.2 (SEM 1.5) \\
Inclusion/exclusion criteria \\
Men were recruited after advertising the study in the local media
\end{tabular}

Interventions

\section{Intervention}

1g of vitamin C and $400 \mathrm{IU}$ vitamin $\mathrm{E}$

\section{Placebo}

Lactose

\section{Duration}

11 weeks

\section{Outcomes}

\section{PRIMARY}

Delayed onset muscle soreness was assessed using a squat using body weight with a 0 to 10 scale where 0 is "normal" and 10 is "very sore" 
Theodorou 2011 (Continued)

\section{SECONDARY}

Range of motion

Isometric peak torque using an isokinetic dynamometer. Isometric knee extensor peak torque at 90 degrees knee flexion was measured. The average of the 3 best maximal voluntary contractions with the dominant leg was recorded.

\begin{tabular}{ll}
\hline Exercise type & Knee extensions on an isokinetic dynamometer \\
\hline Sources of funding & None: the authors had no personal or financial conflicts of interest \\
\hline Notes & 1 capsule per day
\end{tabular}

\section{Risk of bias}

\begin{tabular}{lll}
\hline Bias & Authors' judgement & Support for judgement \\
\hline $\begin{array}{l}\text { Random sequence genera- } \\
\text { tion (selection bias) }\end{array}$ & High risk & $\begin{array}{l}\text { Participants were allocated based on age, BMI and maximum isometric torque } \\
\text { into equal groups then a computer generator was used for the assignment into } \\
\text { groups }\end{array}$ \\
\hline $\begin{array}{l}\text { Allocation concealment } \\
\text { (selection bias) }\end{array}$ & Low risk & No details in manuscript \\
& Authors were emailed in 25 May 2016 via email to request this information \\
\hline $\begin{array}{l}\text { Blinding of participants } \\
\begin{array}{l}\text { and personnel (perfor- } \\
\text { mance bias) } \\
\text { All outcomes }\end{array}\end{array}$ & $\begin{array}{l}\text { Author response: "We used an independent person and a sealed opaque enve- } \\
\text { lope for the allocation concealment." }\end{array}$ \\
\hline
\end{tabular}

\begin{tabular}{lll}
\hline $\begin{array}{l}\text { Blinding of outcome as- } \\
\text { sessment (detection bias) } \\
\text { All outcomes }\end{array}$ & Low risk & Double-blind \\
\hline $\begin{array}{l}\text { Incomplete outcome data } \\
\text { (attrition bias) } \\
\text { All outcomes }\end{array}$ & Low risk & All participants completed the study \\
\hline $\begin{array}{l}\text { Selective reporting (re- } \\
\text { porting bias) }\end{array}$ & Unclear risk & Study protocol published (ClinicalTrials.gov: NCT01290458) \\
& $\begin{array}{l}\text { All the outcomes published in the study protocol were measured in the actual } \\
\text { study }\end{array}$ \\
& $\begin{array}{l}\text { All outcomes reported at all time points } \\
\text { However, adverse effects of antioxidant supplementation were not reported }\end{array}$ \\
\hline $\begin{array}{l}\text { Other bias } \\
\text { Unclear risk }\end{array}$ & $\begin{array}{l}\text { Participants were asked to keep food records for } 3 \text { days before testing, howev- } \\
\text { er no details on whether participants were asked to refrain from using other } \\
\text { supplements and anti-inflammatory medication }\end{array}$ \\
\hline
\end{tabular}

\section{Thompson 2001}

Methods Randomised controlled trial (cross-over design)


Thompson 2001 (Continued)

Separated by 14-day washout

Setting: laboratory, UK
$\mathrm{n}=9$ male, habitually active, male university students
Mean age 28.4 (SEM 1.3) years
Inclusion/exclusion criteria
Participants who smoked or took vitamin supplements were excluded from the study

$\begin{array}{ll}\text { Interventions } & \text { Intervention } \\ 1 \text { g of vitamin C } 2 \text { hours before exercise } \\ \text { Placebo } \\ \text { Carbohydrate sports drink } \\ \text { Duration } \\ \text { Supplement consumed on day of test } 2 \text { hours before exercise with a 14-day washout } \\ \text { PRIMARY } \\ \text { Delayed onset muscle soreness at the quadriceps using a 10-point }(1 \text { to } 10 \mathrm{~cm}) \text { visual analogue scale } \\ \text { where } 0 \text { is "not sore" and } 10 \text { is "very very sore" }\end{array}$

\section{SECONDARY}

Isometric flexion and extension

\begin{tabular}{ll} 
Exercise type & $\begin{array}{l}\text { Loughborough Intermittent Shuttle Running Test - } 90 \text { minutes variable intensity running over } 20 \mathrm{~m} \text { dis- } \\
\text { tance }\end{array}$ \\
\hline Sources of funding & The authors acknowledged the financial support of SmithKline Beecham \\
\hline Notes & Supplements were ingested in a drink \\
\hline
\end{tabular}

\section{Risk of bias}

\begin{tabular}{lll}
\hline Bias & Authors' judgement & Support for judgement \\
\hline $\begin{array}{l}\text { Random sequence genera- } \\
\text { tion (selection bias) }\end{array}$ & Low risk & Details not in the manuscript therefore authors were contacted (19 May 2016) \\
& "A third party independent from the investigators generated a randomisation \\
plan and held the sequence for allocation"
\end{tabular}


Thompson 2001 (Continued)
Incomplete outcome data
(attrition bias)
Low risk All participants complete the study

All outcomes

\begin{tabular}{ll}
\hline $\begin{array}{l}\text { Selective reporting (re- } \\
\text { porting bias) }\end{array}$ & High risk \\
& All outcomes reported at all time points \\
& Adverse effects of antioxidant supplementation were not reported
\end{tabular}

\begin{tabular}{ll}
\hline Other bias & Unclear risk \\
& $\begin{array}{l}\text { No detail on whether participants were asked to refrain from using supple- } \\
\text { ments or anti-inflammatory medication }\end{array}$
\end{tabular}

Thompson 2001a

\begin{tabular}{ll}
\hline Methods & Randomised controlled trial (parallel design) \\
\hline Participants & Setting: laboratory; UK \\
$\mathrm{n}=16$ physically active males (8 in the placebo group and 8 in the vitamin C group) \\
Mean age vitamin C group 25 (SEM 2) years \\
Mean age placebo group 23 (SEM 2) years \\
Inclusion/exclusion criteria \\
Participants who had smoked or took vitamin supplements were excluded from the study. All partici- \\
pants regularly took part in a variety of activities but were unfamiliar with the exercise protocol.
\end{tabular}

$\begin{array}{ll}\text { Interventions } & \text { Intervention } \\ & \text { Vitamin C supplementation; } 1 \mathrm{~g} \text { of vitamin } \mathrm{C} \text { on day } 1 \text { followed by } 400 \mathrm{mg} / \text { day divided into } 2 \text { doses for } \\ 12 \text { days } \\ \text { Placebo } \\ \text { Lactose capsules } \\ \text { Duration } \\ 13 \text { days }\end{array}$

Outcomes PRIMARY

Delayed onset muscle soreness at the quadriceps using a 10-point $(0$ to $10 \mathrm{~cm}$ ) visual analogue scale where 0 is "not sore" and 10 is "very very sore"

\section{SECONDARY}

Isometric quadriceps muscle contraction. Muscle function was assessed in the flexors and extensors of both legs on an isokinetic dynamometer (CYBEX model 770, LUMEX, USA).

Exercise type

Loughborough Intermittent Shuttle Running Test - 90 minutes variable intensity running over 20 m distance 
Thompson 2001a (Continued)

Notes $1 \mathrm{~g}$ given in a solution followed by $400 \mathrm{mg} /$ day doses in capsule form

\section{Risk of bias}

Bias Authors' judgement Support for judgement

\section{Random sequence genera- Low risk} tion (selection bias)

Allocation concealment Unclear risk
(selection bias)

Unclear risk

Details not in the manuscript therefore authors were contacted (19 May 2016)

"A third party independent from the investigators generated a randomisation plan and held the sequence for allocation"

Not reported in the manuscript therefore authors were contacted (19 May 2016)

No response received

Blinding of participants Low risk $\quad$ Double-blind
and personnel (perfor-
mance bias)

\begin{tabular}{lll}
\hline $\begin{array}{l}\text { Blinding of outcome as- } \\
\text { sessment (detection bias) } \\
\text { All outcomes }\end{array}$ & Low risk & Double-blind \\
\hline $\begin{array}{l}\text { Incomplete outcome data } \\
\text { (attrition bias) } \\
\text { All outcomes }\end{array}$ & Low risk & All the participants completed the study \\
\hline $\begin{array}{l}\text { Selective reporting (re- } \\
\text { porting bias) }\end{array}$ & High risk & No published protocol available \\
& All outcomes reported at all time points \\
\hline $\begin{array}{l}\text { Other bias } \\
\text { Low risk }\end{array}$ & Adverse effects of antioxidant supplementation were not reported \\
\hline & $\begin{array}{l}\text { Participants who smoked or took vitamin supplements were excluded. No de- } \\
\text { tail on whether participants kept food records or were instructed to refrain } \\
\text { from taking supplements for the duration of the study and no details on avoid- } \\
\text { ing anti-inflammatory medication }\end{array}$
\end{tabular}

Thompson 2003

\begin{tabular}{ll}
\hline Methods & Randomised controlled trial (parallel design) \\
\hline Participants & Setting: laboratory; UK \\
$\mathrm{n}=16$ male university students (8 participants in each group) \\
Mean age vitamin C group 23.6 ( \pm SEM 1.4) years \\
Mean age placebo group 24.3 ( \pm SEM 1.7) years \\
Inclusion/exclusion criteria \\
Participants who smoked or took vitamin supplements were excluded from the investigation. All partic- \\
ipants were habitually active in a variety of sports, although none were familiar with the exercise proto- \\
col used in the present study.
\end{tabular}


Thompson 2003 (Continued)

$\begin{array}{ll}\text { Interventions } & \text { Intervention } \\ & 200 \text { mg vitamin C } \\ & \text { Placebo } \\ & \text { Carbohydrate sports drink } \\ & \text { Duration } \\ & 3 \text { days }\end{array}$

\begin{tabular}{|c|c|}
\hline \multirow[t]{4}{*}{ Outcomes } & PRIMARY \\
\hline & $\begin{array}{l}\text { Delayed onset muscle soreness was rated on a 10-point scale ranging from } 1 \text { "not sore" to } 10 \text { "very very } \\
\text { sore." Soreness was assessed whilst the participants actively contracted the quadriceps }\end{array}$ \\
\hline & SECONDARY \\
\hline & $\begin{array}{l}\text { Isometric quadriceps muscle contraction. Muscle function was assessed in the flexors and extensors of } \\
\text { both legs on an isokinetic dynamometer (CYBEX model 770, LUMEX, USA). }\end{array}$ \\
\hline
\end{tabular}

\begin{tabular}{ll}
\hline Exercise type & $\begin{array}{l}\text { Loughborough Intermittent Shuttle Running Test - } 90 \text { minutes variable intensity running over } 20 \text { m dis- } \\
\text { tance }\end{array}$ \\
\hline Sources of funding & The authors acknowledged the financial support of SmithKline Beecham, UK \\
\hline Notes & Supplements were ingested in a drink daily \\
\hline
\end{tabular}

\section{Risk of bias}

\begin{tabular}{|c|c|c|}
\hline Bias & Authors' judgement & Support for judgement \\
\hline $\begin{array}{l}\text { Random sequence genera- } \\
\text { tion (selection bias) }\end{array}$ & Low risk & $\begin{array}{l}\text { Details not in the manuscript therefore authors were contacted (19 May 2016) } \\
\text { "A third party independent from the investigators generated a randomisation } \\
\text { plan and held the sequence for allocation" }\end{array}$ \\
\hline $\begin{array}{l}\text { Allocation concealment } \\
\text { (selection bias) }\end{array}$ & Unclear risk & $\begin{array}{l}\text { Not reported in the manuscript therefore authors were contacted (19 May } \\
\text { 2016). } \\
\text { No response received }\end{array}$ \\
\hline $\begin{array}{l}\text { Blinding of participants } \\
\text { and personnel (perfor- } \\
\text { mance bias) } \\
\text { All outcomes }\end{array}$ & Low risk & Double-blind \\
\hline
\end{tabular}

\begin{tabular}{|c|c|c|}
\hline $\begin{array}{l}\text { Blinding of outcome as- } \\
\text { sessment (detection bias) } \\
\text { All outcomes }\end{array}$ & Low risk & Double-blind \\
\hline $\begin{array}{l}\text { Incomplete outcome data } \\
\text { (attrition bias) } \\
\text { All outcomes }\end{array}$ & Low risk & All the participants completed the study \\
\hline $\begin{array}{l}\text { Selective reporting (re- } \\
\text { porting bias) }\end{array}$ & High risk & $\begin{array}{l}\text { No published protocol } \\
\text { Data not reported for all outcomes } \\
\text { Adverse effects of antioxidant supplementation were not reported }\end{array}$ \\
\hline
\end{tabular}


Thompson 2003 (Continued)

Other bias Low risk Participants were asked to record food frequency and to refrain from using anti-inflammatory drugs or other supplements that could reduce soreness

Thompson 2004

\begin{tabular}{ll}
\hline Methods & Randomised controlled trial (parallel design) \\
\hline Participants & Setting: laboratory; UK \\
$\mathrm{n}=14$ male university students \\
Mean age vitamin C group 25.3 (SEM 1.4) years \\
Mean age placebo group 22.6 (SEM 1.7) years \\
Inclusion/exclusion criteria \\
Participants who smoked or took vitamin supplements were excluded from the study. All participants \\
regularly took part in a variety of activities but were unfamiliar with the exercise protocol used in the \\
study.
\end{tabular}

\begin{tabular}{ll}
\hline Interventions & Intervention \\
& 200 mg vitamin C \\
& Placebo \\
& 200 mg lactose \\
Duration & 14 days \\
\hline
\end{tabular}

Outcomes PRIMARY

Muscle soreness was assessed in the quadriceps using a 0 to $100 \mathrm{~mm}$ scale where 0 is "normal" and 100 is "very very sore". In order to activate the sensation of soreness, participants assessed soreness whilst actively contracting the leg extensors against resistance equivalent to $75 \%$ of each individual's one repetition maximum.

\begin{tabular}{|c|c|c|}
\hline Exercise type & \multicolumn{2}{|c|}{30 minutes downhill running at $-18 \%$ gradient } \\
\hline Sources of funding & \multicolumn{2}{|l|}{ None } \\
\hline \multirow[t]{2}{*}{ Notes } & \multicolumn{2}{|c|}{ No details on how many capsules were consumed per day } \\
\hline & \multicolumn{2}{|c|}{$\begin{array}{l}\text { Authors were contacted to request raw data for delayed onset muscle soreness on } 3 \text { November } 2013 \\
\text { and responded on } 4 \text { November } 2013\end{array}$} \\
\hline \multicolumn{3}{|l|}{ Risk of bias } \\
\hline Bias & Authors' judgement & Support for judgement \\
\hline \multirow{2}{*}{$\begin{array}{l}\text { Random sequence genera- } \\
\text { tion (selection bias) }\end{array}$} & \multirow[t]{2}{*}{ Low risk } & Details not in the manuscript therefore authors were contacted (19 May 2016) \\
\hline & & $\begin{array}{l}\text { "A third party independent from the investigators generated a randomisation } \\
\text { plan and held the sequence for allocation" }\end{array}$ \\
\hline
\end{tabular}


Thompson 2004 (Continued)

Allocation concealment $\quad$ Unclear risk $\quad$ Not reported in manuscript therefore authors were contacted (19 May 2016)
(selection bias)

No response received

Blinding of participants Low risk Double-blind

and personnel (perfor-

mance bias)

All outcomes

\begin{tabular}{ll}
\hline Blinding of outcome as- & Low risk \\
sessment (detection bias) & \\
All outcomes & \\
\hline
\end{tabular}

Incomplete outcome data Low risk All the participants completed the study
(attrition bias)

All outcomes

\begin{tabular}{lll}
\hline $\begin{array}{l}\text { Selective reporting (re- } \\
\text { porting bias) }\end{array}$ & High risk & No published protocol available \\
& All outcomes reported at all time points \\
& Adverse effects of antioxidant supplementation were not reported \\
\hline Other bias & Unclear risk & $\begin{array}{l}\text { Vitamin C intake through diet was screened through weighed food records } \\
\text { No detail on whether participants were asked to refrain from using supple- } \\
\text { ments or anti-inflammatory medication }\end{array}$ \\
\hline
\end{tabular}

Trombold 2010

\begin{tabular}{|c|c|}
\hline Methods & $\begin{array}{l}\text { Randomised controlled trial (cross-over design) } \\
\text { Separated by a 14-day washout }\end{array}$ \\
\hline Participants & $\begin{array}{l}\text { Setting: laboratory; USA } \\
\mathrm{n}=16 \text { healthy, non-smoking, recreationally active males, mean age } 24 \text { (SD 1.4) years } \\
\text { Inclusion/exclusion criteria } \\
\text { Participants were disqualified if they had participated in resistance exercise training of any kind in the } \\
\text { previous } 3 \text { months, were currently participating in a formalised endurance training programme or had } \\
\text { previous history of upper body injury. Other exclusion criteria included a recent weight change of more } \\
\text { than } 5 \mathrm{~kg} \text {, history of hypertension, use of anti-inflammatory drugs, angiotensin converting enzyme in- } \\
\text { hibitors lipid-lowering medications or selective serotonin reuptake inhibitors. }\end{array}$ \\
\hline
\end{tabular}

\section{Intervention}

Pomegranate juice POM Wonderful $500 \mathrm{~mL}$ twice daily, $650 \mathrm{mg}$ polyphenols, consisting of $95.5 \%$ ellagitannins, $3.5 \%$ ellagic acid and $1 \%$ anthocyanins

\section{Placebo}

$35 \mathrm{~g}$ carbohydrate + colouring and flavouring to match the pomegranate juice

\section{Duration}

2 doses per day separated by 12 hours; 2 x 9-day treatment periods separated by a 14-day washout 
Trombold 2010 (Continued)

Outcomes

\section{PRIMARY}

Delayed onset muscle soreness of the elbow flexor muscles was determined before each isometric strength test using a 0 to 10 visual analogue scale where 0 is "no soreness" and 10 is "unbearable soreness". The rating was obtained before the measurement of strength while performing unloaded elbow flexion of the tested arm.

\section{SECONDARY}

Maximal isometric strength in elbow extensors was performed on a modified preacher curl bench. Force was recorded using a load cell (LC101-500; Omega Engineering, Stamford, CT) secured to the ground using a galvanised steel cable and a strap secured to the waist of the participant. The participant performed 4 trials, 2 at both 150 degrees and 135 degrees of complete elbow extension, with a 180 -second rest in between each trial. Strength was reported as the average of the peak values at angles 150 and 135 degrees of elbow flexion.

\begin{tabular}{ll}
\hline Exercise type & 2 sets of 20 maximal eccentric elbow flexion exercises \\
\hline Sources of funding & The study was supported by a grant from POM Wonderful, L.L.C. \\
\hline Notes & $\begin{array}{l}2 \text { doses of } 480 \mathrm{~mL} \text { of the drink consumed daily separated by } 12 \text { hours. Participants were reminded to } \\
\text { take the products verbally and via email communication to consume the experimental supplements at } \\
\text { the required times }\end{array}$ \\
& $\begin{array}{l}\text { Authors were contacted to request raw data for delayed onset muscle soreness and maximal voluntary } \\
\text { isometric contraction on } 2 \text { November } 2013 \text { and responded on } 5 \text { December } 2013\end{array}$ \\
\end{tabular}

\section{Risk of bias}

\begin{tabular}{|c|c|c|}
\hline Bias & Authors' judgement & Support for judgement \\
\hline $\begin{array}{l}\text { Random sequence genera- } \\
\text { tion (selection bias) }\end{array}$ & Unclear risk & $\begin{array}{l}\text { No details in manuscript } \\
\text { Authors were contacted on } 26 \text { May } 2016 \text { via email with no response }\end{array}$ \\
\hline $\begin{array}{l}\text { Allocation concealment } \\
\text { (selection bias) }\end{array}$ & Unclear risk & $\begin{array}{l}\text { No details in manuscript } \\
\text { Authors were contacted on } 26 \text { May } 2016 \text { via email with no response }\end{array}$ \\
\hline $\begin{array}{l}\text { Blinding of participants } \\
\text { and personnel (perfor- } \\
\text { mance bias) } \\
\text { All outcomes }\end{array}$ & Low risk & Double-blind \\
\hline $\begin{array}{l}\text { Blinding of outcome as- } \\
\text { sessment (detection bias) } \\
\text { All outcomes }\end{array}$ & Low risk & Double-blind \\
\hline $\begin{array}{l}\text { Incomplete outcome data } \\
\text { (attrition bias) } \\
\text { All outcomes }\end{array}$ & Low risk & All participants completed the study \\
\hline $\begin{array}{l}\text { Selective reporting (re- } \\
\text { porting bias) }\end{array}$ & High risk & $\begin{array}{l}\text { No published protocol available } \\
\text { All outcomes reported at all time points } \\
\text { Adverse effects of antioxidant supplementation were not reported }\end{array}$ \\
\hline Other bias & Low risk & $\begin{array}{l}\text { Participants were asked to refrain from using anti-inflammatory drugs or other } \\
\text { supplements that could reduce soreness }\end{array}$ \\
\hline
\end{tabular}


Trombold 2011

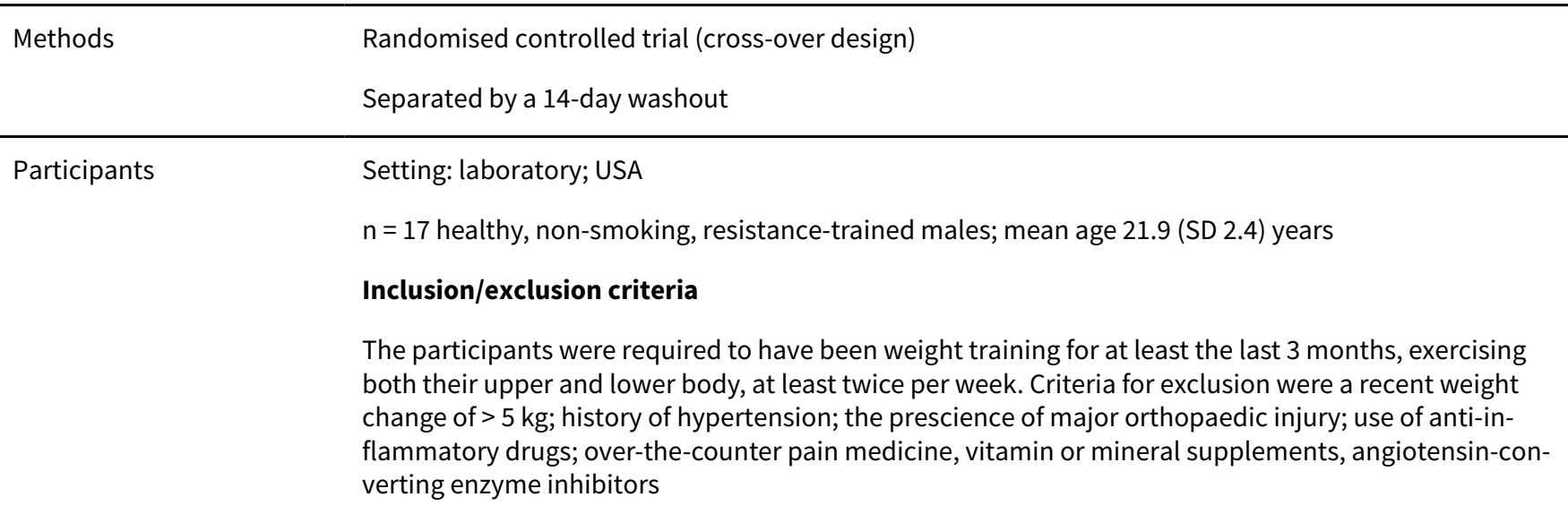

Interventions

Intervention

Pomegranate juice $250 \mathrm{~mL}$ POM Wonderful (LA, USA). Each bottle contained approximately $1979 \mathrm{mg} / \mathrm{L}$ of tannins, $384 \mathrm{mg} / \mathrm{L}$ anthocyanins and $121 \mathrm{mg} / \mathrm{L}$ of ellagic derivatives.

\section{Placebo}

$35 \mathrm{~g}$ carbohydrate + colouring and flavouring to match the pomegranate juice

\section{Duration}

44 days; 15 days of supplementation with a 14-day washout

Outcomes PRIMARY

Delayed onset muscle soreness of the elbow flexor and knee extensor muscles was determined before each isometric strength test using a 0 - to 10 -point visual analogue scale where 0 is "no soreness" and 10 is "unbearable soreness". The rating was obtained before the measurement of strength while performing unloaded elbow flexion and knee extension on the tested arm and leg.

\section{SECONDARY}

Maximal isometric strength in elbows and knee extensors was performed on a modified preacher curl bench and modified knee extension machine respectively. The participant performed 4 trials at both 30 and 45 degrees above elbow extension and 45 and 90 degree below knee extension with 180 -second rest in between each trial. Strength for both tests was reported as the average peak value of each joint angle.

\begin{tabular}{ll}
\hline Exercise type & 3 sets of 20 maximal eccentric elbow extensions on an isokinetic dynamometer \\
\hline Sources of funding & The study was funded by POM Wonderful, L.L.C. \\
\hline Notes & $\begin{array}{l}\text { Supplement taken as } 250 \mathrm{~mL} \text { bottle twice daily separated by } 12 \text { hours. Participants were reminded to } \\
\text { take the products verbally and via email communication to consume the experimental supplements at } \\
\text { the required times }\end{array}$ \\
$\begin{array}{l}\text { Authors were contacted to request raw data for delayed onset muscle soreness and maximal voluntary } \\
\text { isometric contraction on } 2 \text { November } 2013 \text { and responded on } 5 \text { December } 2013\end{array}$ \\
\hline
\end{tabular}

\section{Risk of bias}


Trombold 2011 (Continued)
Random sequence genera- Unclear risk
No details in manuscript
tion (selection bias)
Authors were contacted on 26 May 2016 via email with no response

\begin{tabular}{lll}
\hline $\begin{array}{l}\text { Allocation concealment } \\
\text { (selection bias) }\end{array}$ & Unclear risk & $\begin{array}{l}\text { No details in manuscript } \\
\text { Authors were contacted on } 26 \text { May 2016 via email with no response }\end{array}$ \\
\hline $\begin{array}{l}\text { Blinding of participants } \\
\begin{array}{l}\text { and personnel (perfor- } \\
\text { mance bias) }\end{array}\end{array}$ & Low risk & Double-blind \\
All outcomes &
\end{tabular}

\begin{tabular}{lll}
\hline $\begin{array}{l}\text { Blinding of outcome as- } \\
\text { sessment (detection bias) } \\
\text { All outcomes }\end{array}$ & Low risk & Double-blind \\
\hline $\begin{array}{l}\text { Incomplete outcome data } \\
\text { (attrition bias) } \\
\text { All outcomes }\end{array}$ & Low risk & All participants completed the study \\
\hline $\begin{array}{l}\text { Selective reporting (re- } \\
\text { porting bias) }\end{array}$ & High risk & No published protocol available \\
& All outcomes reported at all time points \\
\hline Other bias & Adverse effects of antioxidant supplementation were not reported \\
\hline
\end{tabular}

BMI: body mass index

EGCG: epigallocatechin gallate

IU: international units

NAC: N-acetyl-cysteine

NSAID: non-steroidal anti-inflammatory drug

PPT: pressure pain threshold

RM: repetition maximum

SD: standard deviation

SE: standard error

SEM: standard error of the mean

VAS: visual analogue scale

Characteristics of excluded studies [ordered by study ID]

Study Reason for exclusion

Aalizadeh 2016

Although delayed onset muscle soreness is in the title, it was not measured

Authors were contacted on 4 February 2017 to confirm pared to a placebo

\begin{tabular}{ll} 
Ammar 2016 & Non-randomised study design \\
\hline Arent 2010a & Delayed onset muscle soreness not measured
\end{tabular}




\begin{tabular}{|c|c|}
\hline Study & Reason for exclusion \\
\hline Askari 2012 & Delayed onset muscle soreness not measured \\
\hline Askari 2013 & Delayed onset muscle soreness not measured \\
\hline Babaei 2009 & Delayed onset muscle soreness not measured \\
\hline Bell 2014 & Delayed onset muscle soreness not measured \\
\hline Bloomer 2006 & Delayed onset muscle soreness not measured \\
\hline \multirow[t]{2}{*}{ Bowtell 2011} & Delayed onset muscle soreness not measured \\
\hline & Tenderness was measured using a handheld algometer \\
\hline Braakhuis 2014 & Delayed onset muscle soreness not measured \\
\hline Bunpo 2016 & Delayed onset muscle soreness not measured \\
\hline Carvalho-Peixoto 2015 & Delayed onset muscle soreness not measured \\
\hline Cavas 2004 & Delayed onset muscle soreness not measured \\
\hline Childs 2001a & Delayed onset muscle soreness not measured \\
\hline Clifford 2017 & Delayed onset muscle soreness not measured \\
\hline Daneshvar 2013 & Delayed onset muscle soreness not measured \\
\hline Dawson 2002 & Delayed onset muscle soreness not measured. \\
\hline Eichenberger 2010 & Delayed onset muscle soreness not measured \\
\hline Fuster-Munoz 2016 & Delayed onset muscle soreness not measured \\
\hline Gaeini 2006 & Delayed onset muscle soreness not measured \\
\hline Gomez-Cabrera 2003 & Delayed onset muscle soreness not measured \\
\hline \multirow[t]{2}{*}{ Hillman 2017} & Tart cherry juice with whey protein \\
\hline & No tart cherry juice only group \\
\hline Itoh 2000 & Delayed onset muscle soreness not measured. \\
\hline Jakeman 1993 & Delayed onset muscle soreness not measured \\
\hline Jowko 2011 & Delayed onset muscle soreness not measured \\
\hline Jowko 2012 & Delayed onset muscle soreness not measured \\
\hline Jowko 2015 & Delayed onset muscle soreness not measured \\
\hline Kaikkonen 1998 & Delayed onset muscle soreness not measured \\
\hline Keong 2006 & Delayed onset muscle soreness not measured \\
\hline
\end{tabular}




\begin{tabular}{|c|c|}
\hline Study & Reason for exclusion \\
\hline Kim 2013 & Delayed onset muscle soreness not measured \\
\hline Kingsley 2006 & Supplementation used was not classed as an antioxidant \\
\hline Kizaki 2015 & Delayed onset muscle soreness not measured \\
\hline Kon 2008 & Delayed onset muscle soreness not measured \\
\hline Kraemer 2007 & Delayed onset muscle soreness not measured \\
\hline Lafay 2009 & Delayed onset muscle soreness not measured \\
\hline Lamprecht 2009a & Delayed onset muscle soreness not measured \\
\hline Leelarungrayub 2011 & Delayed onset muscle soreness not measured \\
\hline Lenn 2002 & $\begin{array}{l}\text { Antioxidant supplement was mixed with fish oils and antioxidant supplement alone not investigat- } \\
\text { ed }\end{array}$ \\
\hline \multirow[t]{2}{*}{ Levers 2015} & Delayed onset muscle soreness not measured \\
\hline & Tenderness was measured using a handheld algometer \\
\hline \multirow[t]{2}{*}{ Levers 2016} & Delayed onset muscle soreness not measured \\
\hline & Tenderness was measured using a handheld algometer \\
\hline Louis 2010 & Delayed onset muscle soreness not measured \\
\hline Margaritis 2003 & Delayed onset muscle soreness not measured \\
\hline Mastaloudis 2006 & Delayed onset muscle soreness not measured \\
\hline Matsumoto 2005 & Delayed onset muscle soreness not measured \\
\hline McKenna 2006 & Delayed onset muscle soreness not measured \\
\hline Meamarbashi 2014 & Delayed onset muscle soreness not measured \\
\hline Meamarbashi 2016 & Delayed onset muscle soreness not measured \\
\hline Medved 2004 & Delayed onset muscle soreness not measured \\
\hline Meydani 1993 & Delayed onset muscle soreness not measured \\
\hline Mizuno 1997 & Delayed onset muscle soreness not measured \\
\hline Morillas-Ruiz 2005 & Delayed onset muscle soreness not measured \\
\hline NCT01555775 & $\begin{array}{l}\text { Antioxidant supplement compared to another dietary supplement (protein-carbohydrate supple- } \\
\text { ment) }\end{array}$ \\
\hline Nieman 2010 & Delayed onset muscle soreness not measured \\
\hline Olesen 2013 & Delayed onset muscle soreness not measured \\
\hline
\end{tabular}




\begin{tabular}{|c|c|}
\hline Study & Reason for exclusion \\
\hline Ostman 2012 & Delayed onset muscle soreness not measured \\
\hline Panza 2016 & Delayed onset muscle soreness not measured \\
\hline Passerieux 2015 & Delayed onset muscle soreness not measured \\
\hline Paulsen 2014a & Delayed onset muscle soreness not measured \\
\hline Petersen 2001 & Delayed onset muscle soreness not measured \\
\hline Pilaczynska-Szczesniak 2005 & Delayed onset muscle soreness not measured \\
\hline \multirow[t]{2}{*}{ Roengrit 2014} & Delayed onset muscle soreness not measured \\
\hline & Tenderness was measured using a handheld algometer \\
\hline \multirow[t]{2}{*}{ Roengrit 2015} & Delayed onset muscle soreness not measured \\
\hline & Tenderness was measured using a handheld algometer \\
\hline \multirow[t]{2}{*}{ Romano-Ely 2006} & Intervention was antioxidants and protein versus carbohydrate only \\
\hline & Protein can reduce muscle soreness \\
\hline Sacheck 2003 & Delayed onset muscle soreness not measured \\
\hline Sanchis-Gomar 2015 & Delayed onset muscle soreness not measured \\
\hline Santos 2016 & Delayed onset muscle soreness not measured \\
\hline Skarpanska-Stejnborn 2008 & Delayed onset muscle soreness not measured. \\
\hline Suzuki 2015 & Delayed onset muscle soreness not measured \\
\hline Taub 2015 & Delayed onset muscle soreness not measured \\
\hline Teixeira 2009a & Delayed onset muscle soreness not measured \\
\hline Toscano 2015 & Delayed onset muscle soreness not measured \\
\hline Yarahmadi 2014 & Delayed onset muscle soreness not measured \\
\hline Yarahmadi 2014a & Delayed onset muscle soreness not measured \\
\hline Yfanti 2010 & Delayed onset muscle soreness not measured \\
\hline Yfanti 2012 & Delayed onset muscle soreness not measured \\
\hline Zoppi 2006 & Delayed onset muscle soreness not measured \\
\hline
\end{tabular}

\section{Characteristics of ongoing studies [ordered by study ID]}


NCT02281981

\begin{tabular}{ll}
\hline Trial name or title & $\begin{array}{l}\text { The effects of repeated bouts of downhill running and curcumin supplementation on arterial stiff- } \\
\text { ness during recovery }\end{array}$ \\
\hline Methods & Randomised controlled trial (double-blind) \\
\hline Participants & Setting: laboratory; USA \\
& Inclusion/exclusion criteria \\
& $\begin{array}{l}\text { The participants were required to have been weight training for at least the last } 3 \text { months, exercis- } \\
\text { ing both their upper and lower body, at least twice per week. Criteria for exclusion were a recent } \\
\text { weight change of }>5 \text { kg; history of hypertension; the prescience of major orthopaedic injury; use } \\
\text { of anti-inflammatory drugs; over-the-counter pain medicine, vitamin or mineral supplements, an- } \\
\text { giotensin-converting enzyme inhibitors. }\end{array}$ \\
\hline
\end{tabular}

Interventions Experimental

Curcumin supplement $200 \mathrm{mg}$, curcuminoids, 7 days of supplementation in capsular form

\section{Placebo}

Sucrose, capsular

\begin{tabular}{ll}
\hline Outcomes & PRIMARY \\
& $\begin{array}{l}\text { Delayed onset muscle soreness (every } 24 \text { hours up to } 72 \text { hours post baseline); subjective analogue } \\
\text { scale } \\
\text { SECONDARY } \\
\text { N/A }\end{array}$ \\
\hline Starting date & November 2014 \\
\hline Contact information & Dr Jamie Burr, Assistant Professor, University of Prince Edward Island \\
\hline Notes & ClinicalTrials.gov identifier: NCT02281981 \\
\hline
\end{tabular}

N/A: not applicable

SD: standard deviation

\section{DATA AND ANALYSES}

Comparison 1. Antioxidant supplementation vs. placebo for delayed onset muscle soreness (all studies)

\begin{tabular}{lllll}
\hline Outcome or subgroup title & No. of studies & $\begin{array}{l}\text { No. of partici- } \\
\text { pants }\end{array}$ & Statistical method & Effect size \\
\hline $\begin{array}{l}1 \text { Muscle soreness up to 6 hours; } \\
\text { random-effects model }\end{array}$ & 21 & 525 & $\begin{array}{l}\text { Std. Mean Difference (IV, Random, } \\
95 \% \text { Cl) }\end{array}$ & $-0.30[-0.56,-0.04]$ \\
\hline $\begin{array}{l}2 \text { Muscle soreness at 24 hours; } \\
\text { random-effects model }\end{array}$ & 41 & 936 & $\begin{array}{l}\text { Std. Mean Difference (IV, Random, } \\
95 \% \text { Cl) }\end{array}$ & $-0.13[-0.27,0.00]$ \\
\hline
\end{tabular}




\begin{tabular}{|c|c|c|c|c|}
\hline Outcome or subgroup title & No. of studies & $\begin{array}{l}\text { No. of partici- } \\
\text { pants }\end{array}$ & Statistical method & Effect size \\
\hline $\begin{array}{l}3 \text { Muscle soreness at } 48 \text { hours; } \\
\text { random-effects model }\end{array}$ & 45 & 1047 & $\begin{array}{l}\text { Std. Mean Difference (IV, Random, } \\
95 \% \mathrm{CI} \text { ) }\end{array}$ & $-0.24[-0.42,-0.07]$ \\
\hline $\begin{array}{l}4 \text { Muscle soreness at } 72 \text { hours; } \\
\text { random-effects model }\end{array}$ & 28 & 657 & $\begin{array}{l}\text { Std. Mean Difference (IV, Random, } \\
95 \% \mathrm{CI} \text { ) }\end{array}$ & $-0.19[-0.38,-0.00]$ \\
\hline $\begin{array}{l}5 \text { Muscle soreness at } 96 \text { hours; } \\
\text { random-effects model }\end{array}$ & 17 & 436 & $\begin{array}{l}\text { Std. Mean Difference (IV, Random, } \\
95 \% \mathrm{CI} \text { ) }\end{array}$ & $-0.05[-0.29,0.19]$ \\
\hline $\begin{array}{l}6 \text { Muscle soreness (follow-ups: } \\
120,144 \text { and } 168 \text { hours); ran- } \\
\text { dom-effects model }\end{array}$ & 7 & & $\begin{array}{l}\text { Std. Mean Difference (IV, Random, } \\
95 \% \mathrm{CI} \text { ) }\end{array}$ & Subtotals only \\
\hline 6.1 at 120 hours & 4 & 128 & $\begin{array}{l}\text { Std. Mean Difference (IV, Random, } \\
95 \% \mathrm{Cl} \text { ) }\end{array}$ & $0.21[-0.26,0.69]$ \\
\hline 6.2 at 144 hours & 1 & 20 & $\begin{array}{l}\text { Std. Mean Difference (IV, Random, } \\
95 \% \mathrm{CI} \text { ) }\end{array}$ & $-0.23[-1.11,0.65]$ \\
\hline 6.3 at 168 hours & 4 & 80 & $\begin{array}{l}\text { Std. Mean Difference (IV, Random, } \\
95 \% \mathrm{CI} \text { ) }\end{array}$ & $-0.04[-0.48,0.41]$ \\
\hline $\begin{array}{l}7 \text { Muscle soreness up to } 6 \text { hours } \\
\text { - all at same scale ( } 0 \text { to } 10 \text {; worst } \\
\text { pain) }\end{array}$ & 21 & 525 & $\begin{array}{l}\text { Mean Difference (IV, Random, } \\
95 \% \mathrm{CI} \text { ) }\end{array}$ & $-0.52[-0.95,-0.08]$ \\
\hline $\begin{array}{l}8 \text { Muscle soreness at } 24 \text { hours - } \\
\text { all at same scale ( } 0 \text { to } 10 \text {; worst } \\
\text { pain) }\end{array}$ & 41 & 936 & $\begin{array}{l}\text { Mean Difference (IV, Random, } \\
95 \% \mathrm{CI} \text { ) }\end{array}$ & $-0.17[-0.42,0.07]$ \\
\hline $\begin{array}{l}9 \text { Muscle soreness at } 48 \text { hours - } \\
\text { all at same scale ( } 0 \text { to } 10 \text {; worst } \\
\text { pain) }\end{array}$ & 45 & 1047 & $\begin{array}{l}\text { Mean Difference (IV, Random, } \\
95 \% \mathrm{CI} \text { ) }\end{array}$ & $-0.41[-0.69,-0.12]$ \\
\hline $\begin{array}{l}10 \text { Muscle soreness at } 72 \text { hours - } \\
\text { all at same scale ( } 0 \text { to } 10 \text {; worst } \\
\text { pain) }\end{array}$ & 28 & 657 & $\begin{array}{l}\text { Mean Difference (IV, Random, } \\
95 \% \mathrm{CI} \text { ) }\end{array}$ & $-0.29[-0.59,0.02]$ \\
\hline $\begin{array}{l}11 \text { Muscle soreness at } 96 \text { hours - } \\
\text { all at same scale ( } 0 \text { to } 10 \text {; worst } \\
\text { pain) }\end{array}$ & 17 & 436 & $\begin{array}{l}\text { Mean Difference (IV, Random, } \\
95 \% \mathrm{CI} \text { ) }\end{array}$ & $-0.03[-0.43,0.37]$ \\
\hline $\begin{array}{l}12 \text { Muscle soreness at } 24 \text { hours. } \\
\text { Subgroup analysis by type of ex- } \\
\text { ercise (whole body aerobic vs. } \\
\text { mechanically induced) }\end{array}$ & 41 & 936 & $\begin{array}{l}\text { Std. Mean Difference (IV, Random, } \\
95 \% \mathrm{CI} \text { ) }\end{array}$ & $-0.13[-0.27,0.00]$ \\
\hline $\begin{array}{l}12.1 \text { Whole body aerobic exer- } \\
\text { cise }\end{array}$ & 17 & 338 & $\begin{array}{l}\text { Std. Mean Difference (IV, Random, } \\
95 \% \mathrm{CI} \text { ) }\end{array}$ & $-0.07[-0.33,0.18]$ \\
\hline 12.2 Mechanically induced & 24 & 598 & $\begin{array}{l}\text { Std. Mean Difference (IV, Random, } \\
95 \% \mathrm{Cl})\end{array}$ & $-0.18[-0.34,-0.01]$ \\
\hline $\begin{array}{l}13 \text { Muscle soreness at } 48 \text { hours. } \\
\text { Subgroup analysis by type of ex- }\end{array}$ & 45 & 1047 & $\begin{array}{l}\text { Std. Mean Difference (IV, Random, } \\
95 \% \mathrm{Cl} \text { ) }\end{array}$ & $-0.24[-0.42,-0.07]$ \\
\hline
\end{tabular}




\begin{tabular}{|c|c|c|c|c|}
\hline Outcome or subgroup title & No. of studies & $\begin{array}{l}\text { No. of partici- } \\
\text { pants }\end{array}$ & Statistical method & Effect size \\
\hline \multicolumn{5}{|l|}{$\begin{array}{l}\text { ercise (whole body aerobic vs. } \\
\text { mechanically induced) }\end{array}$} \\
\hline $\begin{array}{l}13.1 \text { Whole body aerobic exer- } \\
\text { cise }\end{array}$ & 17 & 349 & $\begin{array}{l}\text { Std. Mean Difference (IV, Random, } \\
95 \% \mathrm{CI})\end{array}$ & $-0.12[-0.47,0.23]$ \\
\hline 13.2 Mechanically induced & 28 & 698 & $\begin{array}{l}\text { Std. Mean Difference (IV, Random, } \\
95 \% \mathrm{Cl})\end{array}$ & $-0.31[-0.50,-0.12]$ \\
\hline $\begin{array}{l}14 \text { Muscle soreness at } 24 \text { hours. } \\
\text { Subgroup analysis by funding } \\
\text { sources (funded by food com- } \\
\text { pany or provider of antioxidant } \\
\text { supplements vs. not funded by } \\
\text { food company or provider of an- } \\
\text { tioxidant supplements) }\end{array}$ & 40 & 920 & $\begin{array}{l}\text { Std. Mean Difference (IV, Fixed, } \\
95 \% \mathrm{Cl} \text { ) }\end{array}$ & $-0.13[-0.26,0.01]$ \\
\hline 14.1 Company funding & 17 & 427 & $\begin{array}{l}\text { Std. Mean Difference (IV, Fixed, } \\
95 \% \mathrm{CI} \text { ) }\end{array}$ & $-0.11[-0.31,0.08]$ \\
\hline 14.2 Other funding & 23 & 493 & $\begin{array}{l}\text { Std. Mean Difference (IV, Fixed, } \\
95 \% \mathrm{Cl} \text { ) }\end{array}$ & $-0.14[-0.32,0.05]$ \\
\hline $\begin{array}{l}15 \text { Muscle soreness at } 48 \text { hours. } \\
\text { Subgroup analysis by funding } \\
\text { sources (funded by food com- } \\
\text { pany or provider of antioxidant } \\
\text { supplements vs. not funded by } \\
\text { food company or provider of an- } \\
\text { tioxidant supplements) }\end{array}$ & 44 & 1031 & $\begin{array}{l}\text { Std. Mean Difference (IV, Fixed, } \\
95 \% \mathrm{CI})\end{array}$ & $-0.21[-0.34,-0.09]$ \\
\hline 15.1 Company funding & 18 & 443 & $\begin{array}{l}\text { Std. Mean Difference (IV, Fixed, } \\
95 \% \mathrm{CI})\end{array}$ & $-0.19[-0.38,0.00]$ \\
\hline 15.2 Other funding & 26 & 588 & $\begin{array}{l}\text { Std. Mean Difference (IV, Fixed, } \\
95 \% \mathrm{Cl})\end{array}$ & $-0.23[-0.40,-0.06]$ \\
\hline $\begin{array}{l}16 \text { Muscle tenderness measured } \\
\text { in Newtons (all follow-up times) }\end{array}$ & 2 & & $\begin{array}{l}\text { Mean Difference (IV, Fixed, 95\% } \\
\mathrm{CI})\end{array}$ & Subtotals only \\
\hline 16.1 at 24 hours & 2 & 52 & $\begin{array}{l}\text { Mean Difference (IV, Fixed, 95\% } \\
\mathrm{CI})\end{array}$ & $-1.60[-7.64,4.45]$ \\
\hline 16.2 at 48 hours & 2 & 52 & $\begin{array}{l}\text { Mean Difference (IV, Fixed, 95\% } \\
\mathrm{CI})\end{array}$ & $-2.14[-9.48,5.19]$ \\
\hline 16.3 at 72 hours & 2 & 52 & $\begin{array}{l}\text { Mean Difference (IV, Fixed, 95\% } \\
\mathrm{CI})\end{array}$ & $-0.34[-6.55,5.86]$ \\
\hline 16.4 at 96 hours & 2 & 52 & $\begin{array}{l}\text { Mean Difference (IV, Fixed, 95\% } \\
\mathrm{CI})\end{array}$ & $-2.32[-9.62,4.99]$ \\
\hline $\begin{array}{l}17 \text { Muscle tenderness measured } \\
\text { in } \mathrm{kg} \text { (all follow-up times) }\end{array}$ & 2 & & $\begin{array}{l}\text { Mean Difference (IV, Fixed, 95\% } \\
\mathrm{CI} \text { ) }\end{array}$ & Subtotals only \\
\hline
\end{tabular}




\begin{tabular}{|c|c|c|c|c|}
\hline Outcome or subgroup title & No. of studies & $\begin{array}{l}\text { No. of partici- } \\
\text { pants }\end{array}$ & Statistical method & Effect size \\
\hline 17.1 Up to 6 hours & 1 & 20 & $\begin{array}{l}\text { Mean Difference (IV, Fixed, 95\% } \\
\mathrm{CI})\end{array}$ & $-0.61[-14.10,12.88]$ \\
\hline 17.2 at 24 hours & 2 & 36 & $\begin{array}{l}\text { Mean Difference (IV, Fixed, 95\% } \\
\mathrm{Cl})\end{array}$ & $0.53[-0.95,2.01]$ \\
\hline 17.3 at 48 hours & 2 & 36 & $\begin{array}{l}\text { Mean Difference (IV, Fixed, 95\% } \\
\mathrm{Cl})\end{array}$ & $0.52[-1.08,2.13]$ \\
\hline 17.4 at 72 hours & 1 & 20 & $\begin{array}{l}\text { Mean Difference (IV, Fixed, 95\% } \\
\mathrm{CI})\end{array}$ & $-1.03[-13.01,10.95]$ \\
\hline 17.5 at 96 hours & 1 & 20 & $\begin{array}{l}\text { Mean Difference (IV, Fixed, 95\% } \\
\mathrm{CI} \text { ) }\end{array}$ & $-1.39[-15.12,12.33]$ \\
\hline $\begin{array}{l}1830 \text {-second Wingate average } \\
\text { peak power output (W/kg) (post } \\
7 \text { days of intervention) }\end{array}$ & 1 & & $\begin{array}{l}\text { Mean Difference (IV, Fixed, 95\% } \\
\mathrm{Cl})\end{array}$ & Totals not selected \\
\hline 1920 m Sprint time (s) & 1 & & $\begin{array}{l}\text { Mean Difference (IV, Fixed, 95\% } \\
\mathrm{CI} \text { ) }\end{array}$ & Totals not selected \\
\hline 19.1 at 24 hours & 1 & & $\begin{array}{l}\text { Mean Difference (IV, Fixed, 95\% } \\
\mathrm{CI} \text { ) }\end{array}$ & $0.0[0.0,0.0]$ \\
\hline 19.2 at 48 hours & 1 & & $\begin{array}{l}\text { Mean Difference (IV, Fixed, 95\% } \\
\mathrm{CI} \text { ) }\end{array}$ & $0.0[0.0,0.0]$ \\
\hline 19.3 at 120 hours & 1 & & $\begin{array}{l}\text { Mean Difference (IV, Fixed, 95\% } \\
\mathrm{CI} \text { ) }\end{array}$ & $0.0[0.0,0.0]$ \\
\hline $\begin{array}{l}20 \text { Maximal oxygen consump- } \\
\text { tion ( } \mathrm{mL} / \mathrm{kg} / \mathrm{min}) \text { (post } 42 \text { days } \\
\text { of supplementation) }\end{array}$ & 1 & & $\begin{array}{l}\text { Mean Difference (IV, Fixed, 95\% } \\
\mathrm{CI} \text { ) }\end{array}$ & Totals not selected \\
\hline 21 Agility (seconds) & 1 & & $\begin{array}{l}\text { Mean Difference (IV, Fixed, 95\% } \\
\mathrm{CI})\end{array}$ & Totals not selected \\
\hline 21.1 at 24 hours & 1 & & $\begin{array}{l}\text { Mean Difference (IV, Fixed, 95\% } \\
\mathrm{Cl})\end{array}$ & $0.0[0.0,0.0]$ \\
\hline 21.2 at 48 hours & 1 & & $\begin{array}{l}\text { Mean Difference (IV, Fixed, 95\% } \\
\text { CI) }\end{array}$ & $0.0[0.0,0.0]$ \\
\hline 21.3 at 72 hours & 1 & & $\begin{array}{l}\text { Mean Difference (IV, Fixed, 95\% } \\
\mathrm{CI} \text { ) }\end{array}$ & $0.0[0.0,0.0]$ \\
\hline $\begin{array}{l}226 \text { second sprint maximal } \\
\text { power (Watts) (all follow-up } \\
\text { times) }\end{array}$ & 1 & & $\begin{array}{l}\text { Mean Difference (IV, Fixed, 95\% } \\
\mathrm{Cl})\end{array}$ & Totals not selected \\
\hline 22.1 at 24 hours & 1 & & $\begin{array}{l}\text { Mean Difference (IV, Fixed, 95\% } \\
\mathrm{CI} \text { ) }\end{array}$ & $0.0[0.0,0.0]$ \\
\hline
\end{tabular}




\begin{tabular}{|c|c|c|c|c|}
\hline Outcome or subgroup title & No. of studies & $\begin{array}{l}\text { No. of partici- } \\
\text { pants }\end{array}$ & Statistical method & Effect size \\
\hline 22.2 at 48 hours & 1 & & $\begin{array}{l}\text { Mean Difference (IV, Fixed, 95\% } \\
\mathrm{CI})\end{array}$ & $0.0[0.0,0.0]$ \\
\hline 22.3 at 72 hours & 1 & & $\begin{array}{l}\text { Mean Difference (IV, Fixed, 95\% } \\
\mathrm{CI})\end{array}$ & $0.0[0.0,0.0]$ \\
\hline $\begin{array}{l}23 \text { Maximal voluntary isometric } \\
\text { contraction measured as per- } \\
\text { centage change from baseline }\end{array}$ & 15 & & $\begin{array}{l}\text { Mean Difference (IV, Fixed, 95\% } \\
\mathrm{CI})\end{array}$ & Subtotals only \\
\hline 23.1 Up to 6 hours & 11 & 255 & $\begin{array}{l}\text { Mean Difference (IV, Fixed, 95\% } \\
\mathrm{CI})\end{array}$ & $5.86[3.29,8.42]$ \\
\hline 23.2 at 24 hours & 15 & 375 & $\begin{array}{l}\text { Mean Difference (IV, Fixed, 95\% } \\
\mathrm{CI})\end{array}$ & $2.51[0.99,4.04]$ \\
\hline 23.3 at 48 hours & 15 & 375 & $\begin{array}{l}\text { Mean Difference (IV, Fixed, 95\% } \\
\mathrm{CI})\end{array}$ & $4.46[2.94,5.98]$ \\
\hline 23.4 at 72 hours & 11 & 277 & $\begin{array}{l}\text { Mean Difference (IV, Fixed, 95\% } \\
\mathrm{CI})\end{array}$ & $3.92[0.88,6.96]$ \\
\hline 23.5 at 96 hours & 9 & 252 & $\begin{array}{l}\text { Mean Difference (IV, Fixed, 95\% } \\
\mathrm{CI})\end{array}$ & $5.29[3.65,6.92]$ \\
\hline 23.6 at 168 hours & 2 & 36 & $\begin{array}{l}\text { Mean Difference (IV, Fixed, 95\% } \\
\mathrm{Cl} \text { ) }\end{array}$ & $-7.96[-15.96,0.05]$ \\
\hline $\begin{array}{l}24 \text { Maximal voluntary isometric } \\
\text { contraction measured in New- } \\
\text { ton metres }\end{array}$ & 6 & & $\begin{array}{l}\text { Mean Difference (IV, Fixed, 95\% } \\
\mathrm{CI})\end{array}$ & Subtotals only \\
\hline 24.1 Up to 6 hours & 3 & 84 & $\begin{array}{l}\text { Mean Difference (IV, Fixed, 95\% } \\
\mathrm{CI})\end{array}$ & $-1.50[-4.77,1.76]$ \\
\hline 24.2 at 24 hours & 6 & 148 & $\begin{array}{l}\text { Mean Difference (IV, Fixed, 95\% } \\
\mathrm{CI})\end{array}$ & $-0.63[-6.27,5.01]$ \\
\hline 24.3 at 48 hours & 6 & 148 & $\begin{array}{l}\text { Mean Difference (IV, Fixed, 95\% } \\
\mathrm{Cl} \text { ) }\end{array}$ & $0.80[-5.46,7.06]$ \\
\hline 24.4 at 72 hours & 4 & 94 & $\begin{array}{l}\text { Mean Difference (IV, Fixed, 95\% } \\
\mathrm{CI} \text { ) }\end{array}$ & $-3.62[-11.91,4.67]$ \\
\hline 24.5 at 96 hours & 3 & 96 & $\begin{array}{l}\text { Mean Difference (IV, Fixed, 95\% } \\
\mathrm{CI})\end{array}$ & $-4.65[-16.21,6.92]$ \\
\hline 24.6 at 120 hours & 2 & 58 & $\begin{array}{l}\text { Mean Difference (IV, Fixed, 95\% } \\
\mathrm{Cl} \text { ) }\end{array}$ & $-5.89[-19.14,7.36]$ \\
\hline 24.7 at 168 hours & 1 & 38 & $\begin{array}{l}\text { Mean Difference (IV, Fixed, 95\% } \\
\mathrm{Cl} \text { ) }\end{array}$ & $58.0[13.57,102.43]$ \\
\hline
\end{tabular}




\begin{tabular}{|c|c|c|c|c|}
\hline Outcome or subgroup title & No. of studies & $\begin{array}{l}\text { No. of partici- } \\
\text { pants }\end{array}$ & Statistical method & Effect size \\
\hline $\begin{array}{l}25 \text { Maximal voluntary isometric } \\
\text { contraction measured in New- } \\
\text { tons }\end{array}$ & 6 & & $\begin{array}{l}\text { Mean Difference (IV, Fixed, 95\% } \\
\mathrm{CI})\end{array}$ & Subtotals only \\
\hline 25.1 Up to 6 hours & 4 & 73 & $\begin{array}{l}\text { Mean Difference (IV, Fixed, 95\% } \\
\mathrm{CI})\end{array}$ & $6.50[-55.11,68.10]$ \\
\hline 25.2 at 24 hours & 5 & 87 & $\begin{array}{l}\text { Mean Difference (IV, Fixed, 95\% } \\
\mathrm{CI})\end{array}$ & $23.03[-23.18,69.24]$ \\
\hline 25.3 at 48 hours & 5 & 87 & $\begin{array}{l}\text { Mean Difference (IV, Fixed, 95\% } \\
\mathrm{CI})\end{array}$ & $34.87[-17.80,87.55]$ \\
\hline 25.4 at 72 hours & 4 & 70 & $\begin{array}{l}\text { Mean Difference (IV, Fixed, 95\% } \\
\mathrm{CI})\end{array}$ & $-5.11[-73.42,63.19]$ \\
\hline 25.5 at 96 hours & 1 & 20 & $\begin{array}{l}\text { Mean Difference (IV, Fixed, 95\% } \\
\mathrm{CI})\end{array}$ & $\begin{array}{l}-112.0[-265.08 \\
41.08]\end{array}$ \\
\hline 25.6 at 168 hours & 1 & 18 & $\begin{array}{l}\text { Mean Difference (IV, Fixed, 95\% } \\
\mathrm{CI})\end{array}$ & $\begin{array}{l}-225.0[-534.90 \\
84.90]\end{array}$ \\
\hline $\begin{array}{l}26 \text { Maximal voluntary isometric } \\
\text { contraction measured in New- } \\
\text { ton metres per kg of body mass }\end{array}$ & 2 & & $\begin{array}{l}\text { Mean Difference (IV, Fixed, 95\% } \\
\mathrm{CI})\end{array}$ & Totals not selected \\
\hline 26.1 Up to 6 hours & 2 & & $\begin{array}{l}\text { Mean Difference (IV, Fixed, 95\% } \\
\mathrm{CI})\end{array}$ & $0.0[0.0,0.0]$ \\
\hline 26.2 at 24 hours & 2 & & $\begin{array}{l}\text { Mean Difference (IV, Fixed, 95\% } \\
\mathrm{CI})\end{array}$ & $0.0[0.0,0.0]$ \\
\hline 26.3 at 48 hours & 2 & & $\begin{array}{l}\text { Mean Difference (IV, Fixed, 95\% } \\
\mathrm{CI} \text { ) }\end{array}$ & $0.0[0.0,0.0]$ \\
\hline 26.4 at 72 hours & 2 & & $\begin{array}{l}\text { Mean Difference (IV, Fixed, 95\% } \\
\mathrm{CI} \text { ) }\end{array}$ & $0.0[0.0,0.0]$ \\
\hline 26.5 at 96 hours & 1 & & $\begin{array}{l}\text { Mean Difference (IV, Fixed, 95\% } \\
\mathrm{CI})\end{array}$ & $0.0[0.0,0.0]$ \\
\hline 26.6 at 120 hours & 1 & & $\begin{array}{l}\text { Mean Difference (IV, Fixed, 95\% } \\
\mathrm{CI})\end{array}$ & $0.0[0.0,0.0]$ \\
\hline 26.7 at 144 hours & 1 & & $\begin{array}{l}\text { Mean Difference (IV, Fixed, 95\% } \\
\mathrm{CI})\end{array}$ & $0.0[0.0,0.0]$ \\
\hline 26.8 at 168 hours & 1 & & $\begin{array}{l}\text { Mean Difference (IV, Fixed, 95\% } \\
\mathrm{CI} \text { ) }\end{array}$ & $0.0[0.0,0.0]$ \\
\hline $\begin{array}{l}27 \text { Maximal voluntary isometric } \\
\text { contraction measured in } \mathrm{kg}\end{array}$ & 1 & & $\begin{array}{l}\text { Std. Mean Difference (IV, Fixed, } \\
95 \% \mathrm{CI} \text { ) }\end{array}$ & Totals not selected \\
\hline 27.1 at 24 hours & 1 & & $\begin{array}{l}\text { Std. Mean Difference (IV, Fixed, } \\
95 \% \mathrm{Cl} \text { ) }\end{array}$ & $0.0[0.0,0.0]$ \\
\hline
\end{tabular}




\begin{tabular}{|c|c|c|c|c|}
\hline Outcome or subgroup title & No. of studies & $\begin{array}{l}\text { No. of partici- } \\
\text { pants }\end{array}$ & Statistical method & Effect size \\
\hline 27.2 at 48 hours & 1 & & $\begin{array}{l}\text { Std. Mean Difference (IV, Fixed, } \\
95 \% \mathrm{Cl} \text { ) }\end{array}$ & $0.0[0.0,0.0]$ \\
\hline $\begin{array}{l}28 \text { Range of motion (all fol- } \\
\text { low-up times) }\end{array}$ & 10 & & $\begin{array}{l}\text { Mean Difference (IV, Fixed, 95\% } \\
\mathrm{CI})\end{array}$ & Subtotals only \\
\hline 28.1 Up to 6 hours & 6 & 163 & $\begin{array}{l}\text { Mean Difference (IV, Fixed, 95\% } \\
\mathrm{CI})\end{array}$ & $-0.25[-3.31,2.81]$ \\
\hline 28.2 at 24 hours & 9 & 259 & $\begin{array}{l}\text { Mean Difference (IV, Fixed, 95\% } \\
\mathrm{CI} \text { ) }\end{array}$ & $1.03[-0.91,2.96]$ \\
\hline 28.3 at 48 hours & 9 & 259 & $\begin{array}{l}\text { Mean Difference (IV, Fixed, 95\% } \\
\mathrm{CI} \text { ) }\end{array}$ & $2.71[0.39,5.04]$ \\
\hline 28.4 at 72 hours & 7 & 196 & $\begin{array}{l}\text { Mean Difference (IV, Fixed, 95\% } \\
\mathrm{CI})\end{array}$ & $2.93[-0.02,5.87]$ \\
\hline 28.5 at 96 hours & 6 & 158 & $\begin{array}{l}\text { Mean Difference (IV, Fixed, 95\% } \\
\mathrm{CI})\end{array}$ & $0.79[-1.26,2.84]$ \\
\hline 28.6 at 120 hours & 2 & 63 & $\begin{array}{l}\text { Mean Difference (IV, Fixed, 95\% } \\
\mathrm{CI} \text { ) }\end{array}$ & $-0.34[-2.43,1.76]$ \\
\hline 28.7 at 168 hours & 1 & 38 & $\begin{array}{l}\text { Mean Difference (IV, Fixed, 95\% } \\
\mathrm{CI} \text { ) }\end{array}$ & $5.0[2.77,7.23]$ \\
\hline
\end{tabular}

Analysis 1.1. Comparison 1 Antioxidant supplementation vs. placebo for delayed onset muscle soreness (all studies), Outcome 1 Muscle soreness up to 6 hours; random-effects model.

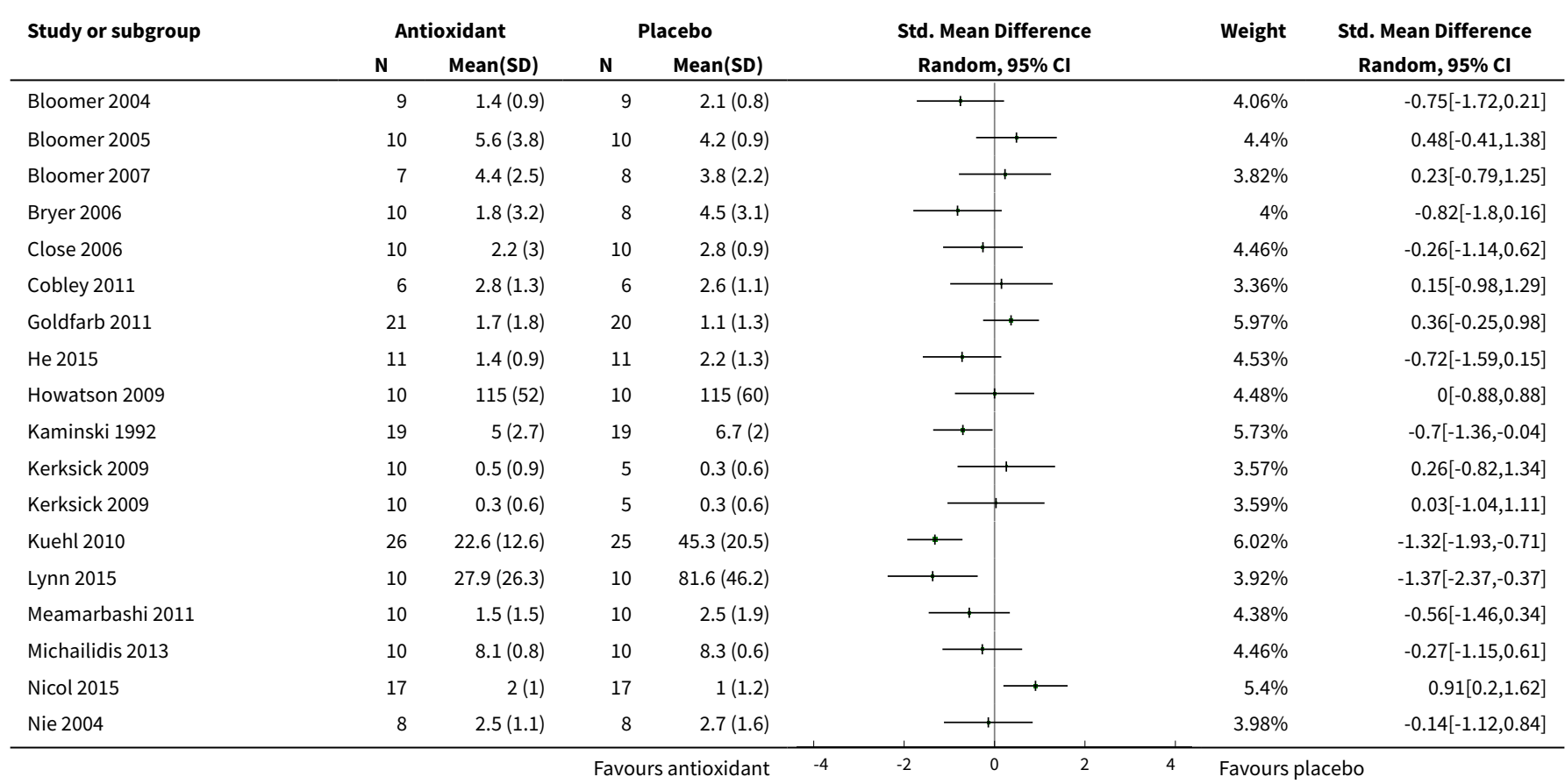




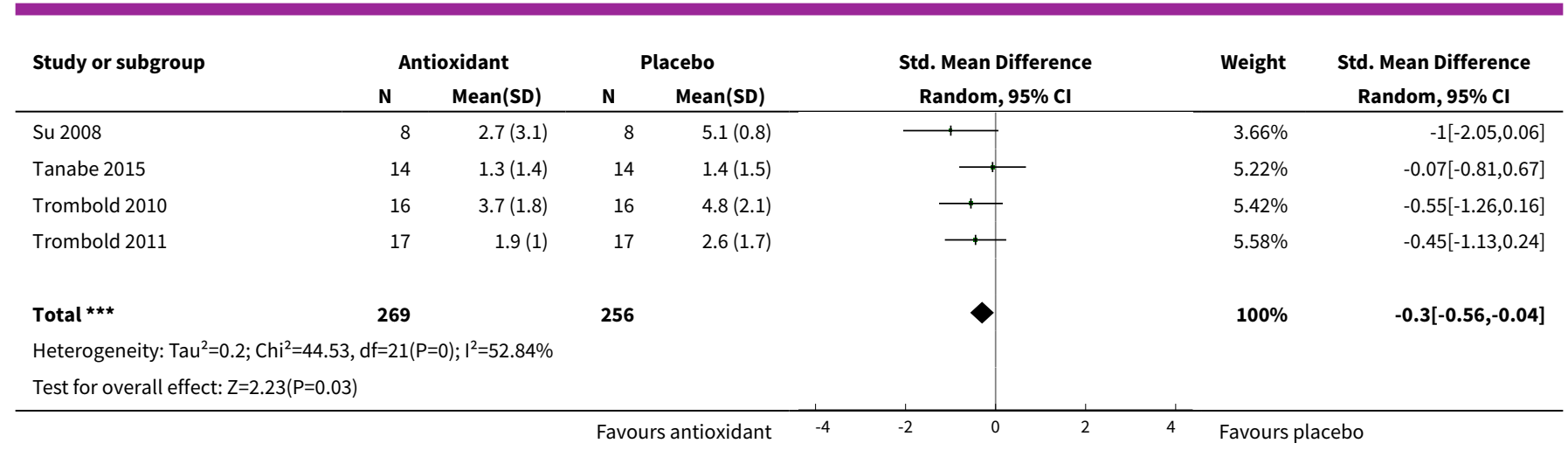

\section{Analysis 1.2. Comparison 1 Antioxidant supplementation vs. placebo for delayed onset muscle soreness (all studies), Outcome 2 Muscle soreness at 24 hours; random-effects model.}

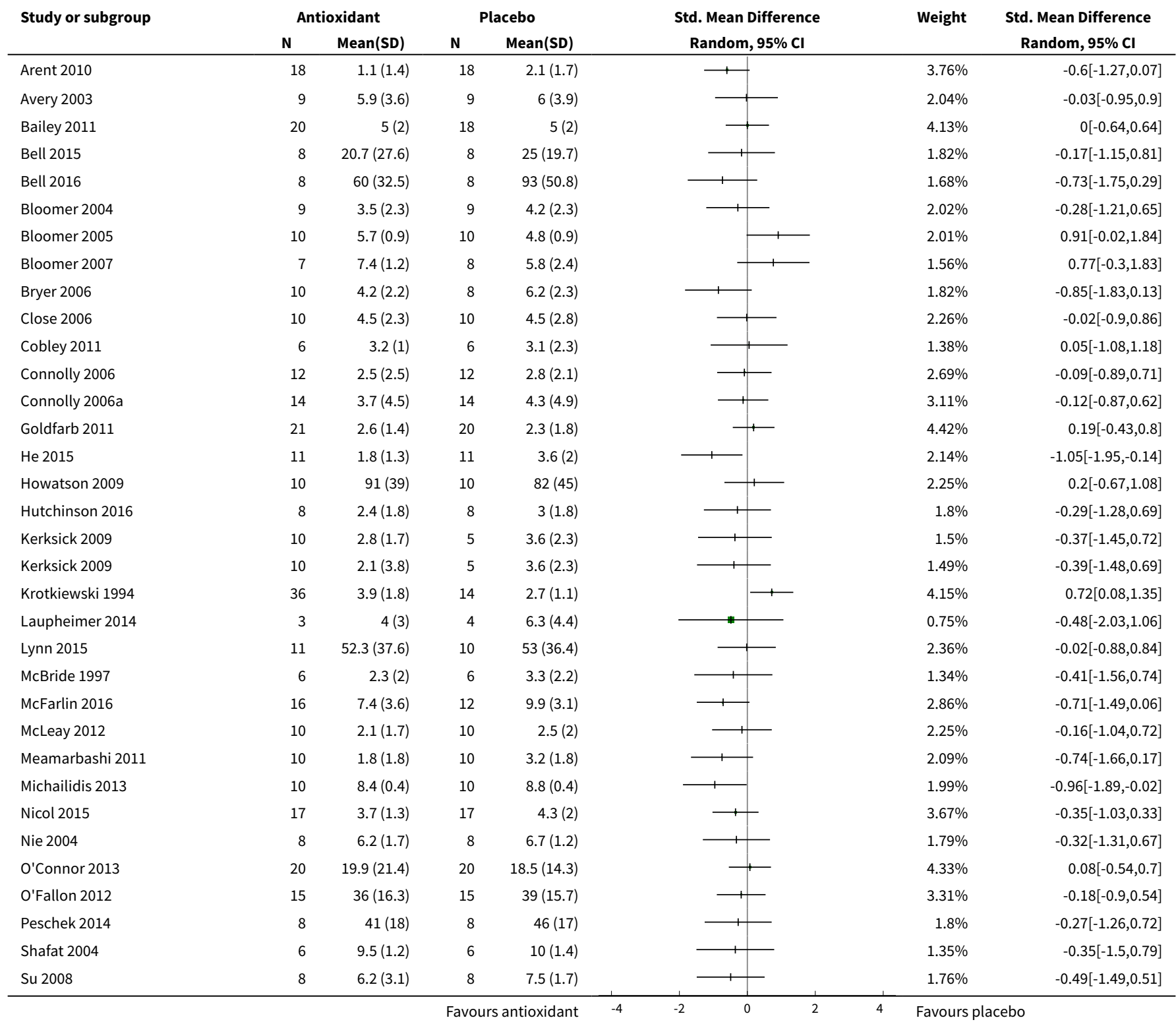




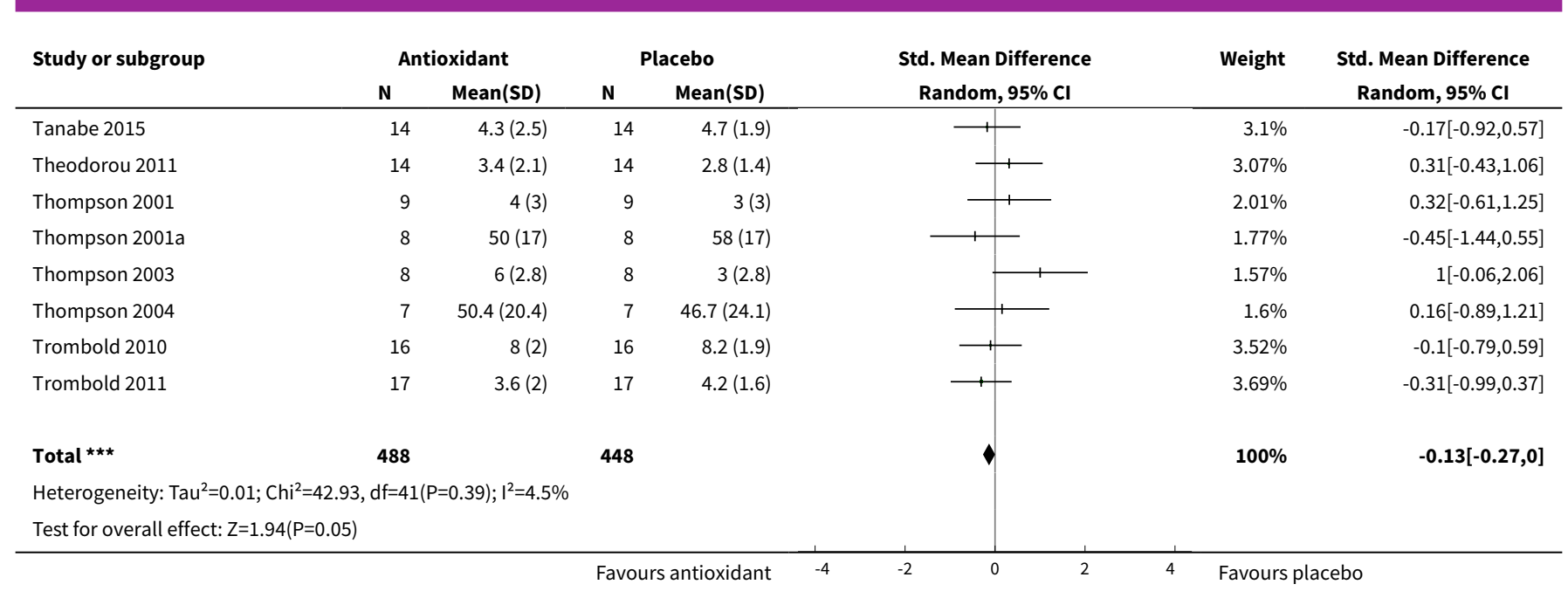

Analysis 1.3. Comparison 1 Antioxidant supplementation vs. placebo for delayed onset muscle soreness (all studies), Outcome 3 Muscle soreness at 48 hours; random-effects model.

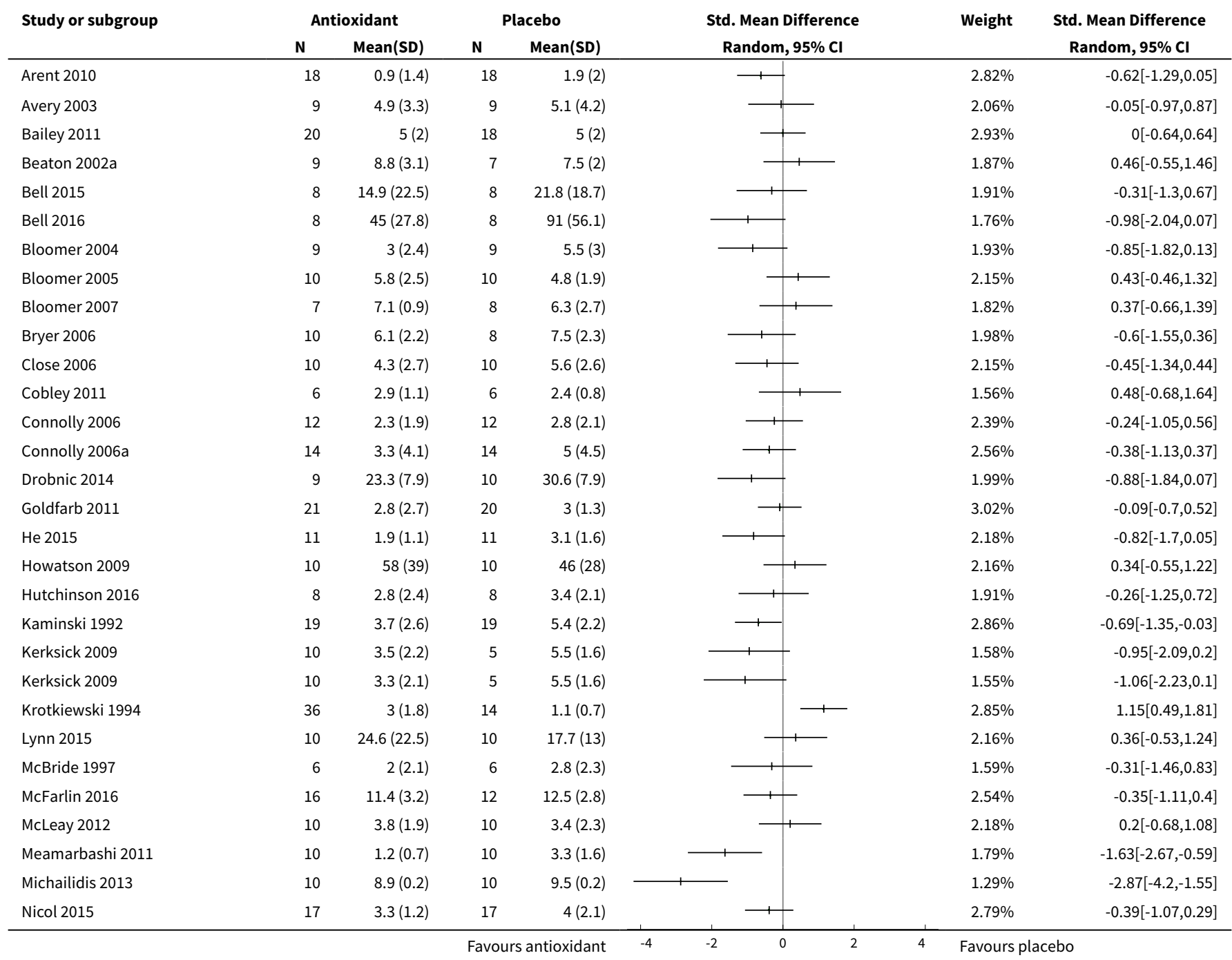




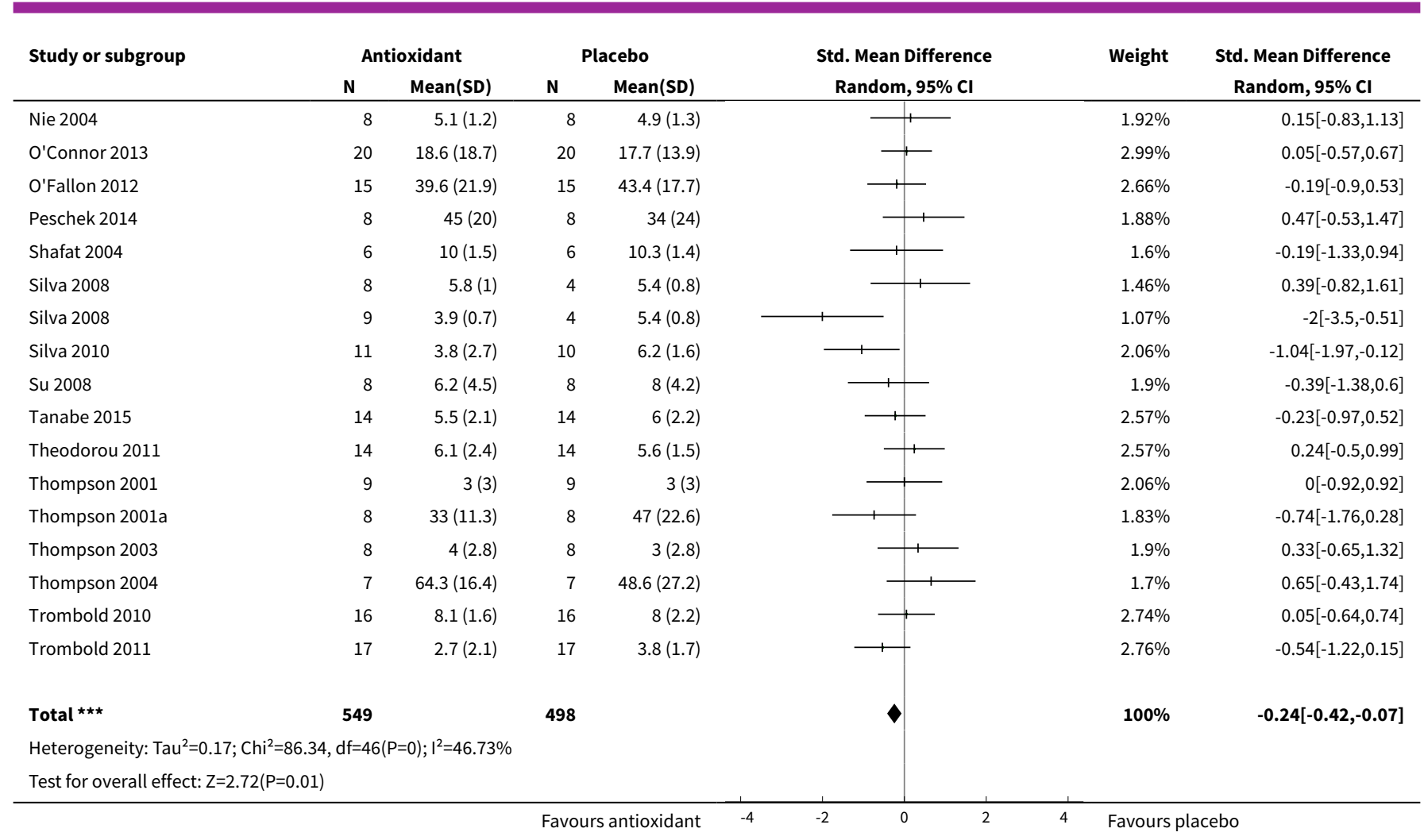

Analysis 1.4. Comparison 1 Antioxidant supplementation vs. placebo for delayed onset
muscle soreness (all studies), Outcome 4 Muscle soreness at 72 hours; random-effects model.

\begin{tabular}{|c|c|c|c|c|c|c|c|}
\hline \multirow[t]{2}{*}{ Study or subgroup } & \multicolumn{2}{|c|}{ Antioxidant } & \multicolumn{2}{|c|}{ Placebo } & \multirow{2}{*}{$\begin{array}{c}\text { Std. Mean Difference } \\
\text { Random, } 95 \% \mathrm{Cl}\end{array}$} & \multirow[t]{2}{*}{ Weight } & \multirow{2}{*}{$\begin{array}{c}\text { Std. Mean Difference } \\
\text { Random, } 95 \% \mathrm{CI}\end{array}$} \\
\hline & $\mathbf{N}$ & Mean(SD) & $\mathbf{N}$ & Mean(SD) & & & \\
\hline Avery 2003 & 9 & $3.6(4.5)$ & 9 & $4.3(5.1)$ & 1 & $3.16 \%$ & $-0.14[-1.06,0.79]$ \\
\hline Bell 2015 & 8 & $10.8(15.5)$ & 8 & $24.4(28.1)$ & \begin{tabular}{l|l}
+1 & -1
\end{tabular} & $2.77 \%$ & $-0.57[-1.57,0.44]$ \\
\hline Bell 2016 & 8 & $11(8.4)$ & 8 & $33(25.2)$ & & $2.49 \%$ & $-1.11[-2.18,-0.03]$ \\
\hline Bloomer 2004 & 9 & $2.5(2.9)$ & 9 & $5.4(3.3)$ & & $2.9 \%$ & $-0.87[-1.84,0.11]$ \\
\hline Bloomer 2005 & 10 & $4.1(2.2)$ & 10 & $3.3(1.3)$ & + & $3.36 \%$ & $0.43[-0.46,1.31]$ \\
\hline Close 2006 & 10 & $3(2.2)$ & 10 & $3.2(2.1)$ & & $3.42 \%$ & $-0.12[-1,0.75]$ \\
\hline Cobley 2011 & 6 & $3.6(1.5)$ & 6 & $2.3(2.4)$ & ? & $2.17 \%$ & $0.6[-0.57,1.77]$ \\
\hline Connolly 2006 & 12 & $2.6(2.1)$ & 12 & $2.2(1.9)$ & + & $3.89 \%$ & $0.2[-0.6,1.01]$ \\
\hline Connolly 2006a & 14 & $2.2(1.1)$ & 3 & $3(1.6)$ & - & $1.88 \%$ & $-0.64[-1.91,0.63]$ \\
\hline Goldfarb 2011 & 21 & $1.8(1.8)$ & 20 & $2.4(2.2)$ & $1-$ & $5.49 \%$ & $-0.29[-0.9,0.33]$ \\
\hline He 2015 & 11 & $0.8(0.8)$ & 11 & $1.7(1.4)$ & & $3.45 \%$ & $-0.77[-1.64,0.1]$ \\
\hline Kerksick 2009 & 10 & $3.2(2)$ & 5 & $4.4(2.2)$ & - & $2.42 \%$ & $-0.52[-1.62,0.58]$ \\
\hline Kerksick 2009 & 10 & $2.6(2)$ & 5 & $4.4(2.2)$ & 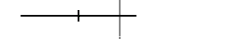 & $2.32 \%$ & $-0.8[-1.92,0.32]$ \\
\hline Krotkiewski 1994 & 36 & $1.6(1.8)$ & 14 & $0.5(0.7)$ & 1 & $5.32 \%$ & $0.68[0.05,1.32]$ \\
\hline McFarlin 2016 & 16 & $4.4(3.6)$ & 12 & $5.2(3.5)$ & + & $4.27 \%$ & $-0.22[-0.97,0.53]$ \\
\hline McLeay 2012 & 10 & $2.7(1.4)$ & 10 & $2.5(1.6)$ & & $3.42 \%$ & $0.08[-0.8,0.95]$ \\
\hline Michailidis 2013 & 10 & $8(0.2)$ & 10 & $8.5(0.2)$ & & $2.06 \%$ & $-2.39[-3.6,-1.19]$ \\
\hline O'Fallon 2012 & 15 & $31.2(26.9)$ & 15 & $30.9(23.9)$ & 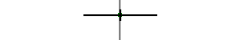 & $4.55 \%$ & $0.01[-0.7,0.73]$ \\
\hline Phillips 2003 & 16 & $3.7(9.5)$ & 19 & $3.2(7.4)$ & 1 & $5 \%$ & $0.06[-0.61,0.72]$ \\
\hline
\end{tabular}




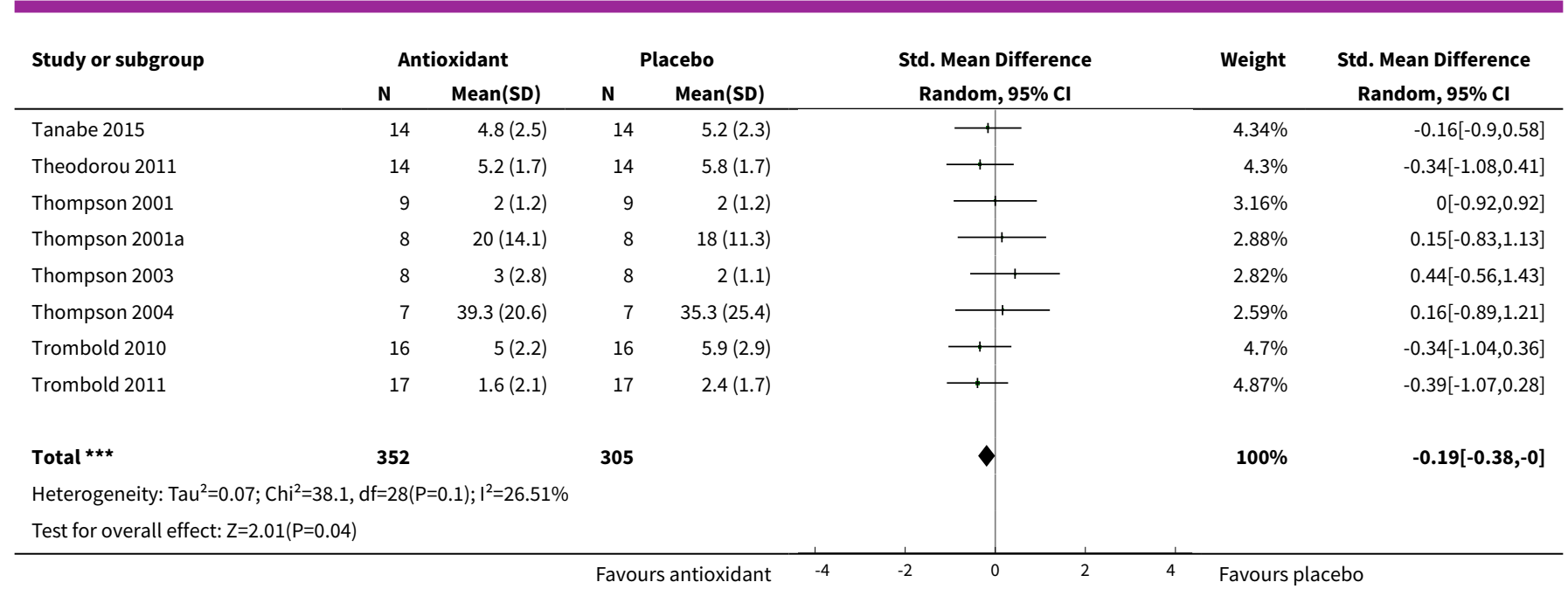

Analysis 1.5. Comparison 1 Antioxidant supplementation vs. placebo for delayed onset muscle soreness (all studies), Outcome 5 Muscle soreness at 96 hours; random-effects model.

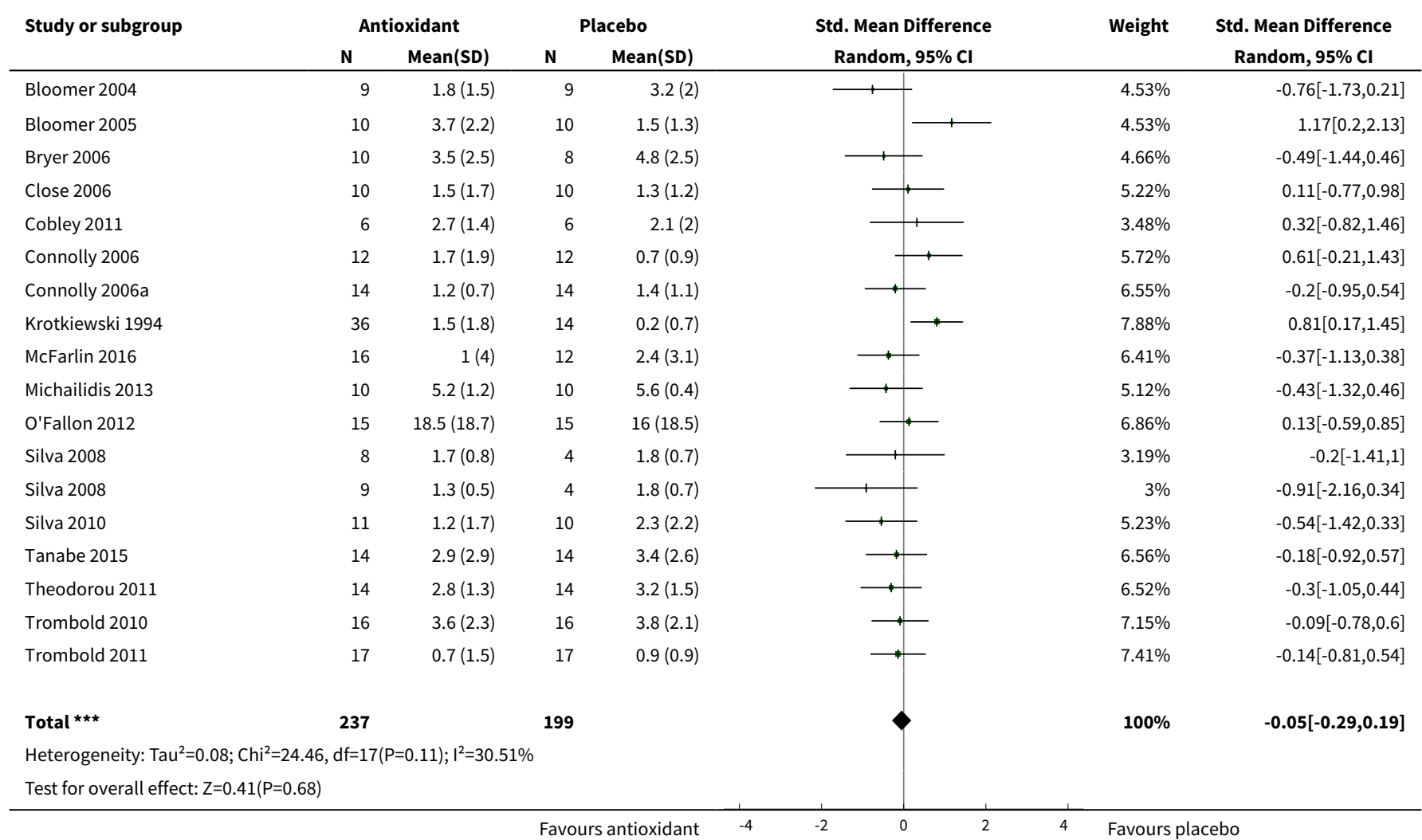


Analysis 1.6. Comparison 1 Antioxidant supplementation vs. placebo for delayed onset muscle soreness (all studies), Outcome 6 Muscle soreness (follow-ups: 120, 144 and 168 hours); random-effects model.

\begin{tabular}{|c|c|c|c|c|c|c|c|}
\hline \multirow[t]{2}{*}{ Study or subgroup } & \multicolumn{2}{|c|}{ Antioxidant } & \multicolumn{2}{|c|}{ Placebo } & \multirow{2}{*}{$\begin{array}{c}\text { Std. Mean Difference } \\
\text { Random, } 95 \% \mathrm{Cl}\end{array}$} & \multirow[t]{2}{*}{ Weight } & \multirow{2}{*}{$\begin{array}{c}\text { Std. Mean Difference } \\
\text { Random, } 95 \% \mathrm{Cl}\end{array}$} \\
\hline & $\mathbf{N}$ & $\operatorname{Mean}(S D)$ & $\mathbf{N}$ & $\operatorname{Mean}(S D)$ & & & \\
\hline \multicolumn{8}{|l|}{ 1.6.1 at 120 hours } \\
\hline Krotkiewski 1994 & 36 & $0.9(1.2)$ & 14 & $0.1(0.4)$ & - & $29.64 \%$ & $0.75[0.12,1.39]$ \\
\hline Michailidis 2013 & 10 & $3.5(1)$ & 10 & $3.8(0.2)$ & $\because-$ & $19.68 \%$ & $-0.4[-1.29,0.49]$ \\
\hline O'Fallon 2012 & 15 & $8.8(11.1)$ & 15 & $8.8(16.5)$ & & $25.95 \%$ & $0[-0.71,0.72]$ \\
\hline Theodorou 2011 & 14 & $1.6(0.8)$ & 14 & $1.4(0.7)$ & \#- & $24.73 \%$ & $0.27[-0.47,1.02]$ \\
\hline \multicolumn{8}{|c|}{ Heterogeneity: $\mathrm{Tau}^{2}=0.09 ; \mathrm{Chi}^{2}=4.94, \mathrm{df}=3(\mathrm{P}=0.18) ; \mathrm{I}^{2}=39.24 \%$} \\
\hline \multicolumn{8}{|c|}{ Test for overall effect: $\mathrm{Z}=0.88(\mathrm{P}=0.38)$} \\
\hline \multicolumn{8}{|l|}{ 1.6.2 at 144 hours } \\
\hline Michailidis 2013 & 10 & $2.4(1.7)$ & 10 & $2.7(0.4)$ & & $100 \%$ & $-0.23[-1.11,0.65]$ \\
\hline 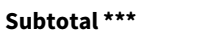 & 10 & & 10 & & & $100 \%$ & $-0.23[-1.11,0.65]$ \\
\hline \multicolumn{8}{|c|}{ Test for overall effect: $Z=0.52(P=0.6)$} \\
\hline \multicolumn{8}{|l|}{ 1.6.3 at 168 hours } \\
\hline Michailidis 2013 & 10 & $1.5(0.8)$ & 10 & $1.6(0.6)$ & & $26.09 \%$ & $-0.14[-1.01,0.74]$ \\
\hline Phillips 2003 & 16 & $0.7(2)$ & 19 & $0.7(0.7)$ & & $45.46 \%$ & $0[-0.67,0.67]$ \\
\hline Silva 2008 & 9 & $0(0)$ & 4 & $0(0)$ & & $14.49 \%$ & $0[-1.18,1.18]$ \\
\hline Silva 2010 & 8 & $0(0)$ & 4 & $0(0)$ & & $13.96 \%$ & $0[-1.2,1.2]$ \\
\hline 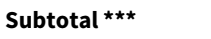 & 43 & & 37 & & & $100 \%$ & $-0.04[-0.48,0.41]$ \\
\hline \multicolumn{8}{|c|}{ Heterogeneity: $\operatorname{Tau}^{2}=0 ; \mathrm{Chi}^{2}=0.07, \mathrm{df}=3(\mathrm{P}=1) ; \mathrm{I}^{2}=0 \%$} \\
\hline Test for overall effec & & & & & & & \\
\hline
\end{tabular}

Analysis 1.7. Comparison 1 Antioxidant supplementation vs. placebo for delayed onset muscle soreness (all studies), Outcome 7 Muscle soreness up to 6 hours - all at same scale (0 to 10; worst pain).

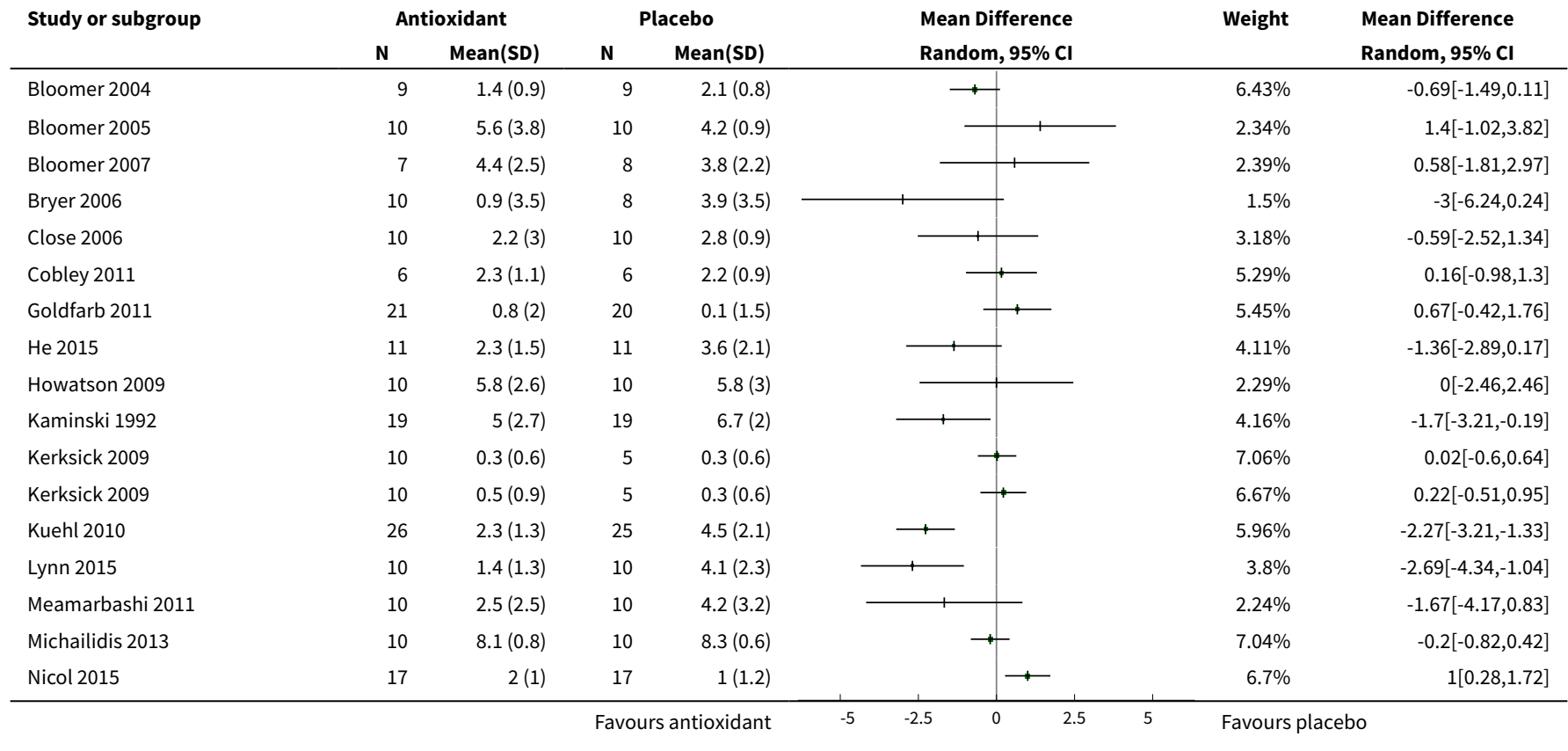




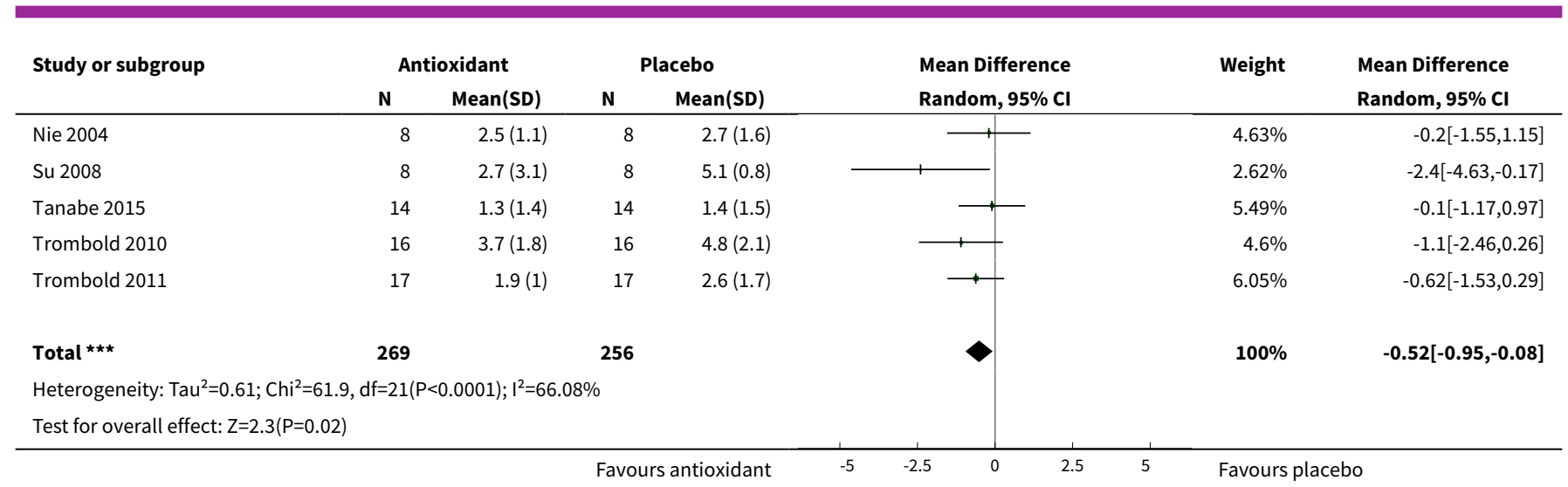

Analysis 1.8. Comparison 1 Antioxidant supplementation vs. placebo for delayed onset muscle soreness (all studies), Outcome 8 Muscle soreness at 24 hours - all at same scale (0 to 10; worst pain).

\begin{tabular}{|c|c|c|c|c|c|c|c|}
\hline \multirow[t]{2}{*}{ Study or subgroup } & \multicolumn{2}{|c|}{ Antioxidant } & \multicolumn{2}{|c|}{ Placebo } & \multirow{2}{*}{$\begin{array}{l}\text { Mean Difference } \\
\text { Random, 95\% CI }\end{array}$} & \multirow[t]{2}{*}{ Weight } & \multirow{2}{*}{$\begin{array}{l}\text { Mean Difference } \\
\text { Random, } 95 \% \mathrm{Cl}\end{array}$} \\
\hline & $\mathbf{N}$ & Mean(SD) & $\mathbf{N}$ & Mean(SD) & & & \\
\hline Arent 2010 & 18 & $1.1(1.4)$ & 18 & $2.1(1.7)$ & $1-$ & $3.9 \%$ & $-0.97[-2,0.06]$ \\
\hline Avery 2003 & 9 & $5.9(3.6)$ & 9 & $6(3.9)$ & 1 & $0.48 \%$ & $-0.1[-3.57,3.37]$ \\
\hline Bailey 2011 & 20 & $5(2)$ & 18 & $5(2)$ & $\longrightarrow$ & $2.85 \%$ & $0[-1.27,1.27]$ \\
\hline Bell 2015 & 8 & $1(1.4)$ & 8 & $1.3(1)$ & -1 & $3.21 \%$ & $-0.22[-1.4,0.96]$ \\
\hline Bell 2016 & 8 & $3(1.6)$ & 8 & $4.7(2.5)$ & - & $1.23 \%$ & $-1.65[-3.74,0.44]$ \\
\hline Bloomer 2005 & 10 & $5.7(0.9)$ & 10 & $4.8(0.9)$ & $\longrightarrow$ & $5.14 \%$ & $0.9[0.07,1.73]$ \\
\hline Bloomer 2007 & 7 & $7.4(1.2)$ & 8 & $5.8(2.4)$ & 1 & $1.44 \%$ & $1.6[-0.31,3.51]$ \\
\hline Bryer 2006 & 10 & $3.6(2.5)$ & 8 & $5.8(2.5)$ & & $1.03 \%$ & $-2.22[-4.53,0.09]$ \\
\hline Close 2006 & 10 & $4.5(2.3)$ & 10 & $4.5(2.8)$ & - & $1.07 \%$ & $-0.05[-2.31,2.21]$ \\
\hline Cobley 2011 & 6 & $2.7(0.8)$ & 6 & $2.6(1.9)$ & - & $1.82 \%$ & $0.09[-1.58,1.76]$ \\
\hline Connolly 2006 & 12 & $2.5(2.5)$ & 12 & $2.8(2.1)$ & - & $1.54 \%$ & $-0.21[-2.05,1.63]$ \\
\hline Goldfarb 2011 & 21 & $1.8(1.5)$ & 20 & $1.4(2)$ & + & $3.59 \%$ & $0.34[-0.75,1.43]$ \\
\hline He 2015 & 11 & $3(2.1)$ & 11 & $6.1(3.4)$ & - & $1.01 \%$ & $-3.03[-5.36,-0.7]$ \\
\hline Howatson 2009 & 10 & $4.6(2)$ & 10 & $4.1(2.3)$ & + & $1.54 \%$ & $0.45[-1.4,2.3]$ \\
\hline Hutchinson 2016 & 8 & $2.4(1.8)$ & 8 & $3(1.8)$ & - & $1.65 \%$ & $-0.56[-2.33,1.21]$ \\
\hline Kerksick 2009 & 10 & $2.1(3.8)$ & 5 & $3.6(2.3)$ & 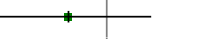 & $0.59 \%$ & $-1.44[-4.55,1.67]$ \\
\hline Kerksick 2009 & 10 & $2.8(1.7)$ & 5 & $3.6(2.3)$ & 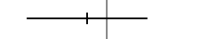 & $1.06 \%$ & $-0.74[-3.01,1.53]$ \\
\hline Krotkiewski 1994 & 36 & $3.9(1.8)$ & 14 & $2.7(1.1)$ & $\longrightarrow$ & $5.14 \%$ & $1.2[0.37,2.03]$ \\
\hline Laupheimer 2014 & 3 & $4(3)$ & 4 & $6.3(4.4)$ & & $0.19 \%$ & $-2.25[-7.74,3.24]$ \\
\hline Lynn 2015 & 11 & $2.6(1.9)$ & 10 & $2.7(1.8)$ & & $2 \%$ & $-0.04[-1.62,1.54]$ \\
\hline McBride 1997 & 6 & $2.3(2)$ & 6 & $3.3(2.2)$ & - & $1.01 \%$ & $-0.92[-3.25,1.41]$ \\
\hline McFarlin 2016 & 16 & $3.7(1.8)$ & 12 & $5(1.6)$ & & $2.94 \%$ & $-1.25[-2.5,-0]$ \\
\hline McLeay 2012 & 10 & $2.1(1.7)$ & 10 & $2.5(2)$ & - & $1.89 \%$ & $-0.31[-1.95,1.33]$ \\
\hline Meamarbashi 2011 & 10 & $3(3)$ & 10 & $5.3(3)$ & 7 & $0.81 \%$ & $-2.33[-4.96,0.3]$ \\
\hline Nie 2004 & 8 & $6.2(1.7)$ & 8 & $6.7(1.2)$ & +1 & $2.34 \%$ & $-0.5[-1.94,0.94]$ \\
\hline O'Connor 2013 & 20 & $2(2.1)$ & 20 & $1.9(1.4)$ & 1 & $3.42 \%$ & $0.14[-0.99,1.27]$ \\
\hline O'Fallon 2012 & 15 & $3.6(1.6)$ & 15 & $3.9(1.6)$ & -1 & $3.35 \%$ & $-0.3[-1.45,0.85]$ \\
\hline Peschek 2014 & 8 & $4.1(1.8)$ & 8 & $4.6(1.7)$ & E & $1.75 \%$ & $-0.5[-2.22,1.22]$ \\
\hline Shafat 2004 & 6 & $0.3(0.2)$ & 6 & $0.2(0.2)$ & + & $11.68 \%$ & $0.07[-0.13,0.27]$ \\
\hline
\end{tabular}




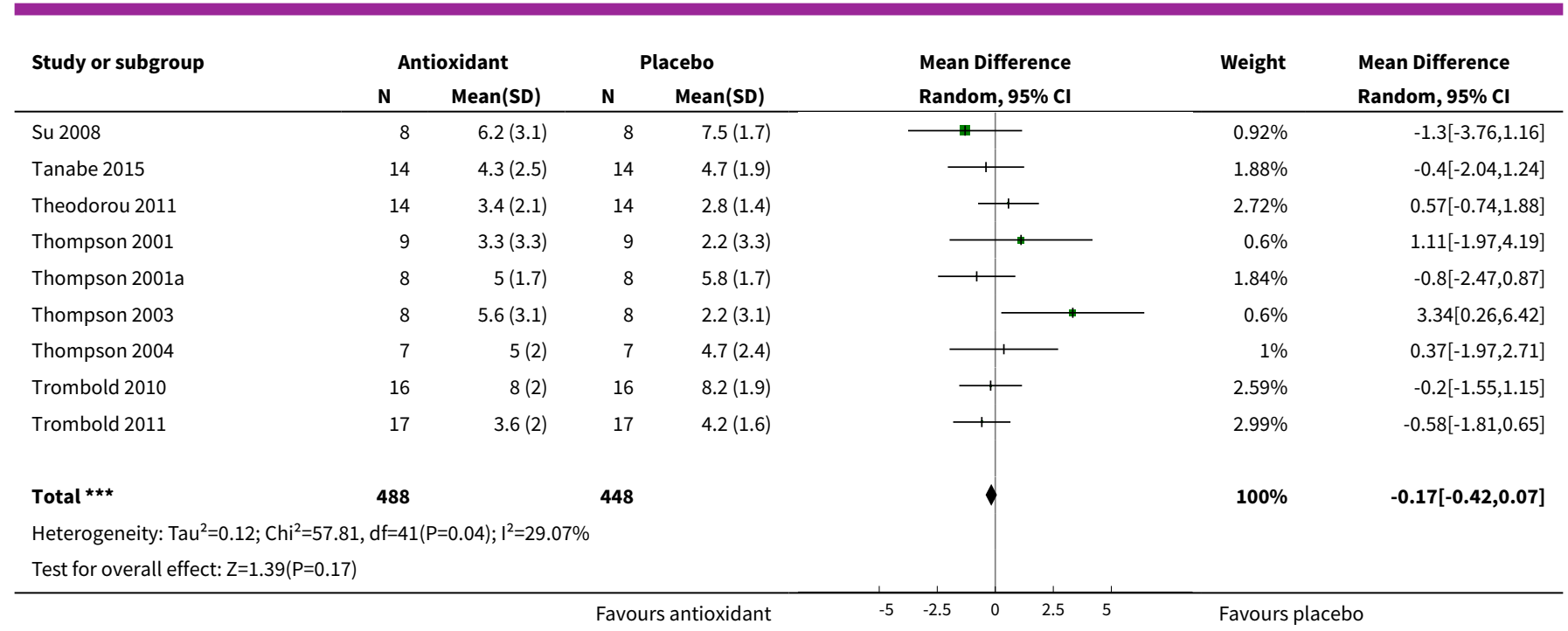

Analysis 1.9. Comparison 1 Antioxidant supplementation vs. placebo for delayed onset muscle soreness (all studies), Outcome 9 Muscle soreness at 48 hours - all at same scale (0 to 10; worst pain).

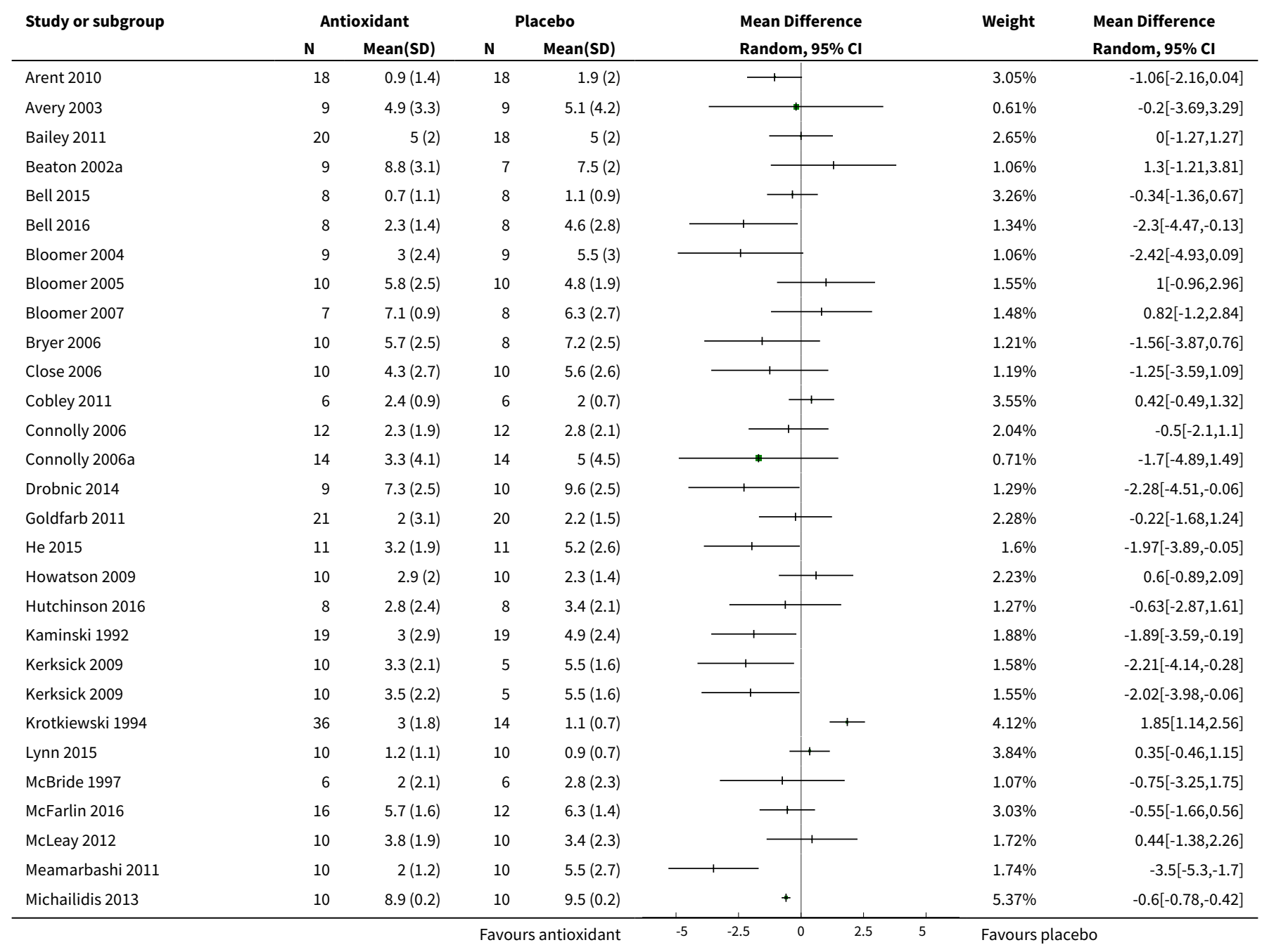




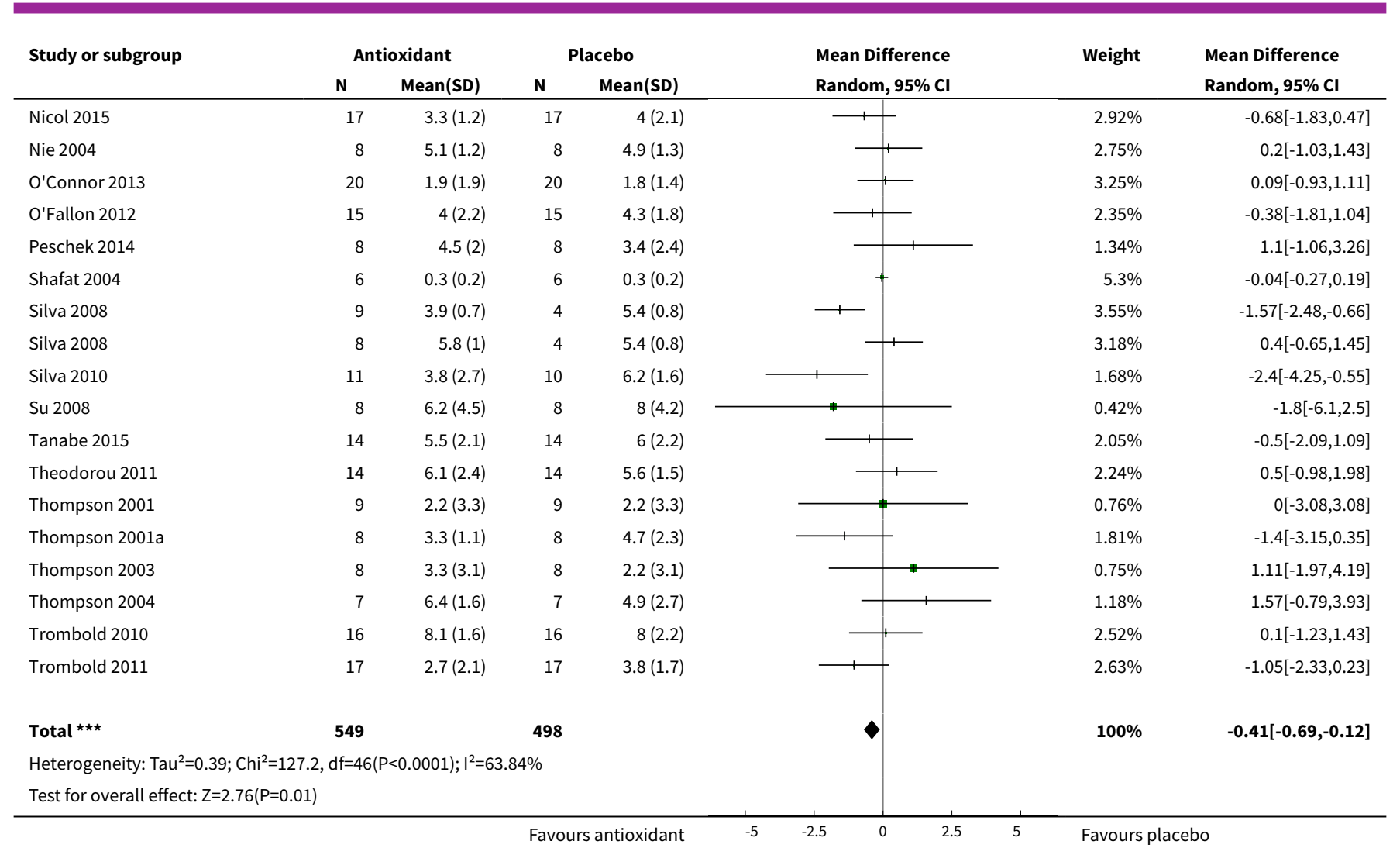

Analysis 1.10. Comparison 1 Antioxidant supplementation vs. placebo for delayed onset muscle soreness (all studies), Outcome 10 Muscle soreness at 72 hours - all at same scale (0 to 10; worst pain).

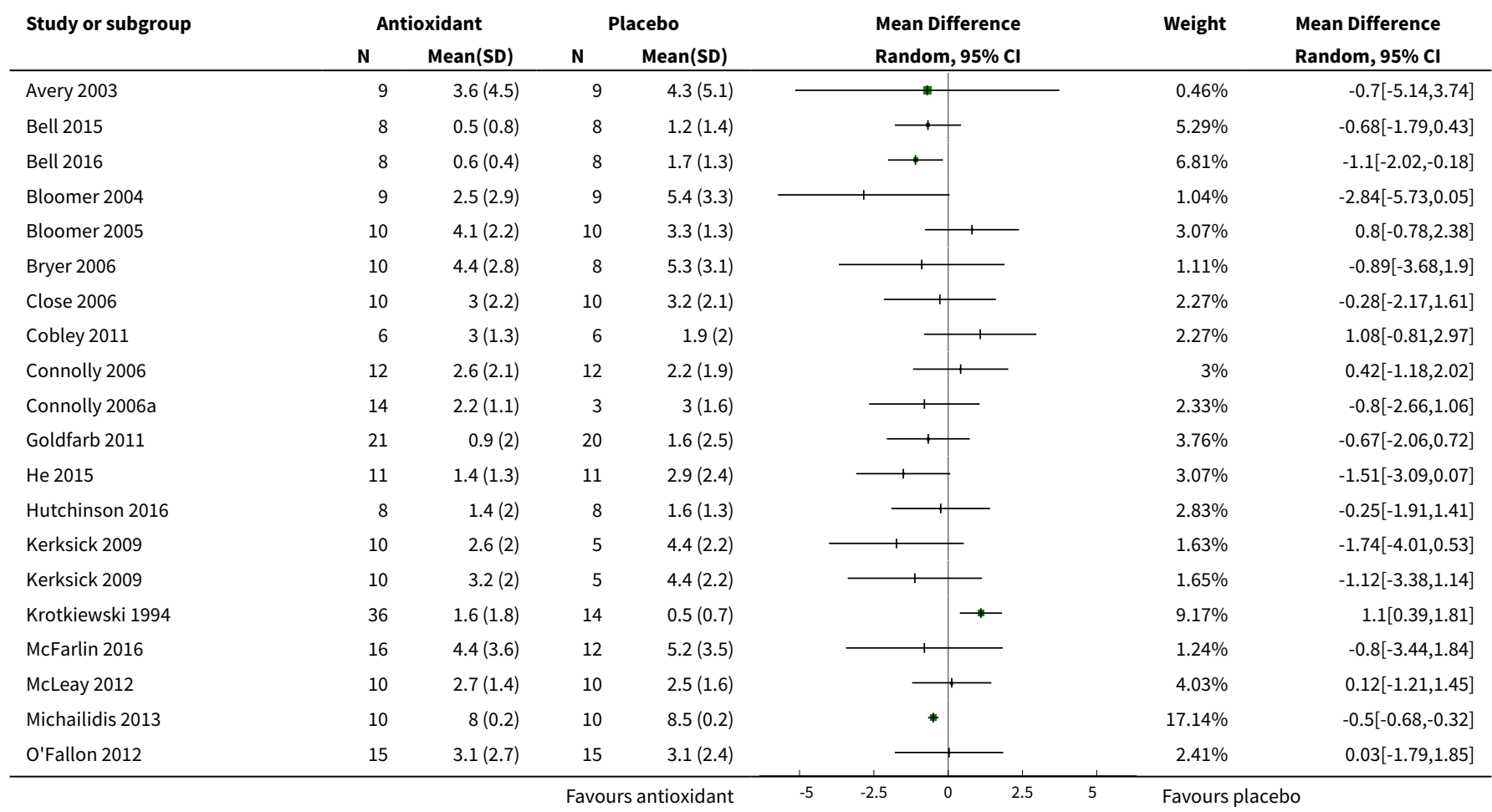




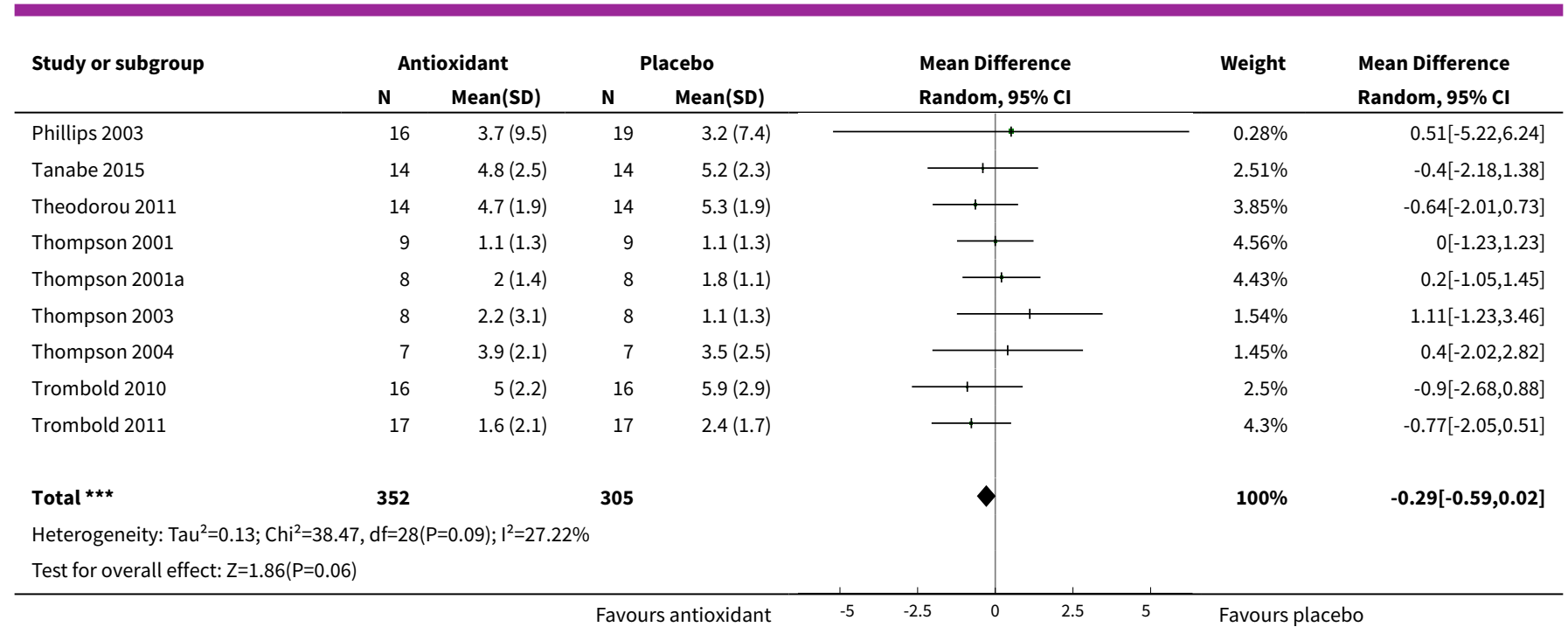

Analysis 1.11. Comparison 1 Antioxidant supplementation vs. placebo for delayed onset muscle soreness (all studies), Outcome 11 Muscle soreness at 96 hours - all at same scale (0 to 10; worst pain).

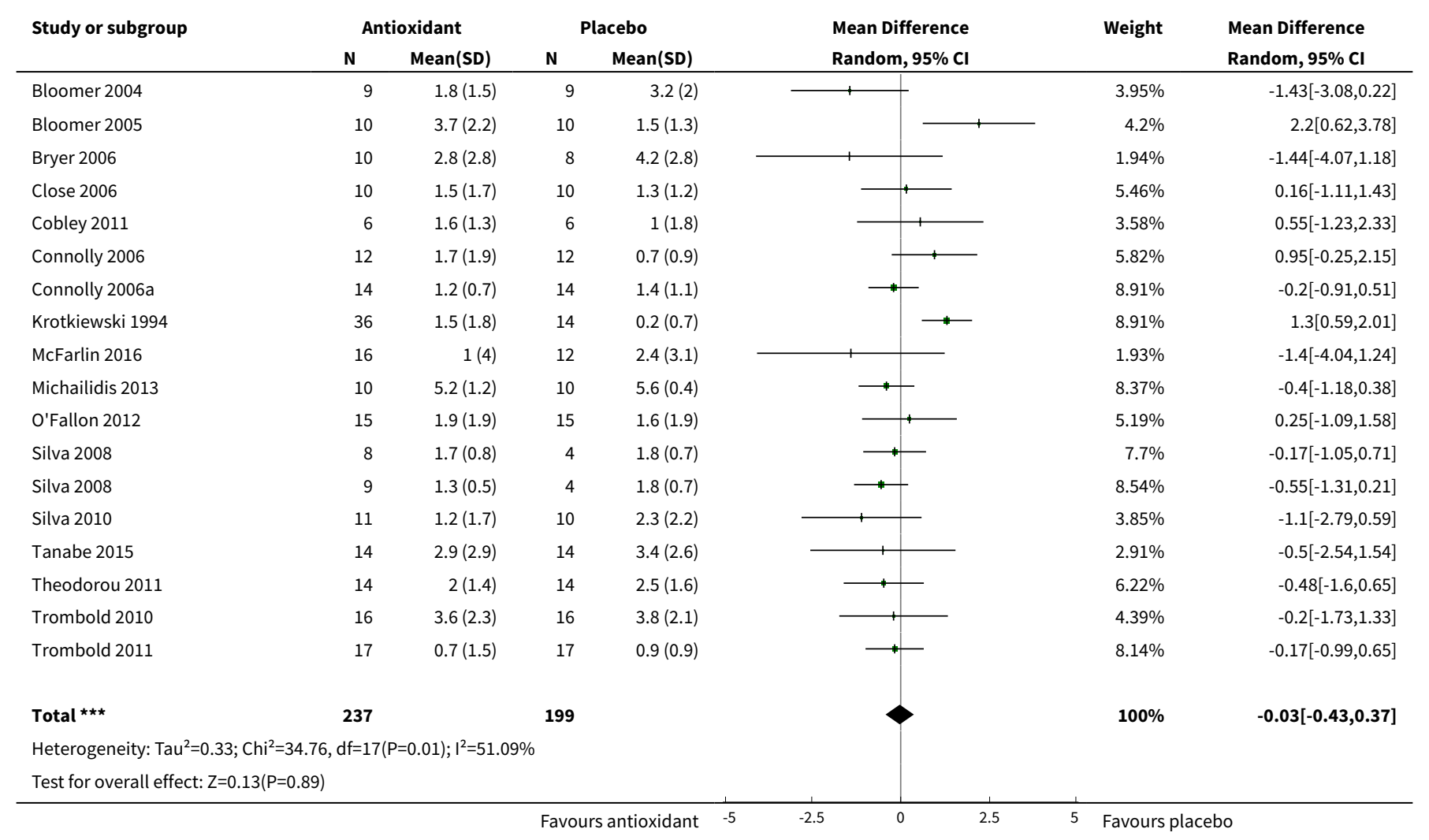


Analysis 1.12. Comparison 1 Antioxidant supplementation vs. placebo for delayed onset muscle soreness (all studies), Outcome 12 Muscle soreness at 24 hours.

Subgroup analysis by type of exercise (whole body aerobic vs. mechanically induced).

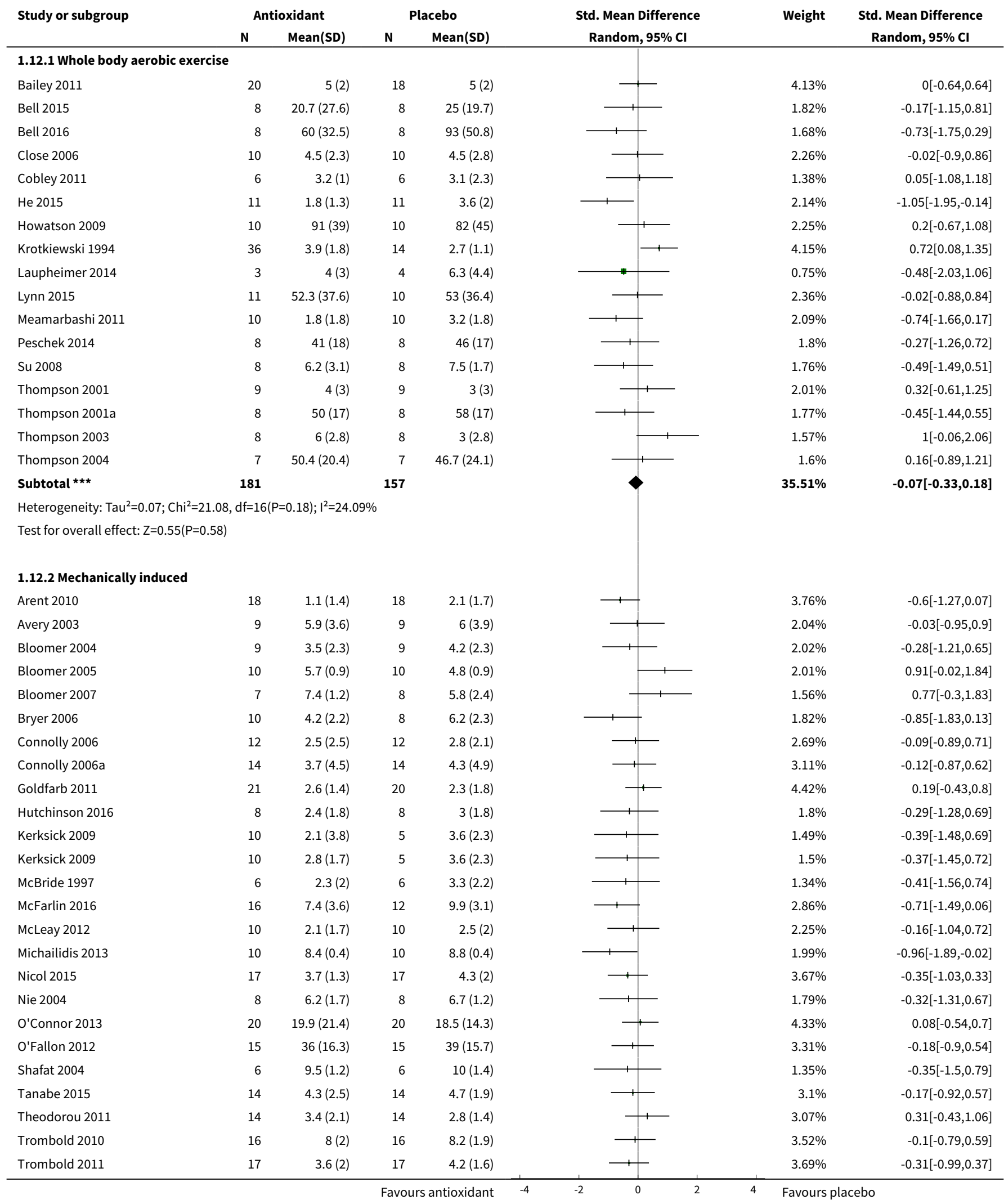




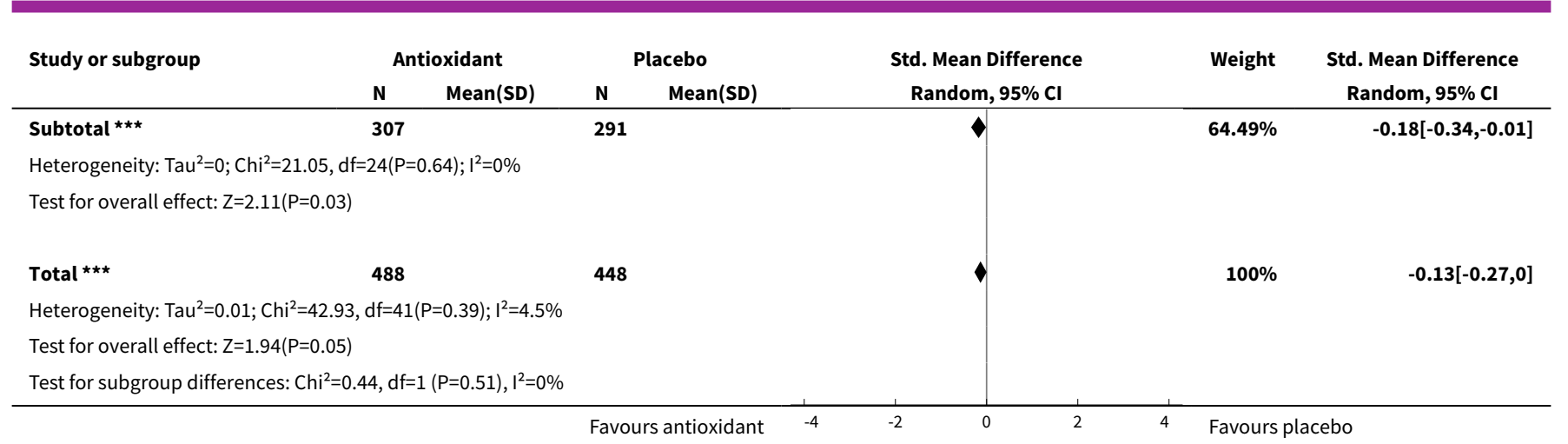

Analysis 1.13. Comparison 1 Antioxidant supplementation vs. placebo for delayed
onset muscle soreness (all studies), Outcome 13 Muscle soreness at 48 hours.
Subgroup analysis by type of exercise (whole body aerobic vs. mechanically induced).

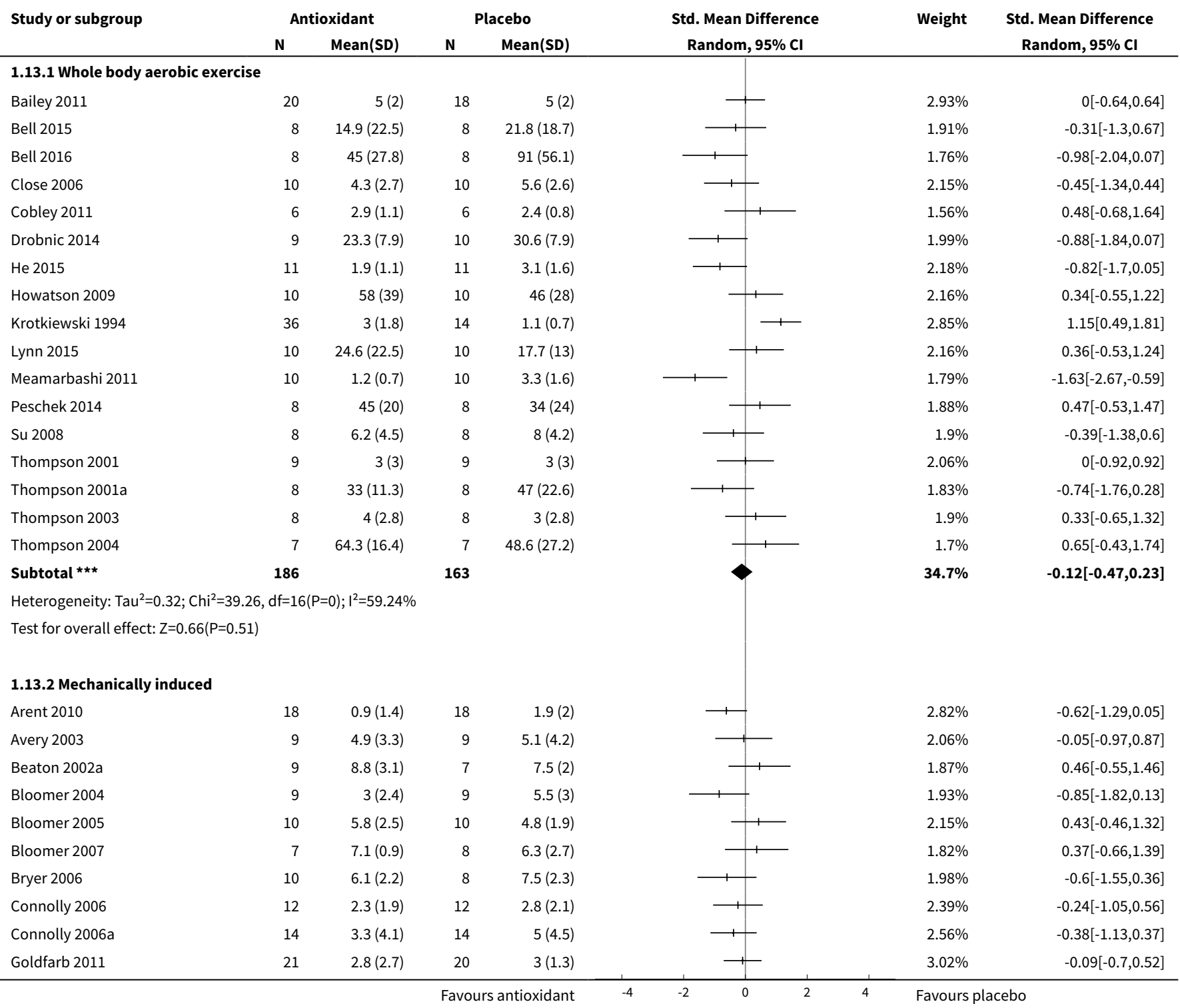




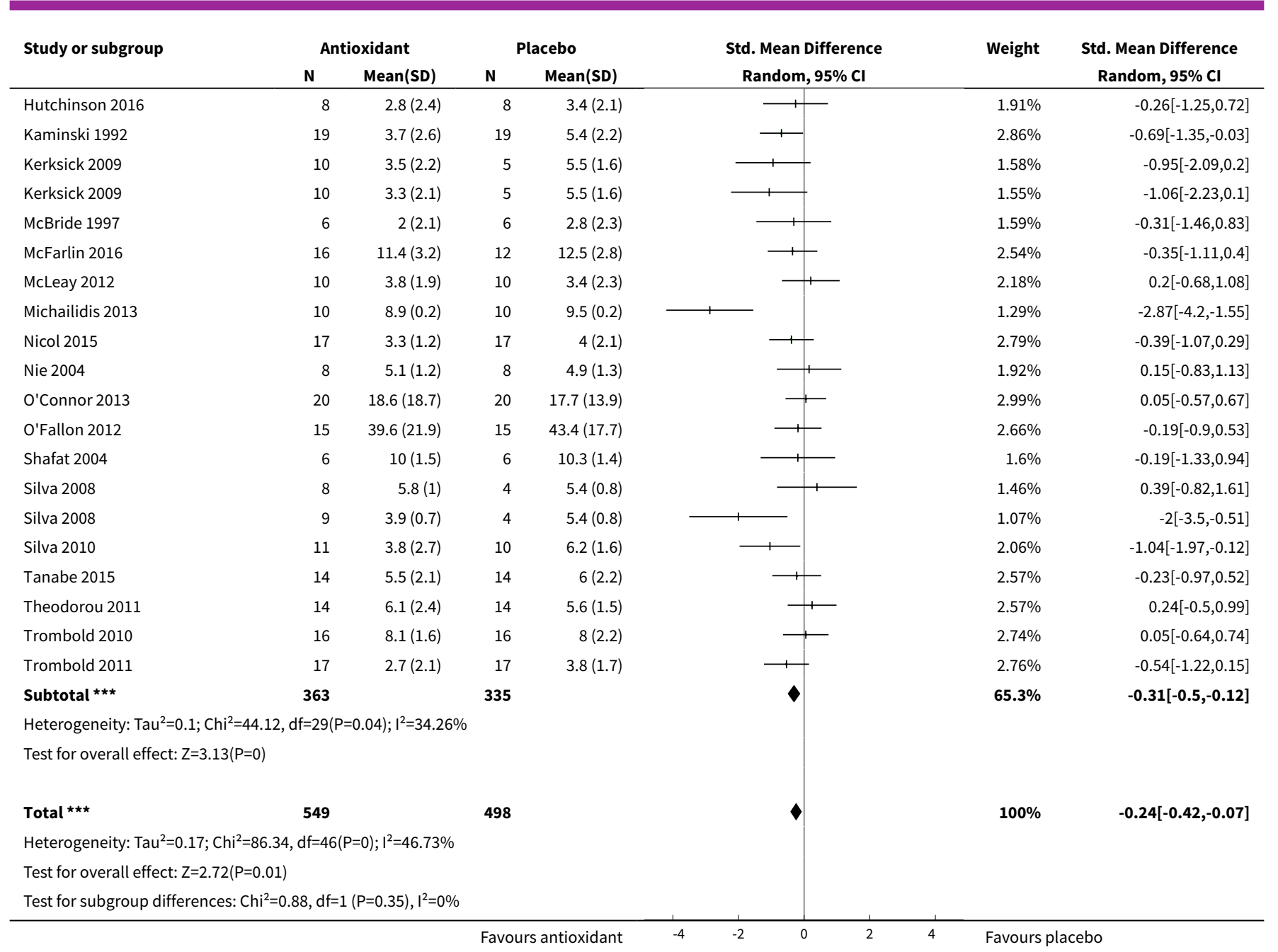

Analysis 1.14. Comparison 1 Antioxidant supplementation vs. placebo for delayed onset muscle soreness (all studies), Outcome 14 Muscle soreness at 24 hours. Subgroup analysis by funding sources (funded by food company or provider of antioxidant supplements vs. not funded by food company or provider of antioxidant supplements).

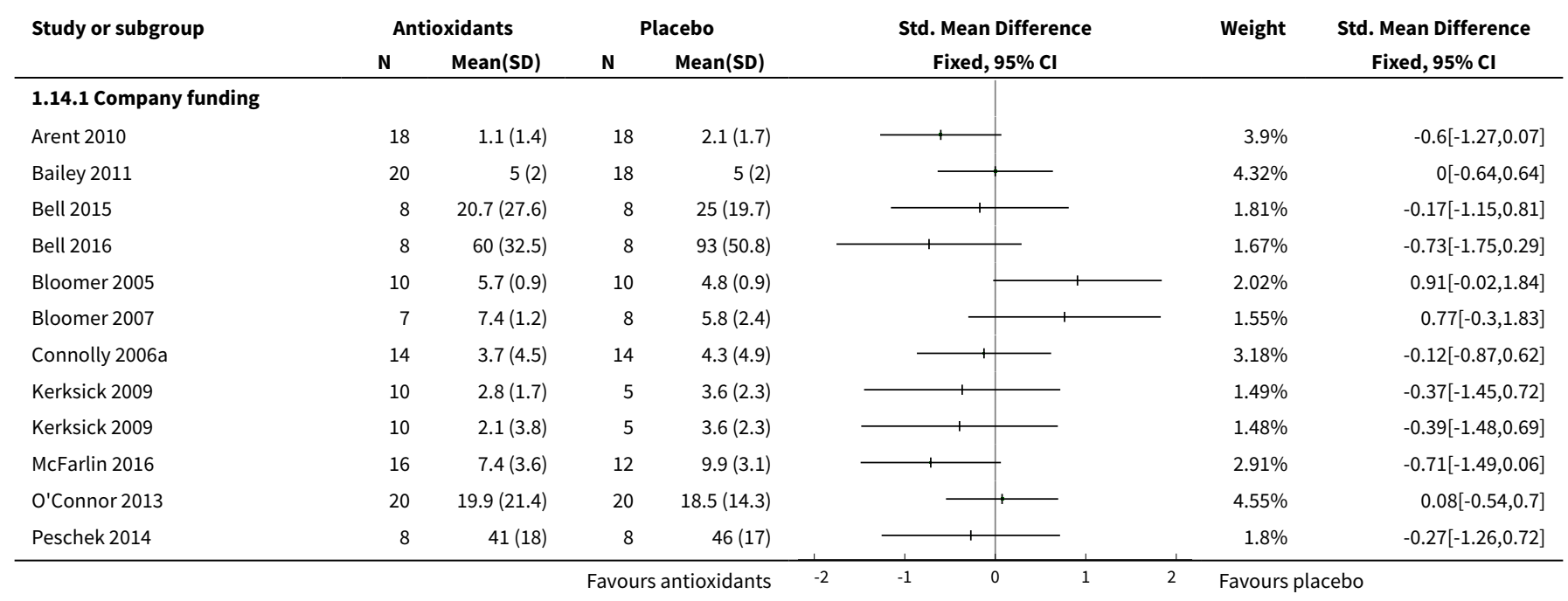




\begin{tabular}{|c|c|c|c|c|c|c|c|}
\hline \multirow{3}{*}{$\begin{array}{l}\text { Study or subgroup } \\
\text { Tanabe } 2015\end{array}$} & \multicolumn{2}{|c|}{ Antioxidants } & \multicolumn{2}{|c|}{ Placebo } & \multirow{2}{*}{$\begin{array}{c}\text { Std. Mean Difference } \\
\text { Fixed, } 95 \% \mathrm{Cl}\end{array}$} & \multirow{3}{*}{$\begin{array}{l}\text { Weight } \\
3.17 \%\end{array}$} & \multirow{3}{*}{$\begin{array}{c}\text { Std. Mean Difference } \\
\text { Fixed, 95\% Cl } \\
-0.17[-0.92,0.57]\end{array}$} \\
\hline & \multirow{2}{*}{$\frac{\mathbf{N}}{14}$} & \multirow{2}{*}{$\frac{\operatorname{Mean}(\text { SD) }}{4.3(2.5)}$} & \multirow{2}{*}{$\frac{\mathbf{N}}{14}$} & \multirow{2}{*}{$\begin{array}{r}\text { Mean(SD) } \\
4.7(1.9)\end{array}$} & & & \\
\hline & & & & & \begin{tabular}{l|l}
1 & \\
1
\end{tabular} & & \\
\hline Thompson 2001 & 9 & $4(3)$ & 9 & $3(3)$ & & $2.02 \%$ & $0.32[-0.61,1.25]$ \\
\hline Thompson 2001a & 8 & $50(17)$ & 8 & $58(17)$ & & $1.76 \%$ & $-0.45[-1.44,0.55]$ \\
\hline Thompson 2003 & 8 & $6(2.8)$ & 8 & $3(2.8)$ & & $1.56 \%$ & $1[-0.06,2.06]$ \\
\hline Trombold 2010 & 16 & $8(2)$ & 16 & $8.2(1.9)$ & & $3.64 \%$ & $-0.1[-0.79,0.59]$ \\
\hline Trombold 2011 & 17 & $3.6(2)$ & 17 & $4.2(1.6)$ & \begin{tabular}{l|l} 
\\
\end{tabular} & $3.82 \%$ & $-0.31[-0.99,0.37]$ \\
\hline Subtotal $\star \star \star$ & 221 & & 206 & & & $46.67 \%$ & $-0.11[-0.31,0.08]$ \\
\hline \multicolumn{8}{|c|}{ Heterogeneity: $\mathrm{Tau}^{2}=0 ; \mathrm{Chi}^{2}=19.92, \mathrm{df}=17(\mathrm{P}=0.28) ; \mathrm{I}^{2}=14.68 \%$} \\
\hline \multicolumn{8}{|c|}{ Test for overall effect: $Z=1.15(P=0.25)$} \\
\hline \multicolumn{8}{|c|}{ 1.14.2 Other funding } \\
\hline Avery 2003 & 9 & $5.9(3.6)$ & 9 & $6(3.9)$ & & $2.05 \%$ & $-0.03[-0.95,0.9]$ \\
\hline Bloomer 2004 & 9 & $3.5(2.3)$ & 9 & $4.2(2.3)$ & & $2.02 \%$ & $-0.28[-1.21,0.65]$ \\
\hline Bryer 2006 & 10 & $4.2(2.2)$ & 8 & $6.2(2.3)$ & - & $1.82 \%$ & $-0.85[-1.83,0.13]$ \\
\hline Close 2006 & 10 & $4.5(2.3)$ & 10 & $4.5(2.8)$ & & $2.28 \%$ & $-0.02[-0.9,0.86]$ \\
\hline Cobley 2011 & 6 & $3.2(1)$ & 6 & $3.1(2.3)$ & & $1.37 \%$ & $0.05[-1.08,1.18]$ \\
\hline Connolly 2006 & 12 & $2.5(2.5)$ & 12 & $2.8(2.1)$ & & $2.73 \%$ & $-0.09[-0.89,0.71]$ \\
\hline Goldfarb 2011 & 21 & $2.6(1.4)$ & 20 & $2.3(1.8)$ & & $4.64 \%$ & $0.19[-0.43,0.8]$ \\
\hline He 2015 & 11 & $1.8(1.3)$ & 11 & $3.6(2)$ & - & $2.15 \%$ & $-1.05[-1.95,-0.14]$ \\
\hline Howatson 2009 & 10 & $91(39)$ & 10 & $82(45)$ & + & $2.26 \%$ & $0.2[-0.67,1.08]$ \\
\hline Hutchinson 2016 & 8 & $2.4(1.8)$ & 8 & $3(1.8)$ & & $1.8 \%$ & $-0.29[-1.28,0.69]$ \\
\hline Krotkiewski 1994 & 36 & $3.9(1.8)$ & 14 & $2.7(1.1)$ & + & $4.35 \%$ & $0.72[0.08,1.35]$ \\
\hline Laupheimer 2014 & 3 & $4(3)$ & 4 & $6.3(4.4)$ & & $0.73 \%$ & $-0.48[-2.03,1.06]$ \\
\hline Lynn 2015 & 11 & $52.3(37.6)$ & 10 & $53(36.4)$ & & $2.39 \%$ & $-0.02[-0.88,0.84]$ \\
\hline McBride 1997 & 6 & $2.3(2)$ & 6 & $3.3(2.2)$ & & $1.32 \%$ & $-0.41[-1.56,0.74]$ \\
\hline McLeay 2012 & 10 & $2.1(1.7)$ & 10 & $2.5(2)$ & & $2.27 \%$ & $-0.16[-1.04,0.72]$ \\
\hline Meamarbashi 2011 & 10 & $1.8(1.8)$ & 10 & $3.2(1.8)$ & - & $2.1 \%$ & $-0.74[-1.66,0.17]$ \\
\hline Michailidis 2013 & 10 & $8.4(0.4)$ & 10 & $8.8(0.4)$ & & $1.99 \%$ & $-0.96[-1.89,-0.02]$ \\
\hline Nicol 2015 & 17 & $3.7(1.3)$ & 17 & $4.3(2)$ & - & $3.81 \%$ & $-0.35[-1.03,0.33]$ \\
\hline Nie 2004 & 8 & $6.2(1.7)$ & 8 & $6.7(1.2)$ & & $1.79 \%$ & $-0.32[-1.31,0.67]$ \\
\hline O'Fallon 2012 & 15 & $36(16.3)$ & 15 & $39(15.7)$ & & $3.4 \%$ & $-0.18[-0.9,0.54]$ \\
\hline Shafat 2004 & 6 & $9.5(1.2)$ & 6 & $10(1.4)$ & & $1.34 \%$ & $-0.35[-1.5,0.79]$ \\
\hline Theodorou 2011 & 14 & $3.4(2.1)$ & 14 & $2.8(1.4)$ & & $3.14 \%$ & $0.31[-0.43,1.06]$ \\
\hline Thompson 2004 & 7 & $50.4(20.4)$ & 7 & $46.7(24.1)$ & & $1.59 \%$ & $0.16[-0.89,1.21]$ \\
\hline 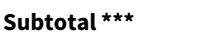 & 259 & & 234 & & & $53.33 \%$ & $-0.14[-0.32,0.05]$ \\
\hline \multicolumn{8}{|c|}{ Heterogeneity: $\operatorname{Tau}^{2}=0 ; \mathrm{Chi}^{2}=22.48, \mathrm{df}=22(\mathrm{P}=0.43) ; \mathrm{I}^{2}=2.12 \%$} \\
\hline \multicolumn{8}{|c|}{ Test for overall effect: $Z=1.47(P=0.14)$} \\
\hline 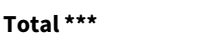 & 480 & & 440 & & & $100 \%$ & $-0.13[-0.26,0.01]$ \\
\hline \multicolumn{8}{|c|}{ Heterogeneity: $\operatorname{Tau}^{2}=0 ; \mathrm{Chi}^{2}=42.43, \mathrm{df}=40(\mathrm{P}=0.37) ; \mathrm{I}^{2}=5.72 \%$} \\
\hline \multicolumn{8}{|c|}{ Test for overall effect: $Z=1.86(P=0.06)$} \\
\hline Test for subgroup di & $3, \mathrm{df}=$ & $(P=0.87), I^{2}=0 \%$ & & & & & \\
\hline
\end{tabular}


Analysis 1.15. Comparison 1 Antioxidant supplementation vs. placebo for delayed onset muscle soreness (all studies), Outcome 15 Muscle soreness at $\mathbf{4 8}$ hours. Subgroup analysis by funding sources (funded by food company or provider of antioxidant supplements vs. not funded by food company or provider of antioxidant supplements).

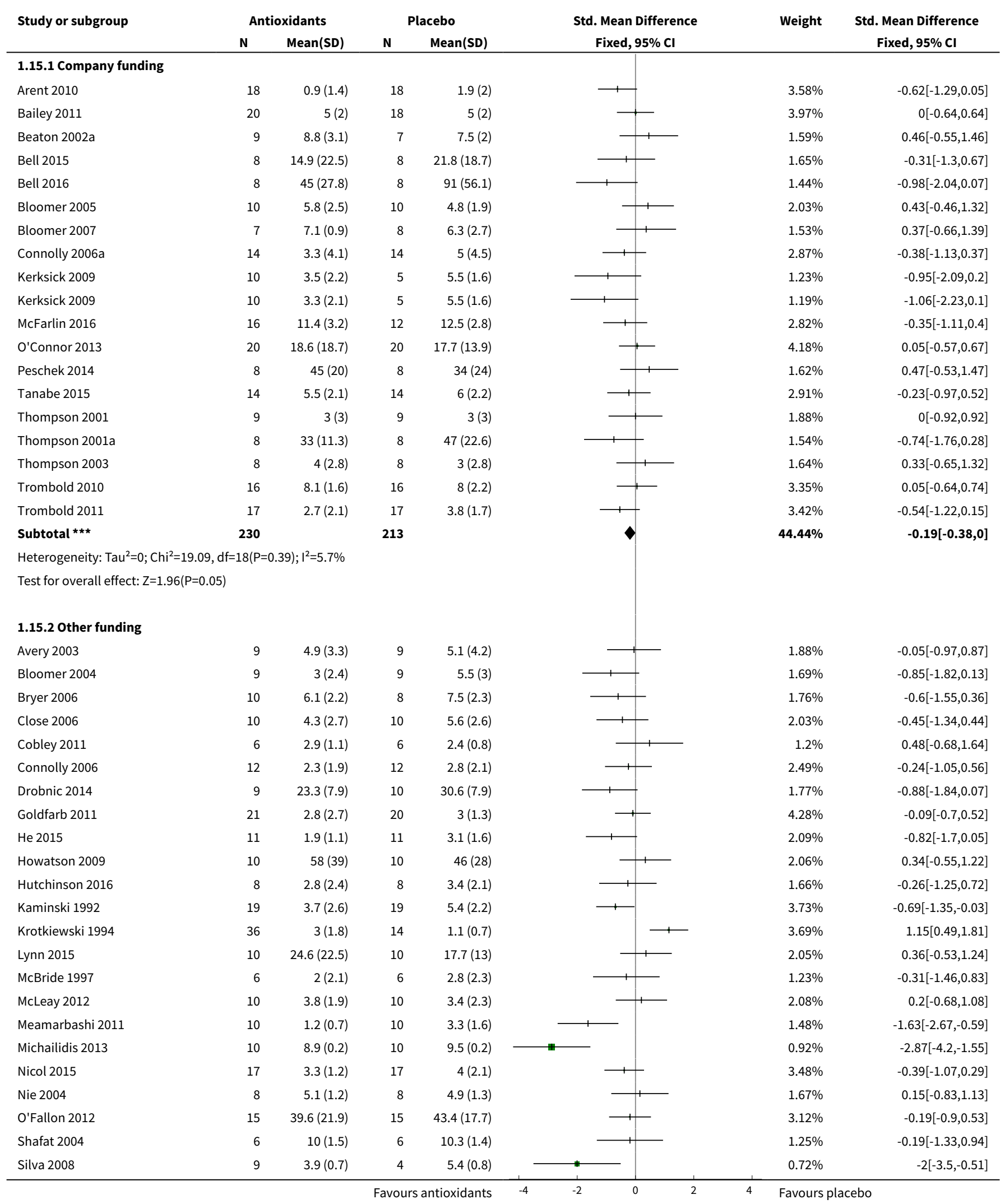




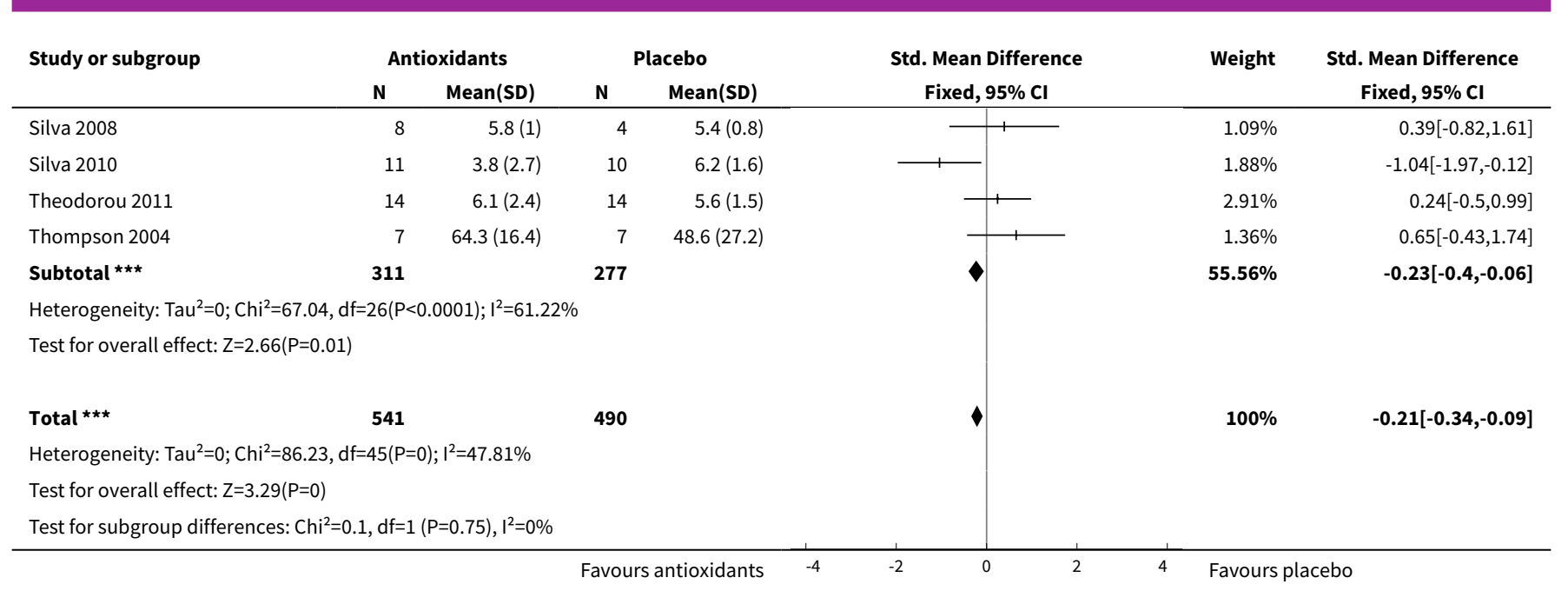
Analysis 1.16. Comparison 1 Antioxidant supplementation vs. placebo for delayed onset muscle
soreness (all studies), Outcome 16 Muscle tenderness measured in Newtons (all follow-up times).

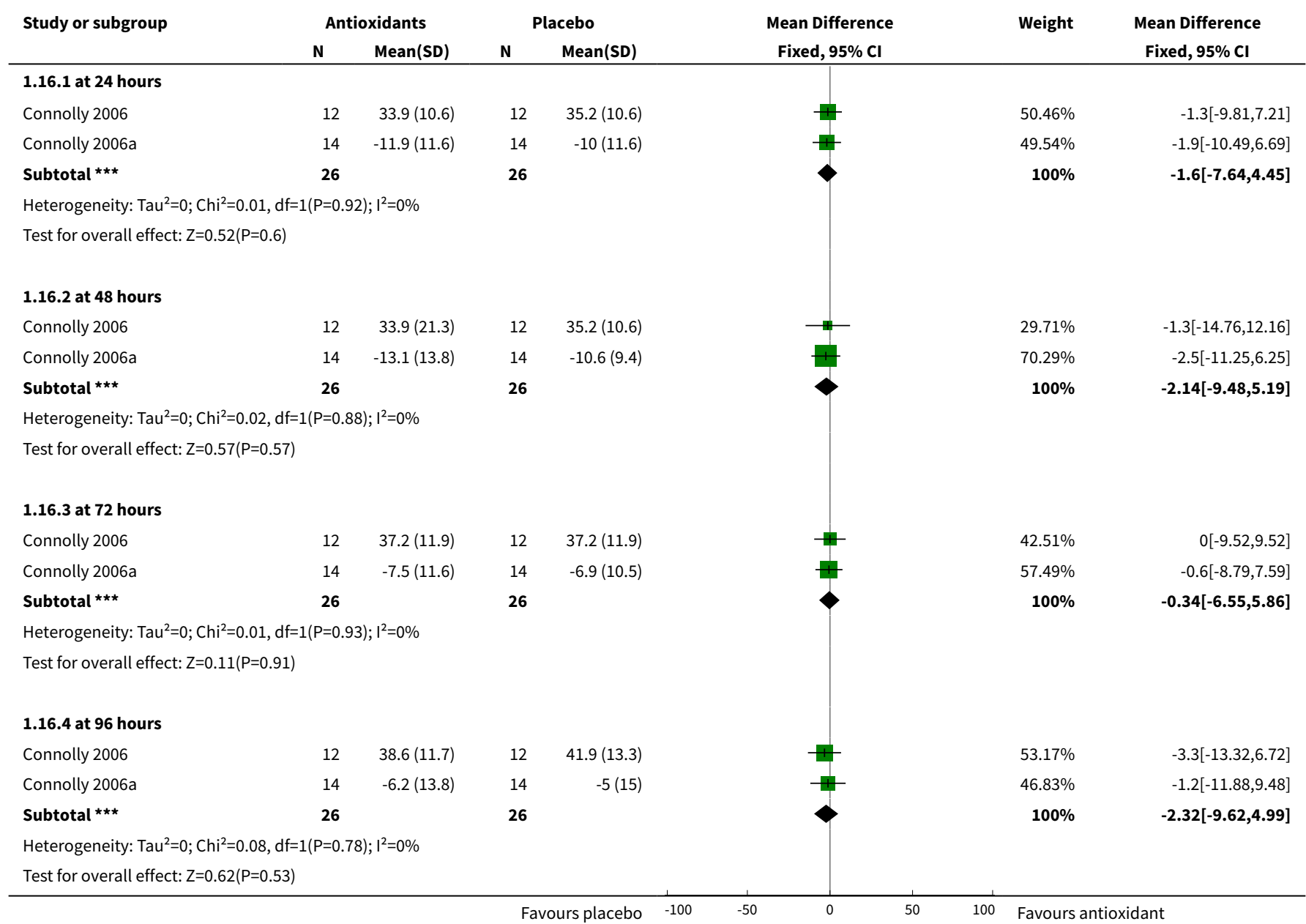


Analysis 1.17. Comparison 1 Antioxidant supplementation vs. placebo for delayed onset muscle soreness (all studies), Outcome 17 Muscle tenderness measured in $\mathrm{kg}$ (all follow-up times).

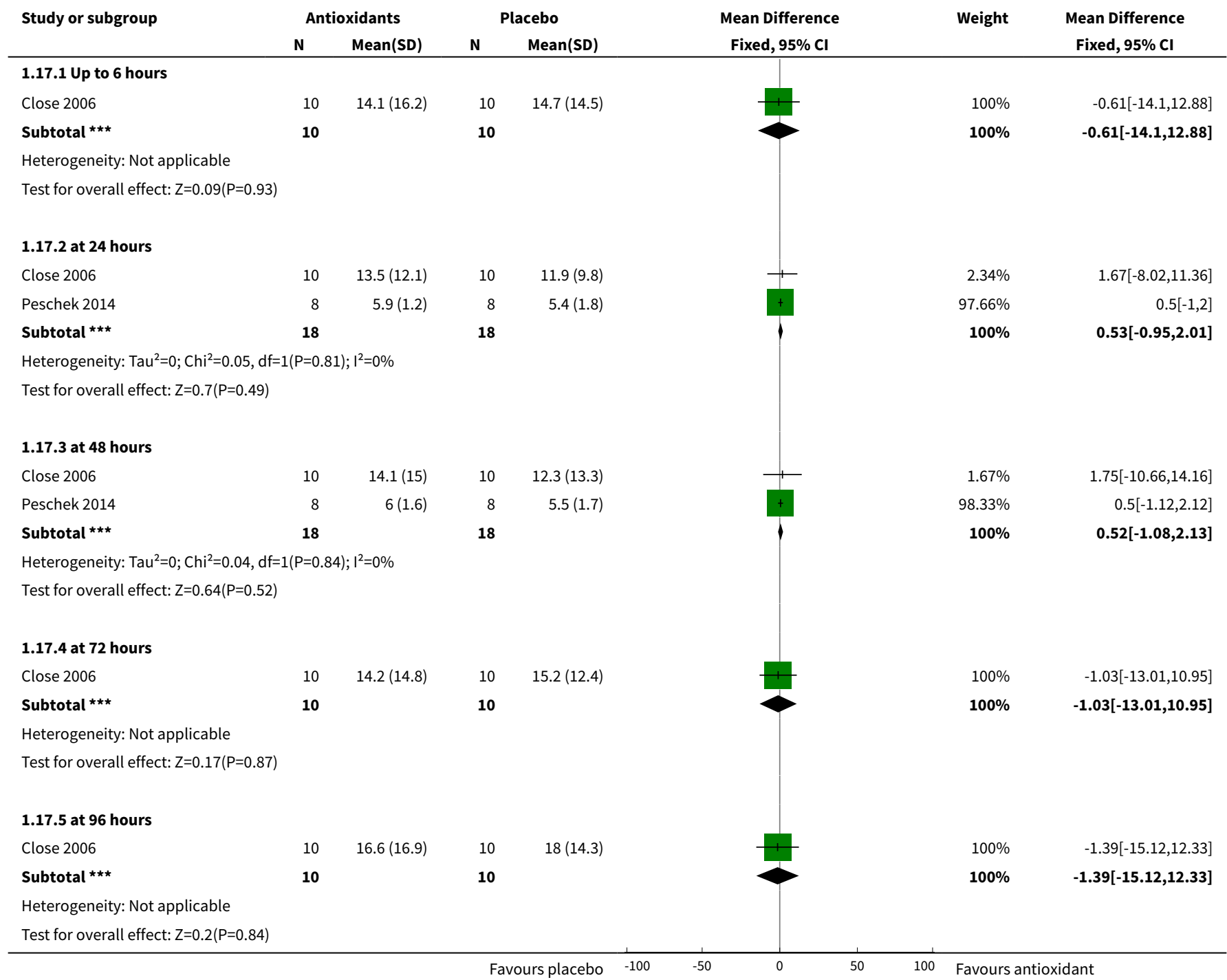

Analysis 1.18. Comparison 1 Antioxidant supplementation vs. placebo for delayed onset muscle soreness (all studies), Outcome 18 30-second Wingate average peak power output (W/kg) (post 7 days of intervention).

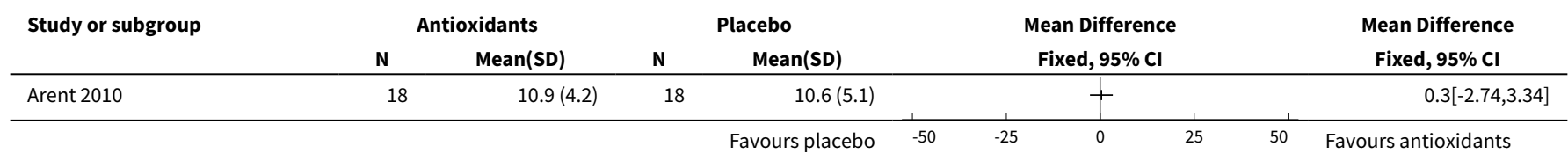


Analysis 1.19. Comparison 1 Antioxidant supplementation vs. placebo for delayed onset muscle soreness (all studies), Outcome $1920 \mathrm{~m}$ Sprint time (s).

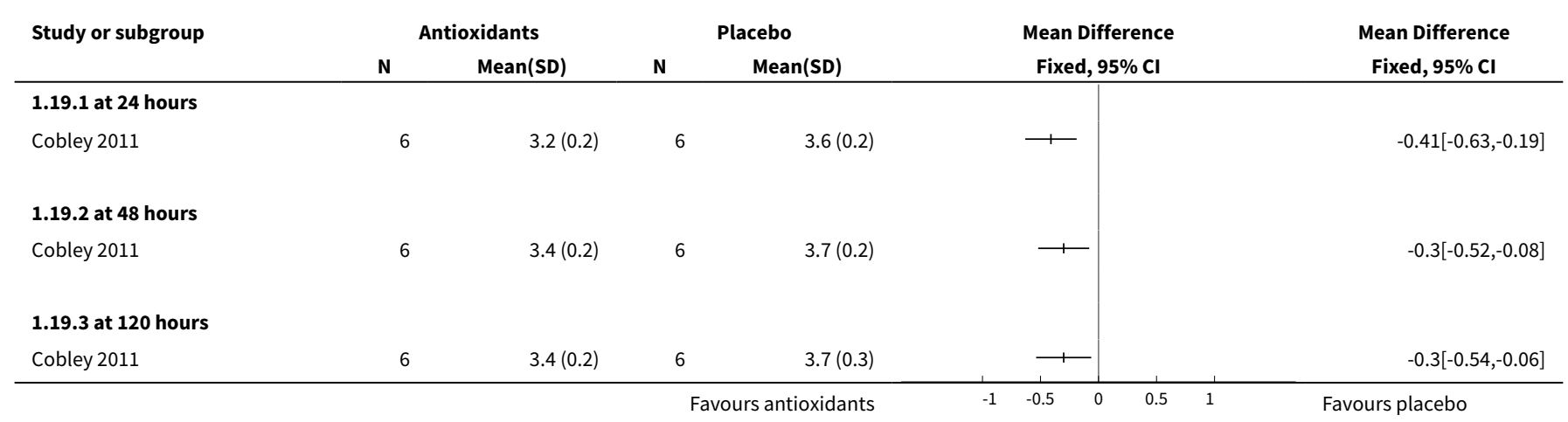

Analysis 1.20. Comparison 1 Antioxidant supplementation vs. placebo for delayed onset muscle soreness (all studies), Outcome 20 Maximal oxygen consumption ( $\mathrm{mL} / \mathrm{kg} / \mathrm{min}$ ) (post 42 days of supplementation).

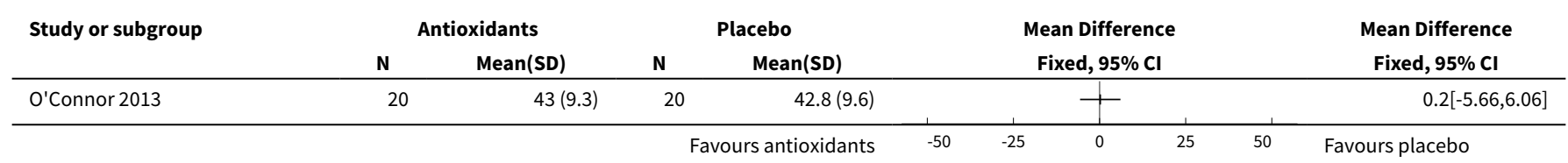

Analysis 1.21. Comparison 1 Antioxidant supplementation vs. placebo for delayed onset muscle soreness (all studies), Outcome 21 Agility (seconds).

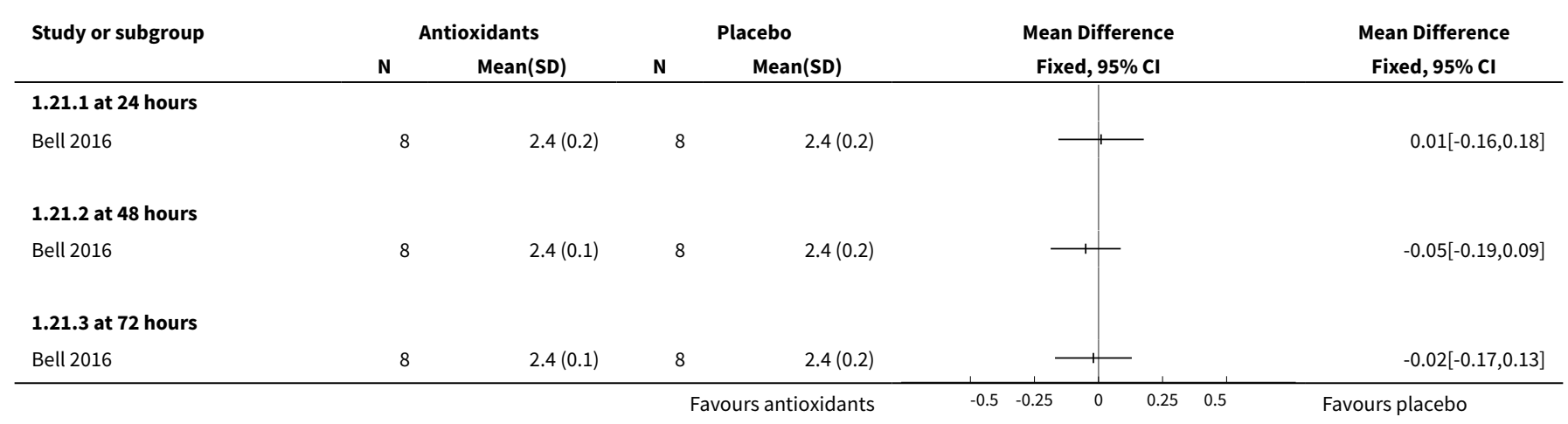

Analysis 1.22. Comparison 1 Antioxidant supplementation vs. placebo for delayed onset muscle soreness (all studies), Outcome 226 second sprint maximal power (Watts) (all follow-up times).

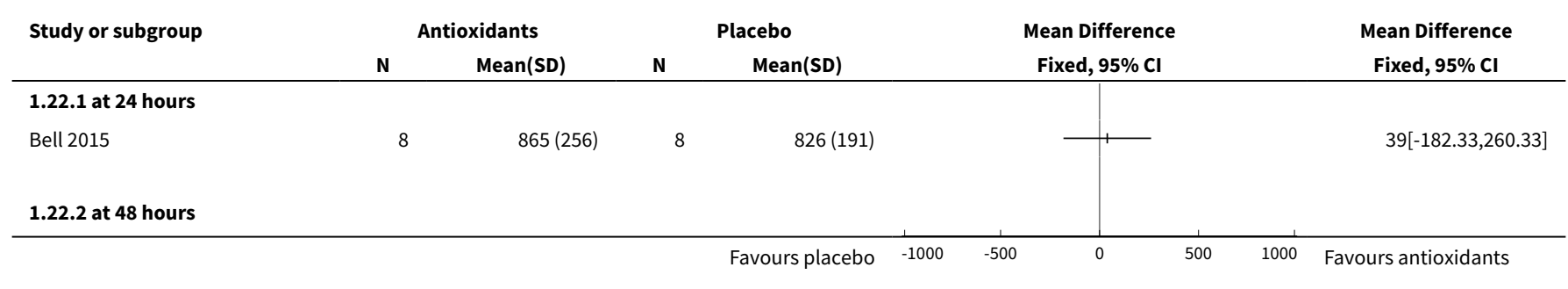




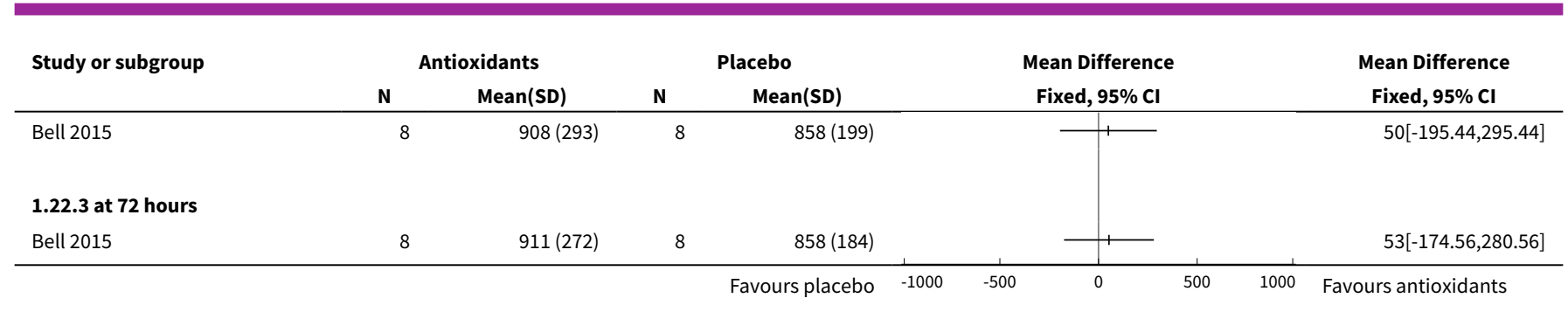

Analysis 1.23. Comparison 1 Antioxidant supplementation vs. placebo for delayed onset muscle soreness (all studies), Outcome 23 Maximal voluntary isometric contraction measured as percentage change from baseline.

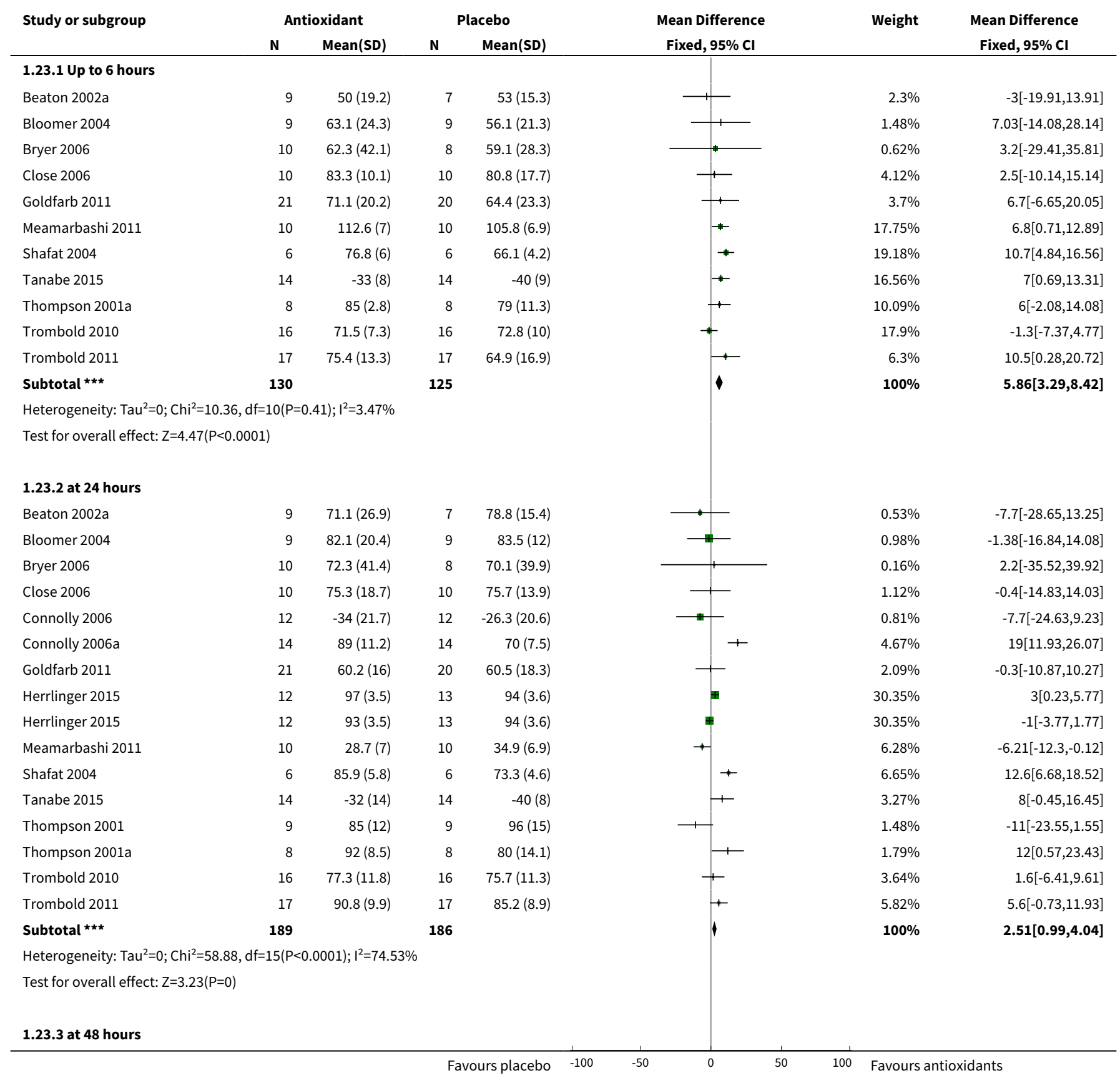




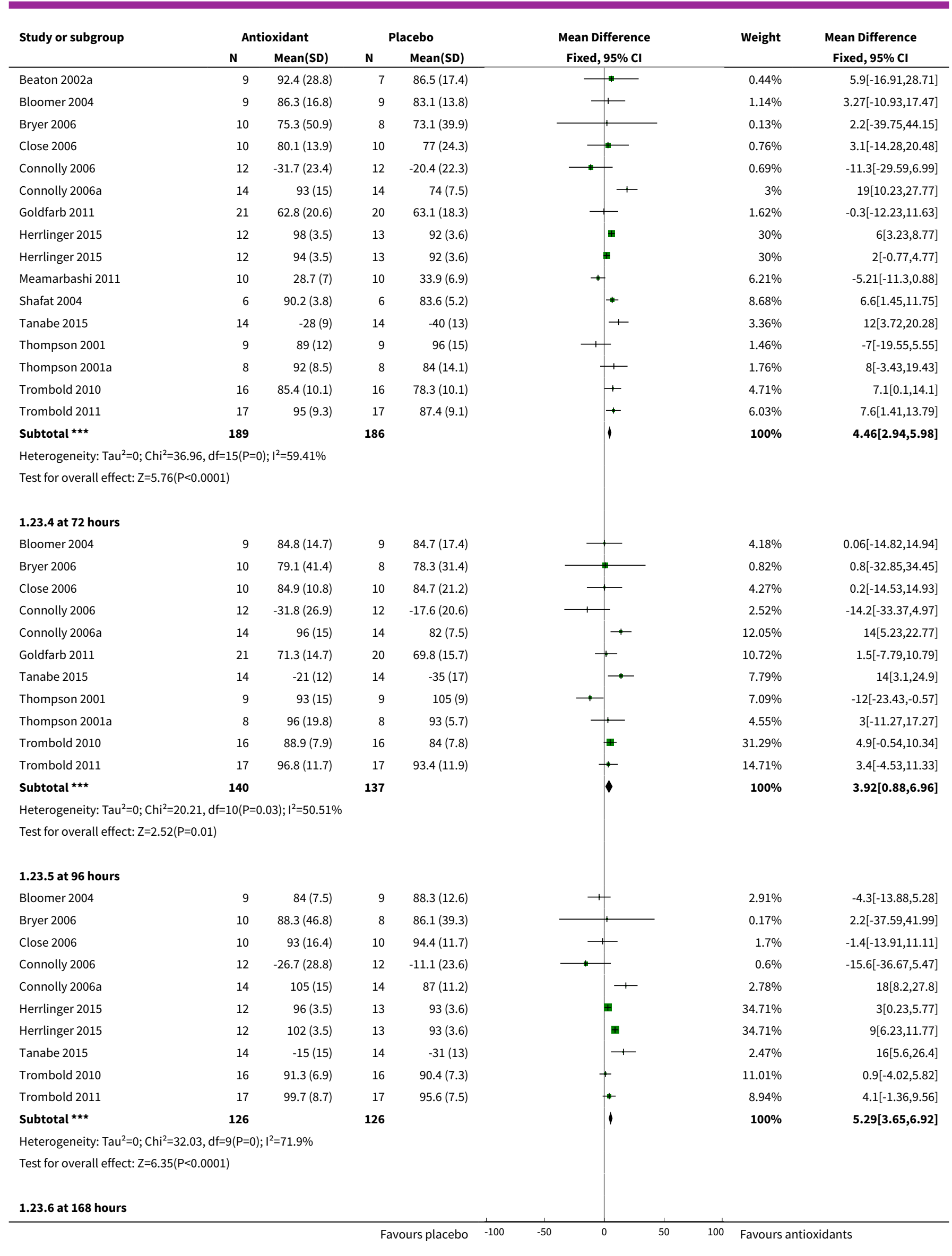




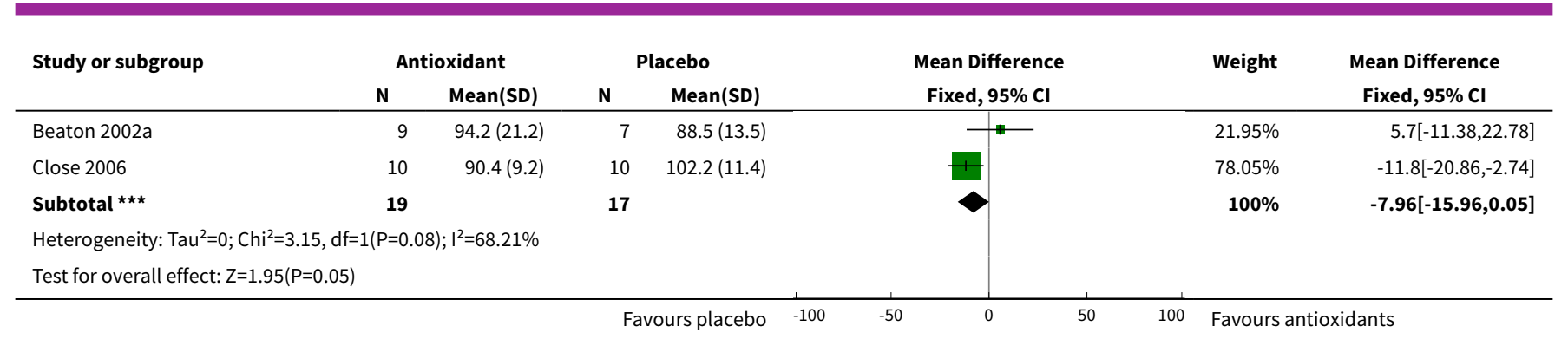

Analysis 1.24. Comparison 1 Antioxidant supplementation vs. placebo for delayed onset muscle soreness (all studies), Outcome 24 Maximal voluntary isometric contraction measured in Newton metres.

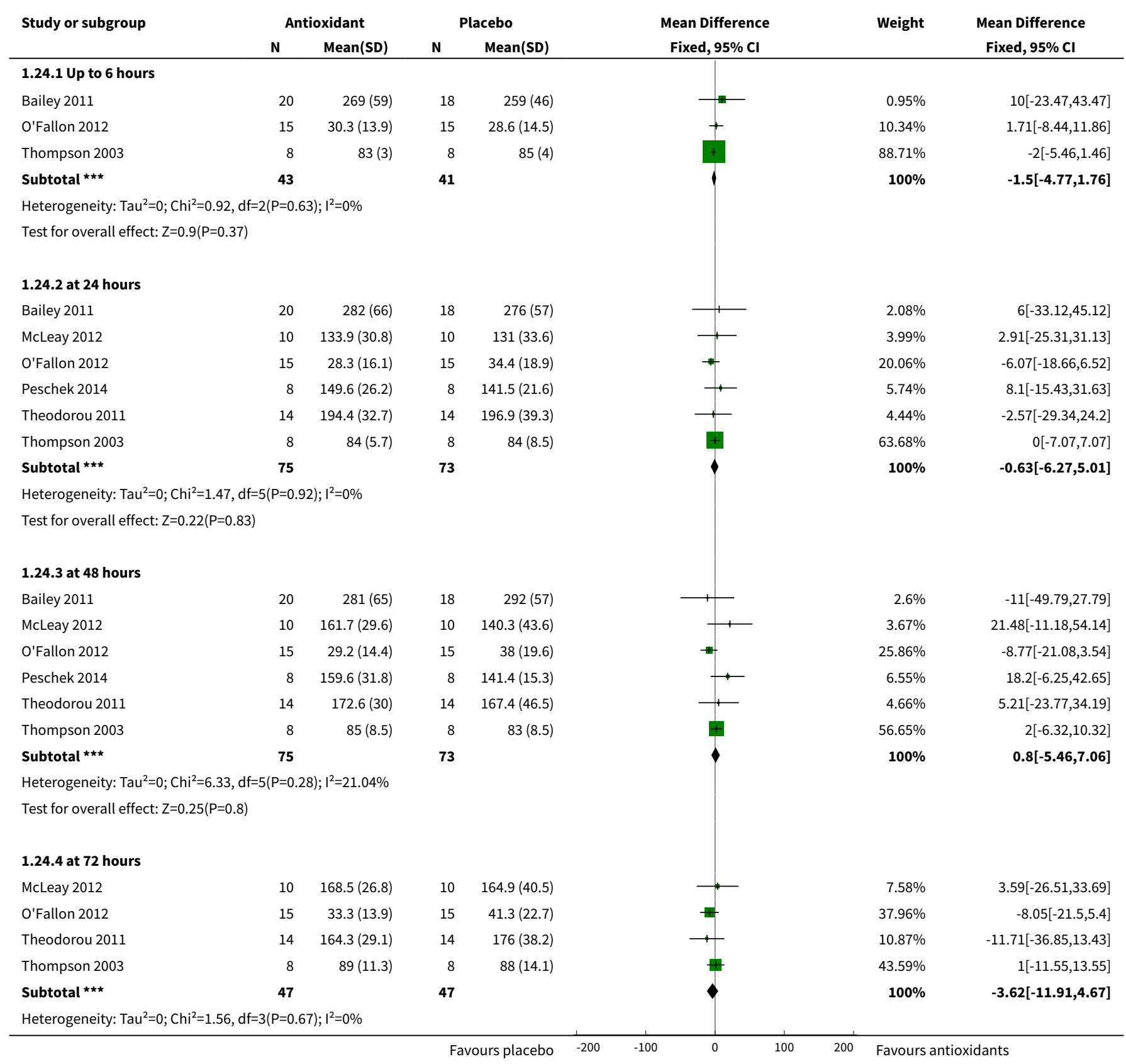




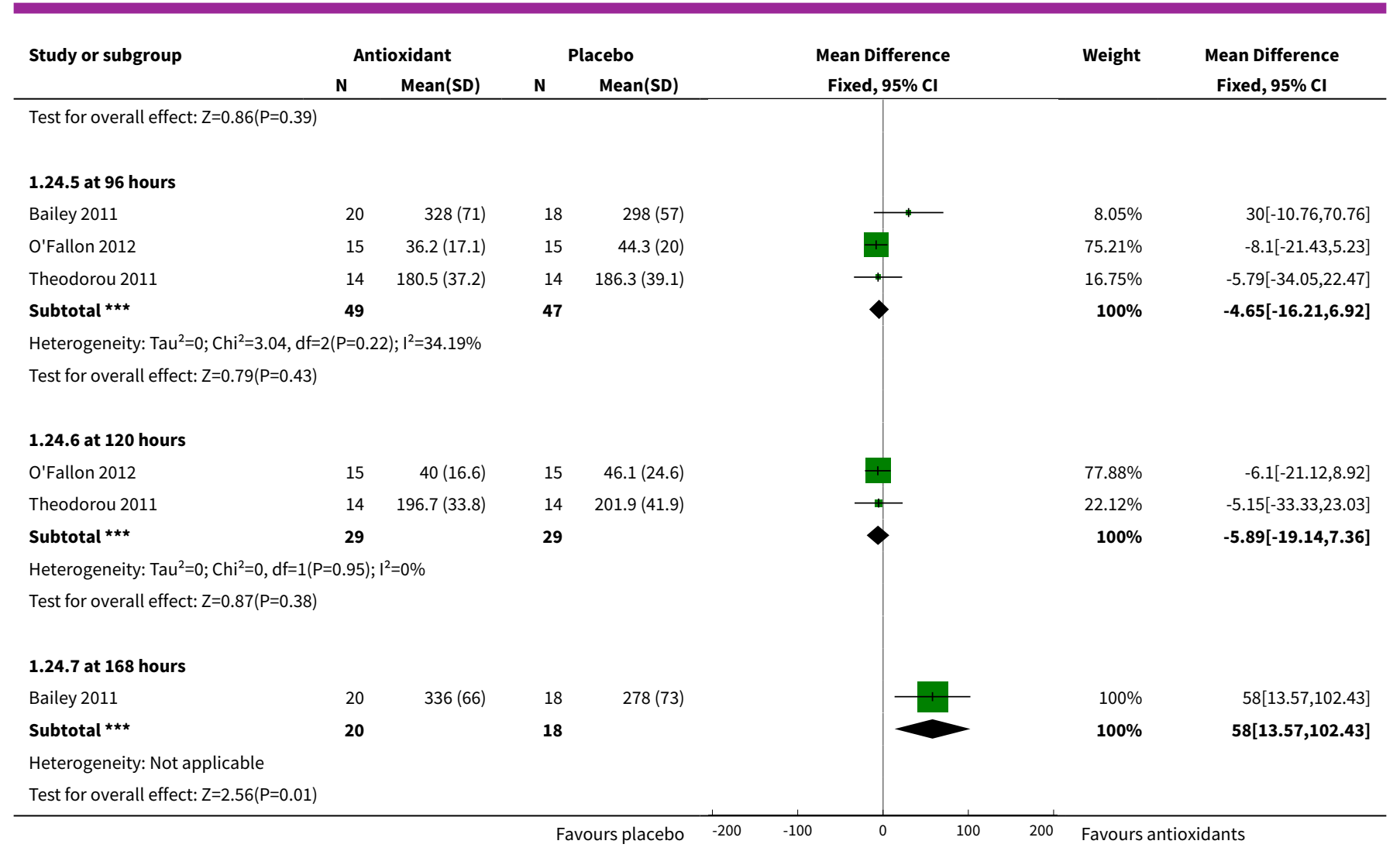

Analysis 1.25. Comparison 1 Antioxidant supplementation vs. placebo for delayed onset muscle soreness (all studies), Outcome 25 Maximal voluntary isometric contraction measured in Newtons.

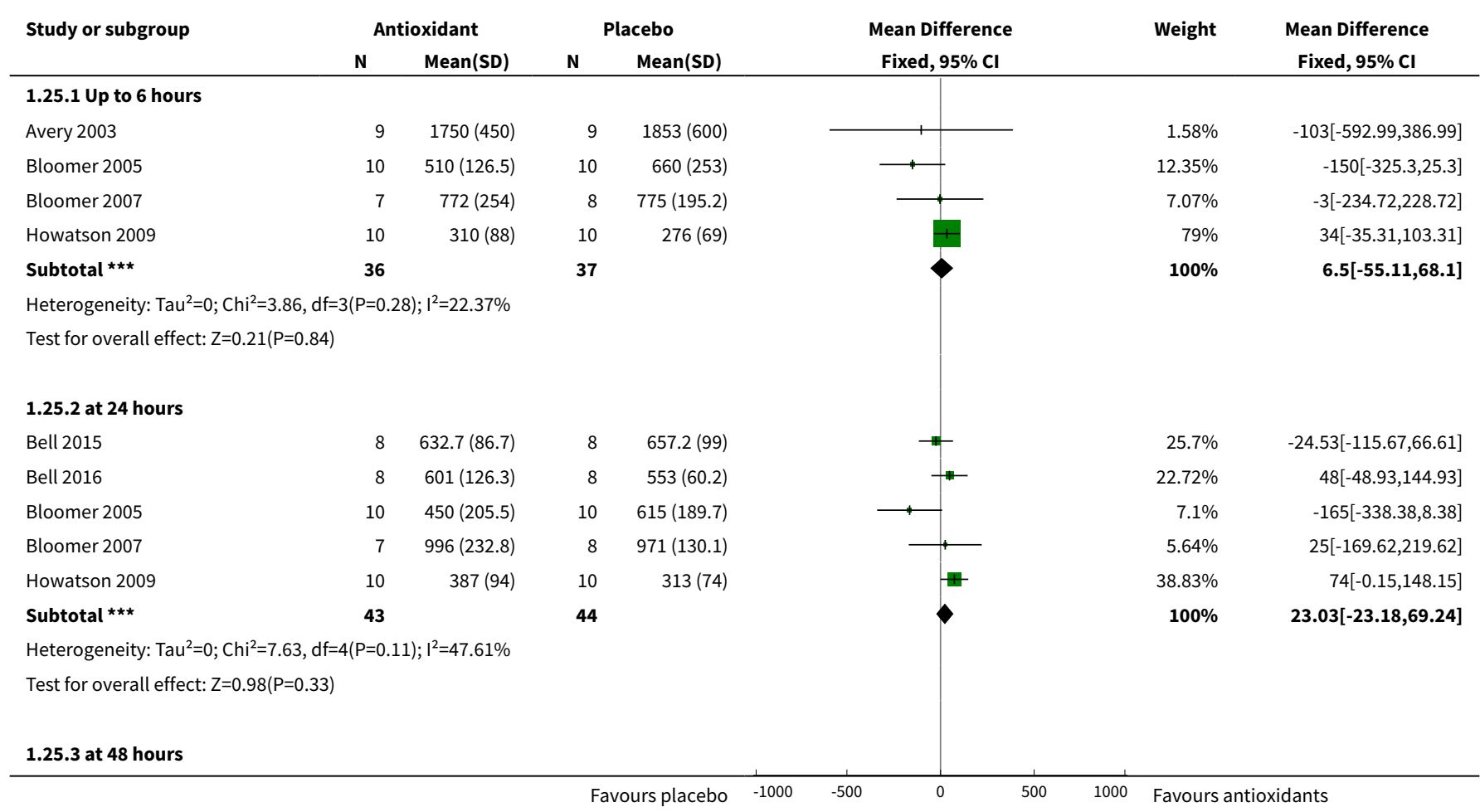




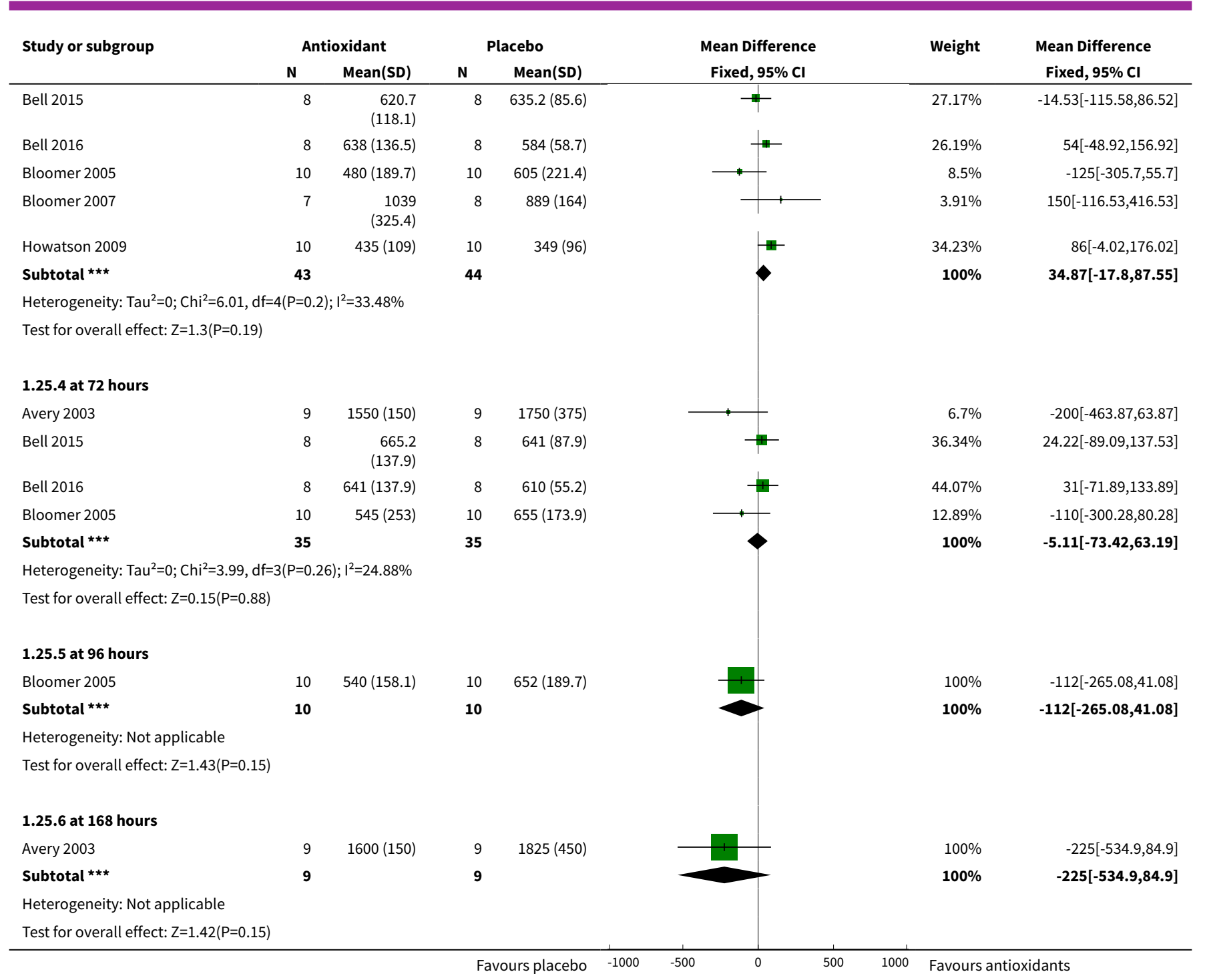

Analysis 1.26. Comparison 1 Antioxidant supplementation vs. placebo for delayed onset muscle soreness (all studies), Outcome 26 Maximal voluntary isometric contraction measured in Newton metres per kg of body mass.

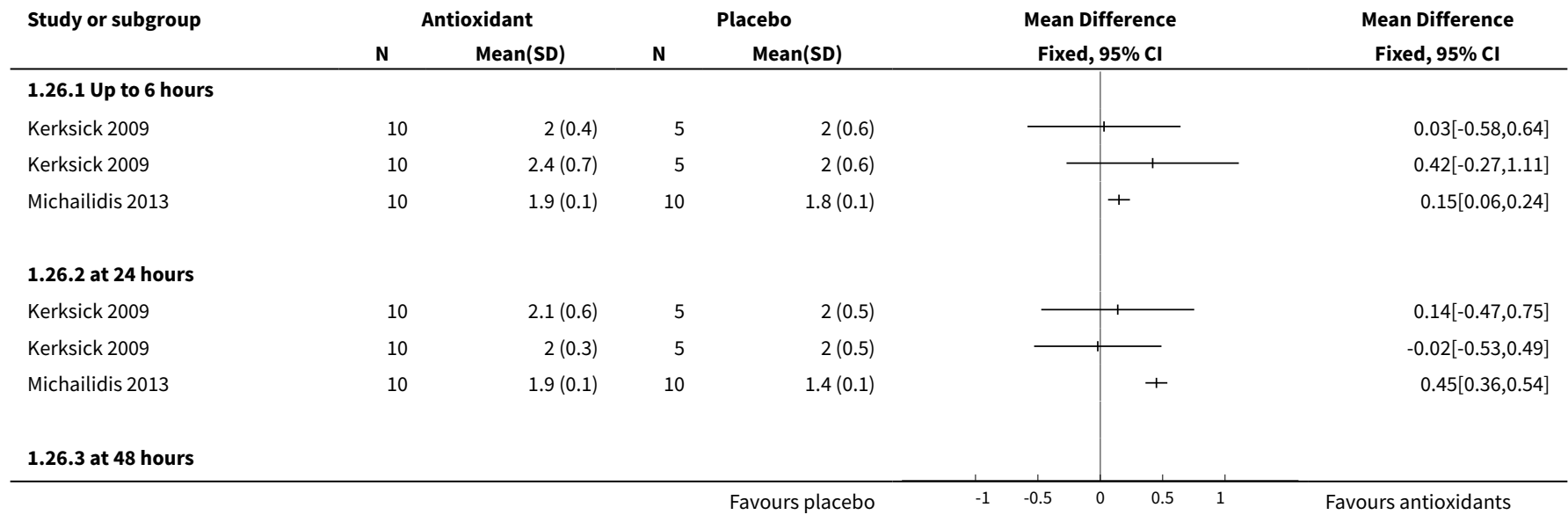




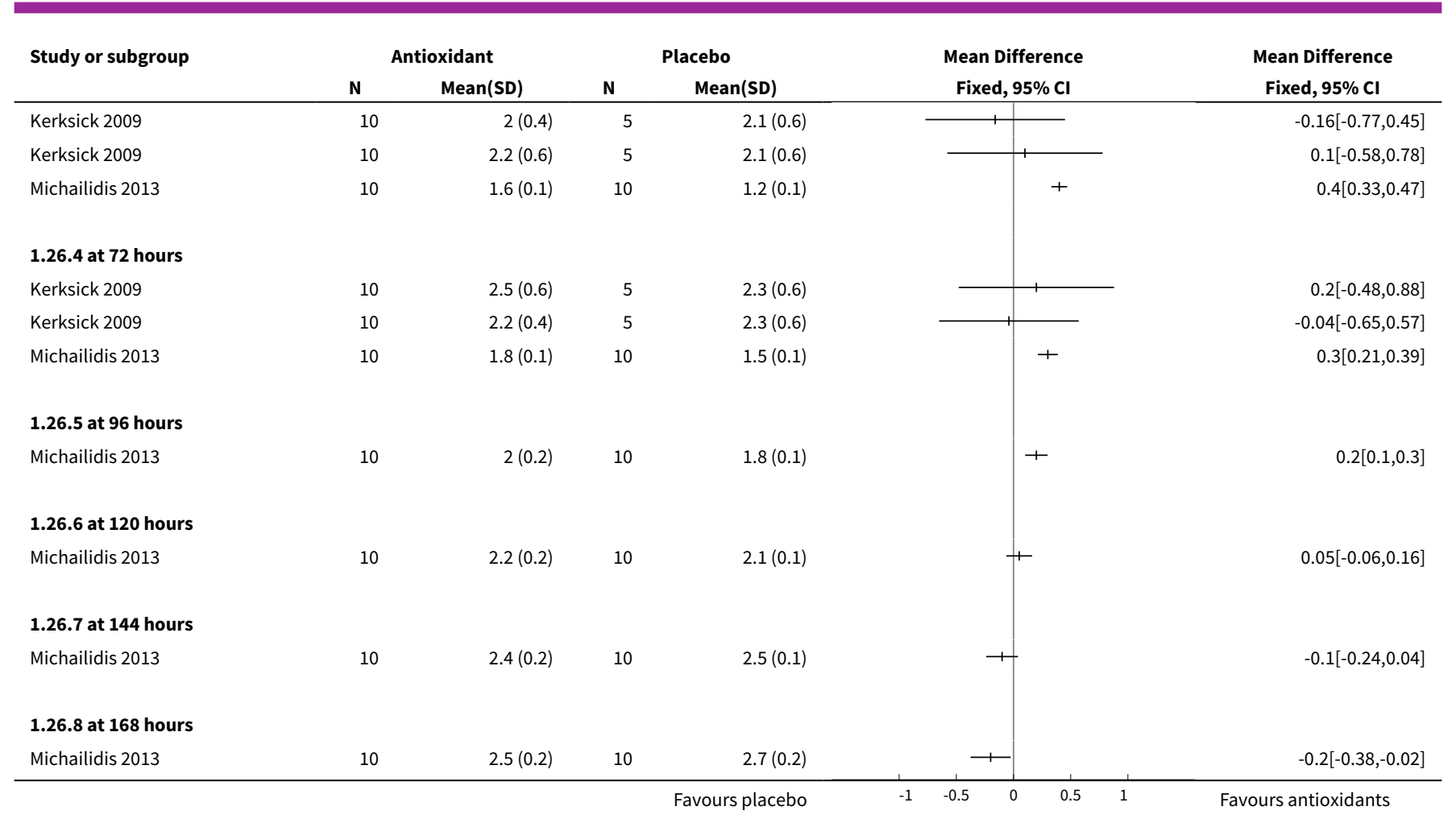

\section{Analysis 1.27. Comparison 1 Antioxidant supplementation vs. placebo for delayed onset muscle soreness (all studies), Outcome 27 Maximal voluntary isometric contraction measured in kg.}

\begin{tabular}{|c|c|c|c|c|c|c|}
\hline \multirow[t]{2}{*}{ Study or subgroup } & \multicolumn{2}{|c|}{ Antioxidant } & \multicolumn{2}{|c|}{ Placebo } & \multirow{2}{*}{$\begin{array}{c}\text { Std. Mean Difference } \\
\text { Fixed, } 95 \% \mathrm{Cl}\end{array}$} & \multirow{2}{*}{$\begin{array}{c}\text { Std. Mean Difference } \\
\text { Fixed, } 95 \% \mathrm{Cl}\end{array}$} \\
\hline & $\mathbf{N}$ & Mean(SD) & $\mathbf{N}$ & Mean(SD) & & \\
\hline \multicolumn{7}{|l|}{ 1.27.1 at 24 hours } \\
\hline O'Connor 2013 & 20 & $6.3(2.7)$ & 20 & $5.7(2.3)$ & + & $0.23[-0.39,0.86]$ \\
\hline \multicolumn{7}{|l|}{ 1.27.2 at 48 hours } \\
\hline O'Connor 2013 & 20 & $6.7(3)$ & 20 & $6.2(2.5)$ & + & $0.18[-0.44,0.8]$ \\
\hline
\end{tabular}

Analysis 1.28. Comparison 1 Antioxidant supplementation vs. placebo for delayed onset muscle soreness (all studies), Outcome 28 Range of motion (all follow-up times).

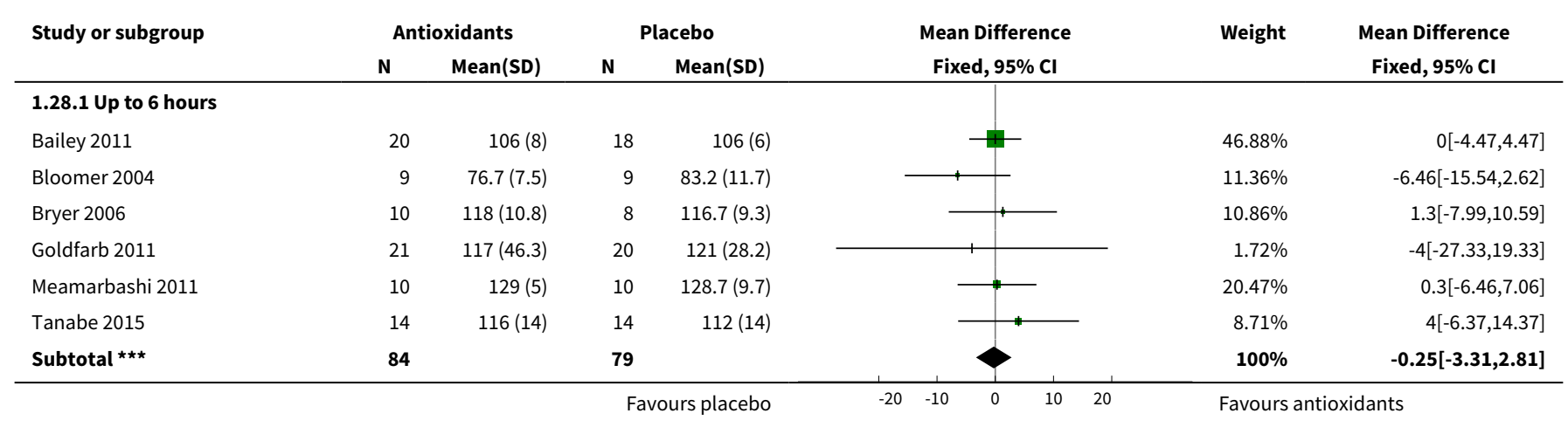




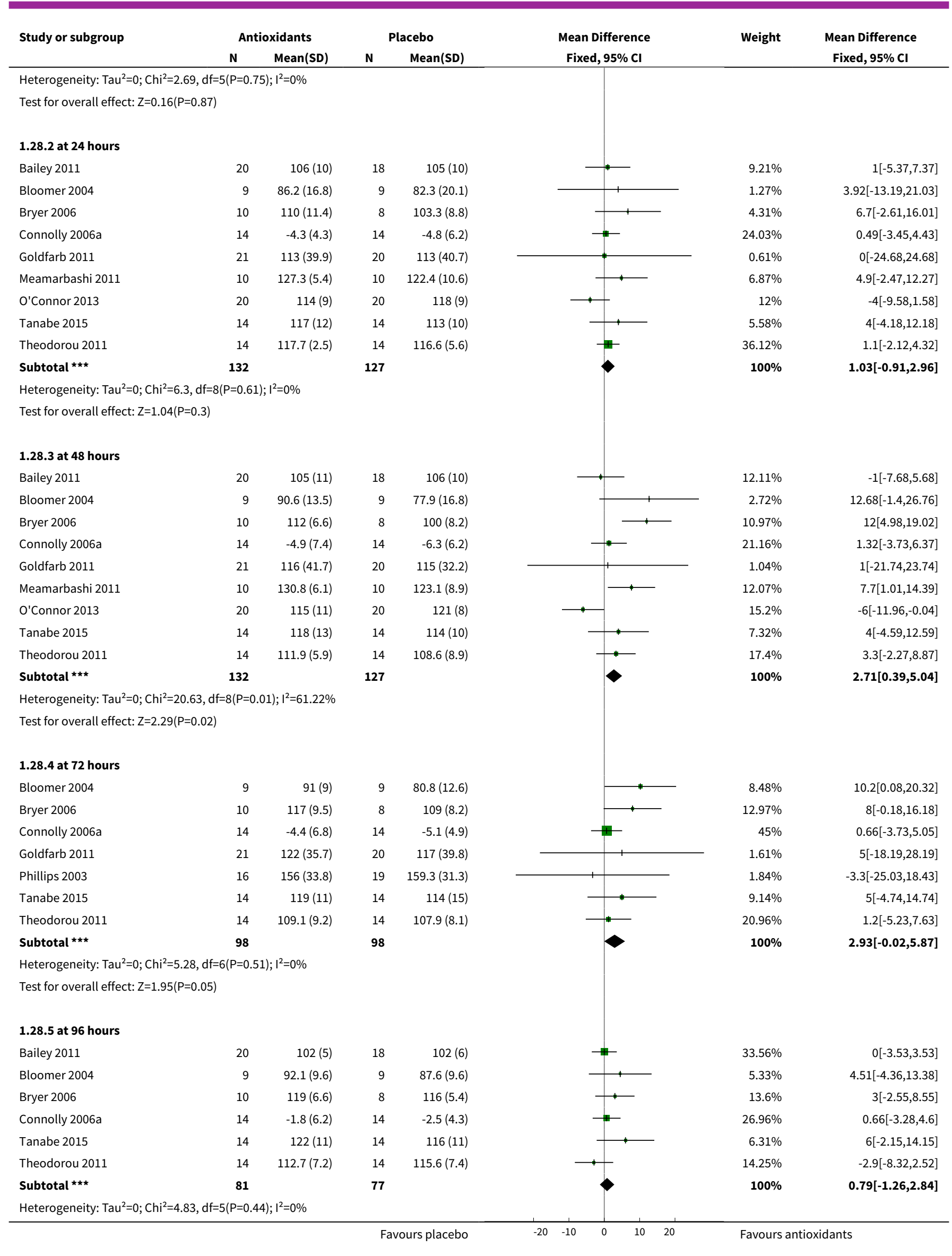




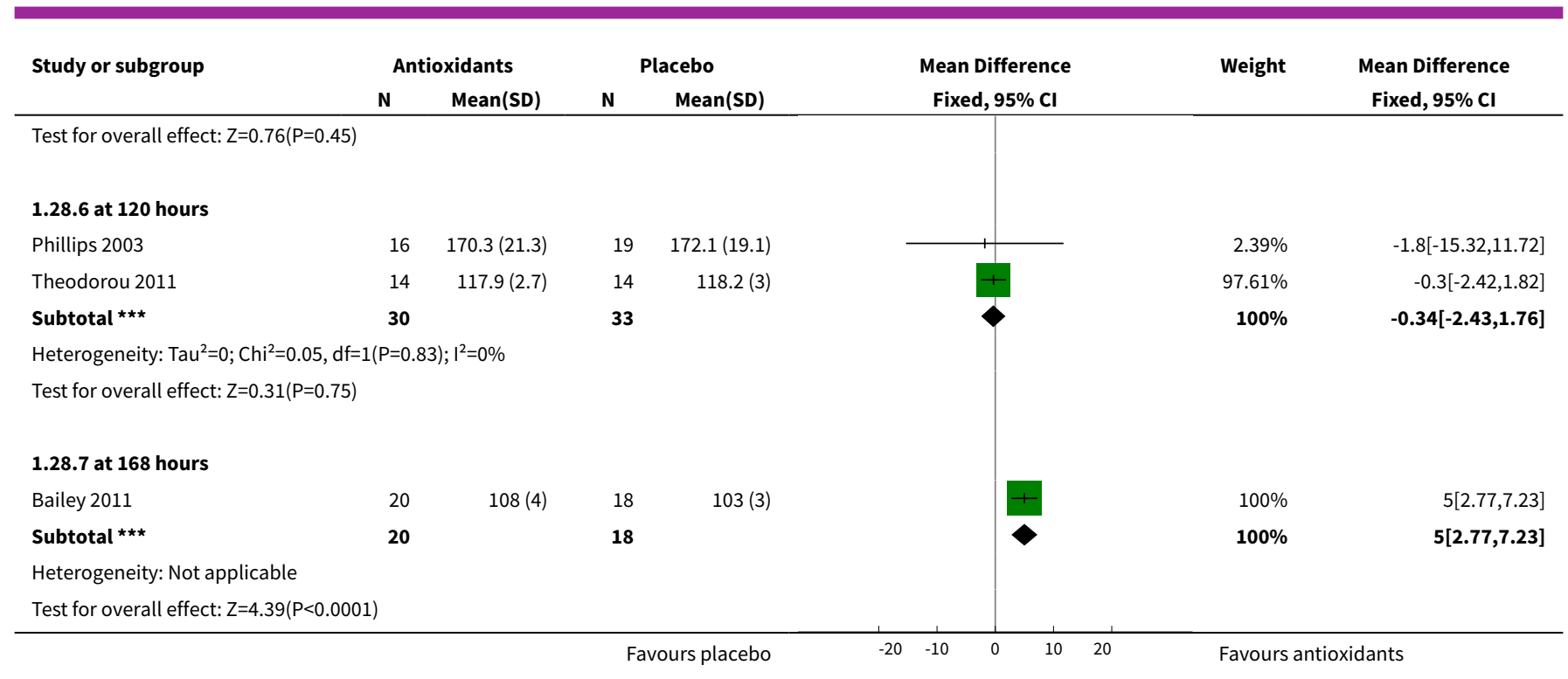

\section{ADDITIONAL TABLES}

Table 1. Antioxidant supplements tested in the included trials

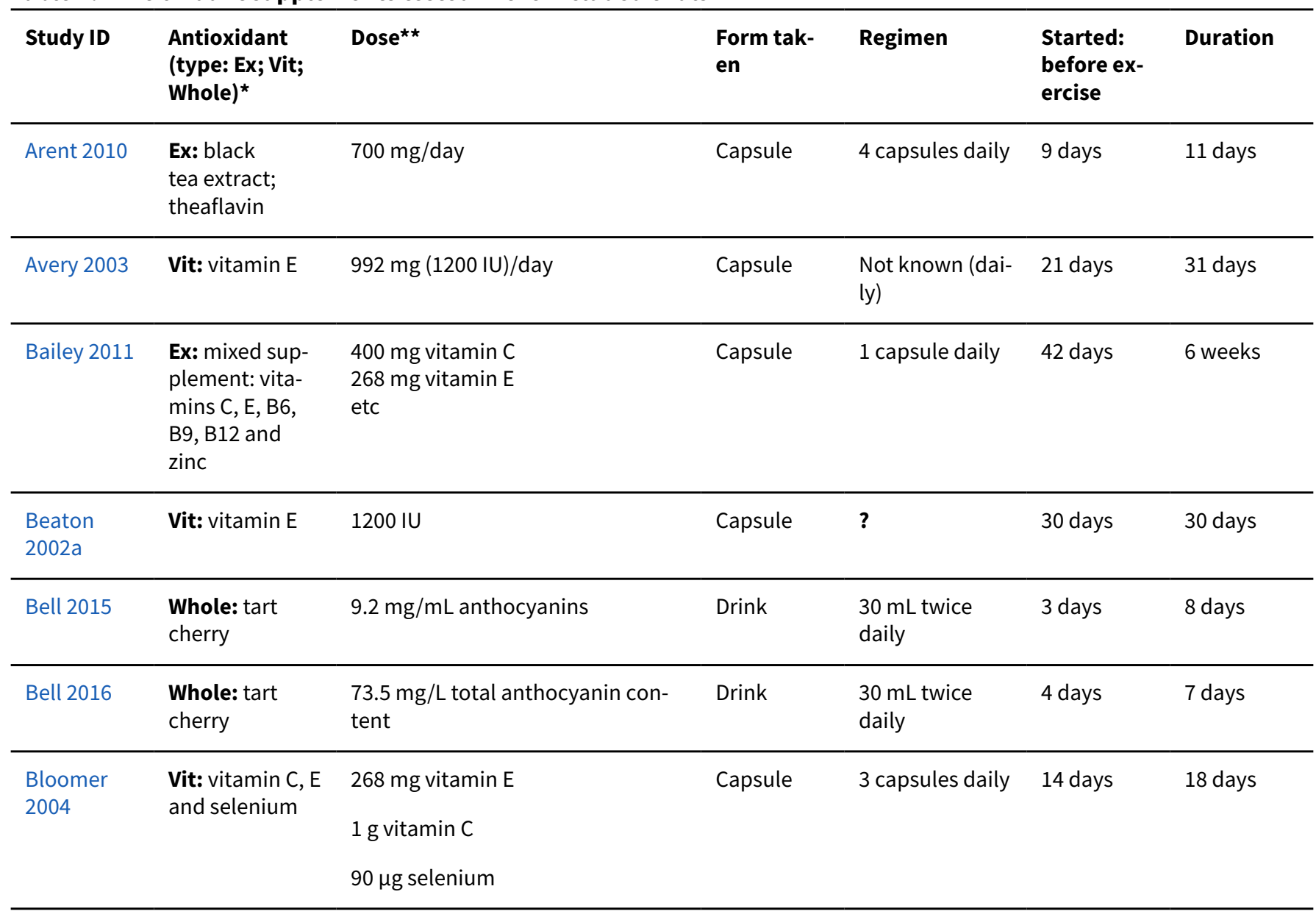


Table 1. Antioxidant supplements tested in the included trials (Continued)

\begin{tabular}{|c|c|c|c|c|c|c|}
\hline $\begin{array}{l}\text { Bloomer } \\
2005\end{array}$ & Ex: astaxanthin & $\begin{array}{l}4 \mathrm{mg} \text { astaxanthin } \\
480 \mathrm{mg} \text { lutein }\end{array}$ & Capsule & 2 capsules daily & 21 days & 25 days \\
\hline $\begin{array}{l}\text { Bloomer } \\
2007\end{array}$ & $\begin{array}{l}\text { Vit: vitamin C } \\
\text { and } E\end{array}$ & $\begin{array}{l}1000 \mathrm{mg} \text { of vitamin C } \\
378 \mathrm{mg} \text { vitamin } \mathrm{E}\end{array}$ & Capsule & 2 capsules daily & 14 days & 14 days \\
\hline Bryer 2006 & Vit: vitamin C & $3 \mathrm{~g} /$ day vitamin C & Capsule & 3 capsules daily & 14 days & 18 days \\
\hline Close 2006 & Vit: vitamin C & $1 \mathrm{~g} /$ day vitamin C & $?$ & $?$ & $\begin{array}{l}0 \text { days (day } \\
\text { of exercise) }\end{array}$ & 14 days \\
\hline $\begin{array}{l}\text { Cobley } \\
2011\end{array}$ & $\begin{array}{l}\text { Ex: N-acetyl- } \\
\text { cysteine }\end{array}$ & $50 \mathrm{mg} / \mathrm{kg} /$ day & $\begin{array}{l}\text { Powder dis- } \\
\text { solved in } \\
\text { water }\end{array}$ & $\begin{array}{l}50 \mathrm{mg} / \mathrm{kg} / \mathrm{day} \\
\text { once daily dis- } \\
\text { solved in } 500 \\
\mathrm{~mL} \text { water }\end{array}$ & 1 hour & 6 days \\
\hline $\begin{array}{l}\text { Connolly } \\
2006\end{array}$ & Vit: vitamin C & $1 \mathrm{~g} /$ day vitamin $\mathrm{C}$ & Capsule & 3 capsules daily & 3 days & 8 days \\
\hline $\begin{array}{l}\text { Connolly } \\
2006 a\end{array}$ & Whole: cherry & $\begin{array}{l}600 \mathrm{mg} \text { phenolic compounds } \\
40 \mathrm{mg} \text { anthocyanins }\end{array}$ & Drink & $\begin{array}{l}2 \times 12 \text { oz bottle } \\
\text { daily }\end{array}$ & 4 days & 8 days \\
\hline $\begin{array}{l}\text { Drobnic } \\
2014\end{array}$ & Ex: curcumin & $400 \mathrm{mg} /$ day curcumin & Capsule & 2 capsules daily & 2 days & 5 days \\
\hline $\begin{array}{l}\text { Goldfarb } \\
2011\end{array}$ & $\begin{array}{l}\text { Ex: Juice Plus } \\
\text { powder }\end{array}$ & $\begin{array}{l}7.5 \mathrm{mg} \text { beta-carotene } \\
276 \mathrm{mg} \text { vitamin C } \\
108 \mathrm{IU} \text { of vitamin E }\end{array}$ & Capsule & 6 capsules daily & 4 days & 8 days \\
\hline He 2015 & $\begin{array}{l}\text { Vit: vitamin } C \\
\text { and vitamin } E\end{array}$ & $\begin{array}{l}100 \mathrm{mg} \text { of vitamin C } \\
268 \mathrm{mg}(400 \mathrm{IU}) \text { of vitamin } E\end{array}$ & Capsule & $?$ & 14 days & 17 days \\
\hline $\begin{array}{l}\text { Herrlinger } \\
2015\end{array}$ & $\begin{array}{l}\text { Ex: black and } \\
\text { green tea }\end{array}$ & $\begin{array}{l}\text { High-dose }=2000 \mathrm{mg} \text { per } \\
\text { day polyphenolic blend } \\
\text { Low-dose }=1000 \mathrm{mg} \text { per day } \\
\text { polyphenolic blend }\end{array}$ & Capsule & 4 capsules daily & 91 days & 91 days \\
\hline $\begin{array}{l}\text { Howatson } \\
2009\end{array}$ & Whole: cherry & $\begin{array}{l}600 \mathrm{mg} \text { phenolic compounds ex- } \\
\text { pressed as gallic acid equivalents, } \\
32 \mathrm{~g} \text { of carbohydrate and at least } \\
40 \mathrm{mg} \text { of anthocyanins }\end{array}$ & Drink & $\begin{array}{l}2 \times 8 \mathrm{fl} \mathrm{oz} \mathrm{bot-} \\
\text { tles per day }\end{array}$ & 5 days & 7 days \\
\hline $\begin{array}{l}\text { Hutchinson } \\
2016\end{array}$ & $\begin{array}{l}\text { Whole: black- } \\
\text { currant nectar }\end{array}$ & $\begin{array}{l}193.25 \mathrm{mg} / \text { day of malvidin gluco- } \\
\text { sides } \\
\begin{array}{l}175.69 \mathrm{mg} / \text { day of cyanidin gluco- } \\
\text { sides }\end{array}\end{array}$ & Drink & $\begin{array}{l}16 \text { oz bottle per } \\
\text { day }\end{array}$ & 8 days & 8 days \\
\hline $\begin{array}{l}\text { Kaminski } \\
1992\end{array}$ & Vit: vitamin C & $1 \mathrm{~g} /$ day vitamin $\mathrm{C}$ & Capsule & 3 capsules daily & 3 days & 10 days \\
\hline $\begin{array}{l}\text { Kerksick } \\
2009\end{array}$ & $\begin{array}{l}\text { Ex: N-acetyl- } \\
\text { cysteine and } \\
\text { epigallocat- }\end{array}$ & $\begin{array}{l}1800 \text { mg/day N-acetyl-cysteine } \\
\text { (NAC) }\end{array}$ & Drink & $?$ & 14 days & 14 days \\
\hline
\end{tabular}


Table 1. Antioxidant supplements tested in the included trials (Continued)

echin gallate $\quad 1800 \mathrm{mg} /$ day epigallocatechin gal-

(EGCG) late (EGCG)

\begin{tabular}{|c|c|c|c|c|c|c|}
\hline $\begin{array}{l}\text { Krotkiewski } \\
1994\end{array}$ & $\begin{array}{l}\text { Ex: pollen ex- } \\
\text { tract }\end{array}$ & 30,000 units per gram of Polbax & $?$ & $?$ & 28 days & 28 days \\
\hline Kuehl 2010 & Whole: cherry & $\begin{array}{l}600 \mathrm{mg} \text { phenolic compounds } \\
40 \mathrm{mg} \text { anthocyanins }\end{array}$ & Drink & $\begin{array}{l}2 \times 335 \mathrm{~mL} \text { bot- } \\
\text { tles daily }\end{array}$ & 7 days & 15 days \\
\hline $\begin{array}{l}\text { Laupheimer } \\
2014\end{array}$ & Ex: resveratrol & $600 \mathrm{mg} /$ day of resveratrol & Capsules & 6 capsules daily & 7 days & 9 days \\
\hline Lynn 2015 & $\begin{array}{l}\text { Whole: bilberry } \\
\text { juice }\end{array}$ & $\begin{array}{l}\text { Total phenol content per } 200 \mathrm{~mL} \\
\text { serving was } 744.14 \pm 81.75 \mathrm{mg}(\mathrm{n} \\
=3) \text { and } 80.04 \pm 3.51 \mathrm{mg}(\mathrm{n}=3) \text { of } \\
\text { total anthocyanins }\end{array}$ & Drink & $2 \times 200 \mathrm{~mL}$ daily & 5 days & 8 days \\
\hline
\end{tabular}

\begin{tabular}{|c|c|c|c|c|c|c|}
\hline $\begin{array}{l}\text { McBride } \\
1997\end{array}$ & Vit: vitamin $\mathrm{E}$ & $992 \mathrm{mg} /$ day of vitamin E (1200 IU) & Capsules & 1 capsule daily & 14 days & 14 days \\
\hline $\begin{array}{l}\text { McCormick } \\
2016\end{array}$ & Whole: cherry & $9.117 \mathrm{mg} / \mathrm{mL}$ anthocyanins & Drink & $\begin{array}{l}90 \mathrm{~mL} \text { daily }(2 \mathrm{x} \\
30 \mathrm{~mL})\end{array}$ & 6 days & 6 days \\
\hline $\begin{array}{l}\text { McFarlin } \\
2016\end{array}$ & Ex: curcumin & $400 \mathrm{mg} /$ day curcumin & Capsules & Capsules & 2 days & 6 days \\
\hline $\begin{array}{l}\text { McLeay } \\
2012\end{array}$ & $\begin{array}{l}\text { Whole: blue- } \\
\text { berry smoothie }\end{array}$ & $\begin{array}{l}\text { Per } 100 \text { mL: total phenolics } 168 \\
\text { mg/gallic acid equ.; anthocyanins } \\
96.6 \text { mg; phenolic acid } 26 \text { mg, } \\
\text { flavonoids } 10.2 \text { mg; vitamin C } 45 \\
\text { mg; vitamin E } 3 \text { mg }\end{array}$ & Drink & $\begin{array}{l}200 \mathrm{~g} \text { blueber- } \\
\text { ries, } 50 \mathrm{~g} \text { ba- } \\
\text { nana }+200 \mathrm{~mL} \\
\text { apple juice dai- } \\
\text { ly }\end{array}$ & $\begin{array}{l}0 \text { days (day } \\
\text { of exercise) }\end{array}$ & 4 days \\
\hline $\begin{array}{l}\text { Meamar- } \\
\text { bashi } 2011\end{array}$ & $\begin{array}{l}\text { Ex: purslane ex- } \\
\text { tract }\end{array}$ & $1200 \mathrm{mg} /$ day purslane extract & Capsules & 2 capsules daily & 3 days & 5 days \\
\hline $\begin{array}{l}\text { Michailidis } \\
2013\end{array}$ & $\begin{array}{l}\text { Vit: } N \text {-acetyl- } \\
\text { cysteine }\end{array}$ & $20 \mathrm{mg} / \mathrm{kg} /$ day $\mathrm{N}$-acetyl-cysteine & Drink & $\begin{array}{l}3 \times 500 \mathrm{~mL} \\
\text { drink daily }\end{array}$ & $\begin{array}{l}0 \text { days (day } \\
\text { of exercise) }\end{array}$ & 9 days \\
\hline Nicol 2015 & Ex: curcumin & $2.5 \mathrm{~g} /$ day of curcumin & Capsules & $\begin{array}{l}10 \text { capsules dai- } \\
\text { ly }(2 \times 5 \text { cap- } \\
\text { sules })\end{array}$ & 2.5 days & 5 days \\
\hline
\end{tabular}

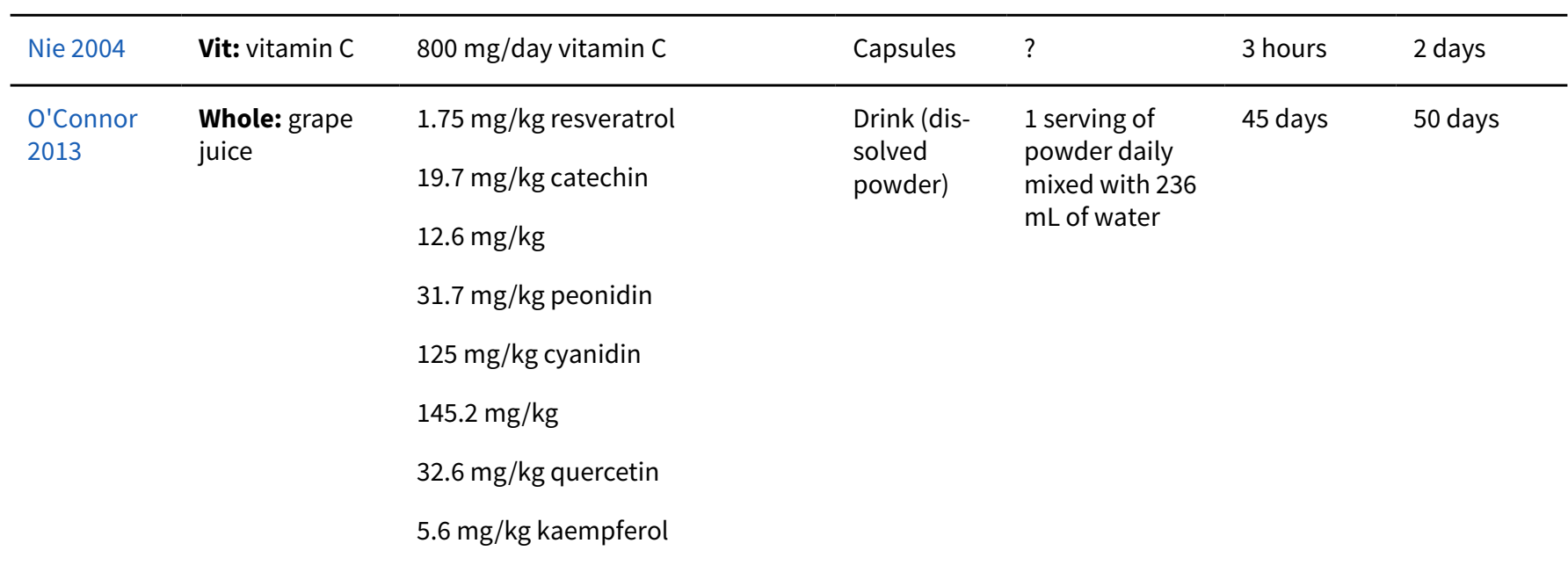


Table 1. Antioxidant supplements tested in the included trials (Continued)

$6.8 \mathrm{mg} / \mathrm{kg}$ isorhamnetin

\begin{tabular}{|c|c|c|c|c|c|c|}
\hline $\begin{array}{l}\text { O'Fallon } \\
2012\end{array}$ & Ex: quercetin & $1000 \mathrm{mg} /$ day quercetin & Bar & 2 bars daily & 7 days & 7 days \\
\hline $\begin{array}{l}\text { Peschek } \\
2014\end{array}$ & Whole: cocoa & $350 \mathrm{mg} /$ day flavanols & Drink & $240 \mathrm{~mL}$ daily & $\begin{array}{l}0 \text { days (day } \\
\text { of exercise) }\end{array}$ & 3 days \\
\hline $\begin{array}{l}\text { Phillips } \\
2003\end{array}$ & $\begin{array}{l}\text { Ex: mixed an- } \\
\text { tioxidants }\end{array}$ & $\begin{array}{l}300 \mathrm{mg} / \text { day tocopherols } \\
800 \mathrm{mg} / \text { day docosahexaenoate } \\
300 \mathrm{mg} / \text { day flavonoids of which } \\
\text { was } 100 \mathrm{mg} \text { hesperetin and } 200 \mathrm{mg} \\
\text { quercetin }\end{array}$ & Capsules & $\begin{array}{l}\text { Vitamin E: } \\
1 \text { capsule; } \\
\text { docosa- } \\
\text { hexaenoate: } \\
3 \text { capsules; } \\
\text { flavonoids: } 3 \\
\text { capsules }\end{array}$ & 14 days & 14 days \\
\hline Shafat 2004 & $\begin{array}{l}\text { Vit: vitamin C+ } \\
\text { vitamin } E\end{array}$ & $\begin{array}{l}500 \mathrm{mg} / \text { day vitamin C } \\
992 \mathrm{mg} / \text { day (1200 IU/day) vitamin } \\
\mathrm{E}\end{array}$ & Capsules & ? & $?$ & 37 days \\
\hline Silva 2008 & $\begin{array}{l}\text { Ex: } \mathrm{N} \text {-acetyl- } \\
\text { cysteine }\end{array}$ & $\begin{array}{l}10 \mathrm{mg} / \mathrm{kg} / \text { day of body mass } \mathrm{N} \text { - } \\
\text { acetyl-cysteine }\end{array}$ & Capsules & 1 capsule daily & 14 days & 21 days \\
\hline Silva 2010 & Vit: vitamin $\mathrm{E}$ & $536 \mathrm{mg} /$ day (800 IU/day) vitamin E & Capsules & 1 capsule daily & 14 days & 21 days \\
\hline Su 2008 & Ex: allicin & $80 \mathrm{mg} /$ day allicin & Capsules & Capsules & 14 days & 16 days \\
\hline $\begin{array}{l}\text { Tanabe } \\
2015\end{array}$ & Ex: curcumin & $150 \mathrm{mg} /$ day curcumin & Capsules & 6 capsules daily & $\begin{array}{l}0 \text { days (day } \\
\text { of exercise; } \\
1 \text { hour be- } \\
\text { fore) }\end{array}$ & 1 day \\
\hline $\begin{array}{l}\text { Theodorou } \\
2011\end{array}$ & $\begin{array}{l}\text { Vit: vitamin C+ } \\
\text { vitamin } E\end{array}$ & $\begin{array}{l}1 \mathrm{~g} / \text { day vitamin C } \\
268 \mathrm{mg} / \text { day (1200 IU/day) vitamin } \\
\mathrm{E}\end{array}$ & Capsules & 1 capsule daily & 28 days & 77 days \\
\hline $\begin{array}{l}\text { Thompson } \\
2001\end{array}$ & Vit: vitamin C & $1 \mathrm{~g} /$ day vitamin $\mathrm{C}$ & Drink & $?$ & $\begin{array}{l}0 \text { days (day } \\
\text { of exercise; } \\
2 \text { hours be- } \\
\text { fore) }\end{array}$ & 1 day \\
\hline $\begin{array}{l}\text { Thompson } \\
\text { 2001a }\end{array}$ & Vit: vitamin C & $\begin{array}{l}1 \mathrm{~g} / \text { day of vitamin } \mathrm{C} \text { on day } 1 \text { fol- } \\
\text { lowed by } 400 \mathrm{mg} / \text { day divided into } \\
2 \text { doses for } 12 \text { days }\end{array}$ & $\begin{array}{l}\text { Drink and } \\
\text { capsules }\end{array}$ & $\begin{array}{l}1 \mathrm{~g} \text { given in a } \\
\text { solution fol- } \\
\text { lowed by } 400 \\
\mathrm{mg} / \text { day doses } \\
\text { in capsules }\end{array}$ & 14 days & 14 days \\
\hline $\begin{array}{l}\text { Thompson } \\
2003\end{array}$ & Vit: vitamin C & $200 \mathrm{mg} /$ day vitamin C & Drink & Daily drink & $\begin{array}{l}0 \text { days (day } \\
\text { of exercise) }\end{array}$ & 3 days \\
\hline $\begin{array}{l}\text { Thompson } \\
2004\end{array}$ & Vit: vitamin C & $200 \mathrm{mg} /$ day vitamin C & Drink & Daily drink & 14 days & 14 days \\
\hline $\begin{array}{l}\text { Trombold } \\
2010\end{array}$ & $\begin{array}{l}\text { Whole: pome- } \\
\text { granate juice }\end{array}$ & $\begin{array}{l}650 \mathrm{mg} / \text { day polyphenols, consist- } \\
\text { ing of } 95.5 \% \text { ellagitannins, 3.5\% el- } \\
\text { lagic acid and } 1 \% \text { anthocyanins }\end{array}$ & Drink & $\begin{array}{l}960 \mathrm{~mL} \text { per day } \\
\text { (as } 2 \times 480 \mathrm{~mL} \\
\text { drinks) }\end{array}$ & 9 days & 32 days \\
\hline
\end{tabular}


Table 1. Antioxidant supplements tested in the included trials (Continued)

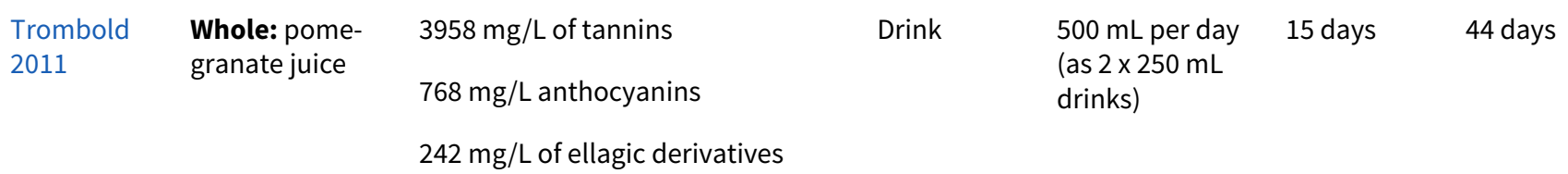

* Types: Extract, mixed or other (e.g. amino-acid derivative) antioxidants; Vitamin; and Whole natural food source.

** Every study included in this review used a dose higher than the recommended daily amount.

Table 2. Details of measurement of muscle soreness in the included trials

\begin{tabular}{|c|c|c|c|c|}
\hline Study ID & Outcome measure & $\begin{array}{l}\text { Score (higher = } \\
\text { worse) }\end{array}$ & $\begin{array}{l}\text { Timing post-ex- } \\
\text { ercise }\end{array}$ & Data extraction \\
\hline Arent 2010 & Muscle soreness during a squat & VAS ( 0 to $10 \mathrm{~cm})$ & 24,48 hours & Text (SDs from SEs) \\
\hline Avery 2003 & $\begin{array}{l}\text { Muscle soreness during shoulder abduc- } \\
\text { tion, shoulder horizontal adduction and } \\
\text { hip flexion (unloaded squat) }\end{array}$ & $\operatorname{VAS}(0$ to $10 \mathrm{~cm})$ & $24,48,72$ hours & Text \\
\hline Bailey 2011 & General soreness at the quadriceps & VAS ( 1 to $10 \mathrm{~cm}$ ) & 24,48 hours & Text \\
\hline Beaton 2002a & General soreness at the quadriceps & VAS (0 to $10 \mathrm{~cm})$ & 48 hours & Text \\
\hline Bell 2015 & Muscle soreness during a squat & $\begin{array}{l}\text { VAS ( } 0 \text { to } 200 \\
\mathrm{~mm})\end{array}$ & $24,48,72$ hours & $\begin{array}{l}\text { Raw data provided by the } \\
\text { authors }\end{array}$ \\
\hline Bell 2016 & Muscle soreness during a squat & $\begin{array}{l}\text { VAS ( } 0 \text { to } 200 \\
\mathrm{~mm} \text { ) }\end{array}$ & $24,48,72$ hours & $\begin{array}{l}\text { Raw data provided by the } \\
\text { authors }\end{array}$ \\
\hline Bloomer 2004 & $\begin{array}{l}\text { Active movement of elbow flexion or ex- } \\
\text { tension, as well as following light palpi- } \\
\text { tation by the investigators }\end{array}$ & VAS (0 to $10 \mathrm{~cm}$ ) & $\begin{array}{l}0,2,6,24,48,72 \\
96 \text { hours }\end{array}$ & $\begin{array}{l}\text { Raw data provided by the } \\
\text { authors } \\
\text { Immediate pain data used } \\
\text { for the up to } 6 \text { hours analy- } \\
\text { sis }\end{array}$ \\
\hline Bloomer 2005 & Dominant leg during knee extension & $\operatorname{VAS}(0$ to $10 \mathrm{~cm})$ & $\begin{array}{l}0,10,24,48,72 \\
96 \text { hours }\end{array}$ & $\begin{array}{l}\text { Raw data provided by the } \\
\text { authors } \\
\text { Immediate pain data used } \\
\text { for the up to } 6 \text { hours analy- } \\
\text { sis }\end{array}$ \\
\hline Bloomer 2007 & $\begin{array}{l}\text { Performance of } 2 \text { (concentric-eccentric) } \\
\text { repetitions of the barbell bench press } \\
\text { exercise using a standard } 20 \mathrm{~kg} \text { barbell }\end{array}$ & $\operatorname{VAS}(0$ to $10 \mathrm{~cm})$ & $0,24,48$ hours & $\begin{array}{l}\text { Raw data provided by the } \\
\text { authors } \\
\text { Immediate pain data used } \\
\text { for the up to } 6 \text { hours analy- } \\
\text { sis }\end{array}$ \\
\hline Bryer 2006 & $\begin{array}{l}\text { Delayed onset muscle soreness was as- } \\
\text { sessed in a rested position and in re- } \\
\text { sponse to palpation on the muscle of } \\
\text { the arms }\end{array}$ & VAS ( 1 to $10 \mathrm{~cm}$ ) & $\begin{array}{l}0,4,24,48,72,96 \\
\text { hours }\end{array}$ & $\begin{array}{l}\text { Text (SDs from SEs) } \\
\text { Immediate pain data used } \\
\text { for the up to } 6 \text { hours analy- } \\
\text { sis }\end{array}$ \\
\hline Close 2006 & $\begin{array}{l}\text { Delayed onset muscle soreness was } \\
\text { measured at the gastrocnemius, ante- } \\
\text { rior tibialis, hamstrings, quadriceps, }\end{array}$ & VAS (0 to $10 \mathrm{~cm}$ ) & $\begin{array}{l}0,24,48,72,96 \\
168,336 \text { hours }\end{array}$ & $\begin{array}{l}\text { Raw data provided by the } \\
\text { authors }\end{array}$ \\
\hline
\end{tabular}


Table 2. Details of measurement of muscle soreness in the included trials gluteals (both sides) and lower back muscles

Immediate pain data used for the up to 6 hours analysis

\begin{tabular}{|c|c|c|c|}
\hline Cobley 2011 & $\begin{array}{l}\text { Total muscle soreness after performing } \\
\text { a } 90 \text { degree squat }\end{array}$ & $\operatorname{VAS}(0$ to $12 \mathrm{~cm})$ & $\begin{array}{l}0,24,48,50,72 \\
96,98 \text { hours }\end{array}$ \\
\hline
\end{tabular}

Raw data provided by the authors

Immediate pain data used for the up to 6 hours analysis

\begin{tabular}{lllll}
\hline Connolly 2006 & $\begin{array}{l}\text { General delayed onset muscle soreness } \\
\text { assessed at the quadriceps }\end{array}$ & VAS (0 to $10 \mathrm{~cm})$ & $\begin{array}{l}\text { 24, 48,72, 96 } \\
\text { hours }\end{array}$ & Text \\
\hline Connolly 2006a & $\begin{array}{l}\text { Pain scores were obtained by asking } \\
\text { participants to verbally rate their overall } \\
\text { discomfort during active elbow flexion } \\
\text { and extension }\end{array}$ & VAS (0 to $10 \mathrm{~cm})$ & $\begin{array}{l}24,48,72,96 \\
\text { hours }\end{array}$ & Text (SDs from SEs) \\
\hline
\end{tabular}

48 hours

VAS (0 to 4$)$

Muscle soreness during descending and climbing stairs. The following 8 sites were measured: anterior right thigh, posterior right thigh, anterior right leg, posterior right leg, anterior left thigh, posterior left thigh, anterior left leg, posterior left leg and added together for a total score.

\begin{tabular}{|c|c|c|c|c|}
\hline Goldfarb 2011 & $\begin{array}{l}\text { Delayed onset muscle soreness was } \\
\text { measured at the elbow flexor with the } \\
\text { arm rested }\end{array}$ & VAS $(1$ to $10 \mathrm{~cm})$ & $\begin{array}{l}0,2,6,24,48,72 \\
\text { hours }\end{array}$ & $\begin{array}{l}\text { Text (SDs from SEs) } \\
\text { Immediate pain data used } \\
\text { for the up to } 6 \text { hours analy- } \\
\text { sis }\end{array}$ \\
\hline He 2015 & $\begin{array}{l}\text { Delayed onset muscle soreness of the } \\
\text { quadriceps, hamstrings, gluteus, gas- } \\
\text { trocnemius and tibialis anterior }\end{array}$ & VAS ( 0 to 6$)$ & $\begin{array}{l}0,24,48,72 \\
\text { hours }\end{array}$ & $\begin{array}{l}\text { Raw data provided by the } \\
\text { authors } \\
\text { Immediate pain data used } \\
\text { for the up to } 6 \text { hours analy- } \\
\text { sis }\end{array}$ \\
\hline Herrlinger 2015 & $\begin{array}{l}\text { Soreness was assessed in a variety of } \\
\text { muscle groups including the gastrocne- } \\
\text { mius, hamstrings, quadriceps, gluteus } \\
\text { maximus, lower back, abdominals and } \\
\text { the whole body }\end{array}$ & Likert ( 0 to 7 ) & $\begin{array}{l}24,48,72,96 \\
\text { hours }\end{array}$ & $\begin{array}{l}\text { The authors of Herrlinger } \\
2015 \text { were contacted on } 2 \\
\text { February } 2017 \text { and again on } \\
\text { 18February } 2017 \text { for miss- } \\
\text { ing data as these were not } \\
\text { available in the manuscript } \\
\text { and could not be extracted } \\
\text { from graphs. No response } \\
\text { was received and this study } \\
\text { was therefore included in } \\
\text { the qualitative analysis but } \\
\text { not the quantitative analy- } \\
\text { sis. }\end{array}$ \\
\hline Howatson 2009 & $\begin{array}{l}\text { Squat down to } 90 \text { degrees (internal joint } \\
\text { angle) rise to the start position }\end{array}$ & $\begin{array}{l}\text { VAS ( } 0 \text { to } 200 \\
\mathrm{~mm} \text { ) }\end{array}$ & $0,24,48$ hours & $\begin{array}{l}\text { Text } \\
\text { Immediate pain data used } \\
\text { for the up to } 6 \text { hours analy- } \\
\text { sis }\end{array}$ \\
\hline
\end{tabular}


Table 2. Details of measurement of muscle soreness in the included trials (Continued)

\begin{tabular}{lllll} 
Hutchinson 2016 & Full range squat with no external weight & VAS (0 to $10 \mathrm{~cm})$ & 24, 48, 72 hours & Text (SDs from SEs) \\
\hline Kaminski 1992 & $\begin{array}{l}\text { General delayed onset muscle soreness } \\
\text { was monitored by self-reporting }\end{array}$ & VAS (1 to $10 \mathrm{~cm})$ & $\begin{array}{l}\text { 0, 10, 24, 48, 58, } \\
72,96 \text { hours }\end{array}$ & $\begin{array}{l}\text { Raw data provided by the } \\
\text { authors }\end{array}$ \\
& & & $\begin{array}{l}\text { Immediate pain data used } \\
\text { for the up to } 6 \text { hours analy- } \\
\text { sis }\end{array}$ \\
\hline Kerksick 2009 & $\begin{array}{l}\text { Delayed onset muscle soreness was as- } \\
\text { sessed at the quadriceps }\end{array}$ & VAS $(0$ to $10 \mathrm{~cm})$ & $6,24,48$ hours & $\begin{array}{l}\text { Raw data provided by the } \\
\text { authors }\end{array}$
\end{tabular}

6 hours post-exercise data used for the up to 6 hours analysis

\begin{tabular}{|c|c|c|c|c|}
\hline Krotkiewski 1994 & General soreness & $\operatorname{VAS}(0$ to $10 \mathrm{~cm})$ & $\begin{array}{l}24,48,72,96 \\
120 \text { hours }\end{array}$ & Text (SDs from SEs) \\
\hline Kuehl 2010 & General soreness in the legs & $\begin{array}{l}\text { VAS (0 to } 100 \\
\mathrm{~mm})\end{array}$ & 0 hours & $\begin{array}{l}\text { Text } \\
\text { Immediate pain data used } \\
\text { for the up to } 6 \text { hours analy- } \\
\text { sis }\end{array}$ \\
\hline Laupheimer 2014 & General soreness in both legs & VAS $(0$ to $10 \mathrm{~cm})$ & 24 hours & $\begin{array}{l}\text { Raw data provided by the } \\
\text { authors }\end{array}$ \\
\hline Lynn 2015 & $\begin{array}{l}\text { Squat to a } 90 \text { angle and returning to a } \\
\text { standing position }\end{array}$ & $\begin{array}{l}\text { VAS ( } 0 \text { to } 200 \\
\mathrm{~mm})\end{array}$ & $0,24,48$ hours & $\begin{array}{l}\text { Text } \\
\text { Immediate pain data used } \\
\text { for the up to } 6 \text { hours analy- } \\
\text { sis }\end{array}$ \\
\hline McBride 1997 & General soreness & VAS $(0$ to $10 \mathrm{~cm})$ & 24,48 hours & Text (SDs from SEs) \\
\hline McCormick 2016 & $\begin{array}{l}\text { Upper body, upper legs, lower legs and } \\
\text { overall body }\end{array}$ & VAS (0 to $10 \mathrm{~cm})$ & $\begin{array}{l}24,48,72,96 \\
120,144 \text { hours }\end{array}$ & $\begin{array}{l}\text { This study was only includ- } \\
\text { ed in the qualitative analy- } \\
\text { sis because the exercise } \\
\text { paradigm was complete- } \\
\text { ly different to all the other } \\
\text { studies included in this re- } \\
\text { view }\end{array}$ \\
\hline McFarlin 2016 & $\begin{array}{l}\text { Muscle soreness measured using a } \\
\text { gauge. Pressure was applied using stan- } \\
\text { dard force ( } 20 \text { to } 30 \mathrm{~N} \text { ) over the distal, } \\
\text { middle and proximal thigh in a seat- } \\
\text { ed position with the knee fully extend- } \\
\text { ed and relaxed. The } 3 \text { ratings for each } \\
\text { quadricep were added together. }\end{array}$ & VAS $(0$ to $10 \mathrm{~cm})$ & $\begin{array}{l}24,48,72,96 \\
\text { hours }\end{array}$ & Text (SDs from SEs) \\
\hline McLeay 2012 & $\begin{array}{l}\text { Step up (concentric muscle action) onto } \\
\text { a } 40 \mathrm{~cm} \text { box then step down (eccentric } \\
\text { muscular contraction) and the soreness } \\
\text { was rated }\end{array}$ & VAS $(0$ to $10 \mathrm{~cm})$ & $24,48,72$ hours & Text \\
\hline $\begin{array}{l}\text { Meamarbashi } \\
2011\end{array}$ & $\begin{array}{l}\text { Participants were requested to rate the } \\
\text { general discomfort in only the quadri- } \\
\text { ceps and calf regions of the right leg }\end{array}$ & VAS ( 0 to 6$)$ & $0,24,48$ hours & Text \\
\hline
\end{tabular}


Table 2. Details of measurement of muscle soreness in the included trials

(Continued)

Immediate pain data used for the up to 6 hours analysis

\begin{tabular}{|c|c|c|c|c|}
\hline Michailidis 2013 & $\begin{array}{l}\text { Palpation of the muscle belly and the } \\
\text { distal region of the vastus medialis, vas- } \\
\text { tus lateralis and rectus femoris after a } \\
\text { squat }\end{array}$ & VAS ( 1 to $10 \mathrm{~cm})$ & $\begin{array}{l}0,2,24,48,72 \\
96,120,144,168 \\
\text { hours }\end{array}$ & $\begin{array}{l}\text { Text } \\
\text { Immediate pain data used } \\
\text { for the up to } 6 \text { hours analy- } \\
\text { sis }\end{array}$ \\
\hline
\end{tabular}

\begin{tabular}{ll}
\hline Nicol $2015 \quad \begin{array}{l}\text { Pain was rated for single leg squat, walk- } \quad \text { VAS }(0 \text { to } 10 \mathrm{~cm}) \quad \text { 0, 24, 48 hours } \\
\text { ing downstairs, passive strength of the } \\
\text { gluteals and single leg vertical jump }\end{array}$
\end{tabular}

Raw data provided by the authors

Immediate pain data used for the up to 6 hours analysis

\begin{tabular}{|c|c|c|c|c|}
\hline Nie 2004 & $\begin{array}{l}\text { Perceived soreness was done during } \\
\text { quadriceps extension }\end{array}$ & VAS (0 to $10 \mathrm{~cm}$ ) & $0,24,48$ hours & $\begin{array}{l}\text { Text } \\
\text { Immediate pain data used } \\
\text { for the up to } 6 \text { hours analy- } \\
\text { sis }\end{array}$ \\
\hline O'Connor 2013 & $\begin{array}{l}\text { Delayed onset muscle soreness in the } \\
\text { arm was rated in response to isometric } \\
\text { strength measurement }\end{array}$ & $\begin{array}{l}\text { VAS ( } 0 \text { to } 100 \\
\mathrm{~mm} \text { ) }\end{array}$ & 24,48 hours & Text \\
\hline O'Fallon 2012 & $\begin{array}{l}\text { Delayed onset muscle soreness at the } \\
\text { elbow flexor }\end{array}$ & $\begin{array}{l}\text { VAS ( } 0 \text { to } 100 \\
\mathrm{~mm})\end{array}$ & $\begin{array}{l}24,48,72,96 \\
120 \text { hours }\end{array}$ & $\begin{array}{l}\text { Raw data provided by the } \\
\text { authors }\end{array}$ \\
\hline Peschek 2014 & $\begin{array}{l}\text { Delayed onset muscle soreness at the } \\
\text { legs }\end{array}$ & VAS $(0$ to $10 \mathrm{~cm})$ & 24,48 hours & Text \\
\hline Phillips 2003 & $\begin{array}{l}\text { Soreness measures were subjectively } \\
\text { evaluated through palpitation for oede- } \\
\text { ma at he elbow }\end{array}$ & $\operatorname{VAS}(0$ to $10 \mathrm{~cm})$ & 72,168 hours & Text (SDs from SEs) \\
\hline Shafat 2004 & $\begin{array}{l}\text { Delayed onset muscle soreness was } \\
\text { evaluated using a questionnaire em- } \\
\text { ploying a visual analogue scale for a to- } \\
\text { tal of } 8 \text { sites ( } 6 \text { sites on the anterior mus- } \\
\text { cle of the upper leg and } 2 \text { sites on the } \\
\text { posterior muscles of the upper leg). The } \\
\text { participants were asked to palpate the } \\
\text { relaxed muscle and rate soreness. }\end{array}$ & $\begin{array}{l}\text { VAS }(1 \text { to } 10 \mathrm{~cm}) \\
(x 8): 8 \text { to } 80 \\
\text { score }\end{array}$ & 24,48 hours & Text \\
\hline Silva 2008 & $\begin{array}{l}\text { Delayed onset muscle soreness at the } \\
\text { elbow flexor }\end{array}$ & VAS (0 to $10 \mathrm{~cm}$ ) & $48,96,168$ hours & Text \\
\hline Silva 2010 & $\begin{array}{l}\text { Muscle soreness of the biceps muscle } \\
\text { was assessed }\end{array}$ & VAS (0 to $10 \mathrm{~cm}$ ) & $48,96,168$ hours & Text (SDs from SEs) \\
\hline Su 2008 & $\begin{array}{l}\text { At the beginning of the exercise test, } \\
\text { participants were instructed to give } \\
\text { CR-10 values }\end{array}$ & Borg CR (0-10) & $0,24,48$ hours & $\begin{array}{l}\text { Text (SDs from SEs) } \\
\text { Immediate pain data used } \\
\text { for the up to } 6 \text { hours analy- } \\
\text { sis }\end{array}$ \\
\hline Tanabe 2015 & $\begin{array}{l}\text { Palpitation of the upper arm and pas- } \\
\text { sively extending the elbow joint }\end{array}$ & $\begin{array}{l}\text { VAS }(0 \text { to } 100 \\
\mathrm{mm})\end{array}$ & $\begin{array}{l}0,24.48,72,96 \\
\text { hours }\end{array}$ & $\begin{array}{l}\text { Raw data provided by the } \\
\text { authors }\end{array}$ \\
\hline
\end{tabular}


Table 2. Details of measurement of muscle soreness in the included trials

(Continued)

Immediate pain data used for the up to 6 hours analysis

\begin{tabular}{llll}
\hline Theodorou 2011 & Squat using body weight & VAS (0 to $10 \mathrm{~cm})$ & $\begin{array}{l}24,48,72,96, \\
120 \text { hours }\end{array}$ \\
\hline Thompson 2001 & Actively contracted the quadriceps & VAS (1 to $10 \mathrm{~cm})$ & $24,48,72$ hours
\end{tabular}

Text

TAS $(1$ to $10 \mathrm{~cm})$. $24,48,72$ hours

Text (SDs from SEs); there are no decimal places; where $\mathrm{SE}=0$, we have put this as $0.4(S D=1.2)$

\begin{tabular}{|c|c|c|c|c|}
\hline Thompson 2001a & Actively contracted the quadriceps & $\begin{array}{l}\text { VAS ( } 0 \text { to } 100 \\
\mathrm{~mm})\end{array}$ & $24,48,72$ hours & Text (SDs from SEs) \\
\hline Thompson 2003 & Actively contracted the quadriceps & VAS $(1$ to $10 \mathrm{~cm})$ & $24,48,72$ hours & $\begin{array}{l}\text { Text (SDs from SEs); there } \\
\text { are no decimal places; } \\
\text { where } \mathrm{SE}=0 \text {, we have put } \\
\text { this as } 0.4(\mathrm{SD}=1.1313)\end{array}$ \\
\hline Thompson 2004 & $\begin{array}{l}\text { Actively contracting the leg extensors } \\
\text { against resistance equivalent to } 75 \% \text { of } \\
\text { each individual's } 1 \text { repetition maximum }\end{array}$ & VAS $(0$ to $10 \mathrm{~cm})$ & $24,48,72$ hours & $\begin{array}{l}\text { Raw data provided by the } \\
\text { authors }\end{array}$ \\
\hline \multirow[t]{2}{*}{ Trombold 2010} & $\begin{array}{l}\text { Unloaded elbow flexion of the tested } \\
\text { arm }\end{array}$ & VAS $(0$ to $10 \mathrm{~cm})$ & $\begin{array}{l}2,24,48,72,96 \\
\text { hours }\end{array}$ & $\begin{array}{l}\text { Raw data provided by the } \\
\text { authors }\end{array}$ \\
\hline & & & & $\begin{array}{l}2 \text { hours post-exercise data } \\
\text { used for the up to } 6 \text { hours } \\
\text { analysis }\end{array}$ \\
\hline \multirow[t]{2}{*}{ Trombold 2011} & $\begin{array}{l}\text { Unloaded elbow flexion and knee exten- } \\
\text { sion on the tested arm and leg }\end{array}$ & VAS $(0$ to $10 \mathrm{~cm})$ & $\begin{array}{l}2,24,48,72,96 \\
\text { hours }\end{array}$ & $\begin{array}{l}\text { Raw data provided by the } \\
\text { authors }\end{array}$ \\
\hline & & & & $\begin{array}{l}2 \text { hours post-exercise data } \\
\text { used for the up to } 6 \text { hours } \\
\text { analysis }\end{array}$ \\
\hline
\end{tabular}

SD: standard deviation

SE: standard error

VAS: visual analogue scale

Table 3. Muscle soreness sensitivity analyses: fixed-effect model

\begin{tabular}{llll}
\hline $\begin{array}{l}\text { Follow-up times } \\
\text { (post-exercise) }\end{array}$ & No. studies & No. participants & SMD (95\% CI) \\
\hline Up to 6 hours & 21 & 525 & $-0.31(-0.49$ to -0.13$)$ \\
\hline 24 hours & 41 & 936 & $-0.13(-0.26$ to -0.00$)$ \\
\hline 48 hours & 45 & 1047 & $-0.22(-0.34$ to -0.09$)$ \\
\hline 72 hours & 28 & 657 & $-0.17(-0.33$ to -0.02$)$ \\
\hline 96 hours & 17 & 436 & $-0.04(-0.23$ to 0.16$)$ \\
\hline
\end{tabular}


Table 3. Muscle soreness sensitivity analyses: fixed-effect model (Continued)

\begin{tabular}{llcl}
120 hours & 4 & 128 & $0.25(-0.12$ to 0.61$)$ \\
\hline 144 hours & 1 & 20 & $-0.23(-1.11$ to 0.65$)$ \\
\hline 168 hours & 4 & 80 & -0.04 (-0.48 to 0.41) \\
\hline
\end{tabular}

$\mathrm{Cl}$ : confidence interval

SMD: standardised mean difference

Table 4. Muscle soreness sensitivity analyses: removal of cross-over trials

\begin{tabular}{lllll}
\hline $\begin{array}{l}\text { Follow-up times } \\
\text { (post-exercise) }\end{array}$ & \multicolumn{2}{l}{ All studies } & Parallel group studies only \\
\cline { 2 - 4 } & No. studies & SMD $(95 \% \mathrm{Cl})$ & No. studies & SMD (95\% CI) \\
\hline Up to 6 hours & 21 & $-0.30(-0.56$ to -0.04$)$ & 15 & $-0.35(-0.67$ to -0.03$)$ \\
\hline 24 hours & 41 & $-0.13(-0.27$ to 0.00$)$ & 32 & $-0.08(-0.25$ to 0.08$)$ \\
\hline 48 hours & 45 & $-0.24(-0.42$ to -0.07$)$ & 34 & $-0.19(-0.40$ to 0.01$)$ \\
\hline 72 hours & 28 & $-0.19(-0.38$ to -0.00$)$ & 22 & $-0.11(-0.30$ to 0.08$)$ \\
\hline 96 hours & 17 & $-0.05(-0.29$ to 0.19$)$ & 12 & $0.01(-0.33$ to 0.34$)$ \\
\hline
\end{tabular}

Table produced independently of the authors by Newton Opiyo and checked by Helen Handoll

\section{AP PE N DICES}

\section{Appendix 1. Search strategies}

\section{CENTRAL (Wiley Online Library)}

\#1 MeSH descriptor: [Exercise] explode all trees (18173)

\#2 MeSH descriptor: [Exercise Test] this term only (7428)

\#3 MeSH descriptor: [Physical Exertion] this term only (3598)

\#4 (\#1 or \#2 or \#3) (25438)

\#5 MeSH descriptor: [Muscle, Skeletal] this term only and with qualifier(s): [Drug effects - DE, Physiopathology - PP] (2094)

\#6 MeSH descriptor: [Muscle Contraction] this term only and with qualifier(s): [Drug effects - DE, Physiopathology - PP] (640)

\#7 MeSH descriptor: [Muscle Cramp] this term only (150)

\#8 MeSH descriptor: [Spasm] this term only (191)

\#9 MeSH descriptor: [Muscle Rigidity] this term only (61)

\#10 MeSH descriptor: [Sprains and Strains] this term only (326)

\#11 MeSH descriptor: [Muscle Weakness] this term only (303)

$\# 12$ MeSH descriptor: [Creatine Kinase] this term only and with qualifier(s): [Blood - BL] (970)

$\# 13$ (\#5 or \#6 or \#7 or \#8 or \#9 or \#10 or \#11 or \#12) (4397)

\#14 \#4 and \#13 (1134)

\#15 (exercise and (muscle* near/2 (damage* or injur $\left.\left.{ }^{\star}\right)\right)$ ):ti,ab,kw (579)

\#16 (sore $^{\star}$ near/3 musc $\left.{ }^{\star}\right):$ ti,ab,kw (561)

$\# 17$ (DOMS or EIMD):ti,ab,kw (190)

\#18 (\#14 or \#15 or \#16 or \#17) (1772)

\#19 MeSH descriptor: [Antioxidants] explode all trees (3991)

\#20 MeSH descriptor: [Ascorbic Acid] explode all trees (1721)

\#21 MeSH descriptor: [Tocopherols] explode all trees (448)

\#22 MeSH descriptor: [Vitamin A] explode all trees (1706)

\#23 MeSH descriptor: [Vitamin E] explode all trees (2122) 
\#24 MeSH descriptor: [beta Carotene] explode all trees (741)

\#25 MeSH descriptor: [Oxidants] explode all trees (455)

\#26 MeSH descriptor: [Oxidation-Reduction] explode all trees (2133)

\#27 MeSH descriptor: [Reactive Oxygen Species] this term only and with qualifier(s): [Antagonists \& inhibitors - Al] (7)

\#28 MeSH descriptor: [Peroxides] explode all trees and with qualifier(s): [Antagonists \& inhibitors - AI] (11)

\#29 MeSH descriptor: [Ubiquinone] this term only (355)

\#30 MeSH descriptor: [Phenol] this term only (66)

\#31 MeSH descriptor: [Glutathione] this term only (580)

\#32 MeSH descriptor: [Glutathione Peroxidase] this term only (402)

\#33 MeSH descriptor: [Curcumin] this term only (100)

\#34 MeSH descriptor: [Flavonoids] explode all trees (2148)

\#35 (antioxidant* or anti-oxidant*):ti,ab,kw (7674)

\#36 "vitamin c" or ascorbic acid:ti,ab,kw (3913)

\#37 "vitamin E" or alpha-tocopherol or beta-tocopherol or gamma-tocopherol or tocopherol*:ti,ab,kw (4630)

\#38 (betacarotene or beta carotene or carotene or carotenoid*):ti,ab,kw (2083)

\#39 (n-acetyl cysteine or n-acetylcysteine or n-acetyl-l-cysteine or acetylcysteine):ti,ab,kw (1441)

\#40 (superoxide dismutase or SOD or dehydroepiandrosterone or glutathione or coenzyme q10 or astaxanthin or zeaxanthin or lycopene or pentoxifylline or polyphenol* or pycnogenol* or flavonoid $^{\star}$ or selenium or anthocyanin $\left.{ }^{\star}\right):$ ti,ab,kw (8882)

$\# 41$ (\#19 or \#20 or \#21 or \#22 or \#23 or \#24 or \#25 or \#26 or \#27 or \#28 or \#29 or \#30 or \#31 or \#32 or \#33 or \#34 or \#35 or \#36 or \#37 or \#38 or \#39 or \#40) (23501)

\#42 (\#18 and \#41) (194)

\section{MEDLINE (Ovid Web)}

1 Exercise/ or Exercise Test/ or Physical Exertion/ (178530)

2 Muscle, Skeletal/de, pp [Drug Effects, Physiopathology] (25164)

3 Muscle Contraction/de, pp [Drug Effects, Physiopathology] (37380)

4 Muscle Cramp/ or Spasm/ or Muscle Rigidity/ or "Sprains and Strains"/ or Muscle Weakness/ (22384)

5 Creatine Kinase/bl [Blood] (14287)

6 or/2-5 (95850)

7 and $/ 1,6$ (4164)

8 (exercise and (muscle* adj2 (damage* or injur $\left.\left.^{\star}\right)\right)$ ).tw. (2188)

9 (sore ${ }^{\star}$ adj3 musc $\left.^{\star}\right)$.tw. (1635)

10 (DOMS or EIMD).tw. (629)

11 or/7-10 (6846)

$12 \exp$ Antioxidants/ (397449)

13 exp Ascorbic Acid/ or exp Tocopherols/ or exp Vitamin A/ or exp Vitamin E/ or beta Carotene/ (106065)

14 exp Oxidants/ (109419)

15 exp Oxidation-Reduction/ (219323)

16 Reactive Oxygen Species/ai [Antagonists \& Inhibitors] (1156)

17 exp Peroxides/ai [Antagonists \& Inhibitors] (1602)

18 Ubiquinone/ or Phenol/ or Glutathione/ or Glutathione Peroxidase/ or Curcumin/ or exp Flavonoids/ (162838)

19 (antioxidant* or anti-oxidant*).tw. (153352)

20 ("vitamin c" or ascorbic acid).tw. (42561)

21 ("vitamin E" or alpha-tocopherol or beta-tocopherol or gamma-tocopherol or tocopherol*).tw. (38259)

22 (betacarotene or beta carotene or carotene or carotenoid $\left.{ }^{\star}\right)$.tw. (25604)

23 ( $n$-acetyl cysteine or n-acetylcysteine or n-acetyl-l-cysteine or acetylcysteine).tw. (16312)

24 (superoxide dismutase or SOD or dehydroepiandrosterone or glutathione or coenzyme q10 or astaxanthin or zeaxanthin or lycopene or pentoxifylline or polyphenol* or pycnogenol* or flavonoid* or selenium or anthocyanin $\left.{ }^{\star}\right)$.tw. (241246)

25 or/12-24 (908015)

26 and/11,25 (701)

27 Randomized controlled trial.pt. (446926)

28 Controlled clinical trial.pt. (91808)

29 randomized.ab. (387435)

30 placebo.ab. (183299)

31 Drug therapy.fs. (1928982)

32 randomly.ab. (270638)

33 trial.ab. (405897)

34 groups.ab. (1669773)

35 or/27-34 (3968345)

36 exp Animals/ not Humans/ (4312930)

3735 not 36 (3428779) 
38 and/26,37 (302)

\section{Embase (Ovid Web)}

1 Exercise/ or Exercise Test/ (308139)

2 Skeletal Muscle/ (110436)

3 Muscle Contraction/ (68260)

4 Muscle Cramp/ or Spasm/ or Muscle Rigidity/ or Sprain/ or Muscle Weakness/ (66779)

5 Creatine Kinase/ (43734)

62 or 3 or 4 or $5(267718)$

71 and 6 (24273)

8 (exercise and (muscle* adj2 (damage* or injur $\left.\left.{ }^{\star}\right)\right)$ ).tw. (2372)

9 (sore $^{\star}$ adj3 musc $\left.{ }^{\star}\right)$.tw. (1733)

10 (DOMS or EIMD).tw. (662)

117 or 8 or 9 or 10 (26382)

12 exp antioxidant/ (185205)

13 exp Ascorbic Acid/ or exp Tocopherol/ or exp Retinol/ or Beta Carotene/ (167284)

14 exp Oxidizing Agent/ (226287)

15 exp Oxidation Reduction Reaction/ (86850)

16 Reactive Oxygen Metabolite/ (130471)

17 exp Peroxide/ (40960)

18 Ubiquinone/ or Phenol/ or Glutathione/ or Glutathione peroxidise/ or Curcumin/ or exp Flavonoid/ (242322)

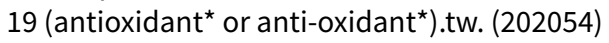

20 ("vitamin C" or ascorbic acid).tw. (49233)

21 ("vitamin E" or alpha-tocopherol or beta-tocopherol or gamma-tocopherol or tocopherol*).tw. (43945)

22 (betacarotene or beta carotene or carotene or carotenoid ${ }^{\star}$ ).tw. (28360)

23 ( $n$-acetyl cysteine or n-acetylcysteine or n-acetyl-l-cysteine or acetylcysteine).tw. (20567)

24 (superoxide dismutase or SOD or dehydroepiandrosterone or glutathione or coenzyme q10 or astaxanthin or zeaxanthin or lycopene or pentoxifylline or polyphenol* or pycnogenol* or flavonoid* or selenium or anthocyanin*).tw. (294093)

25 or/12-24 (897856)

2611 and 25 (1859)

27 Randomized controlled trial/ (476005)

28 Clinical trial/ (1026775)

29 Controlled clinical trial/ (470380)

30 Randomization/ (84507)

31 Single blind procedure/ (29183)

32 Double blind procedure/ (139527)

33 Crossover procedure/ (54944)

34 Placebo/ (327195)

35 Prospective study/ (396959)

36 ((clinical or controlled or comparative or placebo or prospective* or randomi\#ed) adj3 (trial or study)).tw. (995276)

37 (random* adj7 (allocat ${ }^{\star}$ or allot ${ }^{\star}$ or assign* or basis* or divid $^{\star}$ or $^{\star}$ order $\left.^{\star}\right)$ ).tw. (246237)

38 ((singl ${ }^{\star}$ or doubl $^{\star}$ or trebl ${ }^{\star}$ or tripl $\left.{ }^{\star}\right) \operatorname{adj} 7$ (blind* or mask $\left.\left.^{\star}\right)\right)$.tw. (200629)

39 (cross? over ${ }^{\star}$ or (cross adj1 over $\left.{ }^{\star}\right)$ ).tw. (86814)

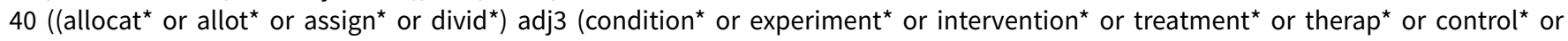
group $\left.\left.{ }^{\star}\right)\right) . t w .(330995)$

41 RCT.tw. (23208)

42 or/27-41 (2480033)

43 Case Study/ or Abstract Report/ or Letter/ (1091413)

4442 not $43(2427252)$

4526 and 44 (476)

\section{SPORTDiscus (Ebsco)}

S1 DE "EXERCISE" OR DE "EXERCISE tests" (84,781)

S2 (((((DE "MYALGIA") OR (DE "DELAYED onset muscle soreness")) OR (DE "MUSCLE cramps")) OR (DE "MUSCLE rigidity")) OR (DE "SPRAINS")) OR (DE "MUSCLE weakness") (4,207)

S3 (DE "SKELETAL muscle") $(1,747)$

S4 DE "MUSCLE contraction" $(10,331)$

S5 DE "CREATINE kinase" $(1,275)$

S6 S2 OR S3 OR S4 OR S5 $(16,480)$

S7 S1 AND S6 $(3,922)$

S8 TX (exercise and (muscle ${ }^{\star} \mathrm{n} 2\left(\right.$ damage $^{\star}$ or injur $\left.\left.\left.{ }^{\star}\right)\right)\right)(2,482)$ 
S9 TX sore* n3 musc* $(2,055)$

S10 TX DOMS or EIMD $(1,006)$

S11 S7 OR S8 OR S9 OR S10 $(7,601)$

S12 DE "ANTIOXIDANTS" (2,399)

S13 (DE "VITAMIN C") OR (DE "VITAMIN E") OR (DE "VITAMIN A") $(1,531)$

S14 DE "OXIDATION-reduction reaction" (280)

S15 DE "FREE radicals (Chemistry)" (485)

S16 ((DE "UBIQUINONES") OR (DE "PHENOLS")) OR (DE "GLUTATHIONE") (612)

S17 TI ( antioxidant* or anti-oxidant* ) OR AB ( antioxidant* or anti-oxidant* $)(4,527)$

S18 TI ( "vitamin c" or ascorbic acid) OR AB ( "vitamin c" or ascorbic acid) $(1,367$ )

S19 TI ( "vitamin E" or alpha-tocopherol or beta-tocopherol or gamma-tocopherol or tocopherol* ) OR AB ( "vitamin E" or alpha-tocopherol or beta-tocopherol or gamma-tocopherol or tocopherol* $)(1,049)$

$\mathrm{S} 20 \mathrm{TI}$ ( betacarotene or beta carotene or carotene or carotenoid*) OR AB ( betacarotene or beta carotene or carotene or carotenoid ${ }^{\star}$ ) (788)

$\mathrm{S} 21 \mathrm{TI}$ ( $\mathrm{n}$-acetyl cysteine or n-acetylcysteine or $\mathrm{n}$-acetyl-l-cysteine or acetylcysteine ) OR AB ( $\mathrm{n}$-acetyl cysteine or n-acetylcysteine or nacetyl-l-cysteine or acetylcysteine) (178)

S22 TI ( superoxide dismutase or SOD or dehydroepiandrosterone or glutathione or coenzyme q10 or astaxanthin or zeaxanthin or lycopene or pentoxifylline or polyphenol* or pycnogenol* or flavonoid* or selenium or anthocyanin*) OR AB ( superoxide dismutase or SOD or dehydroepiandrosterone or glutathione or coenzyme q10 or astaxanthin or zeaxanthin or lycopene or pentoxifylline or polyphenol* or

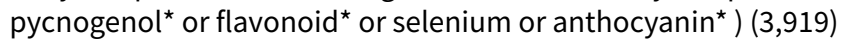

S23 S12 OR S13 OR S14 OR S15 OR S16 OR S17 OR S18 OR S19 OR S20 OR S21 OR S22 (9,624)

S24 S11 AND S23 (312)

S25 TX ( (clinic* N3 trial) or (controlled N3 trial) or (comparative N3 trial) or (placebo N3 trial) or (prospective N3 trial) or (randomi?ed N3 trial) ) or TX ( (clinic* N3 study) or (controlled N3 study) or (comparative N3 study) or (placebo N3 study) or (prospective N3 study) or (randomi?ed N3 study) ) $(74,987)$

S26 (random* N7 allot $\left.{ }^{\star}\right)$ or (random* N7 assign*) or (random* N7 basis*) or (random* N7 divid*) or (random* N7 order $\left.{ }^{\star}\right)(10,503)$

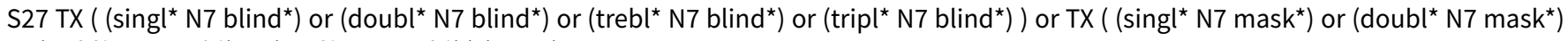
or $\left(\right.$ trebl $^{\star}$ N7 mask $\left.{ }^{\star}\right)$ or $\left(\right.$ tripl $^{\star}$ N7 mask $\left.\left.^{\star}\right)\right)(6,354)$

S28 TX (cross\#over $\left.{ }^{\star}\right)$ or TX (cross N1 over $\left.{ }^{\star}\right)(5,072)$

S29 TX randomi?ed control ${ }^{\star}$ trial $^{*}(12,817)$

S30 TX ( (allocat* N3 condition*) or (allocat* N3 experiment*) or (allocat* N3 intervention*) or (allocat ${ }^{\star}$ N3 treatment ${ }^{\star}$ ) or (allocat ${ }^{\star}$ N3

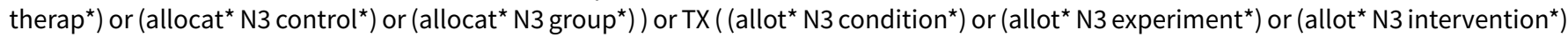

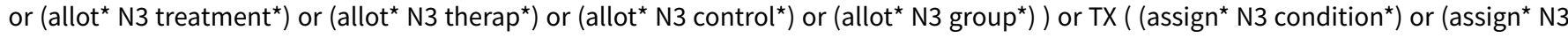

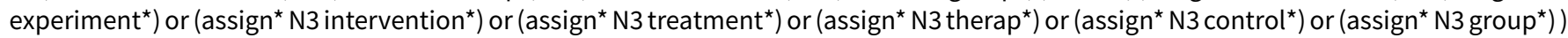

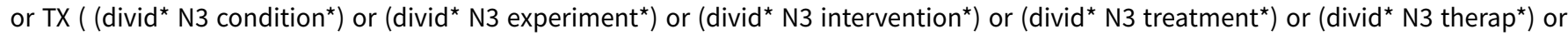
(divid $^{\star}$ N3 control*) or (divid ${ }^{\star}$ N3 group $\left.\left.^{\star}\right)\right)(11,741)$

S31 TX placebo* $(9,181)$

$\mathrm{S} 32 \mathrm{~S} 25$ or S26 or S27 or S28 or S29 or S30 or S31 $(93,140)$

S33 (S26 or S28 or S30 or S25 or S27 or S29 or S31) AND (S24 AND S32) (117)

\section{Appendix 2. WHO International Clinical Trials Registry Platform}

1. musc ${ }^{\star}$ AND oxidative OR musc ${ }^{\star}$ AND antioxidant OR musc* AND exercis* AND supplement*

2. exercis ${ }^{\star}$ AND oxidative OR exercis ${ }^{\star}$ AND antioxidant OR exercis* ${ }^{\star}$ AND vitamin

Total $=282$

\section{Appendix 3. ClinicalTrials.gov}

1. muscle AND (oxidative OR antioxidant) AND exercise

Total $=162$

\section{CONTRIBUTIONS OF AUTHORS}

Mayur Ranchordas identified the research idea for the review, wrote the protocol, extracted the data, wrote the review and is the guarantor. David Rogerson assisted with drafting the protocol and data extraction. Hora Soltani provided feedback on the draft protocol and review. Joseph Costello assisted with data analysis and drafted the final review.

\section{DECLARATIONS OF INTEREST}

Mayur Ranchordas co-authored one of the included studies (Lynn 2015). Decisions on inclusion of this study, the 'Risk of bias' assessment and data extraction were undertaken by other review authors (JC, DR), who had no involvement in the study. David Rogerson: none known. 
Hora Soltani: none known.

Joseph Costello: none known.

\section{SOURCES OF SUPPORT}

\section{Internal sources}

- Sheffield Hallam University, UK.

- University of Portsmouth, UK.

\section{External sources}

- No sources of support supplied

\section{DIFFERENCES BETWEEN PROTOCOLANDREVIEW}

Since publication of the protocol (Ranchordas 2012), we made the following changes.

We updated the Background to reflect current evidence on the potential negative effects of antioxidant supplementation (in particularly long-term use) by impairing exercise adaptations.

In Types of outcome measures, we stipulated that trials that did not record muscle soreness (pain) would be excluded. We included a new primary outcome (subjective recovery) and we elevated adverse effects, originally listed as a secondary outcome, to primary outcome status.

Linked with this was our selection of outcome measures for presentation in Summary of findings for the main comparison. This included limiting the measurement of DOMS to five follow-up periods up to 96 hours.

In Subgroup analysis and investigation of heterogeneity, we removed the subgroup analysis "Type of antioxidants supplement (antioxidants supplements vs. antioxidants-enriched food)". This is because we realised that it was not possible to categorise studies into 'antioxidant supplement' or 'antioxidant-enriched food' as they usually belonged to both categories; for example, tart cherry juice is an antioxidant-enriched food but it is also an antioxidant supplement containing vitamins such as vitamin $\mathrm{C}$.

We merged two previous subgroup comparisons on types of exercise ("Normal sporting activities and laboratory induced DOMS"; "Exercise that requires high oxygen consumption (e.g. running, cycling) and exercise that requires low oxygen consumption (e.g. eccentric exercise in one arm)") as the comparison of "whole body aerobic exercise" versus "mechanical exercise" captured both of these.

We included an additional subgroup analysis on sources of funding where we compared DOMS for studies that were funded by a food company or provider of antioxidant supplements versus studies that were not funded by a food company or provider of antioxidant supplements.

We could not compare the subgroup analysis 'timing of exercise' because of insufficient studies in the 'supplementation after exercise' group.

In Sensitivity analysis, we modified the sensitivity analysis testing the effects of high risk of selection bias to include also trials at unclear risk of selection bias, relating to random sequence generation, allocation concealment or both. Additional sensitivity analysis to explore the effects of excluding cross-over studies on the pooled data for muscle soreness at five time periods were conducted at screening by the Cochrane Editorial Unit.

\section{NDEX TERMS}

\section{Medical Subject Headings (MeSH)}

${ }^{\star}$ Dietary Supplements; ${ }^{\star}$ Exercise; ${ }^{\star}$ Food, Fortified; Antioxidants [adverse effects] [ ${ }^{\star}$ therapeutic use]; Myalgia [ ${ }^{\star}$ drug therapy] [etiology] [ ${ }^{*}$ prevention \& control]; Randomized Controlled Trials as Topic; Time Factors

\section{MeSH check words}

Adolescent; Adult; Female; Humans; Male; Middle Aged 